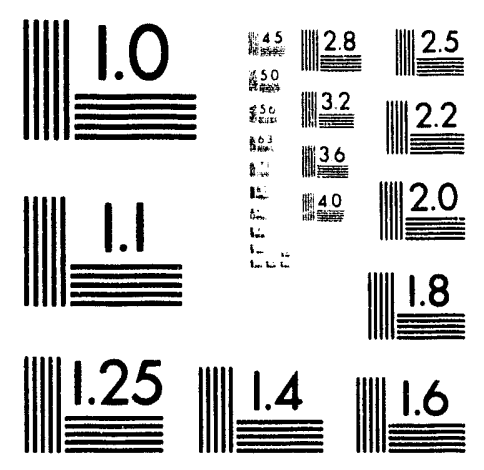



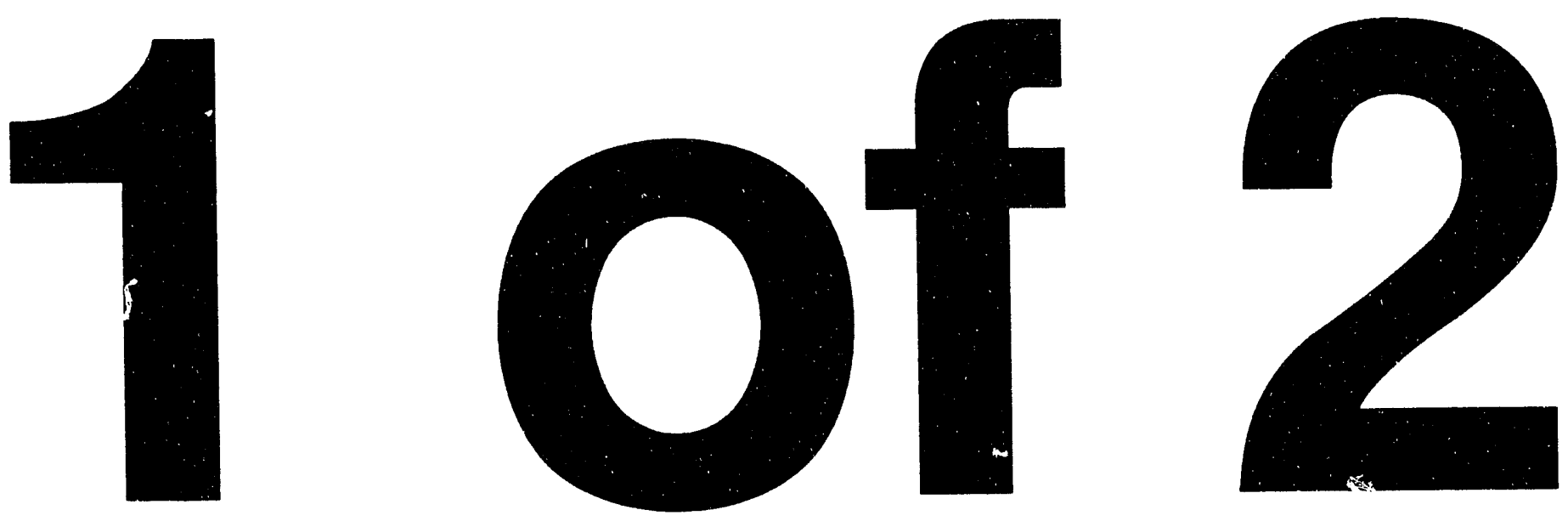


\title{
Error Propagation Equations and Tables for Estimating the Uncertainty in High-Speed Wind Tunnel Test Results
}

\author{
Edward L. Clark \\ Aerodynamics Department \\ Sandia National Laboratories \\ Albuquerque, NM 87185
}

\begin{abstract}
Error propagation equations, based on the Taylor series model, are derived for the nondimensional ratios and coefficients most often encountered in high-speed wind tunnel testing. These include pressure ratio and coefficient, static force and moment coefficients, dynamic stability coefficients, calibration Mach number and Reynolds number. The error equations contain partial derivatives, denoted as sensitivity coefficients, which define the influence of free-stream Mach number, $\mathbf{M}_{\infty}$, on various aerodynamic ratios. To facilitate use of the error equations, sensitivity coefficients are derived and evaluated for nine fundamental aerodynamic ratios, most of which relate free-stream test conditions (pressure, temperature, density or velocity) to a reference condition. Tables of the ratios, $R$, absolute sensitivity coefficients, $\partial R / \partial M_{\infty}$, and relative sensitivity coefficients, $\left(M_{\infty} / R\right)\left(\partial R / \partial M_{\infty}\right)$, are provided as functions of $M_{\infty}$.
\end{abstract}




\section{Acknowledgment}

The author appreciates the detailed reviews and constructive suggestions provided by Don McBride of the Parachute Technology and Unsteady Aerodynamics Department and Walt Gutierrez of the Aerodynamics Department. 


\section{Contents}

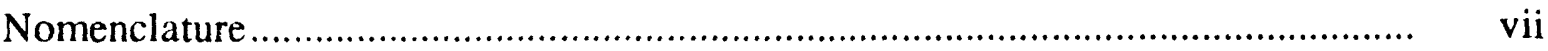

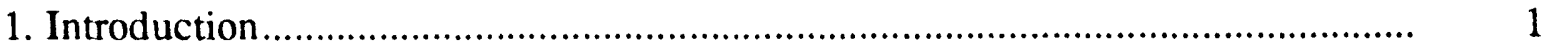

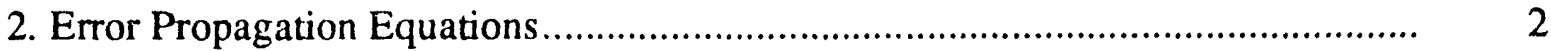

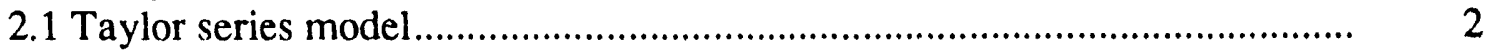

2.2 Application of the model ...................................................................... 4

2.3 Example - pressure ratio ..................................................................... 5

2.3.1 Independent pressure measurements ........................................... 5

2.3.2 Correlated pressures ....................................................................... 6

2.3.2.1 Analytical evaluation-independent variables ............................ 6

2.3.2.2 Analytical evaluation-dependent variables ................................ 7

2.3.2.3 Numerical evaluation .......................................................... 8

2.3.3 Pre-test analysis benefits ............................................................ 8

3. Sensitivity Coefficients - Aerodynamic Ratios ................................................. 9

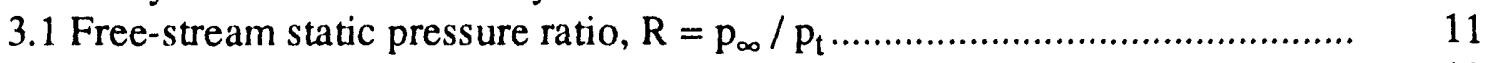

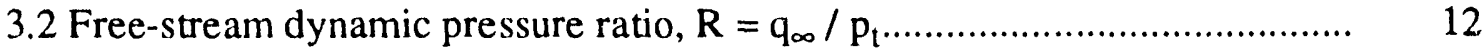

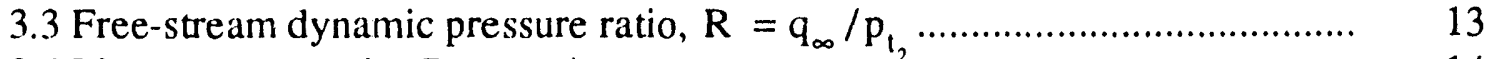

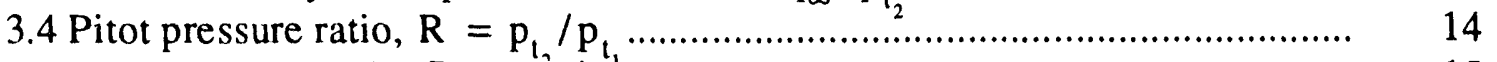

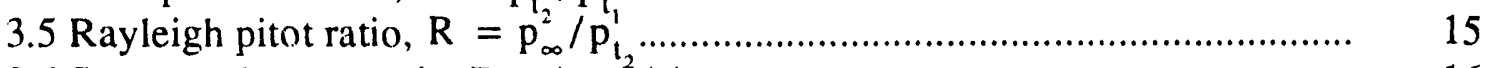

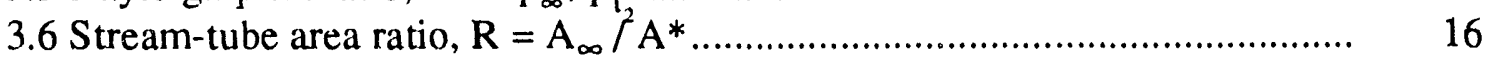

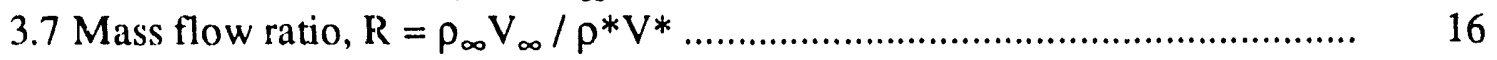

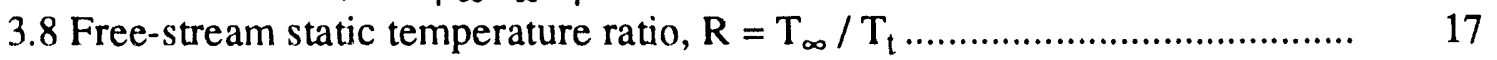

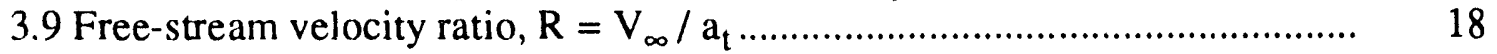

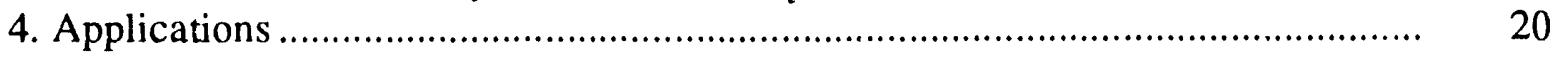

4.1 Pressure ratio, P ............................................................................ 20

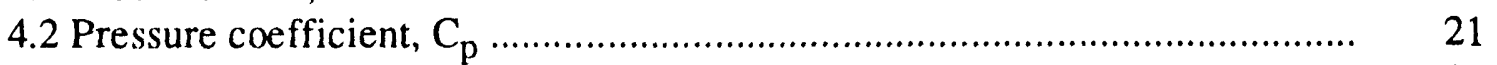

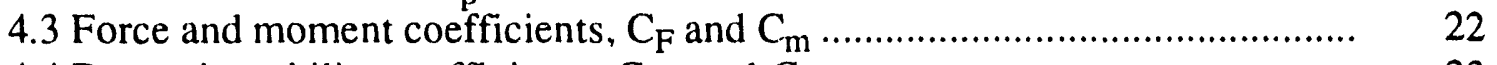

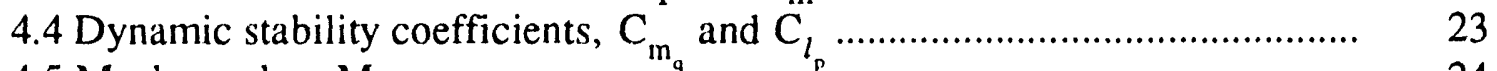

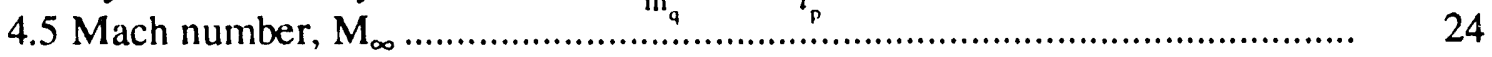

4.6 Reynolds number, Re ...................................................................... 26

4.6.1 Linear viscosity relation............................................................ 27

4.6.1.1 Analytical evaluation-independent variables .......................... 27

4.6.1.2 Analytical evaluation-dependent variables ............................ 29

4.6.1.3 Numerical evaluation ....................................................... 31

4.6.2 Sutherland's viscosity relation .................................................. 32

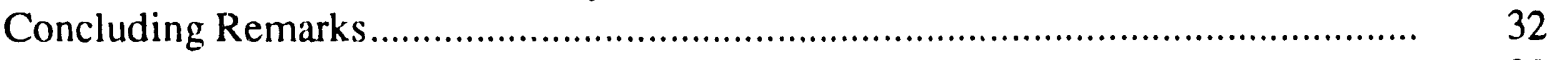

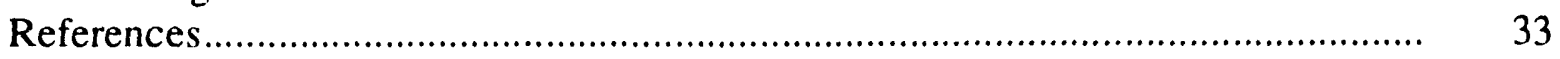

\section{Figures}

1. Variation of $R, \partial R / \partial M_{\infty}$, and $\theta^{\prime} M_{\infty}$ with $M_{\infty}$ for $R=p_{\infty} / p_{t}$ and $\gamma=1.40 \ldots \ldots \ldots \ldots . . . .35$

2. Variation of $R, \partial R / \partial M_{\infty}$, and $\theta^{\prime}{ }_{M}^{\infty}$ with $M_{\infty}$ for $R=q_{\infty} / p_{t}$ and $\gamma=1.40 \ldots \ldots \ldots . . . \quad 36$

3. Variation of $R, \partial R / \partial M_{\infty}$, and $\theta^{\prime}{ }^{\infty}{ }_{\infty}$ with $M_{\infty}$ for $R=q_{\infty} / p_{t_{2}}$ and $\gamma=1.40 \ldots \ldots \ldots . . \quad 37$

4. Variation of $R, \partial R / \partial M_{\infty}$, and $\theta^{\prime} M_{\infty}^{\infty}$ with $M_{\infty}$ for $R=p_{t_{2}} / p_{t_{1}}$ and $\gamma=1.40 \ldots \ldots \ldots . . . \quad 38$ 
5. Variation of $\mathrm{R}, \partial \mathrm{R} / \partial \mathrm{M}_{\infty}$, and $\theta^{\prime} \mathrm{M}_{\infty}$ with $\mathrm{M}_{\infty}$ for $\mathrm{R}=\mathrm{p}_{\infty} / \mathrm{p}_{\mathrm{t}^{2}}$ and $\gamma=1.40 \ldots \ldots \ldots . .39$

6. Variation of $R, \partial R / \partial M_{\infty}$, and $\theta^{\prime} M_{\infty}$ with $M_{\infty}$ for $R=A_{\infty} / A^{2} *$ and $\gamma=1.40 \ldots \ldots . \quad 40$

7. Variation of $R, \partial R / \partial M_{\infty}$, and $\theta^{\prime} M_{\infty}$ with $M_{\infty}$ for $R=\rho_{\infty} V_{\infty} / \rho^{*} V^{*}$ and $\gamma=1.40 \quad 41$

8. Variation of $R, \partial R / \partial M_{\infty}$, and $\theta^{\prime}{ }_{M}^{\infty}$ with $M_{\infty}$ for $R=T_{\infty} / T_{t}$ and $\gamma=1.40 \ldots \ldots \ldots . . .42$

9. Variation of $R, \partial R / \partial M_{\infty}$, and $\theta_{M_{\infty}}^{\prime}$ with $M_{\infty}$ for $R=V_{\infty} / a_{t}$ and $\gamma=1.40 \ldots \ldots \ldots . .43$

10. Dynamic viscosity regimes......................................................................... 44

11. Variation of $\mathrm{Re} / \mathrm{Re}^{*}$ with $\mathrm{M}_{\infty}$, linear viscosity relation ................................... 45

12. Variation of reiative sensitivity coefficient for Reynolds number with $\mathbf{M}_{\infty}$, linear viscosity relation

13. Variation of relative sensitivity coefficient for Reynolds number with $\mathbf{M}_{\infty}$, Sutherland's viscosity relation

14. Variation of relative sensitivity coefficient for Reynolds number with $T_{t}$, Sutherland's viscosity relation

\section{Tables}

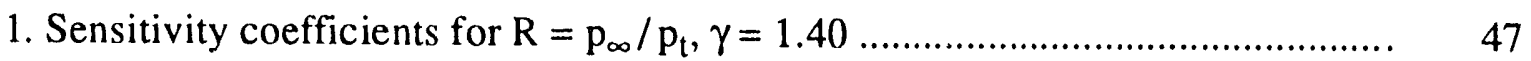

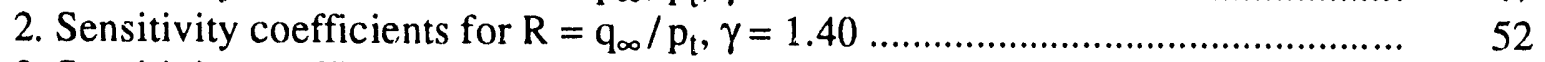

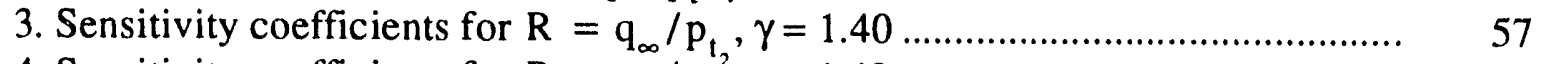

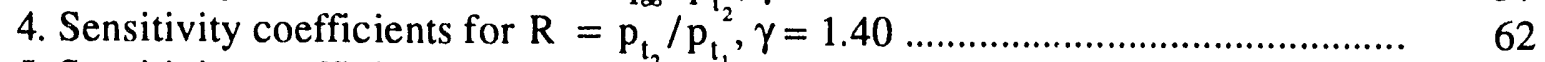

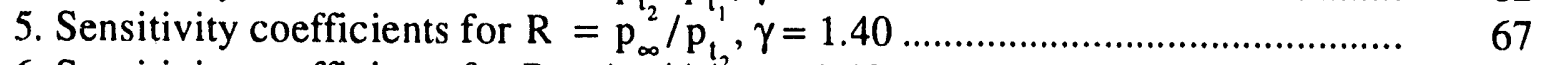

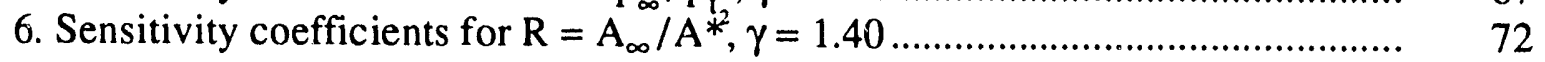

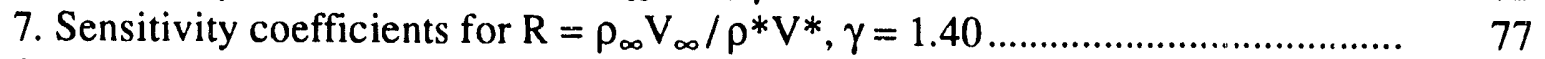

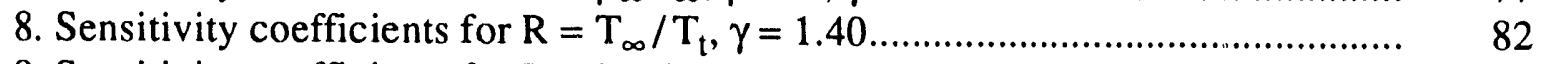

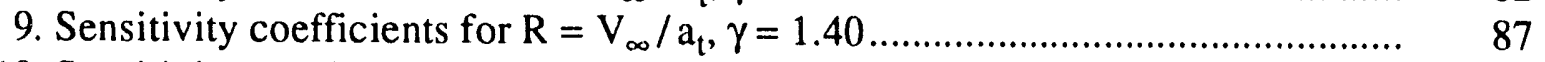

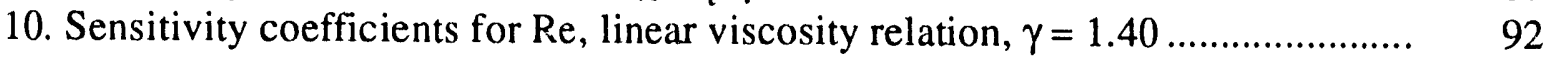

\section{Appendix}

Program DFDX, Sensitivity Coefficient Estimation by Sequential Perturbation...... 


\section{Nomenclature $^{1}$}

\section{Primary symbols}

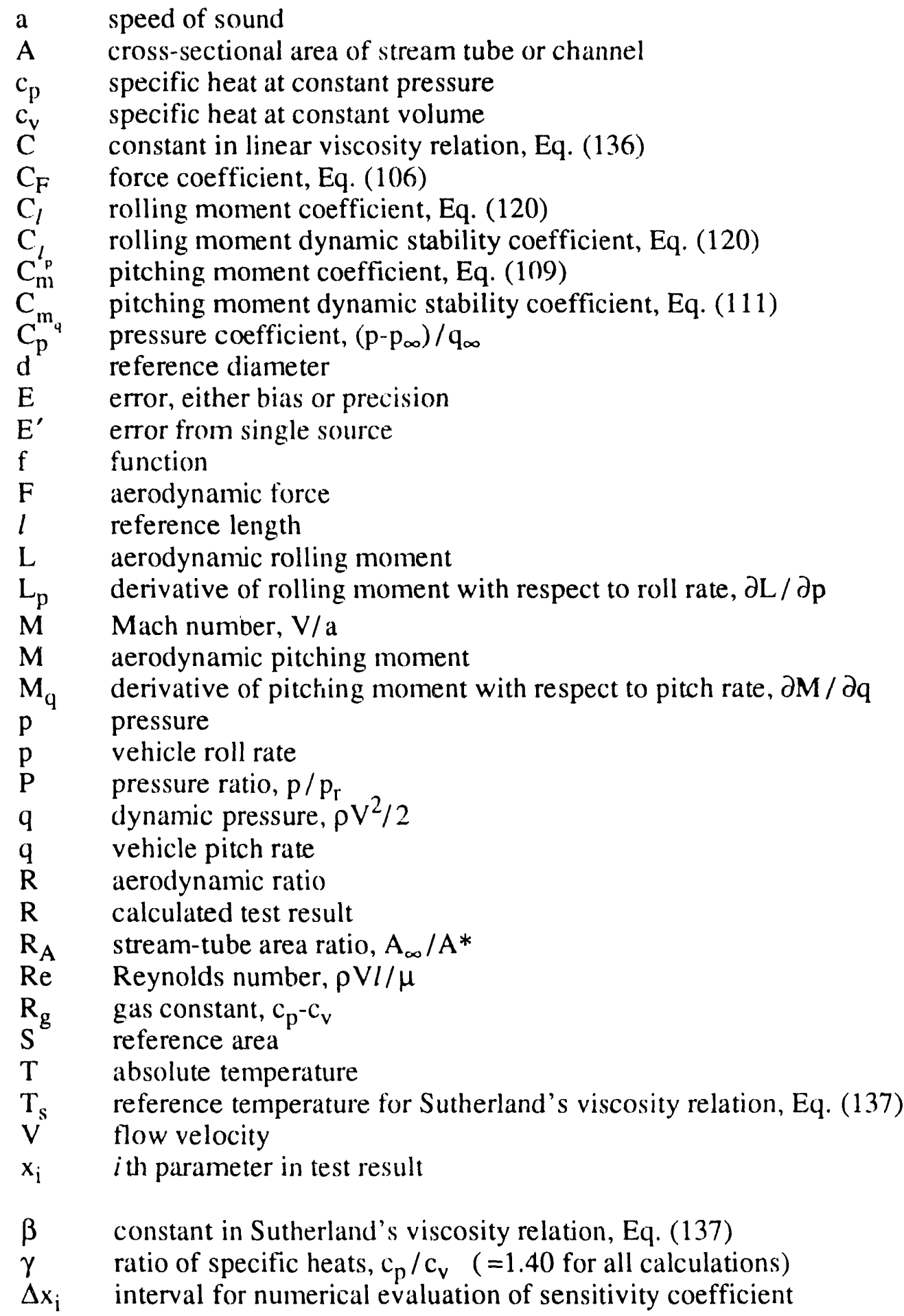

\footnotetext{
${ }^{1}$ Where feasible, the nomenclature of NACA Report 1135, "Equations, Tables, and Charts for Compressible Flow," is used.
} 
$\theta$ absolute sensitivity coefficient, Eq. (5)

$\theta^{\prime} \quad$ relative sensitivity coefficient, Eq. (8)

$\mu \quad$ dynamic (absolute) viscosity

$\rho \quad$ mass density

$\rho_{x_{i} x_{j}} \quad$ coefficient of correlation

\section{Subscripts}

a atmospheric

$\mathrm{g} \quad$ gage pressure measurement

$r$ reference condition

$t$ total (stagnation) condition

1 conditions just upstream of a normal shock wave

2 conditions just downstream of a normal shock wave

$\infty$ free-stream condition

\section{Superscripts}

* critical conditions (local speed equal to local speed of sound, i.e., $M=1.0$ ) 


\section{Error Propagation Equations and Tables for Estimating the Uncertainty in High-Speed Wind Tunnel Test Results}

\section{Introduction}

Evaluation of the uncertainty in an experimental result has always been an important, but frequently neglected, part of the test process. With recent emphasis on quality and traceability of results, it has become essential. Some journals, such as the Journal of Fluids Engineering published by the American Society of Mechanical Engineers (ASME), will no longer accept experimental results unless they include uncertainty estimates. The experimentalist who has learned to use uncertainty estimates finds them invaluable both before and after testing. Pre-test estimates are very useful in selecting the instrumentation and test techniques which will best accomplish the test goals. Post-test estimates provide the user with error bounds which can be indispensable if the data are to be used in design studies. Several organizations including the ASME, Instrument Society of America (ISA), and the International Organization for Standardization (ISO) have established standards which define the uncertainty estimation process. Aerospace organizations will soon be joining this group as the Advisory Group for Aerospace Research \& Development (AGARD) and the American Institute of Aeronautics and Astronautics (AIAA) develop their standards for uncertainty analysis.

Procedures for estimating the uncertainty in experimental measurements are well documented $^{1-6}$. Although there are some differences in the methodologies recommended by various authors, it is generally agreed that the procedure can be divided into three steps: (1) estimate measurement errors, (2) propagate measurement errors to final results and (3) calculate uncertainty. In the first step, the experimentalist defines all independent measurements involved in the experiment. The elemental errors associated with each measurement are then defined, according to categories such as (a) calibration, (b) data acquisition and (c) data reduction. At this point the errors must be classified as bias (fixed or systematic) or precision (random) errors. Finally, the elemental errors are combined by root-sum-squaring, to provide an estimate of the total bias and precision error for each measurement. In most cases, the desired test result is not the actual measurement, but is a calculated result incorporating one or more measurements, for example, a nondimensional ratio or coefficient. Thus, the second step in the uncertainty analysis is to estimate the error in the test result using an error propagation method based on a Taylor series model. The bias and precision errors are propagated separately. Finally, in the third step, the bias and precision errors obtained in the previous step are combined to provide an uncertainty estimate for the test result. The two factors to be combined are the bias error and the precision error multiplied by $t$, the 95 th percentile point for the two-tailed Student $t$ distribution. The combined uncertainty is estimated by direct addition of the two factors, or by a root-sum-squared addition. 
The purpose of the present work is to facilitate, for high-speed aerodynamic testing, the calculations required in step two, that is, propagation of measurement errors to the final result. The Taylor series method requires that the test result functional relationship be differentiated, with respect to each of its parameters, $x_{i}$, to define a set of sensitivity coefficients, $\theta_{x}$. For most experimental aerodynamic results, the calculus and algebra required to evaluate the sensitivity coefficients is difficult. This is especially true for the sensitivity coefficient, $\theta_{M}$, of the free-stream Mach number, $M_{\infty}$. In this report, error propagation equations are derived for many of the nondimensional ratins and coefficients used in highspeed wind tunnel testing. Most of the results are also applicable to low speed wind tunnel tests, but emphasis is on high-speed testing where Mach number is an important parameter. Equations and tabulated values of the sensitivity coefficients, $\theta_{M_{\infty}}$, are provided as functions of $\mathrm{M}_{\infty}$.

\section{Error Propagation Equations}

\subsection{Taylor series model}

The previously cited references ${ }^{1-6}$ all recommend that the Taylor series model be used for error propagation into a result. Detailed derivations of the model are provided in Refs. 1, 2, 4 and 5 and will not be repeated here. Consider a test result, $R$, which is a function of $n$ parameters, $x_{i}$,

$$
R=R\left(x_{1}, x_{2}, \ldots, x_{n}\right) .
$$

Then, the bias or precision error, $E_{R}$, in $R$ is approximated by

$$
E_{R}=\left[\left(\frac{\partial R}{\partial x_{1}} E_{x_{1}}\right)^{2}+\left(\frac{\partial R}{\partial x_{2}} E_{x_{2}}\right)^{2}+\ldots+\left(\frac{\partial R}{\partial x_{n}} E_{x_{11}}\right)^{2}+2 \frac{\partial R}{\partial x_{1}} \frac{\partial R}{\partial x_{2}} \rho_{x_{1} x_{2}} E_{x_{1}} E_{x_{2}}+\ldots\right]^{1 / 2}
$$

where $E_{x}$ is the bias or precision error in $x_{i}$. As was mentioned in the previous section, bias and precision errors are propagated separately and are then combined to estimate the uncertainty in the result. The cross product terms provide the error contribution due to correlated errors and $\rho_{x_{x}}$ is the coefficient of correlation between $x_{1}$ and $x_{2}$. Evaluation of $\rho$ is difficult, and Coleman and Steele ${ }^{7}$ have suggested an alternate equation,

$$
E_{R}=\left[\left(\frac{\partial R}{\partial x_{1}} E_{x_{1}}\right)^{2}+\left(\frac{\partial R}{\partial x_{2}} E_{x_{2}}\right)^{2}+\ldots+\left(\frac{\partial R}{\partial x_{n}} E_{x_{n}}\right)^{2}+2 \frac{\partial R}{\partial x_{1}} \frac{\partial R}{\partial x_{2}} E_{x_{1}}^{\prime} E_{x_{2}}^{\prime}+\ldots\right]^{1 / 2}
$$

where $E_{x_{1}}^{\prime}$ and $E_{x_{2}}^{\prime}$ are the portions of the error in $x_{1}$ and $x_{2}$ that arise from the same source and are presumed to be perfectly correlated $(\rho=1.0)$. This equation is easier to apply than Eq. (2). If the correlation between parameters is a result of the measurements, precision errors are assumed to be independent $(\rho=0)$. However, if the correlation occurs as the result of multiple occurrences of a parameter within the equation for the test result, even precision errors will be correlated and Eq. (2) or (3) must be used. An example of this is given in Section 2.3.2. In any case, if the bias errors are not independent, Eq. (2) or (3) must be used. In evaluating the partial derivatives, it is easy to ignore the sign of the derivatives since 
most of the terms are squared. However, it is essential that the signs be retained for the correlation terms which are not squared.

If the errors are independent, Eq. (2) can be simplified to,

$$
E_{R}=\left[\left(\frac{\partial R}{\partial x_{1}} E_{x_{1}}\right)^{2}+\left(\frac{\partial R}{\partial x_{2}} E_{x_{2}}\right)^{2}+\ldots+\left(\frac{\partial R}{\partial x_{n}} E_{x_{n}}\right)^{2}\right]^{1 / 2} .
$$

The partial derivatives are denoted as absolute sensitivity coefficients, $\theta_{i}$, that is,

$$
\theta_{\mathrm{i}}=\frac{\partial \mathrm{R}}{\partial \mathrm{x}_{\mathrm{i}}}
$$

Then,

$$
E_{R}=\left[\left(\theta_{1} E_{x_{1}}\right)^{2}+\left(\theta_{2} E_{x_{2}}\right)^{2}+\ldots+\left(\theta_{n} E_{x_{n}}\right)^{2}\right]^{1 / 2}
$$

Dividing each side of Eq. (4) by R gives the "relative error" form of the propagation equation,

$$
\frac{E_{R}}{R}=\left[\left(\frac{x_{1}}{R} \frac{\partial R}{\partial x_{1}} \frac{E_{x_{1}}}{x_{1}}\right)^{2}+\left(\frac{x_{2}}{R} \frac{\partial R}{\partial x_{2}} \frac{E_{x_{2}}}{x_{2}}\right)^{2}+\ldots+\left(\frac{x_{n}}{R} \frac{\partial R}{\partial x_{n}} \frac{E_{x_{n}}}{\check{x}_{n}}\right)^{2}\right]^{1 / 2}
$$

This form of the equation is especially useful if the measurement errors are defined as relative errors, $E_{x} / x_{i}$, and if the test result parameters are related only by multiplication and division, e.g., $R^{x_{i}}=x_{1} x_{2} / x_{3}$. When parameters are added or subtracted, e.g., $R=\left(x_{1}+x_{2}\right) / x_{3}$, the relative error form is less useful. This will be seen in the example described in Section 2.3.2. The relative sensitivity coefficient, $\theta^{\prime}{ }_{i}$, is defined as

$$
\theta_{i}^{\prime}=\frac{x_{i}}{R} \frac{\partial R}{\partial x_{i}}
$$

Then,

$$
\frac{E_{R}}{R}=\left[\left(\theta^{\prime}{ }_{1} \frac{E_{x_{1}}}{x_{1}}\right)^{2}+\left(\theta^{\prime} \frac{E_{x_{2}}}{x_{2}}\right)^{2}+\ldots+\left(\theta^{\prime} \frac{E_{x_{n}}}{x_{n}}\right)^{2}\right]^{1 / 2} .
$$

In many cases, analytical evaluation of the sensitivity coefficients is difficult or impossible. Examples include results which involve: (1) complex and/or implicit functions; (2) interpolation of tabulated functions and (3) iterative calculations. The procedure in this case is to use a numerical evaluation of the partial derivatives. Using a central differencing scheme, the derivatives can be approximated by,

$$
\frac{\partial R}{\partial x_{i}}=\lim _{\Delta x_{i} \rightarrow 0}\left[\left(R_{x_{i}+\Delta x_{i} / 2}-R_{x_{i}-\Delta x_{i} / 2}\right) / \Delta x_{i}\right]_{x_{j}=\operatorname{consi}(j \neq i)} .
$$

With this method, nominal values are selected for all of the parameters, $x_{j}$. Then, $R$ is sequentially evaluated by perturbing each $x_{i}(i=1, n)$ by $\pm \Delta x_{i} / 2$ while the remaining $n-1 x_{j}$ 
values remain constant. The two perturbed values of $R$ are differenced and divided by $\Delta x_{i}$. 'The approximate derivatives are used with Eq. (4) to estimate the error in the result. This approach is discussed in detail in Refs. 8 and 9. The advantages of this method are that it avoids complex differentiation and algehra, automatically calculates the effect of correlated variables, and may be the only solution possible. The disadvantage is that it provides only a "point" solution and the functional variation of test result error with a given variable cannot be determined. A simple code. DFDX, which demonstrates this technique is listed in the Appendix. The method is very powerful and was used in the present report to verify the relative sensitivity coefficients for each of the applications listed in Section 4 . For these checks, the increment was $\Delta x_{i}=0.005 x_{i}$ and the numerical results were in excellent agreement ( 4 to 5 significant digits) with the analytical values.

\subsection{Application of the model}

Application of the Taylor series model is straightforward. However, there are two cautions. First, the correct model must be used. If the measurements are independent, Eq. (4) can be used, but if they are not independent, i.e., if two or more of the measurements are correlated, then either Eq. (2) or (3) must be used. This is very important and will be emphasized again in later sections. Second, it is essential that the data reduction equation be solved for the experimental result before performing an uncertainty analysis ${ }^{10}$. This mistake is most likely to occur during a pre-test analysis to estimate the allowable error in a measurement for a given error in the result. For example, let

$$
\mathrm{R}=\mathrm{xy} \text {. }
$$

Estimate the allowable error, $\mathrm{E}_{\mathrm{x}}$, in the measurement, $\mathrm{x}$, for a given error, $\mathrm{E}_{\mathrm{R}}$, in the result, R. From Eq. (4),

$$
\begin{aligned}
E_{R}^{2} & =\left(\frac{\partial R}{\partial x} E_{x}\right)^{2}+\left(\frac{\partial R}{\partial y} E_{y}\right)^{2} \\
& =\left(y E_{x}\right)^{2}+\left(x E_{y}\right)^{2} \\
& =R^{2}\left[\left(\frac{E_{x}}{x}\right)^{2}+\left(\frac{E_{y}}{y}\right)^{2}\right]
\end{aligned}
$$

Then,

$$
E_{x}=x\left[\left(\frac{E_{R}}{R}\right)^{2}-\left(\frac{E_{y}}{y}\right)^{2}\right]^{1 / 2} .
$$

This is the correct estimate of $E_{x}$. However, if the original equation for $R$ is solved for $x$ and $E_{x}$ is estimated from the resulting equation, the result will be in error. Solving Eq. (11) for $\mathrm{x}$ gives,

$$
x=\frac{R}{y}
$$

The error in $\mathrm{x}$ is given by, 


$$
\begin{aligned}
E_{x}^{2} & =\left(\frac{\partial x}{\partial R} E_{R}\right)^{2}+\left(\frac{\partial x}{\partial y} E_{y}\right)^{2} \\
& =\left(\frac{E_{R}}{y}\right)^{2}+\left(\frac{R}{y^{2}} E_{y}\right)^{2}
\end{aligned}
$$

Then,

$$
E_{x}=x\left[\left(\frac{E_{R}}{R}\right)^{2}+\left(\frac{E_{y}}{y}\right)^{2}\right]^{1 / 2} .
$$

Comparison of Eqs. (12) and (14) shows that the second result is incorrect.

\subsection{Example - pressure ratio}

\subsubsection{Independent pressure measurements}

As an example of the use of error propagation equations, consider the simple pressure ratio, $\mathrm{P}$,

$$
P=\frac{p}{p_{r}}
$$

where $\mathrm{p}$ and $\mathrm{p}_{\mathrm{r}}$ are two independent absolute pressure measurements. Typically, in a highspeed wind tunnel test, the reference pressure, $p_{r}$, could be $p_{\infty}$ (measured on the sidewall or with a probe), $p_{t}$ or $p_{t_{2}}$. The measurements are assumed to be independent - this may not be the case if the same standard was used to calibrate both transducers and/or if they share common signal conditioning. From Eq. (4),

$$
E_{P}=\left[\left(\frac{\partial P}{\partial p} E_{p}\right)^{2}+\left(\frac{\partial P}{\partial p_{r}} E_{p_{r}}\right)^{2}\right]^{1 / 2}
$$

Differentiating Eq. (15) and substituting the results in Eq. (16) gives

$$
E_{p}=\left[\left(\frac{1}{p_{r}} E_{p}\right)^{2}+\left(-\frac{p}{p_{r}^{2}} E_{p_{r}}\right)^{2}\right]^{1 / 2},
$$

and simplifying,

$$
E_{P}=\frac{1}{p_{r}}\left[E_{p}^{2}+\left(P E_{p_{r}}\right)^{2}\right]^{1 / 2}
$$

In the relative error form, 


$$
\frac{E_{p}}{P}=\left[\left(\frac{E_{p}}{p}\right)^{2}+\left(\frac{E_{p_{r}}}{p_{r}}\right)^{2}\right]^{1 / 2} .
$$

This is the simplest form of error propagation and shows that the relative error in the result is the root-sum-square of the relative errors in the two measurements.

\subsubsection{Correlated pressures}

Now, assume that the two pressure measurements are gage, not absolute. Then, the two absolute pressures required for the ratio are given by

$$
\begin{gathered}
\mathrm{p}=\mathrm{p}_{\mathrm{g}}+\mathrm{p}_{\mathrm{a}} \\
\mathrm{p}_{\mathrm{r}}=\mathrm{p}_{\mathrm{r}, \mathrm{g}}+\mathrm{p}_{\mathrm{a}}
\end{gathered}
$$

where $p_{g}$ and $p_{r, g}$ are the two independent gage pressure measurements and $p_{a}$ is the measured atmospheric pressure. In this case, the calculated pressures $\mathrm{p}$ and $\mathrm{p}_{\mathrm{r}}$ are correlated by $\mathrm{p}_{\mathrm{a}}$. The pressure ratio, $\mathrm{P}$, is given by,

$$
P=\frac{p_{g}+p_{a}}{p_{r, g}+p_{a}}
$$

Calculation of the error in $\mathrm{P}$ is much more complicated than in the previous case, where $\mathrm{p}$ and $\mathrm{p}_{\mathrm{r}}$ were independent. The error will be evaluated analytically, using two techniques, and numerically with the code DFDX, which was described earlier.

\subsubsection{Analytical evaluation-independent variables}

If the required calculus and algebra associated with determining the sensitivity coefficients permits, it is always best to express the result in terms of the individual measurements, that is, in its most elementary form. This avoids the problems which can occur with

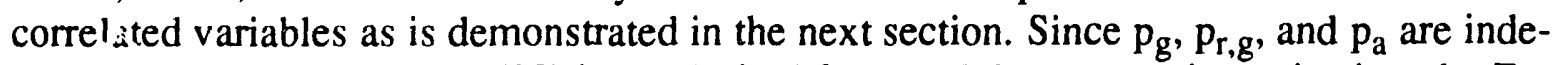
pendent measurements, Eq. (20) is the desired form and the error estimate is given by Eq. (4),

$$
E_{P}=\left[\left(\frac{\partial P}{\partial p_{g}} E_{p_{B}}\right)^{2}+\left(\frac{\partial P}{\partial p_{r, g}} E_{p_{r, g}}\right)^{2}+\left(\frac{\partial P}{\partial p_{a}} E_{p_{a}}\right)^{2}\right]^{1 / 2}
$$

Performing the indicated partial differentiation and simplifying gives,

$$
E_{P}=P\left[\left(\frac{E_{p_{g}}}{p}\right)^{2}+\left(\frac{E_{p_{r, g}}}{p_{r}}\right)^{2}+\left(\frac{1}{p}-\frac{1}{p_{r}}\right)^{2} E_{p_{g}}^{2}\right]^{1 / 2}
$$

or, 


$$
E_{p}=F\left[\left(\frac{E_{p_{g}}}{p}\right)^{2}+\left(\frac{E_{p_{r, g}}}{p_{r}}\right)^{2}+\left(\frac{1}{p^{2}}+\frac{1}{p_{r}^{2}}-\frac{2}{p p_{r}}\right) E_{p_{a}}^{2}\right]^{1 / 2}
$$

Notice that in this equation, the pressures in the denominators are the absolute pressures $p$ and $\mathrm{p}_{\mathrm{r}}$, not the gage nressures $\mathrm{p}_{\mathrm{g}}$ and $\mathrm{p}_{\mathrm{r}, \mathrm{g}}$. Therefore, this is not the usual relative error form.

\subsubsection{Analytical evaluation-dependent variables}

Frequently, it is easier to differentiate the unexpanded equation, Eq. (15) in this case. If we were to take this easier course and treat $p$ and $p_{r}$ as independent variables, we would obtain the error in $\mathrm{P}$ as,

$$
E_{P}=\left[\left(\frac{\partial P}{\partial p} E_{p}\right)^{2}+\left(\frac{\partial P}{\partial p_{r}} E_{p_{r}}\right)^{2}\right]^{1 / 2}
$$

Then, differentiating Eq. (15) and simplifying,

$$
E_{P}=P\left[\left(\frac{E_{p}}{p}\right)^{2}+\left(\frac{E_{p_{r}}}{p_{r}}\right)^{2}\right]^{1 / 2}
$$

The effect of errors in $\mathrm{p}_{\mathrm{a}}$ is concealed in this equation. Expanding $\mathrm{p}$ and $\mathrm{p}_{\mathrm{r}}$, Eq. (19), and estimating their errors gives,

$$
E_{p}^{2}=E_{p_{g}}^{2}+E_{p_{a}}^{2}
$$

and

$$
E_{p_{r}}^{2}=E_{p_{r, g}}^{2}+E_{p_{a}}^{2}
$$

Substituting these expressions into Eq. (25) gives

$$
E_{P}=P\left[\left(\frac{E_{p_{g}}}{p}\right)^{2}+\left(\frac{E_{p_{r, g}}}{p_{r}}\right)^{2}+\left(\frac{1}{p^{2}}+\frac{1}{p_{r}^{2}}\right) E_{p_{a}}^{2}\right]^{1 / 2} .
$$

Comparing Eq. (28) to Eq. (23) shows that there is a missing term, $-2 \mathrm{E}_{\mathrm{p}}^{2} / \mathrm{pp}_{\mathrm{r}}$. Therefore, Eq. (28) will overpredict the error in $E_{p}$. The reason for this is that $p$ and ${ }_{p_{r}}$ were treated as independent variables, whereas they are actually correlated by $\mathrm{p}_{\mathrm{a}}$.

For a correct error estimate with correlated variables, use Eq. (2) or (3). Using Eq. (3),

$$
E_{P}=\left[\left(\frac{\partial P}{\partial p} E_{p}\right)^{2}+\left(\frac{\partial P}{\partial p_{r}} E_{p_{r}}\right)^{2}+2 \frac{\partial P}{\partial p} \frac{\partial P}{\partial p_{r}} E_{p}^{\prime} E_{p_{r}}^{\prime}\left(p_{a}\right)\right]^{1 / 2}
$$


where $E_{p}^{\prime}$ and $E^{\prime}$ are the portions of the error in $p$ and $p_{r}$ that originate from the correlating factor, $p_{a}$. From Eqs. (26) and (27),

$$
\begin{aligned}
& E_{p}^{\prime}=E_{p_{\text {. }}} \\
& E_{p_{r}}^{\prime}=E_{p_{0}} .
\end{aligned}
$$

The sensitivity coefficients are,

$$
\frac{\partial P}{\partial p}=\frac{1}{p_{r}} \quad \text { and } \quad \frac{\partial P}{\partial p_{r}}=-\frac{p}{p_{r}^{2}} \text {. }
$$

Substituting these relations into Eq. (29) and simplifying gives,

$$
E_{p}=P\left[\left(\frac{E p_{g}}{p}\right)^{2}+\left(\frac{E_{p_{r, ~}}}{p_{r}}\right)^{2}+\left(\frac{1}{p^{2}}+\frac{1}{p_{r}^{2}}-\frac{2}{p p_{r}}\right) E_{p_{s}}^{2}\right]^{1 / 2}
$$

which agrees with Eq. (23).

\subsubsection{Numerical evaluation}

Program DFDX described earlier was used with Eq. (20) to estimate the three sensitivity coefficients $-\theta_{p_{g}}, \theta_{p_{r, g}}$ and $\theta_{p_{a}}$. The numerical results agreed with Eq. (23).

\subsubsection{Pre-test analysis benefits}

In addition to demonstrating various error propagation techniques, this example shows the value of pre-test uncertainty analysis. The error in $\mathrm{P}$ due to $\mathrm{p}_{\mathrm{a}}$ is given by,

$$
E_{P}=\frac{\partial P}{\partial p_{a}} E_{p_{a}}
$$

Then, the relative error is

$$
\frac{E_{P}}{P}=\frac{p_{a}}{P} \frac{\partial P}{\partial p_{a}} \frac{E_{p_{a}}}{p_{a}},
$$

or, with the definition of the relative sensitivity coefficient,

$$
\frac{E_{P}}{P}=\theta_{p_{2}}^{\prime} \frac{E_{p_{a}}}{p_{a}} .
$$

Therefore, a relative error of $0.01(1 \%)$ in $\mathrm{p}_{\mathrm{a}}$ will appear as an $0.01 \theta_{\mathrm{p}_{\mathrm{a}}}^{\prime}$ relative error in the ratio, P. Differentiating Eq. (20) with respect to $\mathrm{p}_{\mathrm{a}}$ gives,

$$
\frac{\partial \mathrm{P}}{\partial \mathrm{p}_{\mathrm{a}}}=\frac{1}{\mathrm{p}_{\mathrm{r}}}-\frac{\mathrm{p}}{\mathrm{p}_{\mathrm{r}}^{2}}=\mathrm{P}\left(\frac{1}{\mathrm{p}}-\frac{1}{\mathrm{p}_{\mathrm{r}}}\right)
$$

which is the expression used earlier in Eq. (22). Then, 


$$
\theta_{\mathrm{p}_{\mathrm{a}}}^{\prime}=\frac{\mathrm{p}_{\mathrm{a}}}{\mathrm{P}} \frac{\partial \mathrm{P}}{\partial \mathrm{p}_{\mathrm{a}}}=\left(\frac{1}{\mathrm{p}}-\frac{1}{\mathrm{p}_{\mathrm{r}}}\right) \mathrm{p}_{\mathrm{a}}
$$

This relation has been plotted below for $\mathrm{p}_{a}=15$ psia and values of $p$ and $\mathrm{p}_{r}$ ranging from 1 to $50 \mathrm{psia}$. This figure is useful for pre-test instrumentation selection. If $\mathrm{p}$ and $\mathrm{p}_{\mathrm{r}}$ are based on gage pressure measurements, then, for small relative error in $\mathrm{P}$, one or more of three conditions must exist: (1) $E_{p} / p_{a}$ is very small; (2) $p \approx p_{r}$, or (3) $p$ and $p_{r}$ must be large $(>10$ psia for $\left.\theta_{p_{2}}^{\prime}<1\right)$. If these conditions cannot be met, absolute pressure transducers must be used.

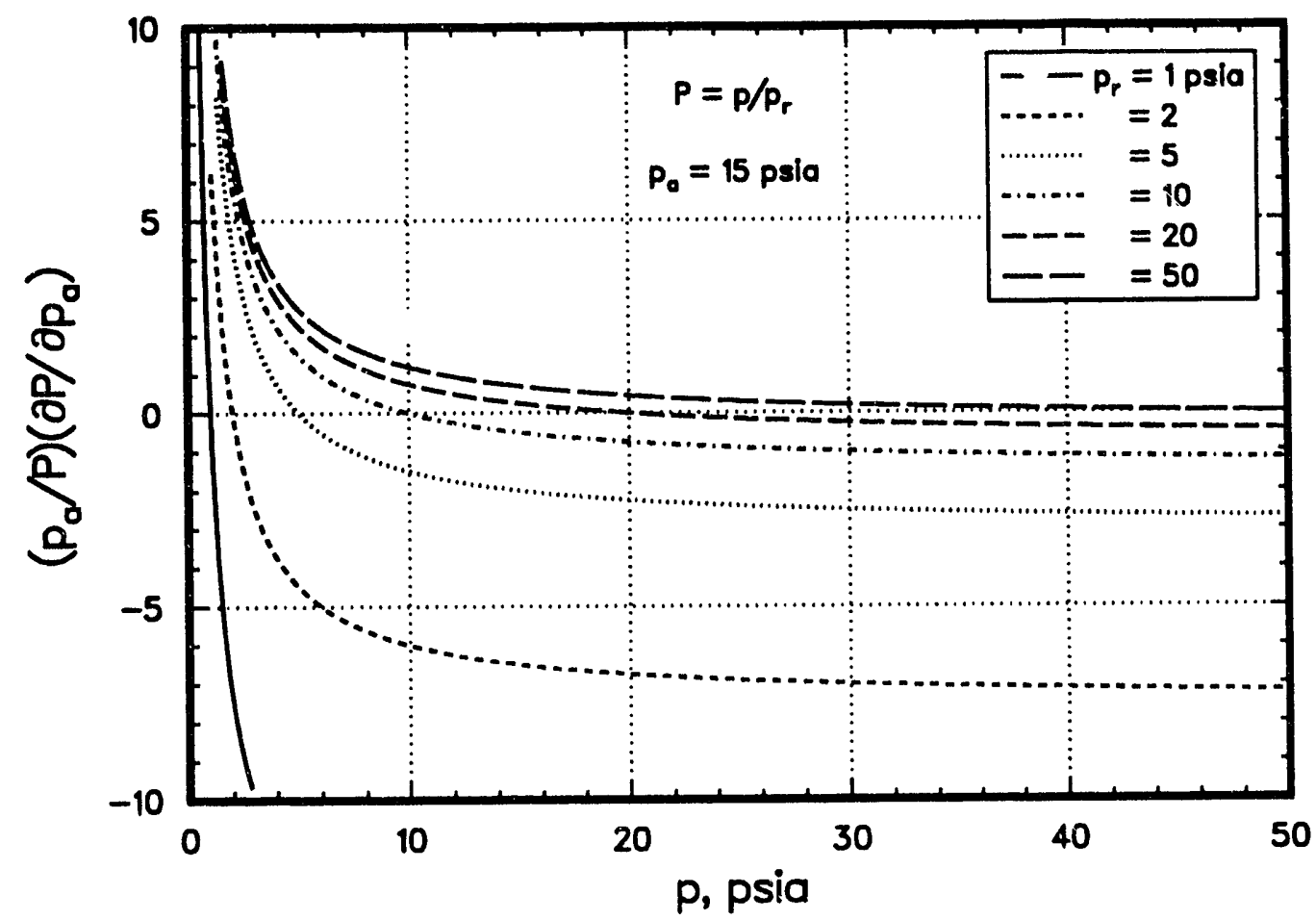

Variation of relative sensitivity coefficient $\left(\mathrm{p}_{\mathrm{a}} / \mathrm{P}\right)\left(\partial \mathrm{P} / \partial \mathrm{p}_{\mathrm{a}}\right)$ with $\mathrm{p}$ and $\mathrm{p}_{\mathrm{r}}$

\section{Sensitivity Coefficients - Aerodynamic Ratios}

The aerodynamic ratios considered in this section are basic to high-speed aerodynamics and, in general, relate calculated free-stream conditions to measured total (stagnation) conditions. There are two reasons for interest in these ratios. First, they provide a means of estimating the uncertainty in the calculated free-stream conditions. Second, they are required for evaluating the uncertainty in the more complex applications which are discussed in Section 4. In all cases, these aerodynamic ratios are functions of only the free-stream Mach number, $\mathrm{M}_{\infty}$, and the ratio of specific heats, $\gamma$. In Section 2.3, the uncertainty in the pressure ratio, $R=p / p_{r}$, was examined. In that case, both pressures were measured values. In the present section, only the total condition is measured-the free-stream value is to be 
calculated from the aerodynamic ratio, $\mathrm{R}$, and the total condition. For example, consider the ratio of free-stream pressure, $p_{\infty}$, to total pressure, $p_{t}$,

$$
R=\frac{p_{\infty}}{p_{t}}=f\left(M_{\infty}, \gamma\right) \text {. }
$$

Then, the free-stream static pressure is calculated with

$$
\mathrm{p}_{\infty}=\mathrm{R}\left(\mathrm{M}_{\infty}, \gamma\right) \mathrm{p}_{\mathrm{t}} \text {. }
$$

Assuming that the variables are independent, the error in $\mathrm{p}_{\infty}$ is given by

$$
E_{p_{\infty}}=\left[\left(\frac{\partial p_{\infty}}{\partial M_{\infty}} E_{M_{\infty}}\right)^{2}+\left(\frac{\partial p_{\infty}}{\partial \gamma} E_{\gamma}\right)^{2}+\left(\frac{\partial p_{\infty}}{\partial p_{t}} E_{p_{t}}\right)^{2}\right]^{1 / 2}
$$

Letting $\mathrm{E}_{\gamma}=0$ and expanding the partial derivative in the first term (chain rule),

$$
E_{p_{\infty}}=\left[\left(\frac{\partial p_{\infty} \partial R}{\partial R} \frac{\partial M_{\infty}}{\partial M_{\infty}}\right)^{2}+\left(\frac{\partial p_{\infty}}{\partial p_{t}} E_{p_{t}}\right)^{2}\right]^{1 / 2} .
$$

Differentiating Eq. (35) and substituting in Eq. (37) gives the absolute error,

$$
E_{p_{\infty}}=\left[\left(p_{t} \frac{\partial R}{\partial M_{\infty}} E_{M_{\infty}}\right)^{2}+\left(R E_{p_{t}}\right)^{2}\right]^{1 / 2}
$$

The sensitivity coefficient for Mach number is,

$$
\theta_{M_{\infty}} \equiv \frac{\partial p_{\infty}}{\partial M_{\infty}}=p_{t} \frac{\partial R}{\partial M_{\infty}}
$$

Dividing both sides of Eq. (38) by $\mathrm{p}_{\infty}$ gives the relative error,

$$
\frac{E_{p_{\infty}}}{p_{\infty}}=\left[\left(\frac{M}{R} \frac{\partial R}{\partial M_{\infty} M_{\infty}}\right)^{2}+\left(\frac{E_{p_{1}}}{p_{t}}\right)^{2}\right]^{1 / 2} \text {. }
$$

The relative sensitivity coefficient for $M_{\infty}$ is

$$
\theta_{M_{\infty}}^{\prime}=\frac{M_{\infty}}{R} \frac{\partial R}{\partial M_{\infty}} \text {. }
$$

In evaluating Eq. (38) or (40), if $\mathrm{p}_{\mathrm{t}}$ is calculated from a gage pressure measurement, $\mathrm{p}_{\mathrm{t}, \mathrm{g}}$, then

$$
\mathrm{p}_{\mathrm{t}}=\mathrm{p}_{\mathrm{t}, \mathrm{g}}+\mathrm{p}_{\mathrm{a}}
$$

where $\mathrm{p}_{\mathrm{a}}$ is measured atmospheric pressure. The error in $\mathrm{p}_{\mathrm{t}}$ is

$$
E_{p_{t}}=\left[\left(\frac{\partial p_{t}}{\partial p_{t, g}} E_{p_{t, g}}\right)^{2}+\left(\frac{\partial p_{t}}{\partial p_{a}} E_{p_{a}}\right)^{2}\right]^{1 / 2}
$$




$$
E_{p_{t}}=\left[E_{p_{h}}^{2}+E_{p_{s}}^{2}\right]^{1 / 2}
$$

This value of $E_{p_{t}}$ would then be substituted in Eq. (38) or (40).

The analysis in this section makes several assumptions. First, it will be assumed that $p_{t}$ is an absolute pressure measurement (or equivalently, that $E_{p}$ is negligible). If this is not the case, Eq. (43) can be used with Eq. (38) or (40). Second, it will be assumed that there is negligible error in $\gamma$, i.e., $\mathrm{E}_{\gamma}=0$. Finally, it is assumed that $\mathrm{M}_{\infty}$ and $\mathrm{p}_{\mathrm{t}}$ are independent. This may not be true in many tunnels where the free-stream Mach number is determined from a calibration relation which is a function of total pressure. In this case there are three options. First, expand the equation of interest to its elemental parameters, which are independent, and differentiate it with respect to each parameter to evaluate the sensitivity coefficients. Equation (4) can then be used to define the error equation. Second, modify the error equation to include the effect of correlated parameters, e.g., use Eq. (3). Then use the sensitivity coefficients for Mach number, which are given in the following sections, with the appropriate error estimates defined by the $\mathrm{M}_{\infty}$ calibration relation. Third, use a numerical evaluation which defines sensitivity coefficients that include the effects of correlated parameters. These coefficients can be used with an error equation based on Eq. (4).

In the following subsections, the derivative $\partial R / \partial M_{\infty}$ and the relative sensitivity coefficient, $\theta^{\prime} M_{\infty}=\left(M_{\infty} / R\right)\left(\partial R / \partial M_{\infty}\right)$, will be evaluated as functions of $M_{\infty}$ for nine fundamental aerodynamic ratios. Values of $R, \partial R / \partial M_{\infty}$, and $\theta^{\prime} M_{\infty}$ are tabulated for $\gamma=1.40$. The calculated values of $R$ were checked by comparing them to the values given in Ref. 11 . Analytical values of $\partial R / \partial M_{\infty}$ were checked by numerical differentiation of the tabulated values of $R$. The reciprocals of the derivative and relative sensitivity coefficient are also tabulated and are useful in estimating the sensitivity of $M_{\infty}$ to the various ratios.

\subsection{Free-stream static pressure ratio, $R=p_{\infty} / p_{t}$}

The equations for free-stream static pressure, $\mathrm{p}_{\infty}$, and its absolute and relative errors are given above by Eqs. (35), (38) and (40), respectively:

$$
\begin{gathered}
p_{\infty}=R\left(M_{\infty}, \gamma\right) p_{t} \\
E_{p_{\infty}}=\left[\left(p_{1} \frac{\partial R}{\partial M_{\infty}} E_{M}\right)^{2}+\left(R E_{p_{1}}\right)^{2}\right]^{1 / 2} \\
\frac{E_{p_{\infty}}}{p_{\infty}}=\left[\left(\frac{M}{R} \frac{\partial R}{\partial M_{\infty} M_{\infty}}\right)^{2}+\left(\frac{E_{p_{t}}}{p_{t}}\right)^{2}\right]^{1 / 2}
\end{gathered}
$$


For an isentropic flow of a perfect gas ${ }^{1}$, Eq.(44) of Ref. 11 gives,

$$
R=\frac{p_{\infty}}{p_{t}}=\left(1+\frac{\gamma-1}{2} M_{\infty}^{2}\right)^{-\frac{\gamma}{\gamma-1}} .
$$

Differentiating Eq. (44) with respect to $M_{\infty}$ gives

$$
\frac{\partial R}{\partial M_{\infty}}=-\frac{\gamma M_{\infty} R}{1+\frac{\gamma-1}{2} M_{\infty}^{2}}
$$

The relative sensitivity coefficient is

$$
\theta^{\prime} M_{\infty}=\frac{M_{\infty}}{R} \frac{\partial R}{\partial M_{\infty}}=-\frac{\gamma M_{\infty}^{2}}{1+\frac{\gamma-1}{2} M_{\infty}^{2}} .
$$

For $\gamma=1.40$, values of $R, \partial R / \partial M_{\infty}$ and $\left(M_{\infty} / R\right)\left(\partial R / \partial M_{\infty}\right)$ are plotted in Figure 1 and tabulated in Table 1 . The free-stream static pressure ratio can be used, with measured values of $\mathrm{p}_{\infty}$ and $\mathrm{p}_{t}$, to calculate Mach number. This application is discussed in Section 4.5.

\subsection{Free-stream dynamic pressure ratio, $R=q_{\infty} / p_{t}$}

The free-stream dynamic pressure, $q_{\infty}$, is calculated from

$$
q_{\infty}=R\left(M_{\infty}, \gamma\right) j_{t}
$$

and the error equations are

$$
E_{q_{\infty}}=\left[\left(p_{t} \frac{\partial R}{\partial M_{\infty}} E_{M_{\infty}}\right)^{2}+\left(R E_{p_{t}}\right)^{2}\right]^{1 / 2}
$$

and

$$
\frac{E_{q_{\infty}}}{q_{\infty}}=\left[\left(\frac{M}{R} \frac{\partial R}{\partial M_{\infty} M_{\infty}}\right)^{2}+\left(\frac{E_{p_{1}}}{p_{t}}\right)^{2}\right]^{1 / 2} .
$$

For an isentropic flow of a perfect gas, Eq. (48) of Ref. 11 gives,

$$
\mathrm{R}=\frac{\mathrm{q}_{\infty}}{\mathrm{p}_{\mathrm{t}}}=\frac{\gamma}{2} \mathrm{M}_{\infty}^{2}\left(1+\frac{\gamma-1}{2} \mathrm{M}_{\infty}^{2}\right)^{-\frac{\gamma}{\gamma-1}}
$$

Differentiating Eq. (50) with respect to $M_{\infty}$ gives

\footnotetext{
${ }^{1}$ Following the notation of Ref. 11 , a "thermally perfect" gas is one which obeys the thermal equation of state, $p=\rho R_{g} T$. A "calorically perfect" gas is one which has constant specific heats, $c_{p}$ and $c_{v}$. A "perfect" gas is both thermally and calorically perfect.
} 


$$
\frac{\partial R}{\partial M_{\infty}}=\frac{R}{M_{\infty}}\left(\frac{2-M_{\infty}^{2}}{1+\frac{\gamma-1}{2} M_{\infty}^{2}}\right)
$$

The relative sensitivity coefficient is

$$
\theta^{\prime} M_{\infty}=\frac{M_{\infty}}{R} \frac{\partial R}{\partial M_{\infty}}=\frac{2-M_{\infty}^{2}}{1+\frac{\gamma-1}{2} M_{\infty}^{2}}
$$

For $\gamma=1.40$, values of $R, \partial R / \partial M_{\infty}$ and $\left(M_{\infty} / R\right)\left(\partial R / \partial M_{\infty}\right)$ are plotted in Figure 2 and tabulated in Table 2.

\subsection{Free-stream dynamic pressure ratio, $R=q_{\infty} / p_{t_{2}}$}

In some instances, it may be desirable to calculate free-stream dynamic pressure from the measured pitot pressure. This is especially true at hypersonic Mach numbers where $R$ is insensitive to $M_{\infty}$. The free-stream dynamic pressure, $q_{\infty}$, is calculated from

$$
\mathrm{q}_{\infty}=\mathrm{R}\left(\mathrm{M}_{\infty}, \gamma\right) \mathrm{p}_{\mathrm{t}_{2}} .
$$

The error equations are

$$
E_{q_{\infty}}=\left[\left(p_{t_{2}} \frac{\partial R}{\partial M_{\infty}} E_{M_{\infty}}\right)^{2}+\left(R E_{p_{t_{2}}}\right)^{2}\right]^{1 / 2}
$$

and

$$
\frac{E_{q_{\infty}}}{q_{\infty}}=\left[\left(\frac{M_{\infty}}{R} \frac{\partial R}{\partial M_{\infty} M_{\infty}}\right)^{2}+\left(\frac{E_{p_{t_{2}}}}{p_{t_{2}}}\right)^{2}\right]^{1 / 2} \text {. }
$$

For $M=M_{\infty}, p_{t_{1}}=p_{t}$ and the ratio can be expressed as

$$
R=\frac{q_{\infty}}{p_{t_{2}}}=\frac{q_{\infty}}{p_{t}} \frac{p_{t_{1}}}{p_{t_{2}}}
$$

At free-stream Mach numbers less than 1.0 there is no shock wave ahead of the pitot tube so $p_{t}=p_{t}$ and $R=q_{\infty} / p_{t}$ (see Section 3.2). For $M_{\infty} \geq 1.0$, with adiabatic flow of a perfect gas, Equs. (48) and (99) of Ref. 11 are substituted into Eq. (56) giving

$$
R=\frac{\gamma}{2} M_{\infty}^{2}\left(1+\frac{\gamma-1}{2} M_{\infty}^{2}\right)^{-\frac{\gamma}{\gamma-1}}\left[\frac{(\gamma+1) M_{\infty}^{2}}{(\gamma-1) M_{\infty}^{2}+2}\right]^{-\frac{\gamma}{\gamma-1}}\left[\frac{\gamma+1}{2 \gamma M_{\infty}^{2}-(\gamma-1)}\right]^{-\frac{1}{\gamma-1}}
$$

Simplifying this equation, 


$$
\mathrm{R}=\frac{\gamma}{2}\left(\frac{2}{\gamma+1}\right)^{\frac{\gamma+1}{\gamma-1}}\left(\frac{2 \gamma \mathrm{M}_{\infty}^{2}-(\gamma-1)}{2 \mathrm{M}_{\infty}^{2}}\right)^{\frac{1}{\gamma-1}}
$$

Differentiating Eq. (57) with respect to $M_{\infty}$ gives

$$
\frac{\partial R}{\partial M_{\infty}}=\frac{2 R}{M_{\infty}}\left[\frac{1}{2 \gamma M_{\infty}^{2}-(\gamma-1)}\right] .
$$

The relative sensitivity coefficient is

$$
\theta_{M_{\infty}}^{\prime}=\frac{M_{\infty}}{R} \frac{\partial R}{\partial M_{\infty}}=\frac{2}{2 \gamma M_{\infty}^{2}-(\gamma-1)} .
$$

For $\gamma=1.40$, values of $R, \partial R / \partial M_{\infty}$ and $\left(M_{\infty} / R\right)\left(\partial R / \partial M_{\infty}\right)$ are plotted in Figure 3 and tabulated in Table 3. With the tabulated values of Table 3, the earlier statement concerning the insensitivity of $\mathrm{q}_{\infty} / \mathrm{p}_{\mathrm{t}}$ to $\mathrm{M}_{\infty}$ can be quantified. For example, with $\mathrm{M}_{\infty}=5.0, \theta^{\prime}{ }_{M_{\infty}}=$ 0.02874 and a $5 \%$ uncertainty in Mach number $\left(\mathrm{E}_{\mathrm{M}}=0.25\right)$ will give a relative error in $\mathrm{q}_{\infty}$ of only $0.02874 \times 0.25 / 5.0=0.0014$. The error decreases with increasing Mach number. Thus, a pitot tube measurement can be used to accurately calculate the local dynamic pressure in hypersonic flow fields even when the local Mach number is not known with high accuracy.

\subsection{Pitot pressure ratio, $R=p_{t_{2}} / p_{t_{1}}$}

The pitot pressure, $\mathrm{p}_{\mathrm{t}_{2}}$, is calculated from

$$
p_{t_{2}}=R\left(M_{\infty}, \gamma\right) p_{t_{1}}
$$

The error equations are

$$
E_{p_{t_{2}}}=\left[\left(p_{t_{1}} \frac{\partial R}{\partial M_{\infty}} E_{M_{\infty}}\right)^{2}+\left(R E_{p_{t_{1}}}\right)^{2}\right]^{1 / 2}
$$

and

$$
\frac{E_{p_{t_{2}}}}{p_{t_{2}}}=\left[\left(\frac{M}{R} \frac{\partial R}{\partial M_{\infty} M_{\infty}}\right)^{2}+\left(\frac{E_{p_{t_{1}}}}{p_{t_{1}}}\right)^{2}\right]^{1 / 2} .
$$

For free-stream Mach numbers less than 1.0, $\mathrm{p}_{\mathrm{t}}=\mathrm{p}_{\mathrm{t}_{1}}$ and $\mathrm{R}=1.0$. For $\mathrm{M}_{\infty} \geq 1.0$ with adiabatic flow of a perfect gas, Eq (99) of Ref. 11 gives, 


$$
R=\frac{p_{t_{2}}}{p_{t_{1}}}=\left[\frac{(\gamma+1) M_{\infty}^{2}}{(\gamma-1) M_{\infty}^{2}+2}\right]^{\frac{\gamma}{\gamma-1}}\left[\frac{\gamma+1}{2 \gamma M_{\infty}^{2}-(\gamma-1)}\right]^{\frac{1}{\gamma-1}} .
$$

Differentiating Eq. (63) with respect to $M_{\infty}$ gives

$$
\frac{\partial R}{\partial M_{\infty}}=\frac{4 \gamma R}{\gamma-1}\left[\frac{1}{M_{\infty}\left[(\gamma-1) M_{\infty}^{2}+2\right]}-\frac{M_{\infty}}{2 \gamma M_{\infty}^{2}-(\gamma-1)}\right] .
$$

The relative sensitivity coefficient is

$$
\theta_{M_{\infty}}^{\prime}=\frac{M_{\infty}}{R} \frac{\partial R}{\partial M_{\infty}}=\frac{4 \gamma M_{\infty}}{\gamma-1}\left[\frac{1}{M_{\infty}\left[(\gamma-1) M_{\infty}^{2}+2\right]}-\frac{M_{\infty}}{2 \gamma M_{\infty}^{2}-(\gamma-1)}\right] .
$$

For $\gamma=1.40$, values of $R, \partial R / \partial M_{\infty}$ and $\left(M_{\infty} / R\right)\left(\partial R / \partial M_{\infty}\right)$ are plotted in Figure 4 and tabulated in Table 4 . The pitot pressure ratio can be used, with measured values of $\mathrm{p}_{\mathrm{t} 1}$ and $\mathrm{p}_{\mathrm{t} 2}$, to calculate Mach number. This application is discussed in Section 4.5.

\subsection{Rayleigh pitot ratio, $R=\mathbf{p}_{\infty} / \mathbf{p}_{\mathrm{t}_{2}}$}

The Rayleigh pitot ratio is normally used, not to calculate $p_{\infty}$ or $p_{t}$, but to calculate $M_{\infty}$ from the two measured pressures. This application will be discussed in more detail in Section 4.5. At free-stream Mach numbers less than 1.0, $\mathrm{p}_{\mathrm{t}_{2}}=\mathrm{p}_{\mathrm{t}}$ and $\mathrm{R}=\mathrm{p}_{\infty} / \mathrm{p}_{\mathrm{t}}$ (see Section 3.1). For $M_{\infty} \geq 1.0$ with adiabatic flow of a perfect gas, ${ }^{2}$. (100) of Ref. 11 gives,

$$
R=\frac{p_{\infty}}{p_{t_{2}}}=\frac{p_{1}}{p_{t_{2}}}=\left[\frac{2}{(\gamma+1) M_{\infty}^{2}}\right]^{\frac{\gamma}{\gamma-1}}\left[\frac{2 \gamma M_{\infty}^{2}-(\gamma-1)}{\gamma+1}\right]^{\frac{1}{\gamma-1}} .
$$

Differentiating Eq. (66) with respect to $\mathrm{M}_{\infty}$ gives

$$
\frac{\partial R}{\partial M_{\infty}}=\frac{R}{M_{\infty}}\left[\frac{2 \gamma\left(1-2 M_{\infty}^{2}\right)}{2 \gamma M_{\infty}^{2}-(\gamma-1)}\right] .
$$

The relative sensitivity coefficient is

$$
\theta^{\prime} M_{\infty}=\frac{M_{\infty}}{R} \frac{\partial R}{\partial M_{\infty}}=\frac{2 \gamma\left(1-2 M_{\infty}^{2}\right)}{2 \gamma M_{\infty}^{2}-(\gamma-1)} .
$$

For $\gamma=1.40$, values of $R, \partial R / \partial M_{\infty}$ and $\left(M_{\infty} / R\right)\left(\partial R / \partial M_{\infty}\right)$ are plotted in Figure 5 and tabulated in Table 5. 


\subsection{Stream-tube area ratio, $R=A_{\infty} / A^{*}$}

The stream-tube area ratio is used to evaluate the mass flow sensitivity (Section 3.7). It will also be used in the applications (Section 4.4) to estimate the error in $q_{\infty} / V_{\infty}$. For an isentropic flow of a perfect gas, Eq. (80) of Ref. 11 gives

$$
R=\frac{A_{\infty}}{A^{*}}=\frac{1}{M_{\infty}}\left[\left(\frac{2}{\gamma+1}\right)\left(1+\frac{\gamma-1}{2} M_{\infty}^{2}\right)\right]^{\frac{\gamma+1}{2(\gamma-1)}} .
$$

Differentiating Eq. (69) with respect to $i M_{\infty}$ gives

$$
\frac{\partial R}{\partial M_{\infty}}=R\left[\frac{M_{\infty}^{2}-1}{M_{\infty}\left(1+\frac{\gamma-1}{2} M_{\infty}^{2}\right)}\right] \text {. }
$$

The relative sensitivity coefficient is

$$
\theta^{\prime} M_{\infty}=\frac{M_{\infty}}{R} \frac{\partial R}{\partial M_{\infty}}=\frac{M_{\infty}^{2}-1}{1+\frac{\gamma-1}{2} M_{\infty}^{2}}
$$

For $\gamma=1.40$, values of $R, \partial R / \partial \mathrm{M}_{\infty}$ and $\left(\mathrm{M}_{\infty} / \mathrm{R}\right)\left(\partial \mathrm{R} / \partial \mathrm{M}_{\infty}\right)$ are plotted in Figure 6 and tabulated in Table 6.

The stream-tube area ratio can also be used to estimate the sensitivity of $\mathrm{M}_{\infty}$ to changes in the sonic throat cross-sectional area and to changes in the test section cross-sectional area (e.g., blockage at subsonic speeds). Since

$$
\begin{aligned}
R & =f\left(M_{\infty}, \gamma\right), \\
E_{R} & =\frac{\partial R}{\partial M_{\infty}} E_{M_{\infty}} .
\end{aligned}
$$

Except for $M_{\infty}=1.0$, where $\partial R / \partial M_{\infty}=0$,

$$
E_{M_{\infty}}=\left(\frac{\partial R}{\partial M_{\infty}}\right)^{-1} E_{R}
$$

Then, with the reciprocal of $\partial R / \partial M_{\infty}$ from Eq. (70) or Table 6, the sensitivity of $M_{\infty}$ to stream-tube area ratio, $R=A_{\infty} / A^{*}$, can be estimated with Eq. (72).

\subsection{Mass flow ratio, $\mathbf{R}=\rho_{\infty} \mathbf{V}_{\infty} / \rho^{\star} \mathbf{V}^{\star}$}

The stream-tube area relation is given in Eq. (79) of Ref. 11. By continuity,

$$
\rho_{\infty} V_{\infty} A_{\infty}=\rho * V^{*} A^{*} \text {. }
$$

Then, 


$$
\mathrm{R}=\frac{\rho_{\infty} \mathrm{V}_{\infty}}{\rho^{*} \mathrm{~V}^{*}}=\frac{\mathrm{A}^{*}}{\mathrm{~A}_{\infty}}=\frac{1}{\mathrm{R}_{\mathrm{A}}}
$$

where $R_{A}=A_{\infty} / A^{*}$ (see Section 3.6). The derivative of $R$ with respect to $M_{\infty}$ is

$$
\frac{\partial \mathrm{R}}{\partial \mathrm{M}_{\infty}}=-\frac{1}{\mathrm{R}_{\mathrm{A}}^{2}} \frac{\partial \mathrm{R}_{\mathrm{A}}}{\partial \mathrm{M}_{\infty}}
$$

The relative sensitivity coefficient is

$$
\theta^{\prime}{ }_{M_{\infty}}=\frac{M_{\infty}}{R} \frac{\partial R}{\partial M_{\infty}}=-\frac{M_{\infty}}{R_{A}} \frac{\partial R_{A}}{\partial M_{\infty}} .
$$

Equations (73), (74) and (75) can be evaluated with Eqs. (69), (70) and (71) from Section 3.6. For $\gamma=1.40$, values of $R, \partial R / \partial M_{\infty}$ and $\left(M_{\infty} / R\right)\left(\partial R / \partial M_{\infty}\right)$ are plotted in Figure 7 and tabulated in Table 7.

To evaluate the reference condition, $\rho^{*} V^{*}$, the following equations are used. For a thermally perfect gas,

$$
\rho^{*}=\frac{p^{*}}{R_{g} T^{*}}
$$

and

$$
\mathrm{V}^{*}=\sqrt{\gamma \mathrm{R}_{\mathrm{g}} \mathrm{T}^{*}}
$$

where $\mathrm{R}_{\mathrm{g}}$ is the gas constant. Multiplying Eqs. (76) and (77) and substituting the isentropic relations for $\mathrm{p}^{*} / \mathrm{p}_{\mathrm{t}}$ and $\mathrm{T}^{*} / \mathrm{T}_{\mathrm{t}}$ (Eqs. (44) and (82) with $\mathrm{M}_{\infty}=1.0$ ),

$$
\rho^{*} \mathrm{~V}^{*}=\mathrm{p}^{*} \sqrt{\frac{\gamma}{\mathrm{R}_{\mathrm{g}} \mathrm{T}^{*}}}=\sqrt{\frac{\gamma}{\mathrm{R}_{\mathrm{g}}}}\left(\frac{\gamma+1}{2}\right)^{-\frac{(\gamma+1)}{2(\gamma-1)}} \frac{\mathrm{p}_{\mathrm{t}}}{\sqrt{\mathrm{T}_{\mathrm{t}}}} .
$$

3.8 Free-stream static temperature ratio, $R=T_{\infty} / T_{t}$

The free-stream static temperature, $T_{\infty}$, is calculated from

$$
T_{\infty}=R\left(M_{\infty}, \gamma\right) T_{t}
$$

and the error equations are

$$
E_{T_{\infty}}=\left[\left(T_{1} \frac{\partial R}{\partial M_{\infty}} E_{M_{\infty}}\right)^{2}+\left(R E_{T_{1}}\right)^{2}\right]^{1 / 2}
$$

and 


$$
\frac{E_{T_{\infty}}}{T_{\infty}}=\left[\left(\frac{M_{\infty}}{R} \frac{\partial R}{\partial M_{\infty} M_{\infty}}\right)^{2}+\left(\frac{E_{T_{1}}}{T_{1}}\right)^{2}\right]^{1 / 2} .
$$

For an adiabatic flow of a perfect gas, Eq. (43) of Ref. 11 gives,

$$
\mathrm{R}=\frac{\mathrm{T}_{\infty}}{\mathrm{T}_{1}}=\left(1+\frac{\gamma-1}{2} \mathrm{M}_{\infty}^{2}\right)^{-1} .
$$

Differentiating Eq. (82) with respect to $\mathrm{M}_{\infty}$ gives

$$
\frac{\partial R}{\partial M_{\infty}}=\frac{-(\gamma-1) R M_{\infty}}{1+\frac{\gamma-1}{2} M_{\infty}^{2}}
$$

The relative sensitivity coefficient is

$$
\theta^{\prime}{ }_{\infty}=\frac{M_{\infty}}{R} \frac{\partial R}{\partial M_{\infty}}=\frac{-(\gamma-1) M_{\infty}^{2}}{1+\frac{\gamma-1}{2} M_{\infty}^{2}} .
$$

For $\gamma=1.40$, values of $R, \partial R / \partial M_{\infty}$ and $\left(M_{\infty} / R\right)\left(\partial R / \partial M_{\infty}\right)$ are plotted in Figure 8 and tabulated in Table 8.

\subsection{Free-stream velocity ratio, $R=V_{\infty} / a_{t}$}

The free-stream static velocity, $\mathrm{V}_{\infty}$, is calculated from

$$
V_{\infty}=R\left(M_{\infty}, \gamma\right) a_{t}
$$

and the error equations are

$$
E_{v_{\infty}}=\left[\left(a_{t} \frac{\partial R}{\partial M_{\infty}} E_{M_{\infty}}\right)^{2}+\left(R E_{a_{t}}\right)^{2}\right]^{1 / 2}
$$

and

$$
\frac{E_{V_{\infty}}}{V_{\infty}}=\left[\left(\frac{M}{R} \frac{\partial R}{\partial M_{\infty} M_{\infty}}\right)^{2}+\left(\frac{E_{a_{1}}}{a_{1}}\right)^{2}\right]^{1 / 2} .
$$

For a thermally perfect gas, the speed of sound, a, is given by Eq. (29b) of Ref. 11 as

$$
\mathrm{a}=\sqrt{\gamma \mathrm{R}_{\mathrm{g}} \mathrm{T}}
$$

where $R_{\mathrm{g}}$ is the gas constant. For stagnation condition,

$$
a_{t}=\sqrt{\gamma R_{g} T_{t}}
$$


The error in $a_{t}$ can then be expressed in terms of the error in $T_{t}$ as,

$$
\frac{E_{a_{t}}}{a_{t}}=\frac{E_{T_{t}}}{2 T_{t}} \text {. }
$$

Substituting this relation into Eq. (87) gives an alternative error equation,

$$
\frac{E_{V_{\infty}}}{V_{\infty}}=\left[\left(\frac{M}{R} \frac{\partial R}{\partial M_{\infty} M_{\infty}}\right)^{2}+\left(\frac{E_{T_{t}}}{2 T_{t}}\right)^{2}\right]^{1 / 2} .
$$

From the definition of Mach number, $M_{\infty}=V_{\infty} / a_{\infty}$,

$$
R=\frac{V_{\infty}}{a_{t}}=M_{\infty} \frac{a_{\infty}}{a_{t}} \text {. }
$$

Then, with Eq. (88),

$$
R=M_{\infty} \sqrt{\frac{T_{\infty}}{T_{t}}} .
$$

Substituting Eq. (82) into Eq. (89) gives

$$
R=M_{\infty}\left(1+\frac{\gamma-1}{2} M_{\infty}^{2}\right)^{-1 / 2}
$$

Differentiating Eq. (90) with respect to $\mathrm{M}_{\infty}$ gives

$$
\frac{\partial R}{\partial M_{\infty}}=\frac{R}{M_{\infty}\left(1+\frac{\gamma-1}{2} M_{\infty}^{2}\right)}
$$

The relative sensitivity coefficient is

$$
\theta_{M_{\infty}}^{\prime}=\frac{M_{\infty}}{R} \frac{\partial R}{\partial M_{\infty}}=\frac{1}{1+\frac{\gamma-1}{2} M_{\infty}^{2}} .
$$

For $\gamma=1.40$, values of $R, \partial R / \partial M_{\infty}$ and $\left(M_{\infty} / R\right)\left(\partial R / \partial M_{\infty}\right)$ are plotted in Figure 9 and tabulated in Table 9.

Frequently, the velocity ratio is given as

$$
\mathrm{R} *=\frac{\mathrm{V}_{\infty}}{\mathrm{a}^{*}} \text {. }
$$

From Eq. (33) of Ref. 11,

$$
\frac{a_{t}}{a^{*}}=\sqrt{\frac{\gamma+1}{2}}
$$


Ther,

$$
R *=\sqrt{\frac{\gamma+1}{2}} R
$$

where, $R=V_{\infty} / a_{t}$. Differentiating Eq. (95),

$$
\frac{\partial R^{*}}{\partial M_{\infty}}=\sqrt{\frac{\gamma+1}{2}} \frac{\partial R}{\partial M_{\infty}}
$$

and

$$
\theta_{M_{\infty}^{\prime}}=\frac{M_{\infty}}{R^{*}} \frac{\partial R^{*}}{\partial M}=\frac{M_{\infty}}{R} \frac{\partial R}{\partial M_{\infty}} .
$$

\section{Applications}

In this suction, error estimates will be given for several nondimensional ratios and coefficients which are frequently used in presenting the results of high-speed wind tunnel tests. These estimates will rely heavily on the results of Section 3 . It will be assumed that the variables are independent. For those results which involve both an arbitrary measured pressure and a measured tunnel condition pressure, such as total pressure, $p_{t}$, this implies that the two pressures are absolute measurements or are gage measurements with a negligible error in the mersured atmospheric pressure. If this is not the case, a more complicated analysis, similar tc that in Section 2.3 .2 will be required. Also it is assumed that $\mathrm{M}_{\infty}$ and $\mathrm{p}_{\mathrm{t}}$ are not correlated through th? tunnel calibration. If this is not true, the equations may be much more complex and a numerical estimate (Section 2.1) may be required. Finally, it is assumed that there is no error in the ratio of specific heats, $\gamma$.

\subsection{Pressure ratio, $P$}

For the first application we will again examine that ubiquitous parameter, the pressure ratio, $P$. In Section 2.3 the error in $P$ was examined, where $P=p / p_{r}$ and both $p$ and $p_{r}$ were measured pressures. In Section 3.1 the error in $p_{\infty}$ was evaluated, where $p_{\infty}=P\left(M_{\infty}, \gamma\right) p_{t}$, with $\mathrm{p}_{\mathrm{t}}$ a measured pressure

In the present application, the error in the ratio, $\mathrm{P}$, will be determined for

$$
P=\frac{p}{p_{\infty}}
$$

In this equation, $p$ is an arbitrary measured pressure and $p_{\infty}$ is calculated from $M_{\infty}, \gamma$, and the measured total pressure, $p_{t}$, using Eq. (44). Assuming that the variables in Eq. (98) are independent, the error in $\mathrm{P}$ is given by 


$$
E_{p}=P\left[\left(\frac{E_{p}}{p}\right)^{2}+\left(\frac{E_{p_{\infty}}}{p_{\infty}}\right)^{2}\right]^{1 / 2}
$$

where $E_{p}$ is the error in the measured pressure and $E_{p_{\infty}}$ was given by Eq. (40) as,

$$
\frac{E_{p_{\infty}}}{p_{\infty}}=\left[\left(\frac{M}{R} \frac{\partial R}{\partial M_{\infty} M_{\infty}}\right)^{2}+\left(\frac{E_{p_{t}}}{p_{t}}\right)^{2}\right]^{1 / 2}
$$

where $R=p_{\infty} / p_{t}, \quad E_{M_{\infty}}$ is the error in the free-stream Mach number, and $E_{p_{t}}$ is the error in the measured total pressure. The relative sensitivity coefficient, $\left(M_{\infty} / R\right)\left(\partial R / \partial M_{\infty}\right)$, is given by Eq. (46) and is tabulated in Table 1 for $\gamma=1.40$.

\subsection{Pressure coefficient, $C_{p}$}

The pressure coefficient, $\mathrm{C}_{\mathrm{p}}$, is defined as

$$
C_{p}=\frac{p-p_{\infty}}{q_{\infty}}
$$

For high-speed wind tunnels, the dynamic pressure is usually calculated from the measured total pressure and the free-stream Mach number with Eq. (50). The static pressure, $\mathrm{p}_{\infty}$ is calculated with Eq. (44). For a thermally perfect gas, $\mathrm{q}_{\infty}$ and $\mathrm{p}_{\infty}$ are related by Eq. (47) of Ref. 11,

$$
\mathrm{q}_{\infty}=\frac{\gamma}{2} \mathrm{p}_{\infty} \mathrm{M}_{\infty}^{2}
$$

Then, substituting Eq. (101) in Eq. (100),

$$
\begin{aligned}
C_{p} & =\frac{p-p_{\infty}}{\frac{\gamma}{2} p_{\infty} M_{\infty}^{2}} \\
& =\frac{2}{\gamma M_{\infty}^{2}}\left(\frac{p}{p_{\infty}}-1\right)
\end{aligned}
$$

and substituting $\mathrm{p}_{\infty}=\mathrm{R}\left(\mathrm{M}_{\infty}, \gamma\right) \mathrm{p}_{\mathrm{t}}$ gives

$$
C_{p}=\frac{2}{\gamma M_{\infty}^{2}}\left(\frac{p}{p_{t} R}-1\right) .
$$

Assuming $\mathrm{p}, \mathrm{p}_{\mathrm{t}}$ and $\mathrm{M}_{\infty}$ are independent, the error in $\mathrm{C}_{\mathrm{p}}$ is given by

$$
E_{C_{p}}=\left[\left(\frac{\partial C_{p}}{\partial p} E_{p}\right)^{2}+\left(\frac{\partial C_{p}}{\partial p_{t}} E_{p_{t}}\right)^{2}+\left(\frac{\partial C_{p}}{\partial M_{\infty}} E_{M_{\infty}}\right)^{2}\right]^{1 / 2}
$$




$$
E_{C_{p}}=C_{p}\left(\frac{P}{P-1}\right)\left\{\left(\frac{E_{p}}{p}\right)^{2}+\left(\frac{E_{p_{1}}}{p_{t}}\right)^{2}+\left[2\left(\frac{P-1}{P}\right)+\frac{M_{\infty}}{R} \frac{\partial R}{\partial M_{\infty}}\right]^{2}\left(\frac{E_{M_{\infty}}}{M_{\infty}}\right)^{2}\right\}^{1 / 2}
$$

where $P=p / p_{\infty}$ and $R=p_{\infty} / p_{t}$. If desired, $P$ can be replaced with $C_{p}$ by using the relation,

$$
\mathrm{P}=1+\frac{\gamma \mathrm{M}_{\infty}^{2}}{2} \mathrm{C}_{\mathrm{p}}
$$

The relative sensitivity coefficient, $\left(M_{\infty} / R\right)\left(\partial R / \partial M_{\infty}\right)$, is given by Eq. $(46)$ and is tabulated in Table 1 for $\gamma=1.40$.

\subsection{Force and moment coefficients, $C_{F}$ and $C_{m}$}

Nondimensional force coefficients are defined by

$$
C_{F}=\frac{F}{q_{\infty} S}
$$

where $\mathrm{F}$ is an aerodynamic force, $\mathrm{q}_{\infty}$ the free-stream dynamic pressure and $\mathrm{S}$ a reference area. The error in the force coefficient is given by

$$
E_{C_{F}}=C_{F}\left[\left(\frac{E_{F}}{F}\right)^{2}+\left(\frac{E_{q_{\infty}}}{q_{\infty}}\right)^{2}+\left(\frac{E_{S}}{S}\right)^{2}\right]^{1 / 2}
$$

where $E_{F}$ is the error in the measured force, $E_{S}$ the error in the reference area and $E_{q_{m}}$ is given by Eq. (49) as

$$
\frac{E_{q_{\infty}}}{q_{\infty}}=\left[\left(\frac{M_{\infty}}{R} \frac{\partial R}{\partial M_{\infty} M_{\infty}}\right)^{2}+\left(\frac{E_{p_{t}}}{p_{t}}\right)^{2}\right]^{1 / 2}
$$

where $R=q_{\infty} / p_{t}, E_{M_{\infty}}$ is the error in the free-stream Mach number and $E_{p_{t}}$ is the error in the measured total pressure. The relative sensitivity coefficient, $\left(M_{\infty} / R\right)\left(\partial R / \partial M_{\infty}\right)$, is given by Eq. (52) and is tabulated in Table 2 for $\gamma=1.40$. Frequently, $S=\pi d^{2} / 4$, where $d$ is a reference diameter. Then,

$$
\frac{E_{S}}{S}=2 \frac{E_{d}}{d} .
$$

Nondimensional moment coefficients are defined by

$$
C_{m}=\frac{M}{q_{\infty} S l}
$$

where $M$ is an aerodynamic moment and $l$ is a reference length. The error in $C_{m}$ is given by 


$$
E_{C_{m}}=C_{m}\left[\left(\frac{E_{M}}{M}\right)^{2}+\left(\frac{E_{q_{\infty}}}{q_{\infty}}\right)^{2}+\left(\frac{E_{s}}{S}\right)^{2}+\left(\frac{E_{l}}{l}\right)^{2}\right]^{1 / 2}
$$

This equation is similar to Eq. (107) with $\mathrm{E}_{\mathrm{M}}$ the error in the measured moment, $\mathrm{M}$, and $\mathrm{E}_{l}$ the error in the reference length. Frequently, $l=\mathrm{d}$ and $S=\pi \mathrm{d}^{2} / 4$. Then, $l$ and $S$ are correlated and the last two terms of Eq. (110) must be replaced by

$$
\left(\frac{3 E_{d}}{d}\right)^{2}
$$

to avoid underestimating the error contribution due to $\mathrm{d}$.

\subsection{Dynamic stability coefficients, $\mathrm{C}_{\mathrm{m}_{q}}$ and $\mathrm{C}_{\mathrm{I}_{\mathrm{p}}}$}

Nondimensional dynamic stability coefficients are defined as derivatives of the moment coefficient with respect to a normalized angular rate. For example, the pitching moment coefficient derivative, $\mathrm{C}_{\mathrm{m}_{\mathrm{q}}}$, is defined by

$$
\mathrm{C}_{\mathrm{m}_{\mathrm{q}}}=\frac{\partial \mathrm{C}_{\mathrm{m}}}{\partial\left(\mathrm{q} l / \mathrm{V}_{\infty}\right)}=\frac{\partial\left(\mathrm{M} / \mathrm{q}_{\infty} \mathrm{S} l\right)}{\partial\left(\mathrm{q} l / \mathrm{V}_{\infty}\right)}=\frac{\partial \mathrm{M} / \partial \mathrm{q}}{\mathrm{q}_{\infty} \mathrm{s} l^{2} / \mathrm{V}_{\infty}}=\frac{\mathrm{M}_{\mathrm{q}}}{\mathrm{q}_{\infty} \mathrm{s} l^{2} / \mathrm{V}_{\infty}}
$$

The derivative, $M_{q}$, is determined from the experiment. Note that in these equations, $M$ is the aerodynamic pitching moment, whereas $M_{\infty}$ is the free-stream Mach number, and $q$ is the angular pitch rate, whereas $q_{\infty}$ is the free-stream dynamic pressure. The estimated error in $\mathrm{C}_{\mathrm{m}_{\mathrm{q}}}$ is

$$
E_{C_{m_{q}}}=C_{m_{q}}\left[\left(\frac{E_{M_{q}}}{M_{q}}\right)^{2}+\left(\frac{E_{q_{\infty} / V_{\infty}}}{q_{\infty} / V_{\infty}}\right)^{2}+\left(\frac{E_{s}}{S}\right)^{2}+\left(\frac{2 E_{l}}{l}\right)^{2}\right]^{1 / 2}
$$

As was noted in the previous section, if $l=\mathrm{d}$ and $\mathrm{S}=\pi \mathrm{d}^{2} / 4, l$ and $\mathrm{S}$ are correlated and the last two terms in Eq. (112) should be replaced with $\left(4 \mathrm{E}_{\mathrm{d}} / \mathrm{d}\right)^{2}$. By definition,

$$
\frac{q_{\infty}}{V_{\infty}}=\frac{\rho_{\infty} v_{\infty}^{2}}{2 V_{\infty}}=\frac{\rho_{\infty} V_{\infty}}{2}
$$

For a thermally perfect gas,

$$
\rho_{\infty}=\frac{p_{\infty}}{R_{g} T_{\infty}}
$$

and

$$
\mathrm{V}_{\infty}=\mathrm{M}_{\infty} \sqrt{\gamma \mathrm{R}_{\mathrm{g}} \mathrm{T}_{\infty}}
$$


Substituting these equations into Eq. (113) and using Eqs. (44) and (82) to relate $p_{\infty}$ to $p_{t}$ and $T_{\infty}$ to $T_{t}$, respectively, gives

$$
\frac{\mathrm{q}_{\infty}}{\mathrm{V}_{\infty}}=\frac{1}{2} \sqrt{\frac{\gamma}{\mathrm{R}_{\mathrm{g}}}} \frac{\mathrm{p}_{\mathrm{t}}}{\mathrm{T}_{\mathrm{t}}} \mathrm{M}_{\infty}\left(1+\frac{\gamma-1}{2} \mathrm{M}_{\infty}^{2}\right)^{-\frac{(\gamma+1)}{2(\gamma-1)}}
$$

The relative error in $q_{\infty} / V_{\infty}$ is given by

$$
\frac{E_{q_{\infty} / V_{\infty}}}{q_{\infty} / V_{\infty}}=\left[\left(\frac{E_{p_{1}}}{p_{t}}\right)^{2}+\left(\frac{E_{T_{1}}}{2 T_{t}}\right)^{2}+\left(\frac{M_{\infty}}{R} \frac{\partial R E_{M_{\infty}}}{\partial M_{\infty} M_{\infty}}\right)^{2 / 2}\right.
$$

where $R=q_{\infty} / V_{\infty}$. Differentiating Eq. (116) with respect to $M_{\infty}$ gives

$$
\frac{M_{\infty}}{R} \frac{\partial R}{\partial M_{\infty}}=\frac{1-M_{\infty}^{2}}{1+\frac{\gamma-1}{2} M_{\infty}^{2}}
$$

Comparing Eq. (118) with Eq. (71) shows that

$$
\frac{M_{\infty}}{R} \frac{\partial R}{\partial M_{\infty}}=-\frac{M_{\infty}}{R_{A}} \frac{\partial R_{A}}{\partial M_{\infty}}
$$

where $R_{A}=A_{\infty} / A^{*}$. Then, Eq. (71) and the results tabulated in Table 6 can be used to evaluate $\left(M_{\infty} / R\right)\left(\partial R / \partial M_{\infty}\right)$ for $R=q_{\infty} / V_{\infty}$. Equations (117) and (112) are used to estimate the error in $\mathrm{C}_{\mathrm{m}_{\mathrm{q}}}$.

The rolling moment coefficient derivative, $\mathrm{C}_{l_{\mathrm{p}}}$, is defined by,

$$
\mathrm{C}_{l_{\mathrm{p}}}=\frac{\partial \mathrm{C}_{l}}{\partial\left(\mathrm{p} l / \mathrm{V}_{\infty}\right)}=\frac{\partial\left(\mathrm{L} / \mathrm{q}_{\infty} \mathrm{S} l\right)}{\partial\left(\mathrm{p} / / \mathrm{V}_{\infty}\right)}=\frac{\partial \mathrm{L} / \partial \mathrm{p}}{\mathrm{q}_{\infty} \mathrm{S} l^{2} / \mathrm{V}_{\infty}}=\frac{\mathrm{L}_{\mathrm{p}}}{\mathrm{q}_{\infty} \mathrm{S} l^{2} / \mathrm{V}_{\infty}}
$$

The error in $\mathrm{C}_{l_{\mathrm{p}}}$ is given by

$$
\mathrm{E}_{\mathrm{C}_{l_{\mathrm{p}}}}=\mathrm{C}_{l_{\mathrm{p}}}\left[\left(\frac{\mathrm{E}_{\mathrm{L}_{\mathrm{p}}}}{\mathrm{L}_{\mathrm{p}}}\right)^{2}+\left(\frac{\mathrm{E}_{\mathrm{q}_{\infty} / \mathrm{V}_{\infty}}}{\mathrm{q}_{\infty} / \mathrm{V}_{\infty}}\right)^{2}+\left(\frac{\mathrm{E}_{\mathrm{s}}}{\mathrm{S}}\right)^{2}+\left(\frac{2 \mathrm{E}_{l}}{l}\right)^{2}\right]^{1 / 2}
$$

which is evaluated with Eqs. (71) and (117) as indicated above for Eq. (112).

\subsection{Mach number, $M_{\infty}$}

In high-speed wind tunnels, the free-stream Mach number is usually determined during tunnel calibration by one of three methods, each involving a measured pressure ratio, $R$. First, at subsonic and transonic Mach numbers, a static pipe may be used to measure freestream pressure, $p_{\infty}$. The measured tunnel total pressure, $p_{t}$, is used in the ratio, $R=p_{\infty} / p_{t}$ with the isentropic flow equation to determine Mach number. From Eq. (44), 


$$
\mathrm{R}=\frac{\mathrm{p}_{\infty}}{\mathrm{p}_{\mathrm{t}}}=\left(1+\frac{\gamma-1}{2} \mathrm{M}_{\infty}^{2}\right)^{-\frac{\gamma}{\gamma-1}}
$$

Solving for $\mathrm{M}_{\infty}$ gives

$$
M_{\infty}^{2}=\frac{2}{\gamma-1}\left[\left(\frac{p_{\infty}}{p_{t}}\right)^{-\frac{\gamma-1}{\gamma}}-1\right] .
$$

Second, at supersonic and hypersonic Mach numbers, the static pressure can be very low and the Mach number is usually determined with a pitot tube which measures the total pressure, $\mathrm{p}_{\mathrm{t}_{2}}$, behind the tube's normal shock. This pressure is divided by the tunnel total pressure, $p_{t}$, to give a ratio, $R$, which is related to Mach number by the normal shock relation, Eq. (63),

$$
\mathrm{R}=\frac{\mathrm{p}_{\mathrm{t}_{2}}}{\mathrm{p}_{\mathrm{t}}}=\left[\frac{(\gamma+1) \mathrm{M}_{\infty}^{2}}{(\gamma-1) \mathrm{M}_{\infty}^{2}+2}\right]^{\frac{\gamma}{\gamma-1}}\left[\frac{\gamma+1}{2 \gamma \mathrm{M}_{\infty}^{2}-(\gamma-1)}\right]^{\frac{1}{\gamma-1}} .
$$

This equation is solved numerically for $\mathrm{M}_{\infty}$, by using an iterative root solver. Finally, a pitot-static probe may be used to determine Mach number. In this case, the ratio and Mach number dependency is given by the Rayleigh formula, Eq. (66),

$$
\mathrm{R}=\frac{\mathrm{p}_{\infty}}{\mathrm{p}_{\mathrm{t}_{2}}}=\left[\frac{2}{(\gamma+1) \mathrm{M}_{\infty}^{2}}\right]^{\frac{\gamma}{\gamma-1}}\left[\frac{2 \gamma \mathrm{M}_{\infty}^{2}-(\gamma-1)}{\gamma+1}\right]^{\frac{1}{\gamma-1}} .
$$

Again, this equation is solved numerically for $\mathrm{M}_{\infty}$.

The error equation for the Mach number calculated from any of these three methods is the same. Let

$$
\mathrm{R}\left(\mathrm{M}_{\infty}, \gamma\right)=\frac{\mathrm{p}_{\mathrm{x}}}{\mathrm{p}_{\mathrm{y}}}
$$

The uncertainty in the measured ratio is given by,

$$
E_{R}=R\left[\left(\frac{E_{p_{x}}}{p_{x}}\right)^{2}+\left(\frac{E_{p_{y}}}{p_{y}}\right)^{2}\right]^{1 / 2} .
$$

Although an explicit relation for $\mathrm{M}_{\infty}$ is not possible for two of the ratios, the uncertainty in $M_{\infty}$ can be determined implicitly, when $\partial R / \partial M_{\infty} \neq 0$, by solving the error equation,

$$
E_{R}=\frac{\partial R}{\partial M_{\infty}} E_{M_{\infty}}
$$


to give

$$
E_{M_{\infty}}=\frac{\partial M_{\infty}}{\partial R} E_{R}
$$

Substituting Eq. (127) in Eq. (129) gives

$$
\frac{E_{M_{\infty}}}{M_{\infty}}=\frac{R}{M_{\infty}} \frac{\partial M_{\infty}}{\partial R}\left[\left(\frac{E_{p_{x}}}{p_{x}}\right)^{2}+\left(\frac{E_{p_{y}}}{p_{y}}\right)^{2}\right]^{1 / 2}
$$

Substituting the measured pressures for $\mathrm{p}_{\mathrm{x}}$ and $\mathrm{p}_{\mathrm{y}}$ gives the following estimates of error in calibration Mach number for the three methods:

(1) For $\mathrm{R}=\mathrm{p}_{\infty} / \mathrm{p}_{\mathrm{t}}$, the relative error in Mach number is

$$
\frac{E_{M_{\infty}}}{M_{\infty}}=\frac{R}{M_{\infty}} \frac{\partial M_{\infty}}{\partial R}\left[\left(\frac{E_{p_{\infty}}}{p_{\infty}}\right)^{2}+\left(\frac{E_{p_{t}}}{p_{t}}\right)^{2}\right]^{1 / 2} \text {. }
$$

For nonzero values of $M_{\infty}$ and $\partial R / \partial M_{\infty}$,

$$
\frac{R}{M_{\infty}} \frac{\partial M_{\infty}}{\partial R}=\left(\frac{M_{\infty}}{R} \frac{\partial R}{\partial M_{\infty}}\right)^{-1}
$$

Then, $\left(R / M_{\infty}\right)\left(\partial M_{\infty} / \partial R\right)$ is given by the reciprocal of Eq. (46) and is tabulated in Table 1.

(2) For $\mathrm{R}=\mathrm{p}_{\mathrm{t}_{2}} / \mathrm{p}_{\mathrm{t}}$, the relative error in Mach number is

$$
\frac{E_{M_{\infty}}}{M_{\infty}}=\frac{R}{M_{\infty}} \frac{\partial M_{\infty}}{\partial R}\left[\left(\frac{E_{p_{t_{2}}}}{p_{t_{2}}}\right)^{2}+\left(\frac{E_{p_{t}}}{p_{t}}\right)^{2}\right]^{1 / 2}
$$

where $\left(R / M_{\infty}\right)\left(\partial M_{\infty} / \partial R\right)$ is given by the reciprocal of Eq. (65) and is tabulated in Table 4.

(3) For $\mathrm{R}=\mathrm{p}_{\infty} / \mathrm{p}_{\mathrm{t}_{2}}$, the relative error in Mach number is

$$
\frac{E_{M_{\infty}}}{M_{\infty}}=\frac{R}{M_{\infty}} \frac{\partial M_{\infty}}{\partial R}\left[\left(\frac{E_{p_{\infty}}}{p_{\infty}}\right)^{2}+\left(\frac{E_{p_{t_{2}}}}{p_{t_{2}}}\right)^{2}\right]^{1 / 2}
$$

where $\left(R / M_{\infty}\right)\left(\partial M_{\infty} / \partial R\right)$ is given by the reciprocal of Eq. (68) and is tabulated in Table 5 .

\subsection{Reynolds number, Re}

The free-stream Reynolds number is defined as

$$
\operatorname{Re}=\frac{\rho_{\infty} \mathrm{V}_{\infty} l}{\mu_{\infty}}
$$


where $\rho_{\infty}$ and $V_{\infty}$ are the free-stream static density and velocity, respectively. The reference length, $l$, may be an actual measurement, such as model length or diameter which has an associated error, or a defined value, such as " 1 foot" which has no error. The dynamic viscosity, $\mu_{\infty}$, is a function of the free-stream temperature, $T_{\infty}$. In most cases, the viscosity is adequately described by two functions. For $T<T_{S}$, where $T_{S}=198.7^{\circ} R$, a linear relation can be used,

$$
\mu_{\infty}=\mathrm{CT}_{\infty}
$$

where $C$ is a constant. For $T \geq T_{S}$, Sutherland's relation (Eq. (A3) of Ref. 11) is often used,

$$
\mu_{\infty}=\frac{\beta T_{\infty}^{3 / 2}}{T_{\infty}+T_{S}}
$$

The first relation is generally used for hypersonic tunnels, while the second is used for transonic and supersonic tunnels. If a data reduction code uses both of the above viscosity relations, it may not be obvious which relation is used to reduce a particular set of data. In this case, a plot which delineates the two regimes is useful. Such a plot can be generated with the function,

$$
\mathrm{T}_{\mathrm{t}}=\mathrm{T}_{\mathrm{S}}\left(1+\frac{\gamma-1}{2} \mathrm{M}_{\infty}^{2}\right)
$$

A plot of this function is shown in Figure 10.

Since $\rho_{\infty}, V_{\infty}$ and $\mu_{\infty}$ are complex functions of $M_{\infty}$ and $T_{t}$, an analytical estimate of the error in $\mathrm{Re}$ is difficult. This is especially true if Sutherland's relation is required. In the following sections, error estimates for $\mathrm{Re}$ will be developed for both viscosity relations.

\subsubsection{Linear viscosity relation}

Three approaches will be demonstrated for Reynolds number with the linear viscosity relaition. These are: (1) analytical evaluation of the fully expanded equation with independer.t variables; (2) analytical evaluation of a partially expanded equation with correlated terms and (3) numerical evaluation.

\subsubsection{Analytical evaluation-independent variables}

It is always recommended that the equation for the parameter of interest be fully expanded, so that all of the variables are independent, before differentiating the parameter with respect to each of the variables. In many cases this is not practical. For the present example, Reynolds number is given by,

$$
\mathrm{Re}=\frac{\rho_{\infty} \mathrm{V}_{\infty} l}{\mathrm{CT}_{\infty}}
$$

For a thermally perfect gas, Eqs. (114) and (115) are substituted into Eq. (139) to give, 


$$
\operatorname{Re}=\sqrt{\frac{\gamma}{\mathrm{R}_{\mathrm{g}}}} \frac{l}{\mathrm{C}} \frac{\mathrm{M}_{\infty} \mathrm{p}_{\infty}}{\mathrm{T}_{\infty}^{3 / 2}} .
$$

To express $R e$ as a function of tunnel total conditions, $p_{t}$ and $T_{t}$, substitute Eqs. (44) and (82) in Eq. (140) and simplify,

$$
\operatorname{Re}=\sqrt{\frac{\gamma}{R_{g}}} \frac{l}{C_{T_{t}^{3 / 2}}} \frac{\mathrm{p}_{\mathrm{t}}}{\mathrm{M}_{\infty}}\left(1+\frac{\gamma-1}{2} \mathrm{M}_{\infty}^{2}\right)^{\frac{\gamma-3}{2(\gamma-1)}} .
$$

To show the variation of Reynolds number with Mach number, $\operatorname{Re}$ is normalized by $\operatorname{Re}^{*}$, the Reynolds number at $M_{\infty}=1.0$. Setting $M_{\infty}=1.0$ in Eq. (141) gives

$$
\mathrm{Re}^{*}=\sqrt{\frac{\gamma}{\mathrm{R}_{\mathrm{g}}}} \frac{l}{\mathrm{C}} \frac{\mathrm{p}_{\mathrm{t}}}{\mathrm{T}_{\mathrm{t}}^{3 / 2}}\left(\frac{\gamma+1}{2}\right)^{\frac{\gamma-3}{2(\gamma-1)}}
$$

Dividing Eq. (141) by Eq. (142),

$$
\frac{\operatorname{Re}}{\operatorname{Re}^{*}}=M_{\infty}\left[\frac{2+(\gamma-1) M_{\infty}^{2}}{\gamma+1}\right]^{\frac{\gamma-3}{2(\gamma-1)}}
$$

This relation is plotted in Figure 11 for $\gamma=1.40$.

Assuming that the variables in $\mathrm{Eq}$. (141) are independent and there are negligible errors in $\gamma, \mathrm{R}_{\mathrm{g}}$ and $\mathrm{C}$, the Taylor series model for independent variables, Eq. (4), will be used to estimate the error in $\mathrm{Re}$. Then,

$$
\mathrm{E}_{\mathrm{Re}}=\left[\left(\frac{\partial \mathrm{Re}}{\partial \mathrm{M}_{\infty}} \mathrm{E}_{\mathrm{M}_{\infty}}\right)^{2}+\left(\frac{\partial \mathrm{Re}}{\partial \mathrm{p}_{\mathrm{t}}} \mathrm{E}_{\mathrm{p}_{\mathrm{t}}}\right)^{2}+\left(\frac{\partial \mathrm{Re}}{\partial \mathrm{T}_{\mathrm{t}}} \mathrm{E}_{\mathrm{T}_{1}}\right)^{2}+\left(\frac{\partial \mathrm{Re}}{\partial l} \mathrm{E}_{l}\right)^{2}\right]^{1 / 2}
$$

If $l$ is a constant, $E_{l}=0$. Performing the indicated differentiation of Eq. (141) gives

$$
E_{R e}=R_{e}\left\{\left[\frac{1+(\gamma-2) M_{\infty}^{2}}{1+\frac{\gamma-1}{2} M_{\infty}^{2}}\right]^{2}\left(\frac{E_{M_{\infty}}}{M_{\infty}}\right)^{2}+\left(\frac{E_{p_{t}}}{p_{t}}\right)^{2}+\left(-\frac{3 E_{T}}{2 T_{t}}\right)^{2}+\left(\frac{E_{l}}{l}\right)^{2}\right\}^{1 / 2} .
$$

The term in brackets, [...], is the relative sensitivity coefficient, $\left(\mathrm{M}_{\infty} / \mathrm{Re}\right)\left(\partial \mathrm{Re} / \partial \mathrm{M}_{\infty}\right)$, for Reynolds number with respect to Mach number. Values of the coefficient are plotted in Figure 12 and tabulated in Table 10 for $\gamma=1.40$. The minus sign on the $E_{t}$ term has no significance in the evaluation of $\mathrm{E}_{\mathrm{Re}}$, but is included for comparison with the numerical evaluation of Section 4.6.1.3. 


\subsubsection{Analytical evaluation-dependent variables}

It is frequently much easier to evaluate an expression if it is not fully expanded to the principal variables. However, in this case the variables may be correlated and the appropriate uncertainty equation must be used. Let

$$
\operatorname{Re}=\frac{\operatorname{Rp} * \mathrm{~V} * l}{\mu_{\infty}}
$$

where

$$
R=\frac{\rho_{\infty} V_{\infty}}{\rho^{*} V^{*}}=f\left(M_{\infty}, \gamma\right),
$$

and the function, $f\left(\mathrm{M}_{\infty}, \gamma\right)$, is defined by Eqs. (73) and (69) as,

$$
R=M_{\infty}\left[\left(\frac{2}{\gamma+1}\right)\left(1+\frac{\gamma-1}{2} M_{\infty}^{2}\right)\right]^{-\frac{\gamma+1}{2(\gamma-1)}}
$$

$\rho * V^{*}$ is given by Eq. (78),

$$
\rho^{*} V^{*}=\sqrt{\frac{\gamma}{R_{g}}}\left(\frac{\gamma+1}{2}\right)^{-\frac{(\gamma+1)}{2(\gamma-1)}} \frac{p_{t}}{\sqrt{T_{t}}}
$$

and, by use of Eqs. (136) and (82), $\mu_{\infty}$ can be expressed as,

$$
\mu_{\infty}=\mathrm{CT}_{\mathrm{t}}\left(1+\frac{\gamma-1}{2} \mathrm{M}_{\infty}^{2}\right)^{-1}
$$

Therefore, $R$ and $\mu_{\infty}$ are correlated through $M_{\infty}$ while $\rho^{*} V^{*}$ and $\mu_{\infty}$ are correlated through $T_{t}$. The estimated error in $R e$ is given by Eq. (3), with the present variables,

$$
\begin{aligned}
\mathrm{E}_{\mathrm{Re}}^{2}= & \left(\frac{\partial \operatorname{Re}}{\partial \mathrm{R}} \mathrm{E}_{\mathrm{R}}\right)^{2}+\left(\frac{\partial \mathrm{Re}}{\partial \rho^{*} \mathrm{~V}^{*}} \mathrm{E}_{\rho^{*} \mathrm{~V}^{*}}\right)^{2}+\left(\frac{\partial \mathrm{Re}}{\partial l} \mathrm{E}_{l}\right)^{2}+\left(\frac{\partial \mathrm{Re}}{\partial \mu_{\infty}} \mathrm{E}_{\mu_{\infty}}\right)^{2} \\
& +2 \frac{\partial \operatorname{Re}}{\partial \mathrm{R}} \frac{\partial \operatorname{Re}}{\partial \mu_{\infty}} \mathrm{E}_{\mathrm{R}}^{\prime} \mathrm{E}_{\mu_{\infty}^{\prime}}\left(\mathrm{M}_{\infty}\right)+2 \frac{\partial \mathrm{Re}}{\partial \rho^{*} \mathrm{~V}^{*}} \frac{\partial \operatorname{Re}}{\partial \mu_{\infty}} \mathrm{E}_{\rho^{*} \mathrm{~V}^{*}} \mathrm{E}_{\mu_{\infty}^{\prime}}\left(\mathrm{T}_{\mathrm{t}}\right)
\end{aligned}
$$

The various error terms are defined by the following equations, where the primed error terms include only the error due to the indicated measurement:

$$
\begin{gathered}
E_{R}=\frac{\partial R}{\partial M_{\infty}} E_{M_{\infty}} \\
E_{R}^{\prime}\left(M_{\infty}\right)=E_{R}
\end{gathered}
$$




$$
\begin{gathered}
E_{\rho^{*} \mathrm{~V}^{*}}=\rho^{*} \mathrm{~V}^{*}\left[\left(\frac{E_{p_{t}}}{p_{t}}\right)^{2}+\left(-\frac{E_{T_{t}}}{2 T_{t}}\right)^{2}\right]^{1 / 2} \\
E_{\rho^{*} \mathrm{~V}^{*}}^{\prime}\left(T_{t}\right)=-\frac{\rho^{*} V^{*}}{2} \frac{E_{T_{t}}}{T_{t}} \\
E_{\mu_{\infty}}=\mu_{\infty}\left\{\left[-\frac{(\gamma-1) M_{\infty}^{2}}{1+\frac{\gamma-1}{2} M_{\infty}^{2}}\right]^{2}\left(\frac{E_{M_{\infty}}}{M_{\infty}}\right)^{2}+\left(\frac{E_{T_{t}}}{T_{t}}\right)^{2}\right\}^{1 / 2} \\
E_{\mu_{\infty}^{\prime}}^{\prime}\left(M_{\infty}\right)=-\frac{(\gamma-1) M_{\infty}^{2} \mu_{\infty}}{\left(1+\frac{\gamma-1}{2} M_{\infty}^{2}\right)} \frac{E_{M_{\infty}}}{M_{\infty}} \\
E_{\mu_{\infty}}^{\prime}\left(T_{t}\right)=\mu_{\infty} \frac{E_{T_{t}}}{T_{t}}
\end{gathered}
$$

Evaluating the partial derivatives in Eq. (150) and substituting the error terms from Eqs. (151) through (157) gives

$$
\begin{aligned}
\left(\frac{E_{R e}}{R e}\right)^{2}= & \left(\frac{M_{\infty}}{R} \frac{\partial R}{\partial M_{\infty}}\right)^{2}\left(\frac{E_{M_{\infty}}}{M_{\infty}}\right)^{2}+\left(\frac{E_{p_{t}}}{p_{t}}\right)^{2}+\left(\frac{E_{T}}{2 T_{t}}\right)^{2}+\left(\frac{E_{l}}{l}\right)^{2} \\
& +\left[\frac{(\gamma-1) M_{\infty}^{2}}{1+\frac{\gamma-1}{2} M_{\infty}^{2}}\right]^{2}\left(\frac{E_{M_{\infty}}}{M_{\infty}}\right)^{2}+\left(\frac{E_{T}}{T_{t}}\right)^{2} \\
& +2\left(\frac{\left.M_{\infty} \frac{\partial R}{R} \frac{(\gamma-1) M_{\infty}^{2}}{\partial M_{\infty}}\right)\left[\frac{E_{M_{\infty}}}{M_{\infty}}\right)^{2}+\left(\frac{E_{T}}{T_{1}}\right)^{2}}{1+\frac{\gamma-1}{2} M_{\infty}^{2}}\right]
\end{aligned}
$$

For $R=\rho_{\infty} V_{\infty} / \rho^{*} V^{*}$, the expression for $\left(M_{\infty} / R\right)\left(\partial R / \partial M_{\infty}\right)$ is obtained by substituting Eq. (71) into Eq. (75),

$$
\frac{M_{\infty}}{R} \frac{\partial R}{\partial M_{\infty}}=\frac{1-M_{\infty}^{2}}{1+\frac{\gamma-1}{2} M_{\infty}^{2}} .
$$

Substituting this equation into the previous one and simplifying gives, 


$$
E_{R e}=R_{e}\left\{\left[\frac{1+(\gamma-2) M_{\infty}^{2}}{1+\frac{\gamma-1}{2} M_{\infty}^{2}}\right]^{2}\left(\frac{E_{M_{\infty}}}{M_{\infty}}\right)^{2}+\left(\frac{E_{p_{t}}}{p_{t}}\right)^{2}+\left(\frac{3 E_{T}}{2 T_{t}}\right)^{2}+\left(\frac{E_{l}}{l}\right)^{2}\right\}^{1 / 2}
$$

This result agrees with Eq. (145), which was obtained by differentiating the fully expanded Reynolds number equation with independent variables.

\subsubsection{Numerical evaluation}

The numerical evaluation code, DFDX, which is listed in the Appendix, uses Reynolds number, with linear viscosity, as its example function. For a relative interval, $\Delta \mathrm{x}_{\mathrm{i}} / \mathrm{x}_{\mathrm{i}}$, of 0.005 , four test cases were evaluated $(\gamma=1.40)$ and the results are listed below:

\begin{tabular}{|c|c|c|c|c|}
\hline Case & Parameter & $\mathrm{i}$ & $x_{i}$ & $\frac{\partial \operatorname{Re} / \partial x_{i}}{\operatorname{Re} / x_{i}}$ \\
\hline \multirow[t]{4}{*}{1} & $\mathrm{M}_{\infty}$ & 1 & 5.0 & -2.333 \\
\hline & $\mathrm{p}_{\mathrm{t}}, \mathrm{psia}$ & 2 & 150.0 & 1.000 \\
\hline & $\mathrm{T}_{t},{ }^{\circ} \mathrm{R}$ & 3 & 800.0 & -1.500 \\
\hline & $l, \mathrm{ft}$ & 4 & 1.0 & 1.000 \\
\hline \multirow[t]{4}{*}{2} & $\mathrm{M}_{\infty}$ & 1 & 8.0 & -2.710 \\
\hline & $p_{t}, p s i a$ & 2 & 300.0 & 1.000 \\
\hline & $\mathrm{T}_{t},{ }^{\circ} \mathrm{R}$ & 3 & 1500.0 & -1.500 \\
\hline & $l, \mathrm{ft}$ & 4 & 1.0 & 1.000 \\
\hline \multirow[t]{4}{*}{3} & $\mathbf{M}_{\infty}$ & 1 & 8.0 & -2.710 \\
\hline & $\mathrm{p}_{\mathrm{l}}, \mathrm{psia}$ & 2 & 900.0 & 1.000 \\
\hline & $\mathrm{T}_{\mathrm{t}},{ }^{\circ} \mathrm{R}$ & 3 & 1100.0 & -1.500 \\
\hline & $l, \mathrm{ft}$ & 4 & 1.5 & 1.000 \\
\hline \multirow[t]{4}{*}{4} & $\mathrm{M}_{\infty}$ & 1 & 14.0 & -2.901 \\
\hline & $\mathrm{p}_{\mathrm{t}}, \mathrm{psia}$ & 2 & 2000.0 & 1.000 \\
\hline & $\mathrm{T}_{1},{ }^{\circ} \mathrm{R}$ & 3 & 2300.0 & -1.500 \\
\hline & $l, \mathrm{ft}$ & 4 & 1.0 & 1.000 \\
\hline
\end{tabular}

These examples show several important results. First, the relative sensitivity of Reynolds number to Mach number agrees with the analytical solution presented in Table 10 . Second, cases 2 and 3 show that the Mach number sensitivity is independent of $p_{t}$ and $T_{t}$ as 
it should be. Finally, the relative sensitivity of Reynolds number to $\mathrm{p}_{t}$ and $l$ is 1.0 and to $\mathrm{T}_{\mathrm{t}}$ is -1.5 as was shown in Eq. (145).

\subsubsection{Sutherland's viscosity relation}

Although the equation for Reynolds number with Sutherland's viscosity relation, Eq. (137), could be expanded to the basic variables- $M_{\infty}, p_{t}, T_{t}$ and $l$-and then differentiated to obtain sensitivity coefficients, the calculus and algebra would be formidable. In addition, because of the sum, $T_{\infty}+T_{S}$, in the expression for $\mu_{\infty}$, it is not possible to uncouple the effects of $M_{\infty}$ and $T_{t}$ in the error equation, as was done for the linear relation. That is, the sensitivity of $\operatorname{Re}$ to $M_{\infty}$ is a function of $T_{t}$ and the sensitivity of $\operatorname{Re}$ to $T_{t}$ is a function of $\mathbf{M}_{\infty}$. Therefore, simple expressions for the sensitivity coefficients cannot be obtained and numerical evaluation of the coefficients is the best method. Relative sensitivity coefficients for Reynolds number are presented in Figures 13 and 14. In Figure 13, the sensitivity of $\operatorname{Re}$ to Mach number is shown. For the linear viscosity relation, the curve is the same as that shown in Figure 12. Although the trend with Mach number is similar for the linear and Sutherland's relations, there is a significant effect of $T_{t}$ when Sutherland's viscosity relation is used. The curve for each value of $T_{t}$ intersects the linear relation curve when $\mathrm{T}_{\infty}=\mathrm{T}_{\mathrm{S}}=198.7^{\circ} \mathrm{R}$. The Reynolds number sensitivity to total temperature is constant for the linear relation, as shown in Eq. (145) and Figure 14. For Sutherland's viscosity relation, the sensitivity coefficient is strongly dependent on both $T_{t}$ and $M_{\infty}$. As before, the curves intersect at $\mathrm{T}_{\infty}=\mathrm{T}_{\mathrm{S}}$.

\section{Concluding Remarks}

Estimation of the uncertainty in results from high-speed wind tunnel tests is hindered by the need to evaluate the sensitivity coefficients, $\partial \mathrm{R} / \partial \mathrm{M}_{\infty}$, for various aerodynamic ratios, $R$. The ratios can be complex functions of $M_{\infty}$ and calculating the partial derivative is a demanding task. To simplify the error estimation procedure, sensitivity coefficients were evaluated for nine fundamental aerodynamic ratios. In general, these ratios relate a freestream test condition (pressure, temperature, density or velocity) to a reference (total or sonic) condition. Methods of applying these sensitivity coefficients in error estimation were demonstrated for several nondimensional ratios and coefficients which are used in high-speed testing. In addition, the sensitivity coefficients can be applied directly to estimating the error in calculated free-stream conditions. The presence of dependent or correlated variables in a calculated test result is frequently a challenge. Examples were given which compared two analytical methods for estimating the error when variables are dependent. Also, a numerical method which approximates the partial derivatives was discussed and an example code which implements this procedure was given. 


\section{References}

1. Abernathy, R. B., Thompson, J. W., Jr., et al, "Handbook - Uncertainty in Gas Turbine Measurements," AEDC TR-73-5, Arnold Engineering Development Center, Feb., 1973. Also published as: "Measurement Uncertainty Handbook," Instrument Society of America, 1980.

2. "Measurement Uncertainty for Fluid Flow in Closed Conduits," ANSI/ASME MFC-2M-1983, American Society of Mechanical Engineers, Aug., 1984

3. "Fluid Flow Measurement Uncertainty," ISO TC30 SC9, Draft revision to ISO/ DIS 5168, International Standardization Organization, Dec, 1985.

4. "Measurement Uncertainty," ANSI/ASME PTC 19.1-1985, American Society of Mechanical Engineers, April, 1986.

5. Coleman, H. W. and Steele, W. G., Jr., Experimentation and Uncertainty Analysis for Engineers, John Wiley \& Sons, 1989.

6. Dieck, R. H., Measurement Uncertainty: Methods and Applications, Instrument Society of America, 1992

7. Coleman and Steele, op. cit., p. 80.

8. Moffat, R. J., "Using Uncertainty Analysis in the Planning of an Experiment," Transactions of the ASME, Journal of Fluids Engineering, Vol. 107, June 1985, pp. 173178.

9. Jones, P.A. and Friedman, M.A., "Propagating Bias and Precision Errors Using the Perturbation Method," ISA Transactions, Vol. 29, No. 4, 1990, pp. 71-77.

10. Coleman and Steele, op. cit., p. 43 and Example 3.3 (p. 48).

11. Ames Research Staff, "Equations, Tables and Charts for Compressible Flow," NACA Report 1135, 1953. 
intentionally Left Blank 


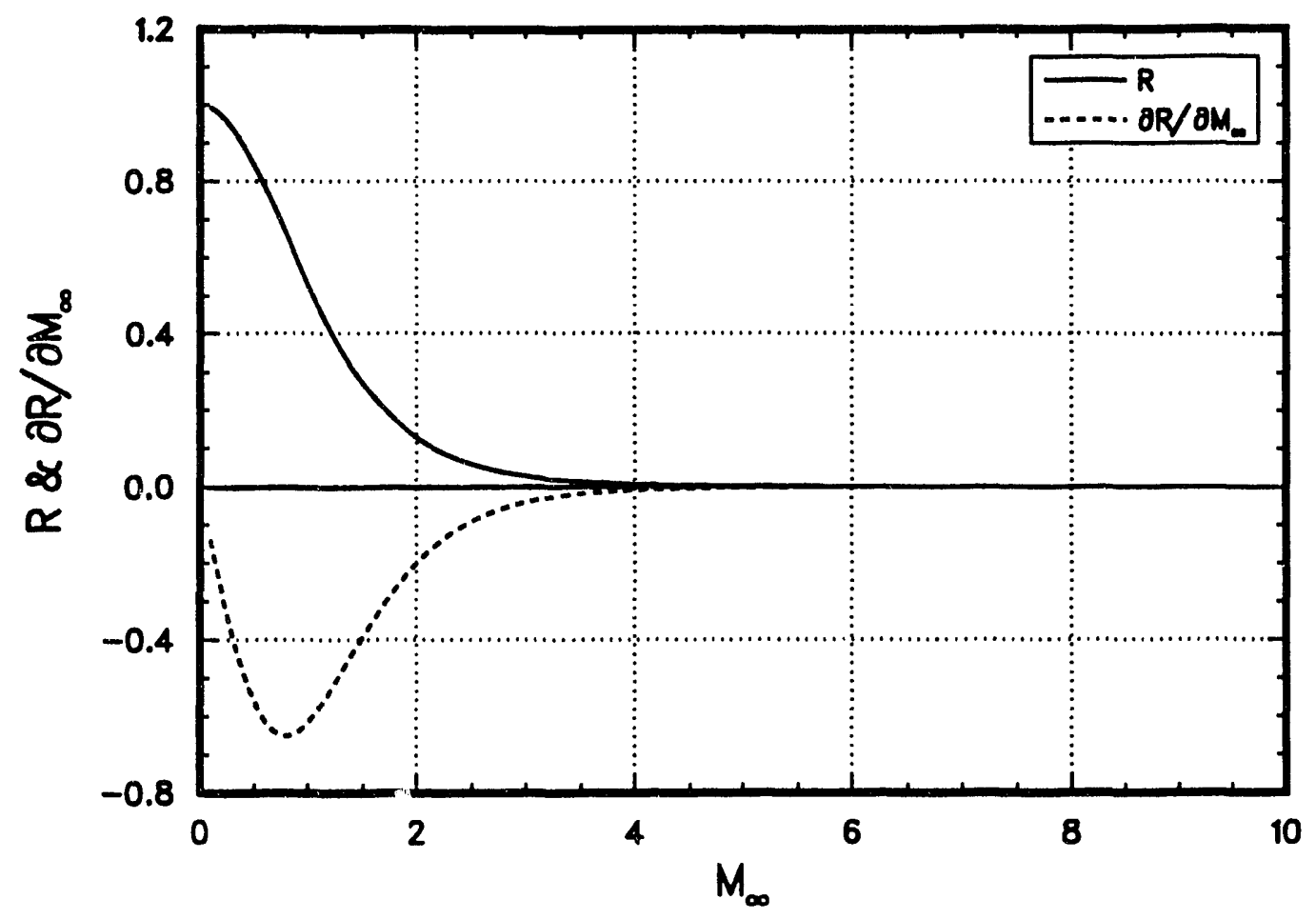

a. $R$ and $\partial R / \partial M_{\infty}$

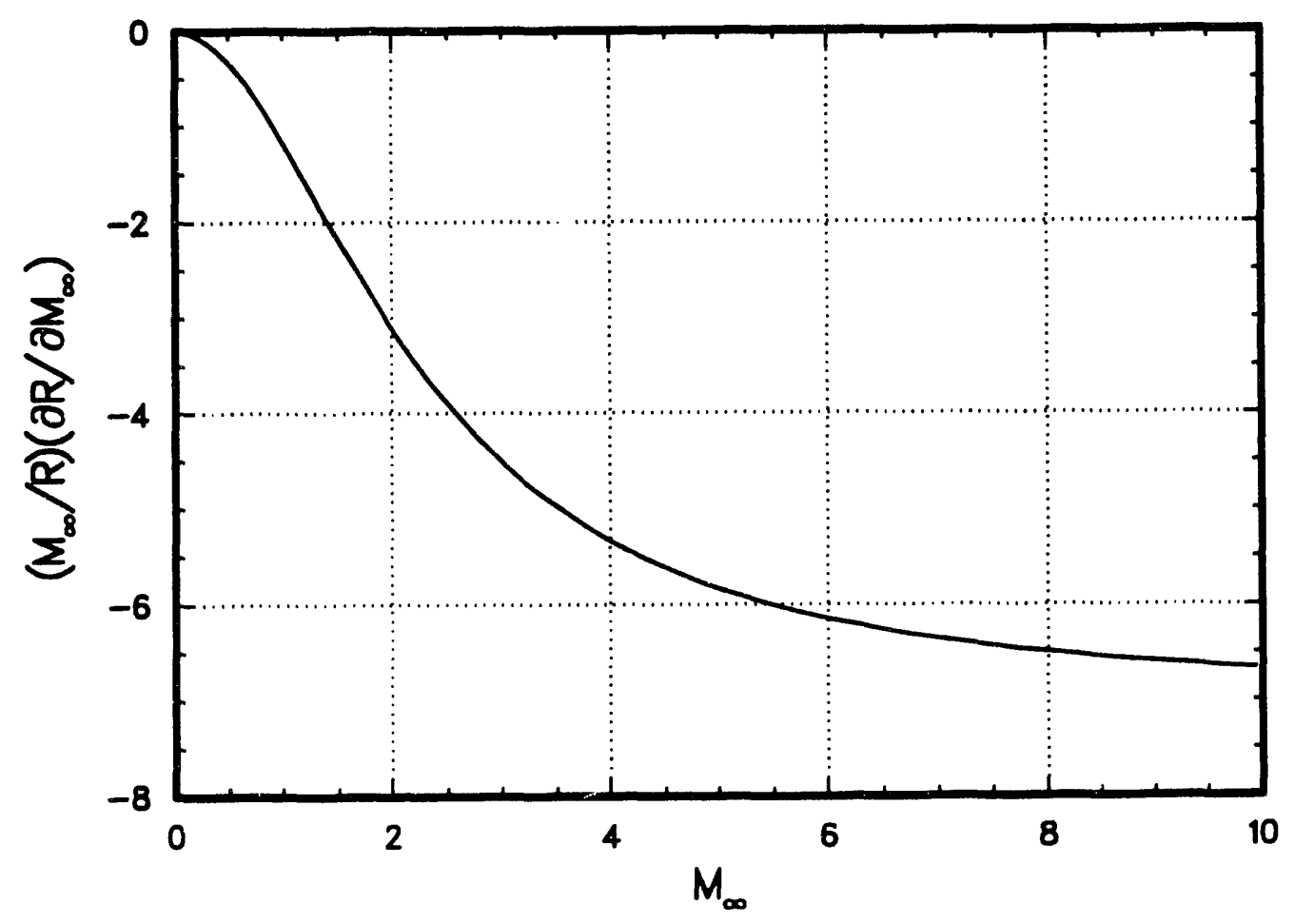

b. $\theta_{M_{\infty}}^{\prime}=\left(M_{\infty} / R\right)\left(\partial R / \partial M_{\infty}\right)$

Figure 1. Variation of $R, \partial R / \partial M_{\infty}$, and $\theta^{\prime}{ }_{M_{\infty}}$ with $M_{\infty}$ for $R=p_{\infty} / p_{t}$ and $\gamma=1.40$ 


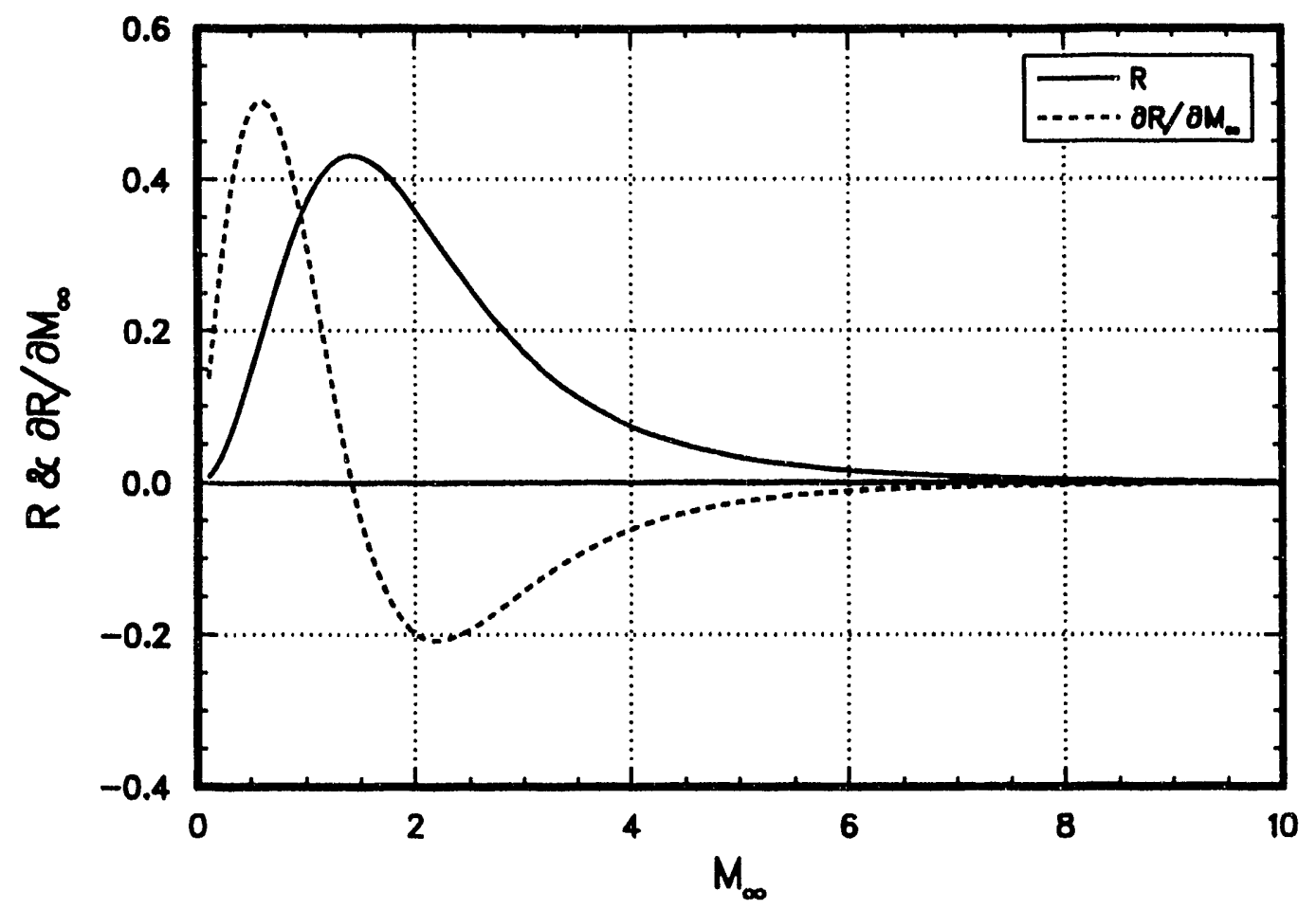

a. $R$ and $\partial R / \partial M_{\infty}$

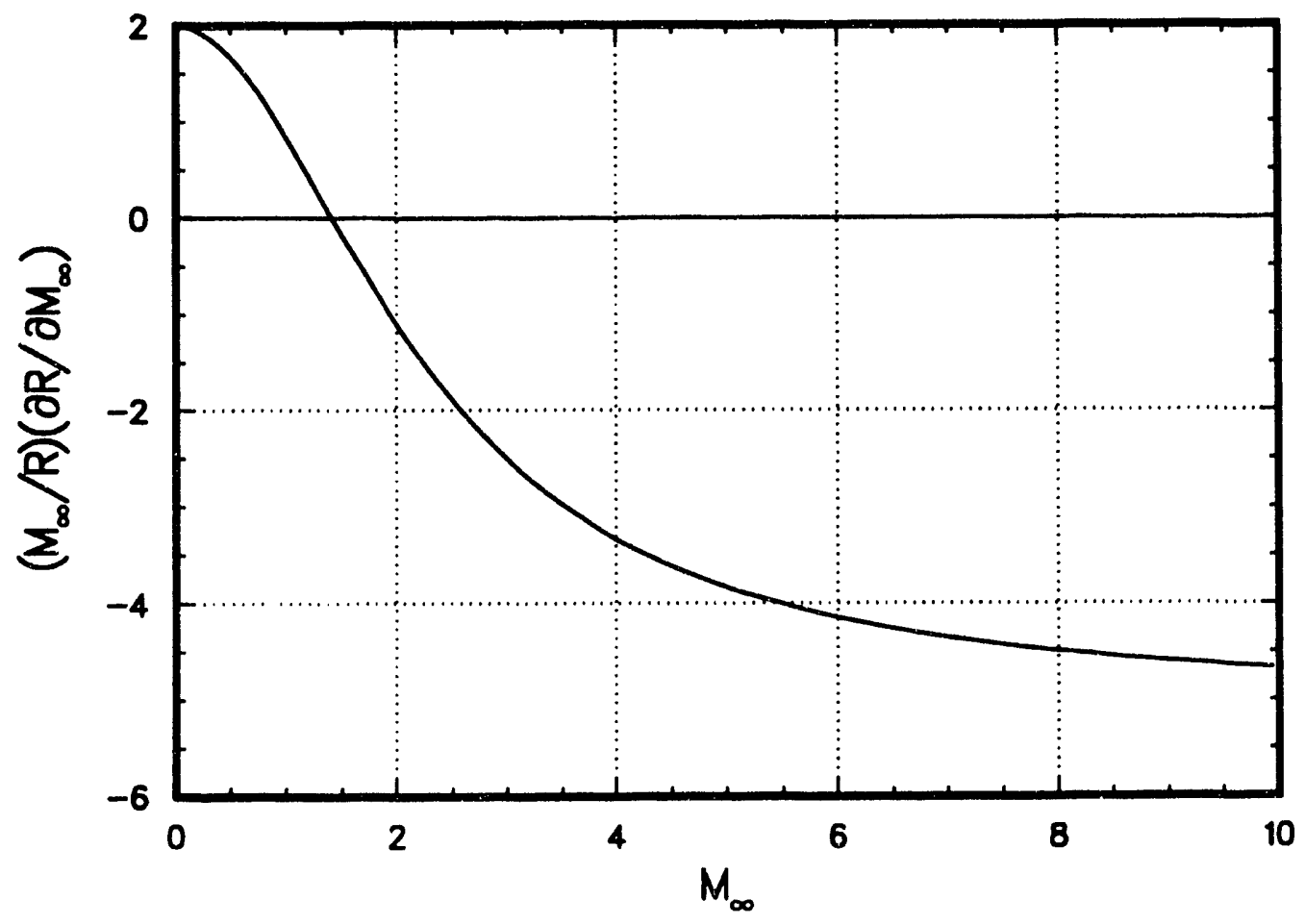

b. $\theta^{\prime}{ }_{M_{\infty}}=\left(M_{\infty} / R\right)\left(\partial R / \partial M_{\infty}\right)$

Figure 2. Variation of $R, \partial R / \partial M_{\infty}$, and $\theta^{\prime}{ }_{M_{\infty}}$ with $M_{\infty}$ for $R=q_{\infty} / p_{t}$ and $\gamma=1.40$ 


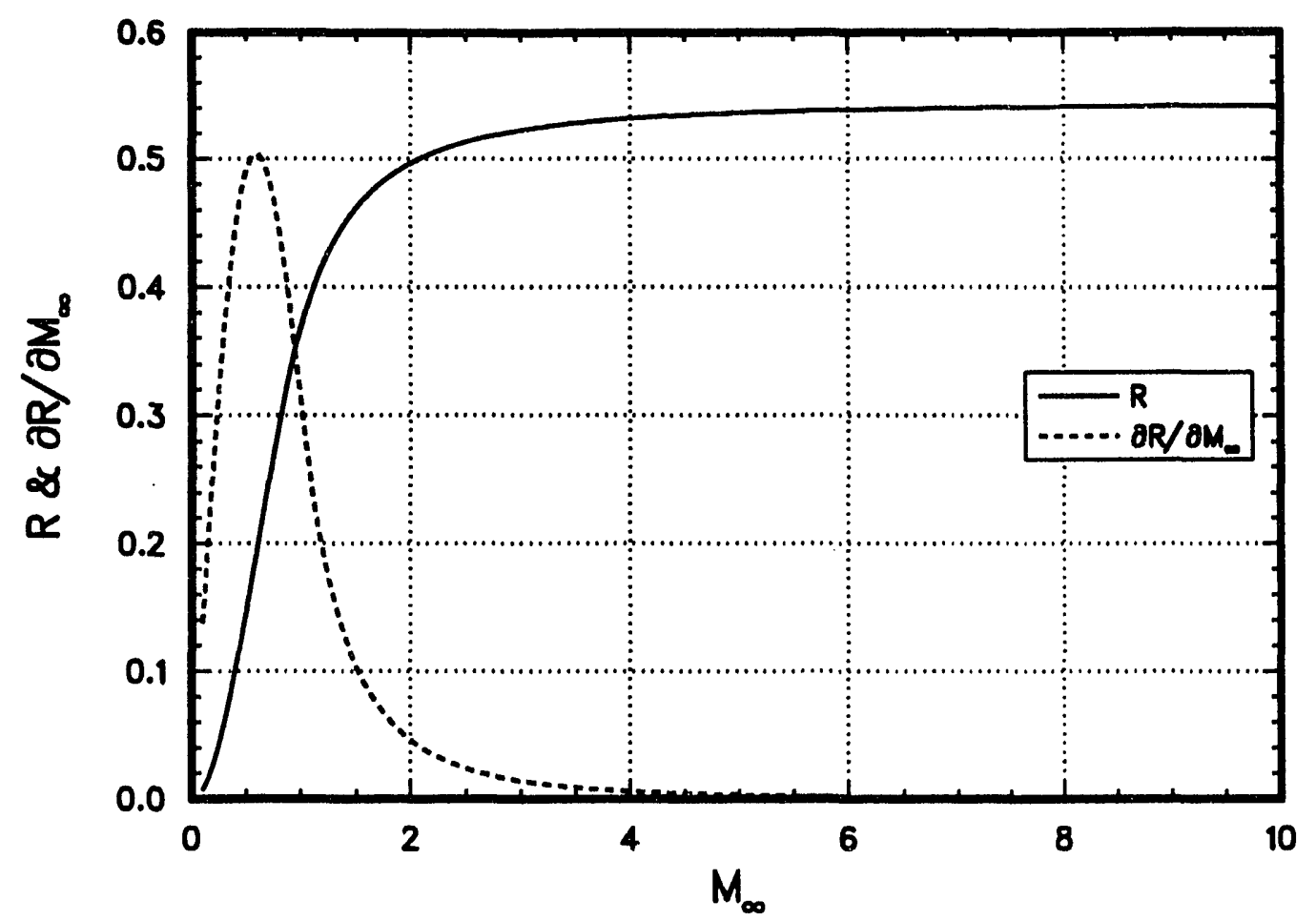

a. $R$ and $\partial R / \partial M_{\infty}$

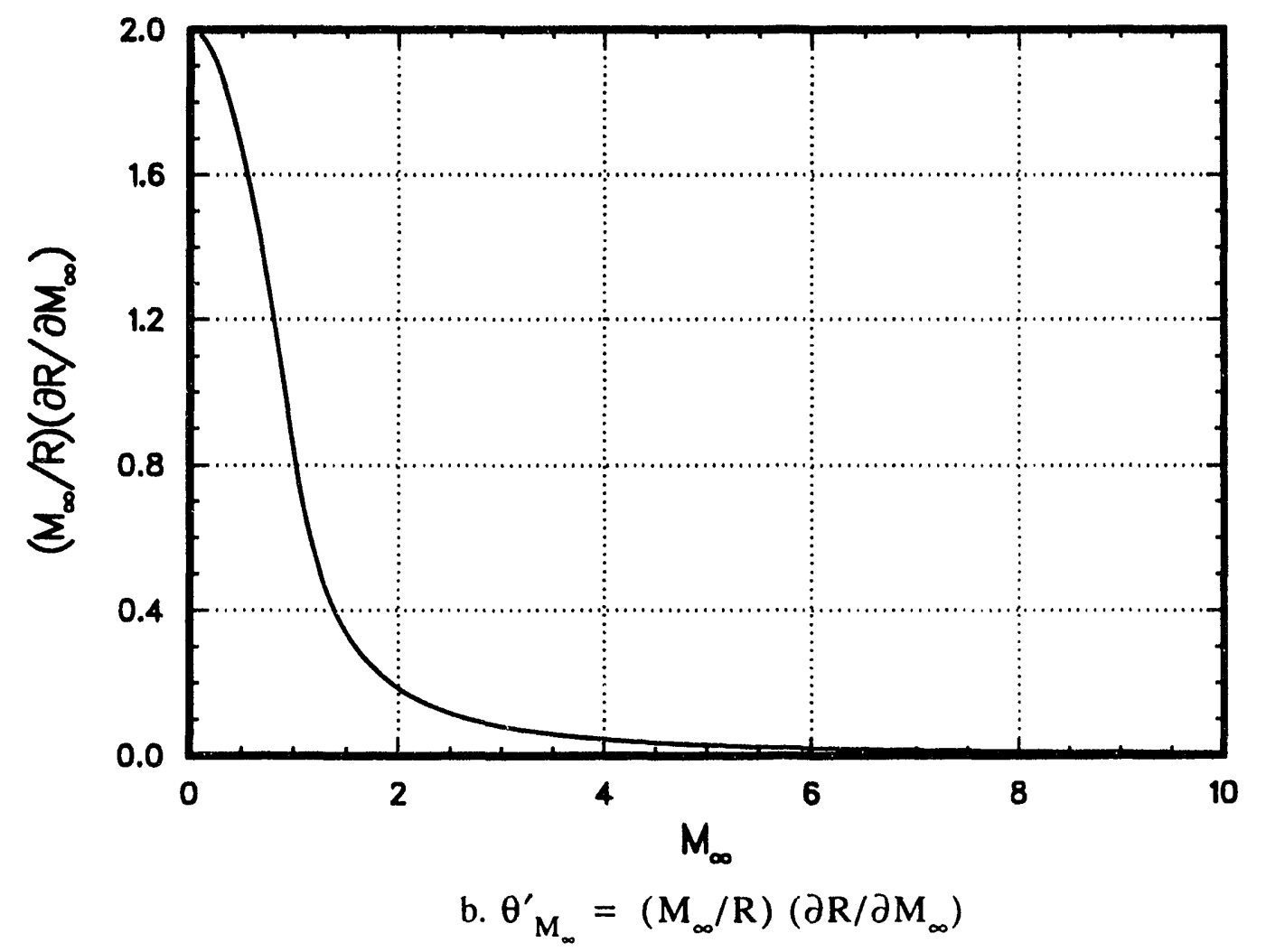

Figure 3. Variation of $R, \partial R / \partial M_{\infty}$, and $\theta^{\prime}{ }_{M_{\infty}}$ with $M_{\infty}$ for $R=q_{\infty} / p_{t_{2}}$ and $\gamma=1.40$ 


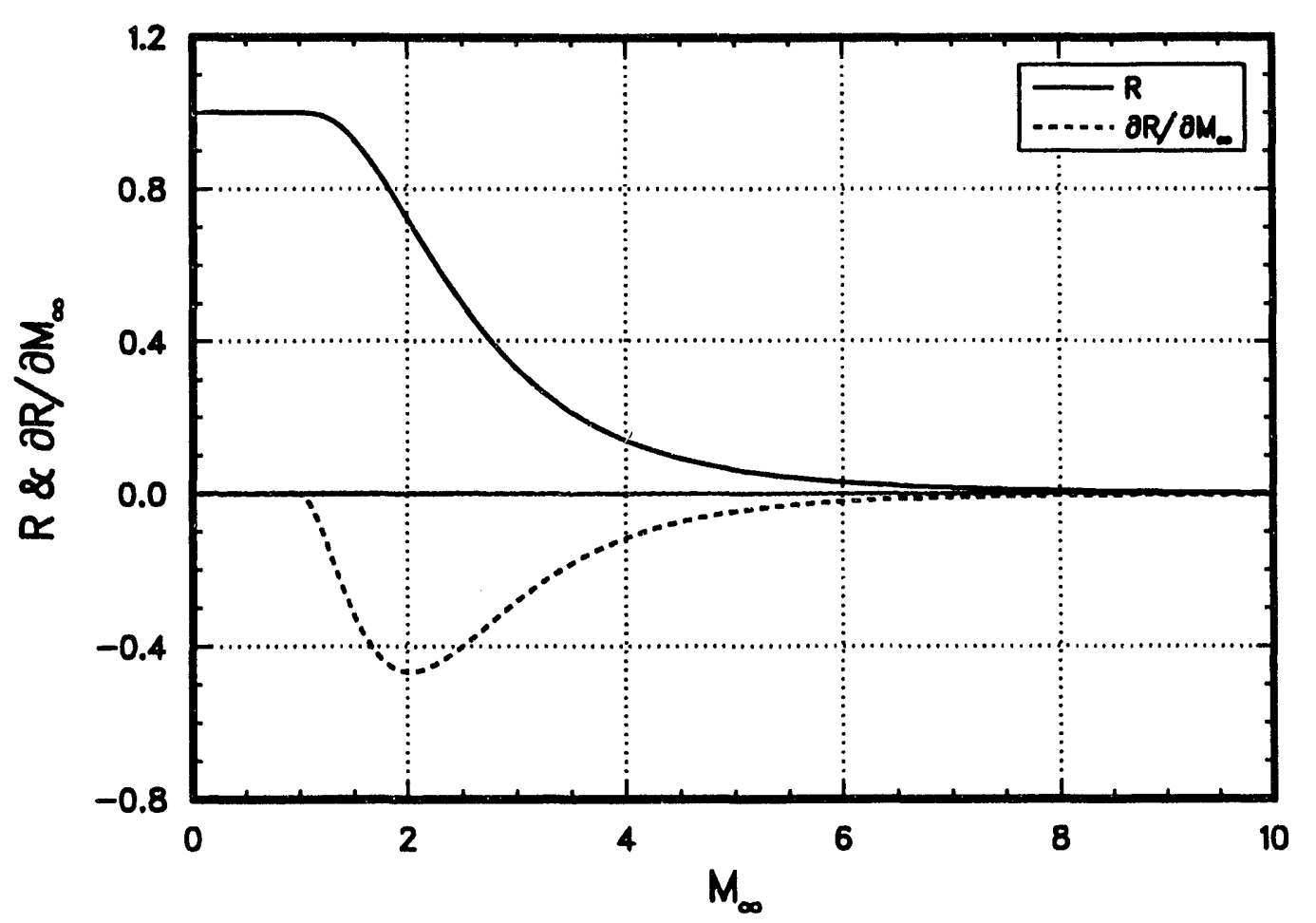

a. $R$ and $\partial R / \partial M_{\infty}$

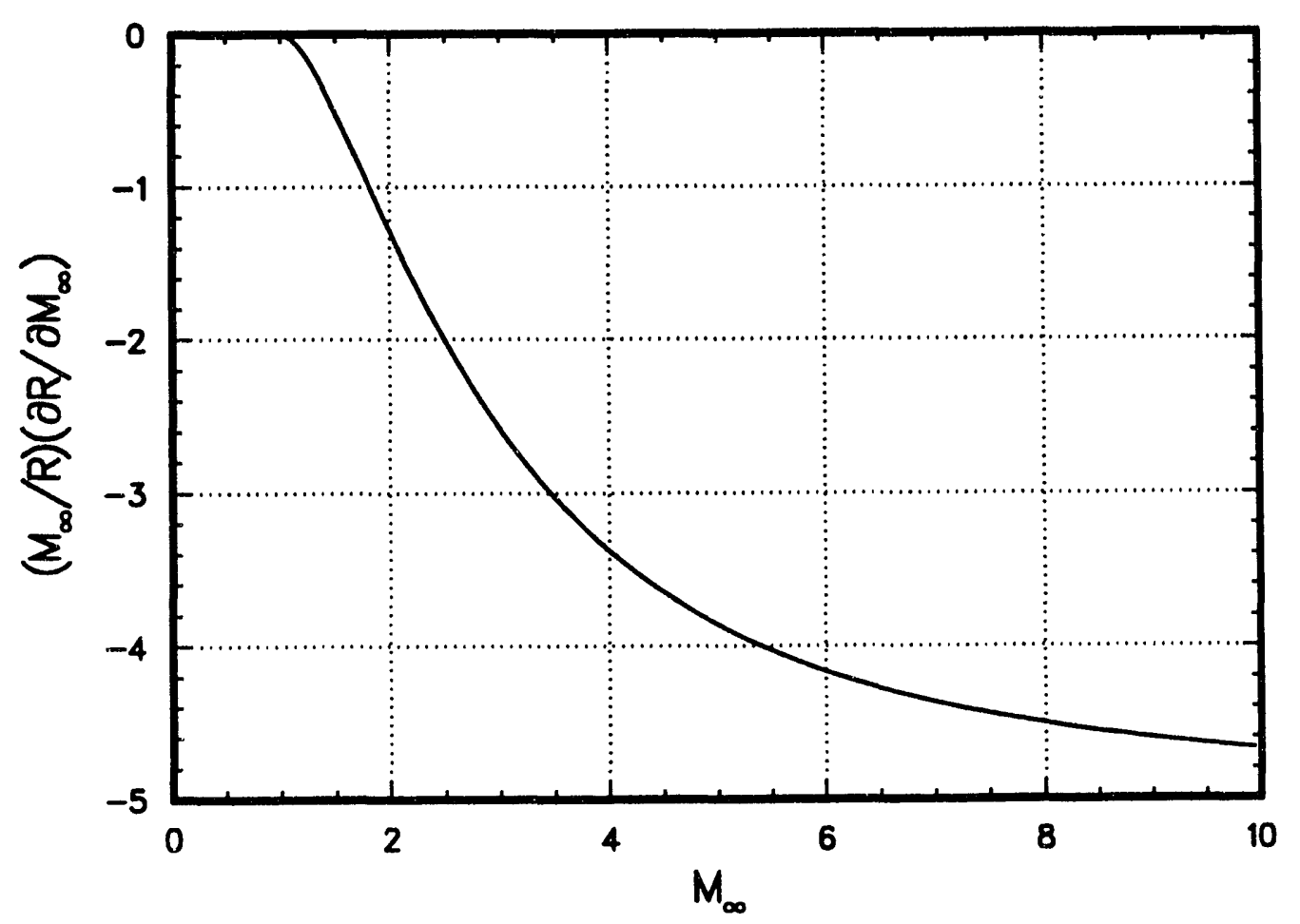

b. $\theta_{M_{\infty}}^{\prime}=\left(M_{\infty} / R\right)\left(\partial R / \partial M_{\infty}\right)$

Figure 4. Variation of $R, \partial R / \partial M_{\infty}$, and $\theta^{\prime}{ }_{M_{\infty}}$ with $M_{\infty}$ for $R=p_{t_{2}} / p_{t_{1}}$ and $\gamma=1.40$ 


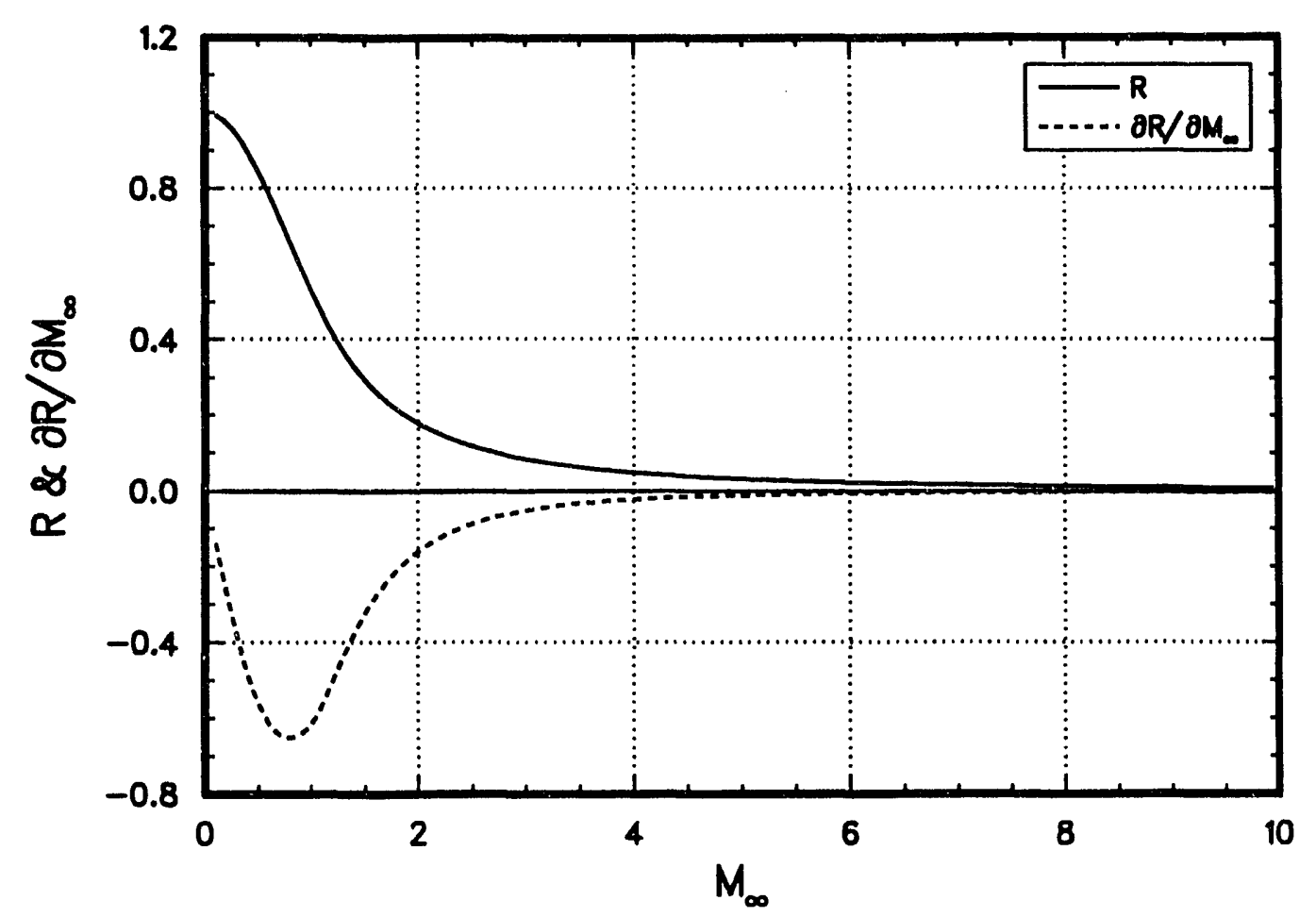

a. $R$ and $\partial R / \partial M_{\infty}$

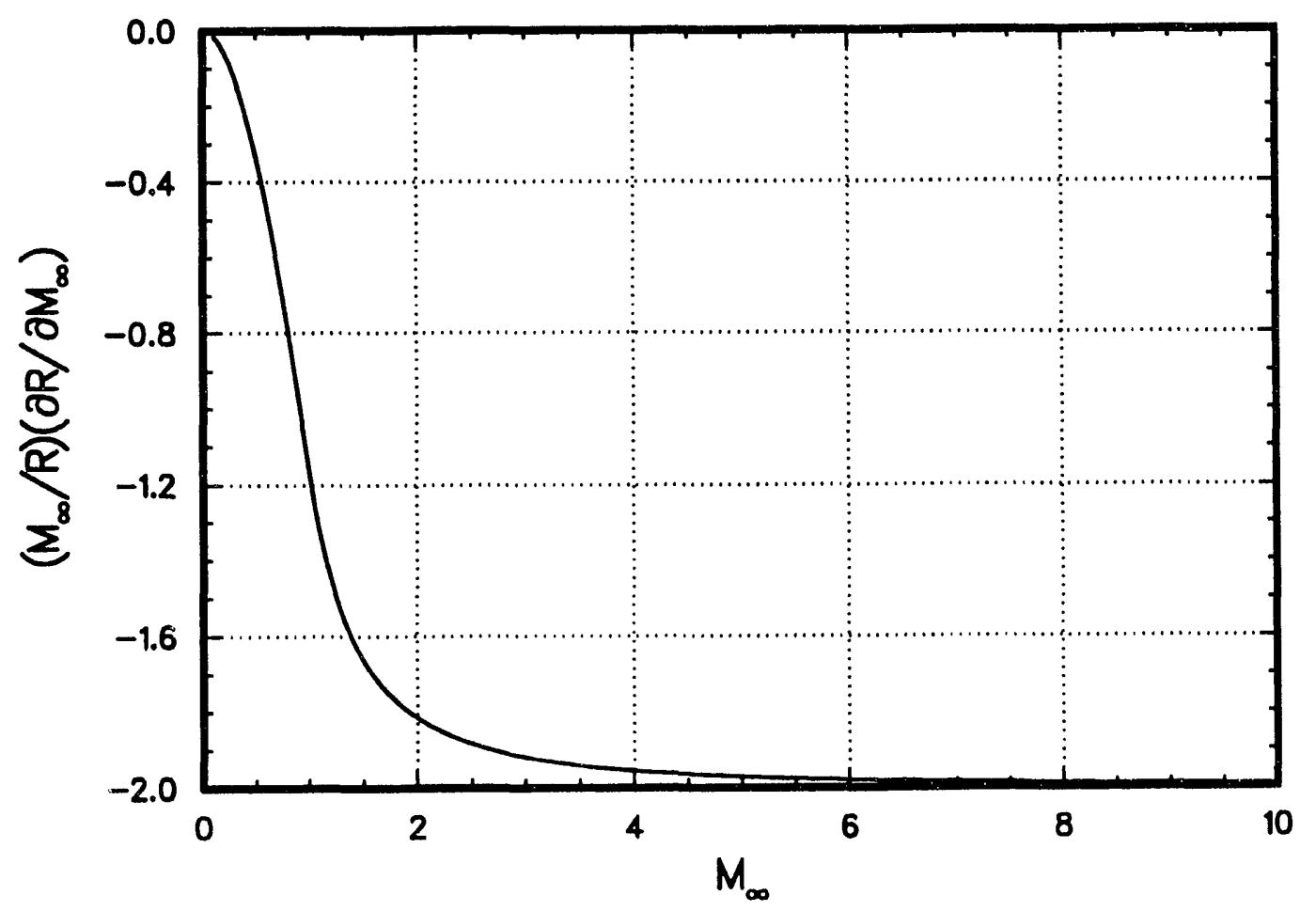

b. $\theta^{\prime}{ }_{M}=\left(M_{\infty} / R\right)\left(\partial R / \partial M_{\infty}\right)$

Figure 5 Variation of $R, \partial R / \partial M_{\infty}$, and $\theta^{\prime}{ }_{M_{\infty}}$ with $M_{\infty}$ for $R=p_{\infty} / p_{t_{2}}$ and $\gamma=1.40$ 


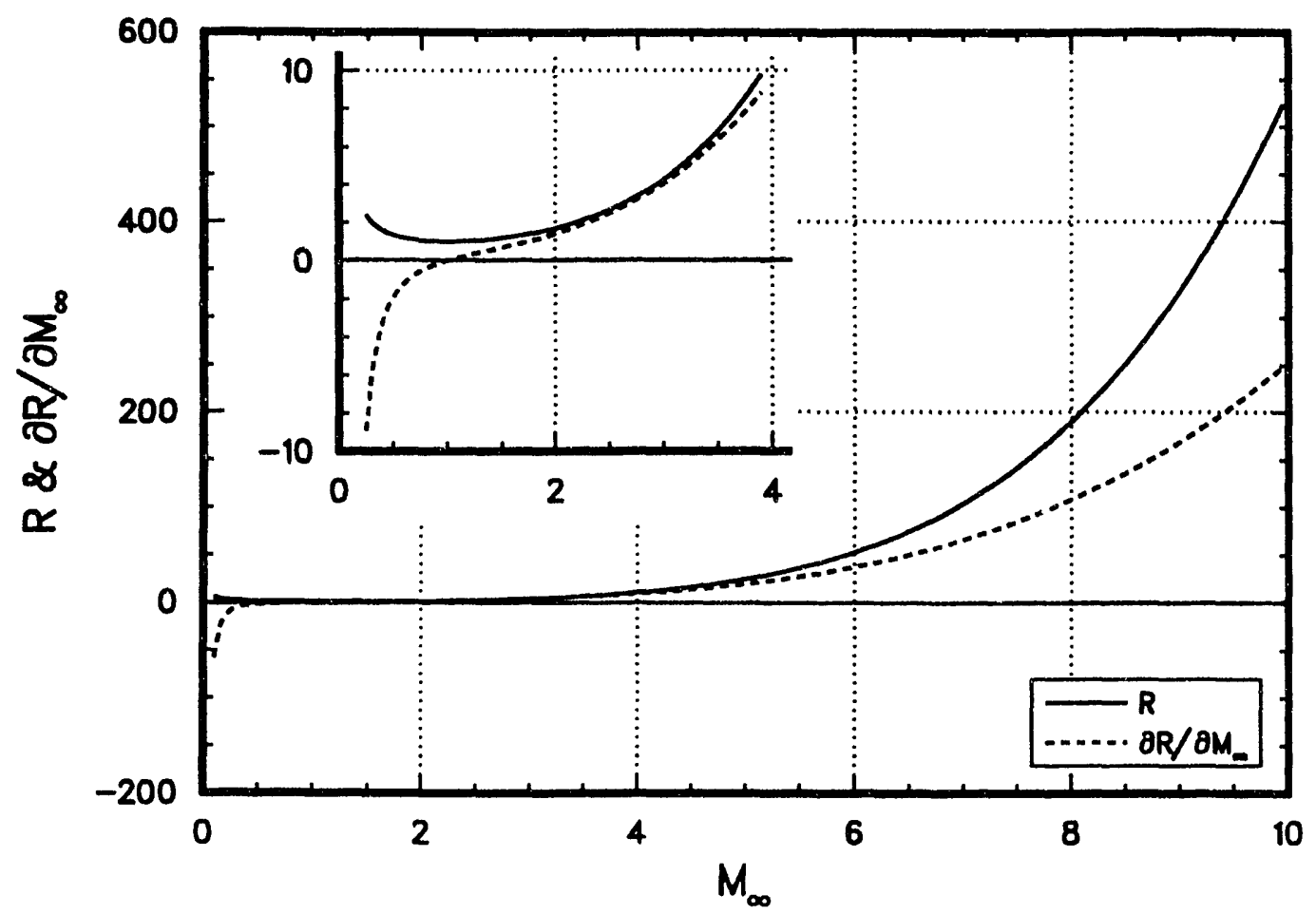

a. $R$ and $\partial R / \partial M_{\infty}$

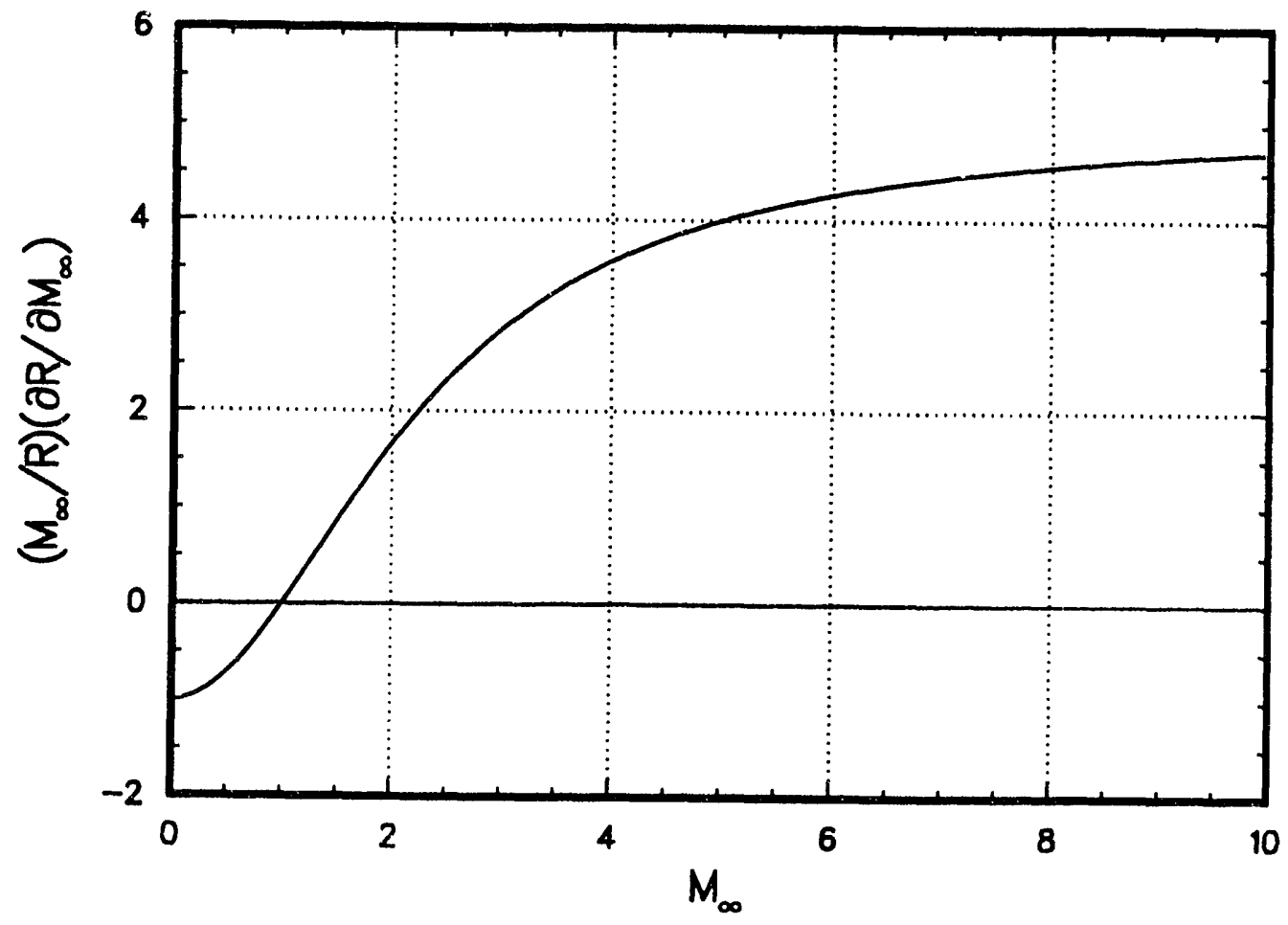

b. $\theta_{M_{\infty}^{\prime}}^{\prime}=\left(M_{\infty} / R\right)\left(\partial R / \partial M_{\infty}\right)$

Figure 6. Variation of $R, \partial R / \partial M_{\infty}$, and $\theta^{\prime}{ }_{M_{\infty}}$ with $M_{\infty}$ for $R=A_{\infty} / A^{*}$ and $\gamma=1.40$ 


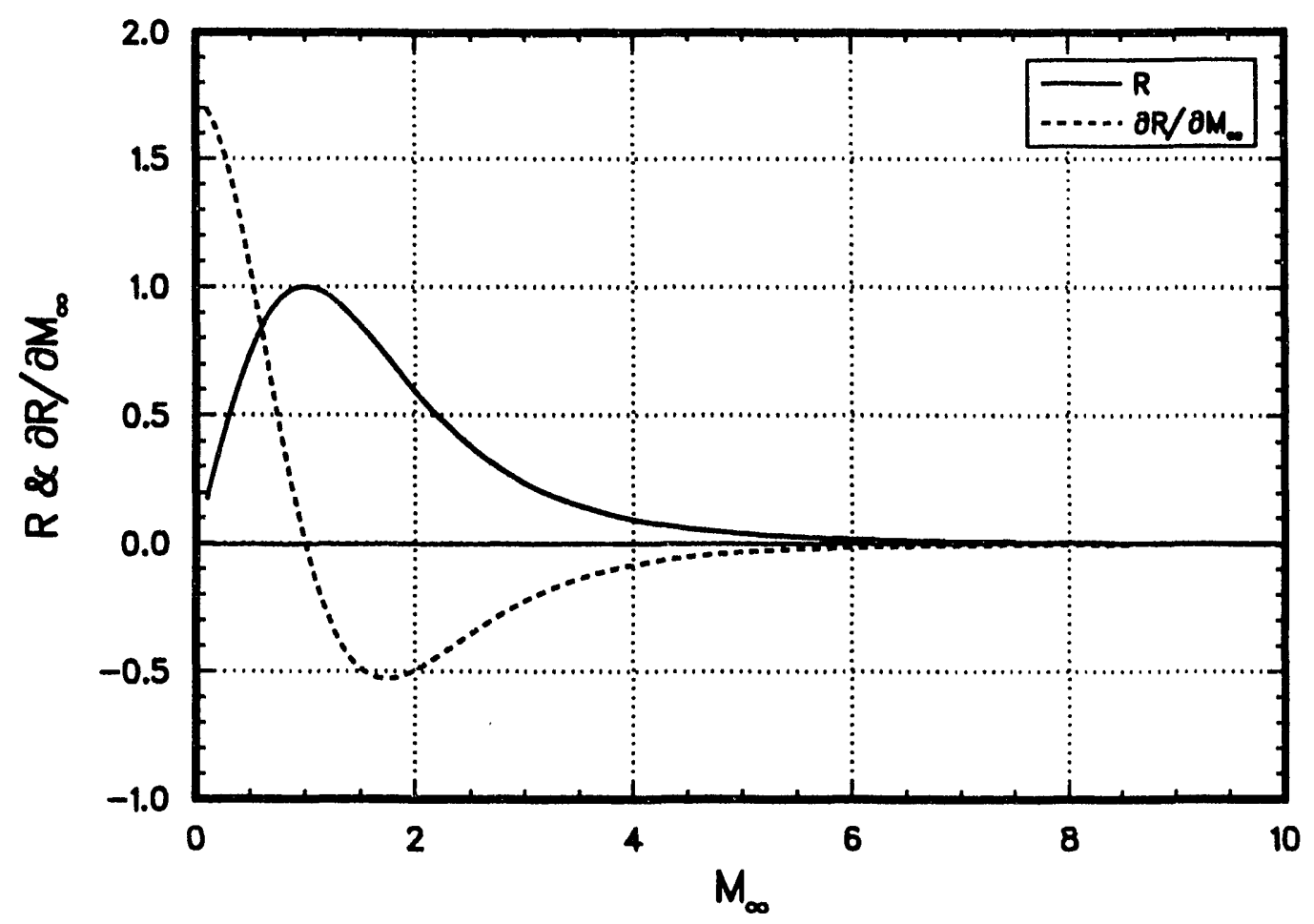

a. $R$ and $\partial R / \partial M_{\infty}$

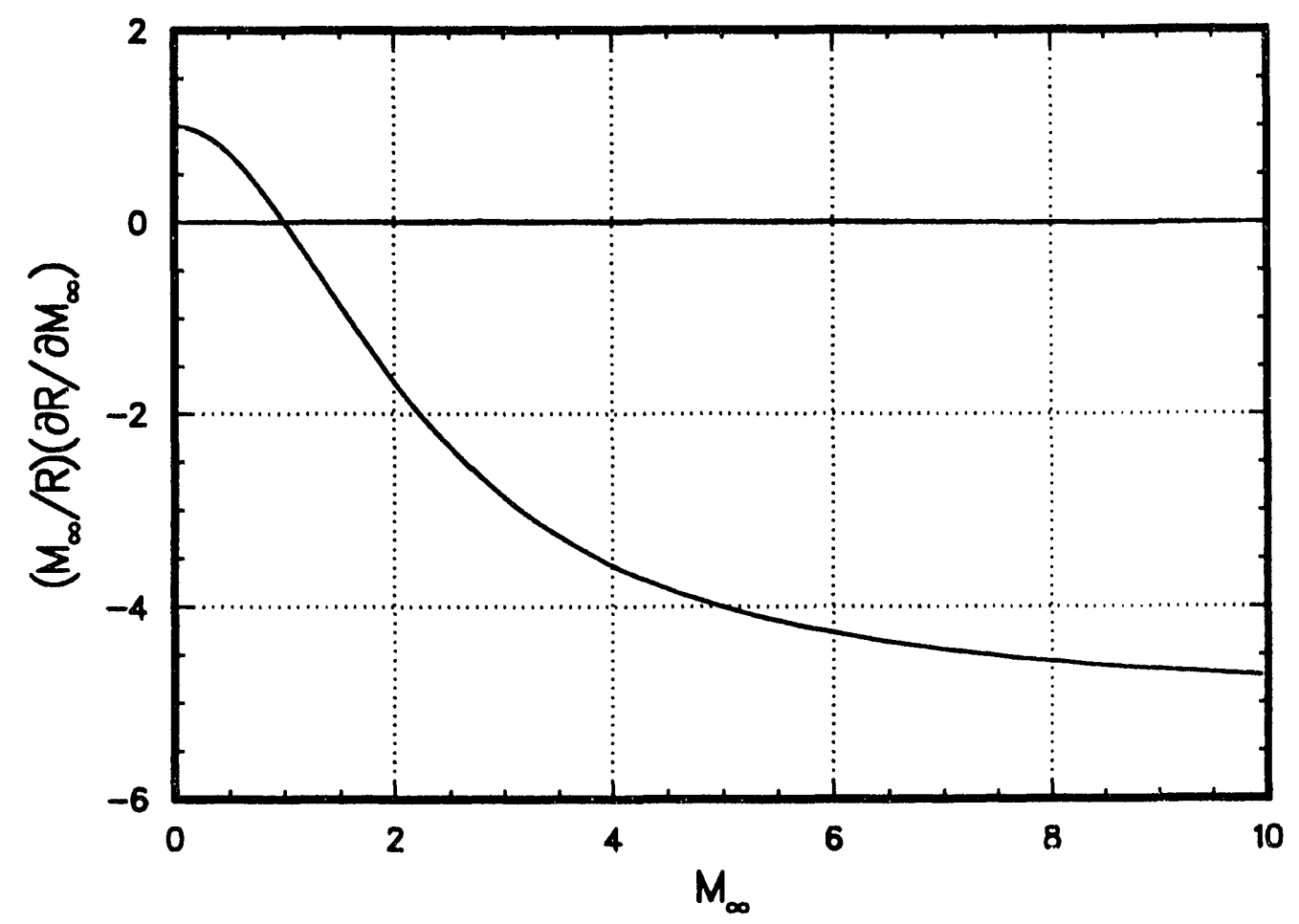

b. $\theta^{\prime}{ }_{M_{\infty}}=\left(M_{\infty} / R\right)\left(\partial R / \partial M_{\infty}\right)$

Figure 7. Variation of $R, \partial R / \partial M_{\infty}$, and $\theta^{\prime}{ }_{M_{\infty}}$ with $M_{\infty}$ for $R=\rho_{\infty} V_{\infty} / \rho^{*} V^{*}$ and $\gamma=1.40$ 


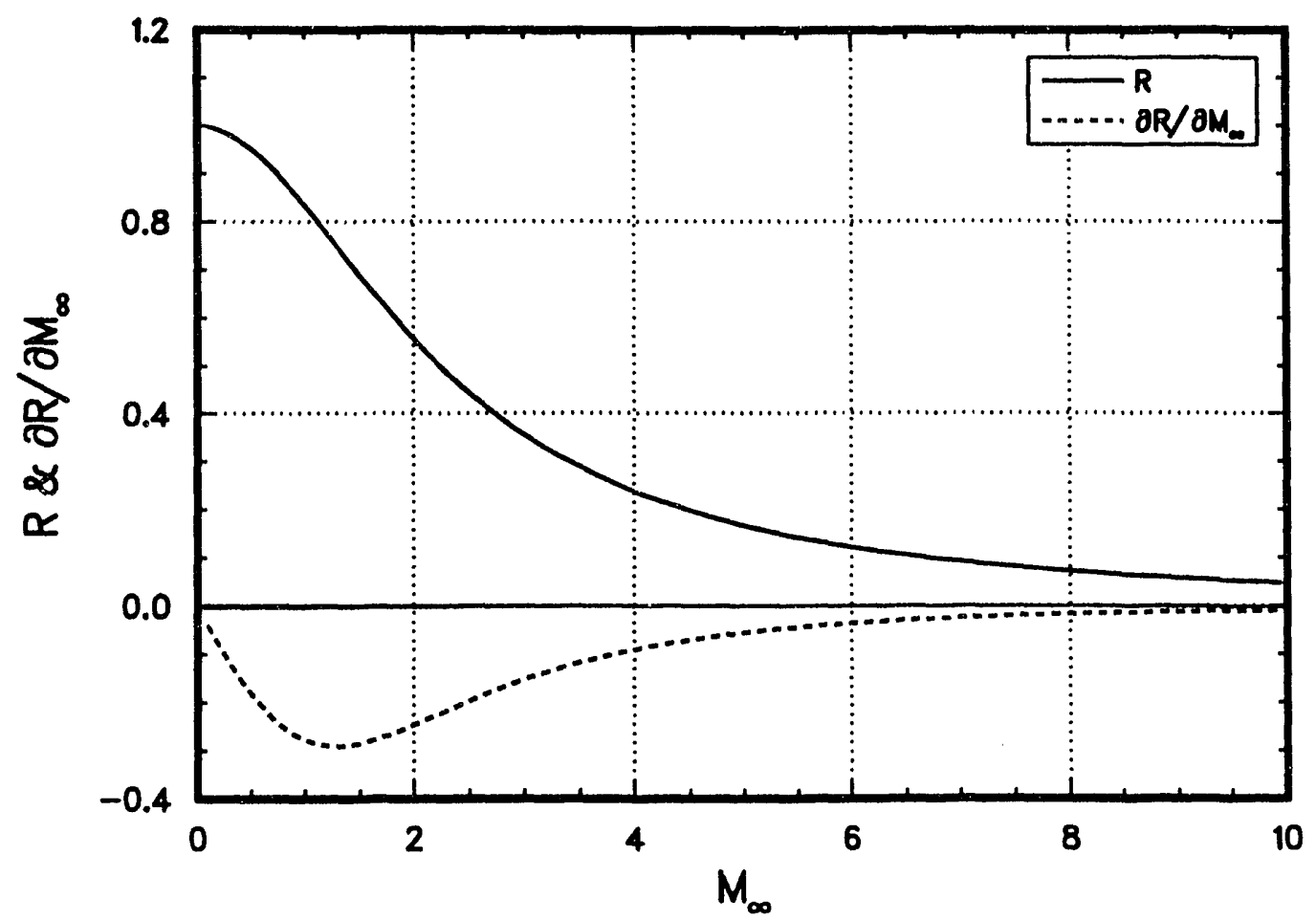

a. $R$ and $\partial R / \partial M_{\infty}$

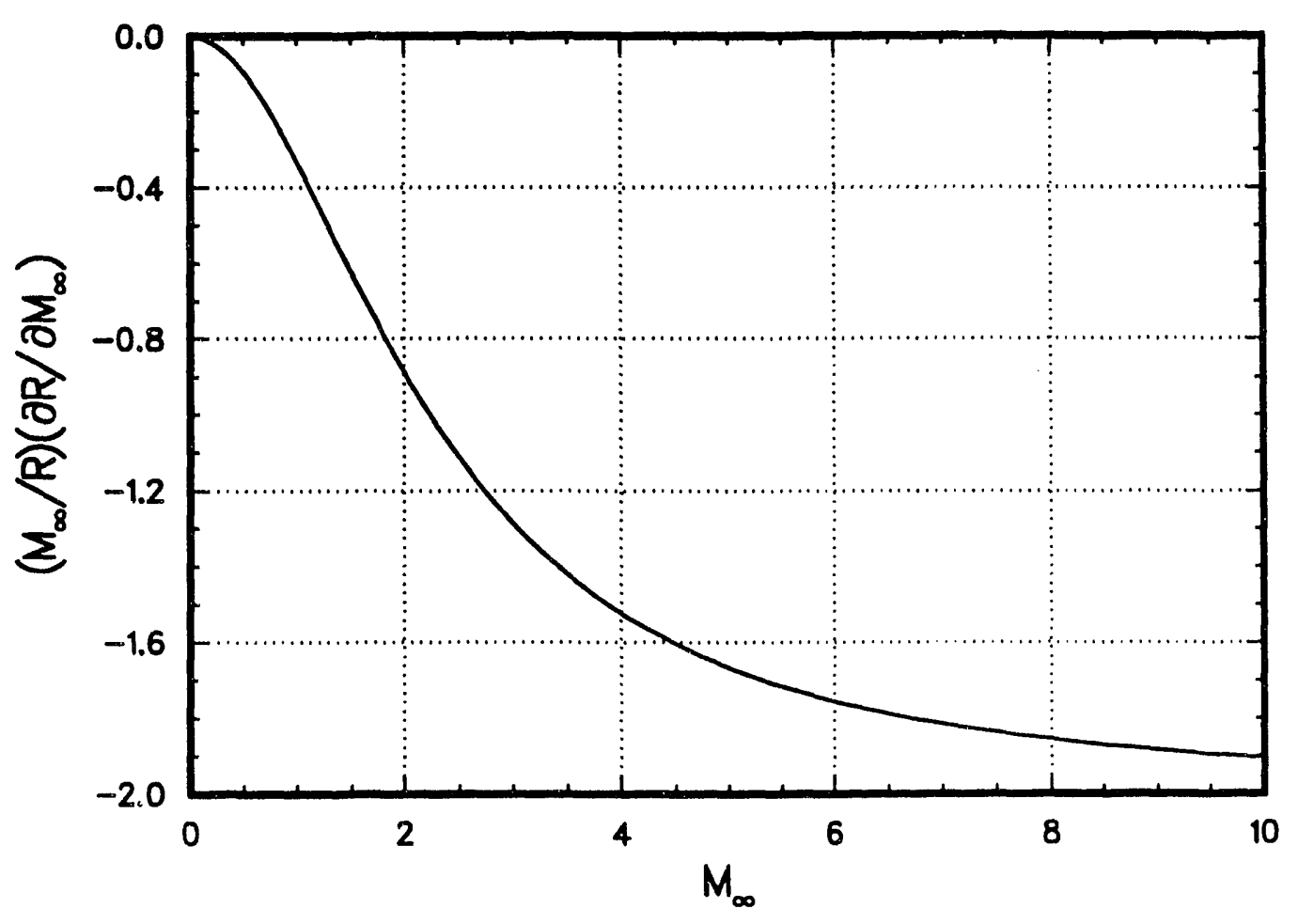

b. $\theta^{\prime}{ }_{M_{\infty}}=\left(M_{\infty} / R\right)\left(\partial R / \partial M_{\infty}\right)$

Figure 8. Variation of $R, \partial R / \partial M_{\infty}$, and $\theta^{\prime}{ }_{M_{\infty}}$ with $M_{\infty}$ for $R=T_{\infty} / T_{t}$ and $\gamma=1.40$ 


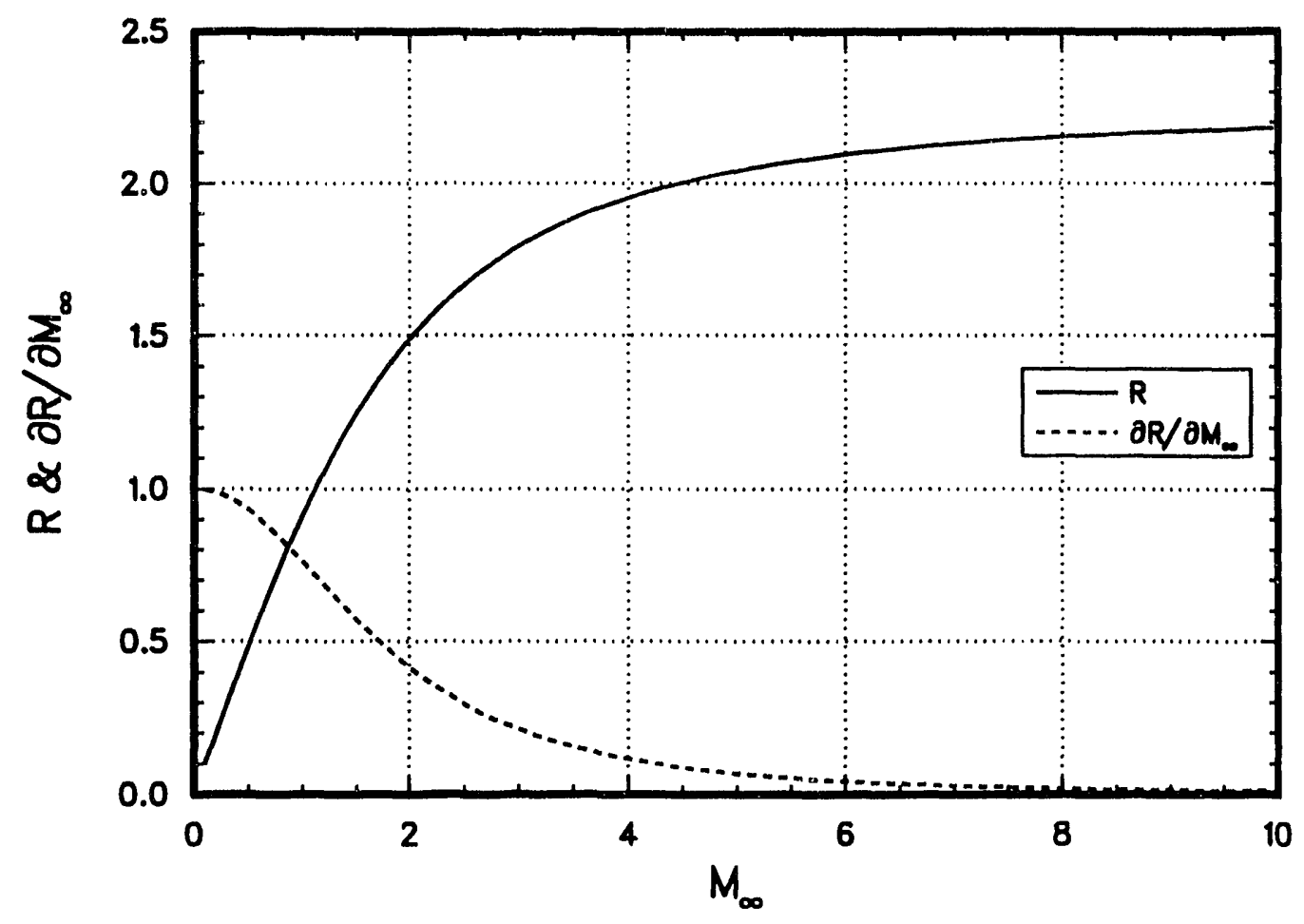

a. $R$ and $\partial R / \partial M_{\infty}$

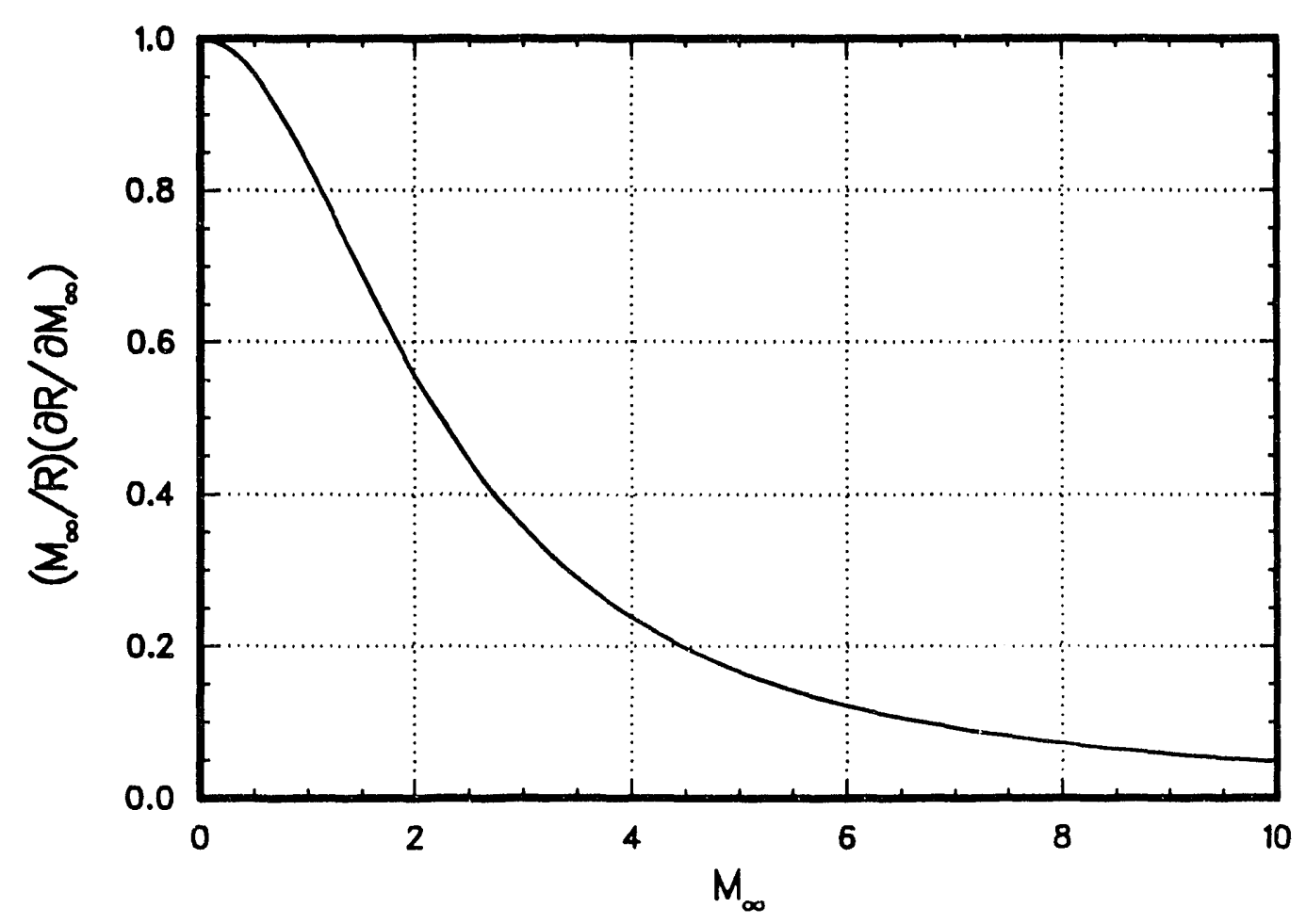

b. $\theta_{M_{\ldots}}=\left(M_{\infty} / R\right)\left(\partial R / \partial M_{\infty}\right)$

Figure 9. Variation of $R, \partial R / \partial M_{\infty}$, and $\theta^{\prime} M_{\infty}$ with $M_{\infty}$ for $R=V_{\infty} / a_{1}$ and $\gamma=1.40$ 


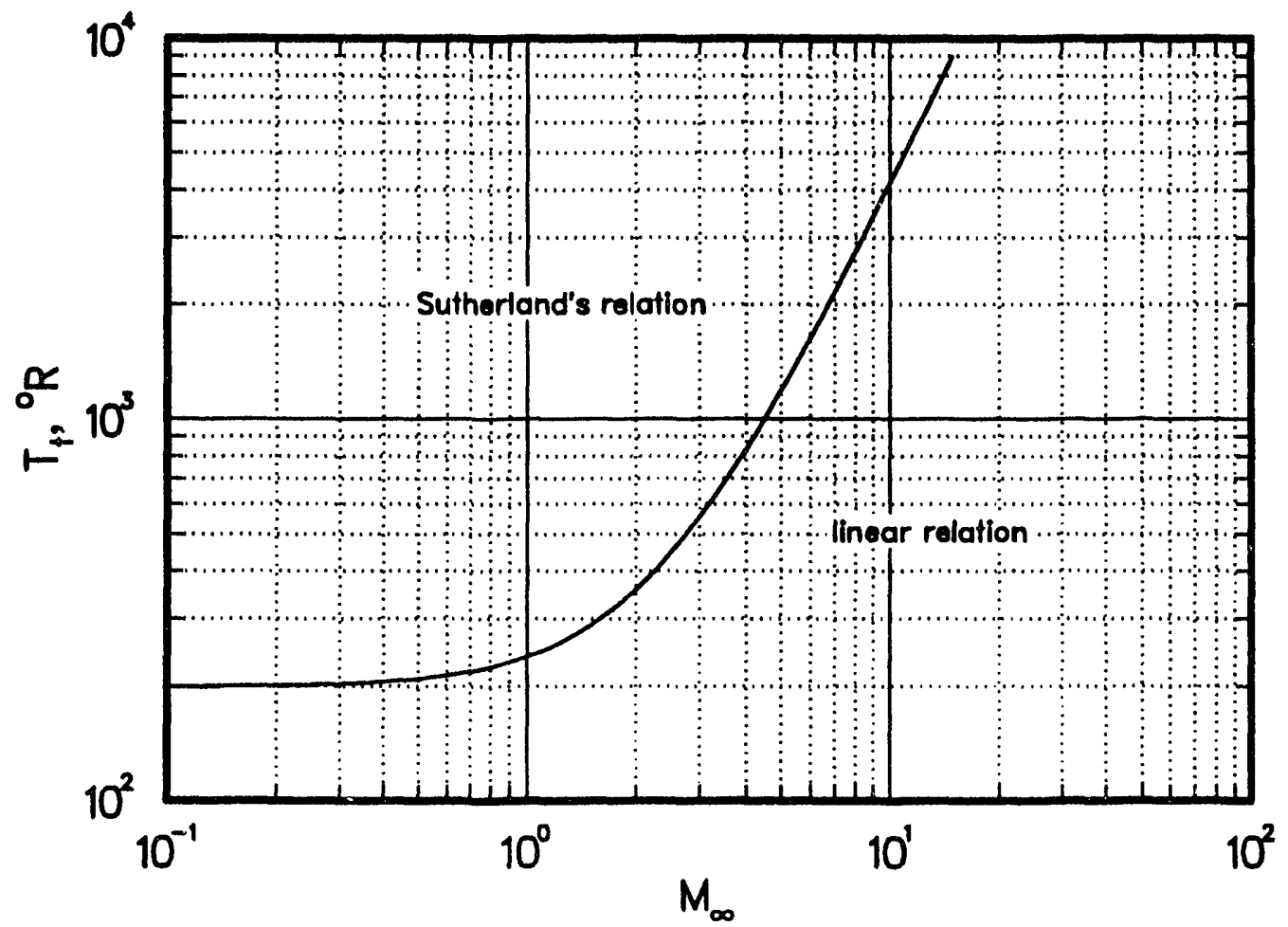

Figure 10 . Dynamic viscosity regimes 


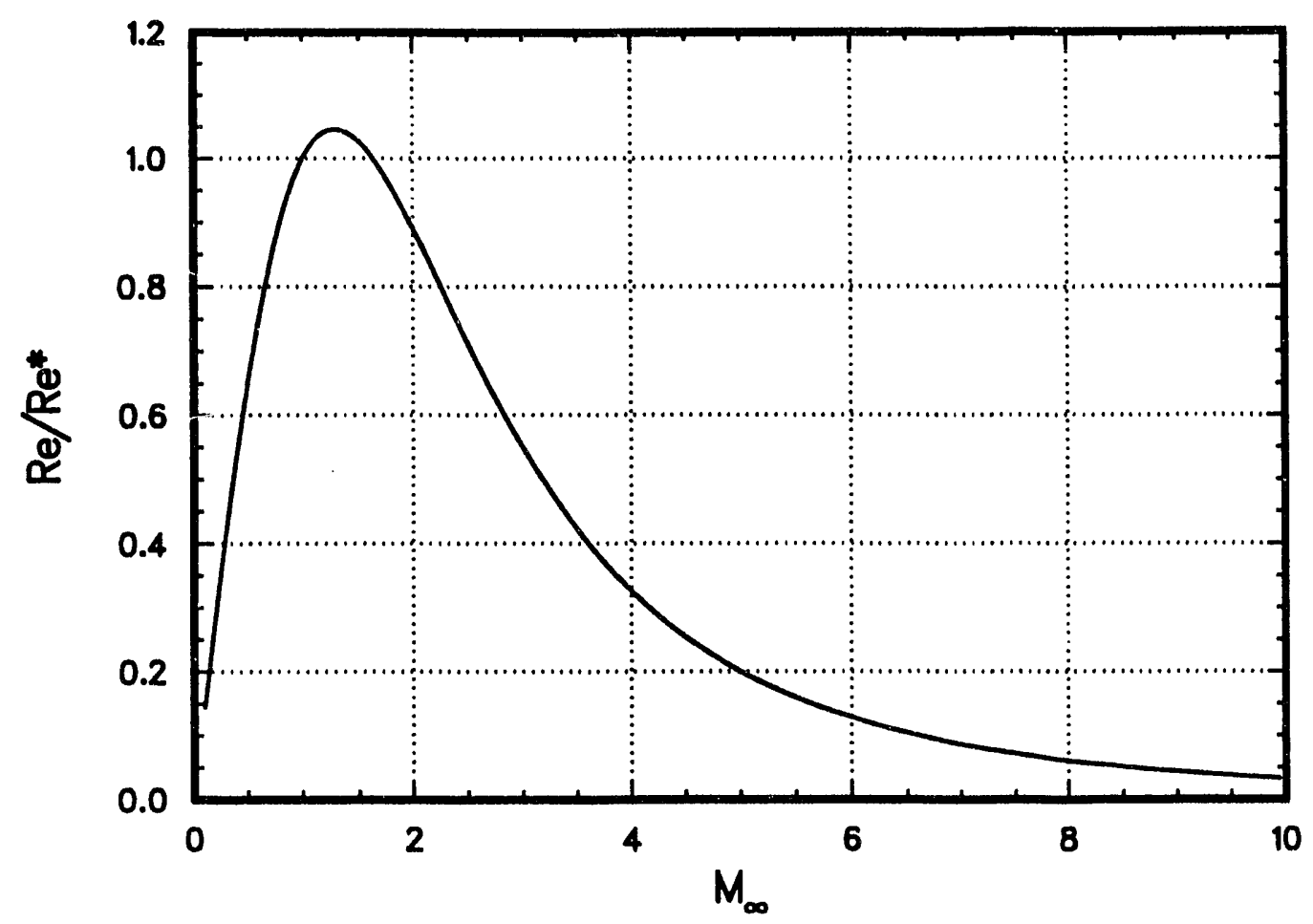

Figure 11. Variation of $\mathrm{Re} / \mathrm{Re}^{*}$ with $\mathrm{M}_{\infty}$, linear viscosity relation

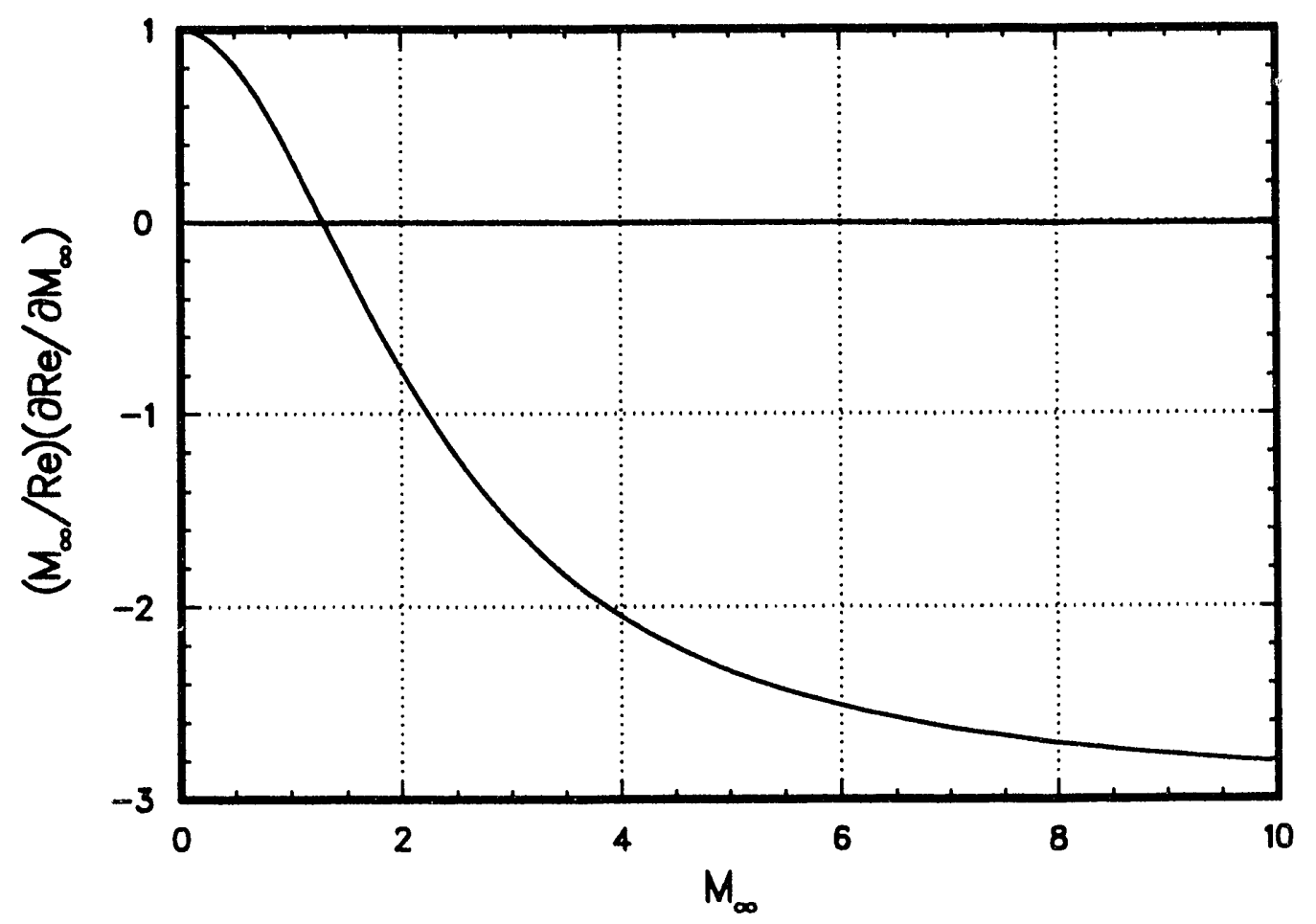

Figure 12. Variation of relative sensitivity coefficient for Reynolds number with $\mathrm{M}_{\infty}$, linear viscosity relation 


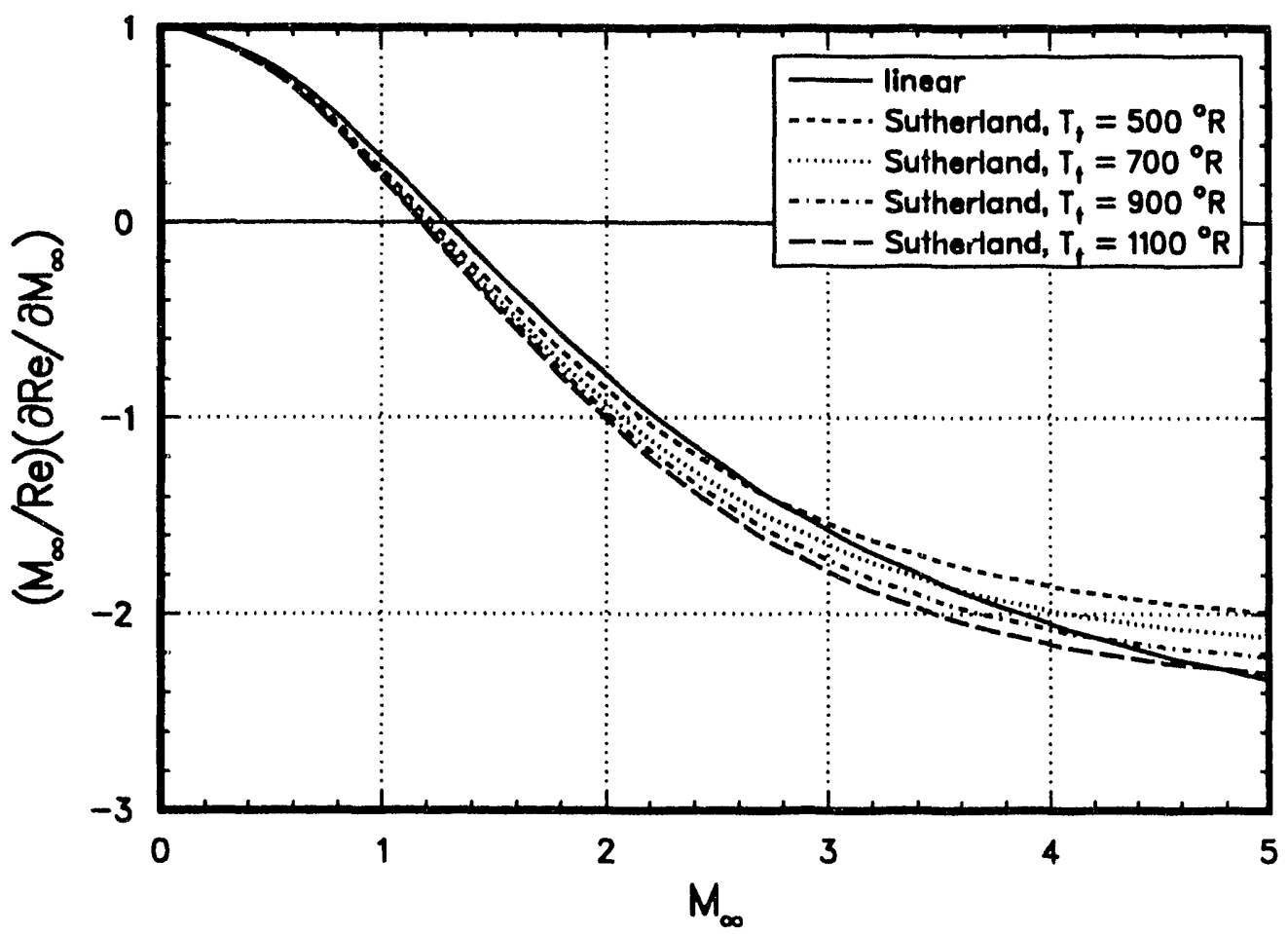

Figure 13. Variation of relative sensitivity coefficient for Reynolds number with $\mathrm{M}_{\infty}$, Sutherland's viscosity relation

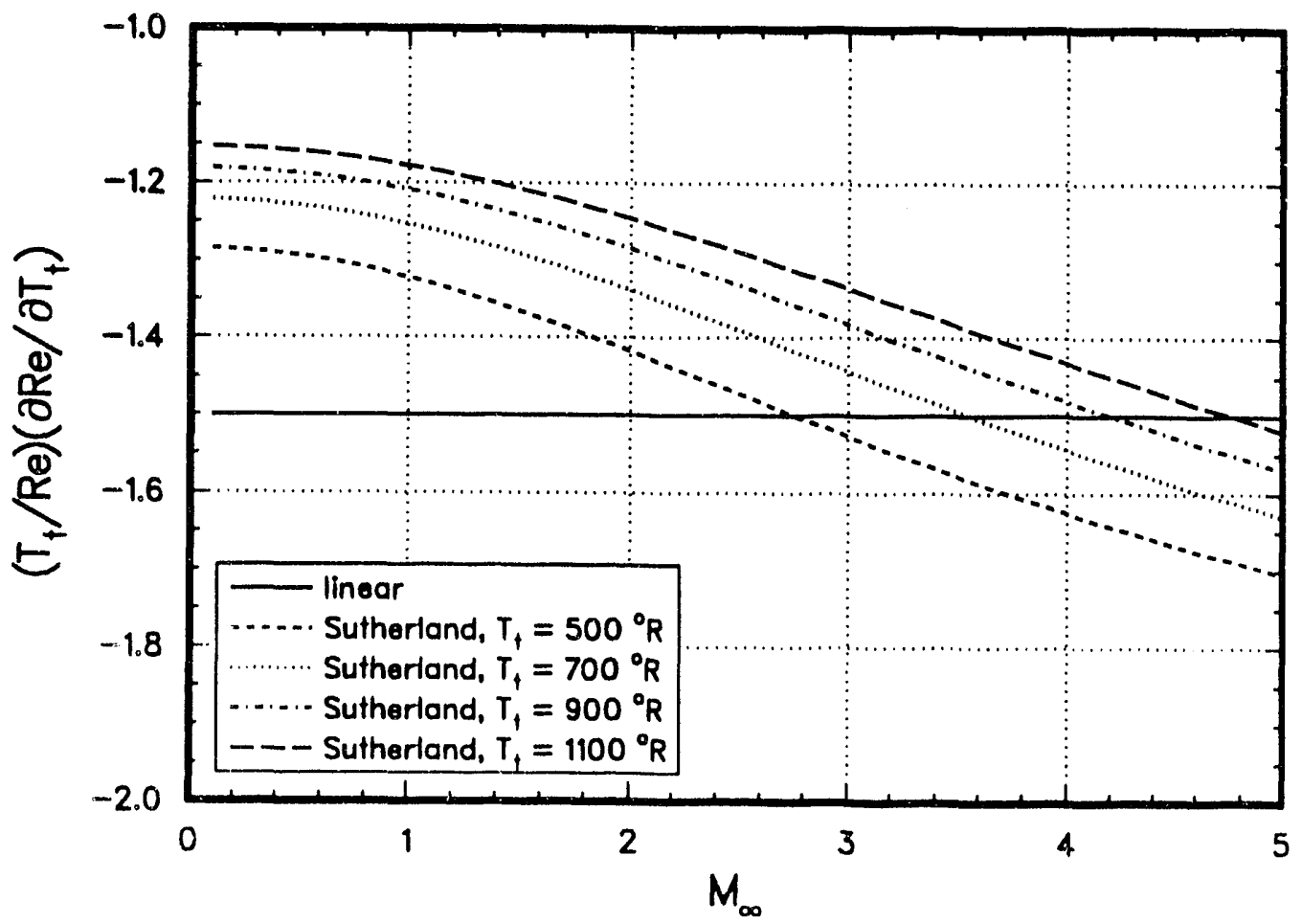

Figure 14. Variation of relative sensitivity coefficient for Reynolds number with $T_{t}$, Sutherland's viscosity relation 
Table 1 . Sensitivity coefficients for $\mathrm{R}=\mathrm{p}_{\infty} / \mathrm{p}_{\mathrm{t}}$ $\gamma=1.40$

\begin{tabular}{|c|c|c|c|c|c|}
\hline $\mathrm{M}_{\infty}$ & $\mathrm{R}$ & $\frac{\partial \mathrm{R}}{\partial \mathrm{M}_{\infty}}$ & $\frac{\mathrm{M}_{\infty}}{\mathrm{R}} \frac{\partial \mathrm{R}}{\partial \mathrm{M}_{\infty}}$ & $\frac{\partial \mathrm{M}_{\infty}}{\partial \mathrm{R}}$ & $\frac{R}{M_{\infty}} \frac{\partial M_{\infty}}{\partial R}$ \\
\hline 0.1 & $9.930 \mathrm{E}-1$ & $-1.387 E-1$ & $-1.397 E-2$ & $-7.207 E+0$ & $-7.157 E+1$ \\
\hline 0.2 & $9.725 E-1$ & $-2.701 E-1$ & $-5.556 E-2$ & $-3.702 E+0$ & $-1.800 E+1$ \\
\hline 0.3 & $9.395 E-1$ & $-3.876 E-1$ & $-1.238 E-1$ & $-2.580 E+0$ & $-8.079 E+0$ \\
\hline 0.4 & $8.956 E-1$ & $-4.860 E-1$ & $-2.171 E-1$ & $-2.058 E+0$ & $-4.607 E+0$ \\
\hline 0.5 & $8.430 E-1$ & $-5.620 E-1$ & $-3.333 E-1$ & $-1.779 E+0$ & $-3.000 E+0$ \\
\hline 0.6 & $7.840 E-1$ & $-6.143 E-1$ & $-4.701 E-1$ & $-1.628 E+0$ & $-2.127 E+0$ \\
\hline 0.7 & $7.209 E-1$ & $-6.435 E-1$ & $-6.248 E-1$ & $-1.554 E+0$ & $-1.601 E+0$ \\
\hline 0.8 & $6.560 E-1$ & $-6.514 E-1$ & $-7.943 E-1$ & $-1.535 E+0$ & $-1.259 E+0$ \\
\hline 0.9 & $5.913 E-1$ & $-6.411 E-1$ & $-9.759 E-1$ & $-1.560 E+0$ & $-1.025 E+0$ \\
\hline 1.0 & $5.283 E-1$ & $-6.163 E-1$ & $-1.167 E+0$ & $-1.623 E+0$ & $-8.571 E-1$ \\
\hline 1.1 & $4.684 \mathrm{E}-1$ & $-5.807 E-1$ & $-1.364 E+0$ & $-1.722 E+0$ & $-7.332 E-1$ \\
\hline 1.2 & $4.124 E-1$ & $-5.379 E-1$ & $-1.565 E+0$ & $-1.859 E+0$ & $-6.389 E-1$ \\
\hline 1.3 & $3.609 E-1$ & $-4.909 E-1$ & $-1.768 E+0$ & $-2.037 E+0$ & $-5.655 E-1$ \\
\hline 1.4 & $3.142 E-1$ & $-4.425 E-1$ & $-1.971 E+0$ & $-2.260 E+0$ & $-5.073 E-1$ \\
\hline 1.5 & $2.724 \mathrm{E}-1$ & $-3.945 E-1$ & $-2.172 E+0$ & $-2.535 E+0$ & $-4.603 E-1$ \\
\hline 1.6 & $2.353 E-1$ & $-3.485 E-1$ & $-2.370 E+0$ & $-2.869 E+0$ & $-4.219 E-1$ \\
\hline 1.7 & $2.026 E-1$ & $-3.056 \mathrm{E}-1$ & $-2.564 E+0$ & $-3.273 E+0$ & $-3.900 E-1$ \\
\hline 1.8 & $1.740 E-1$ & $-2.661 \mathrm{E}-1$ & $-2.752 E+0$ & $-3.758 E+0$ & $-3.633 E-1$ \\
\hline 1.9 & $1.492 E-1$ & $-2.305 E-1$ & $-2.935 E+0$ & $-4.338 E+0$ & $-3.407 E-1$ \\
\hline 2.0 & $1.278 \mathrm{E}-1$ & $-1.988 E-1$ & $-3.111 E+0$ & $-5.030 E+0$ & $-3.214 E-1$ \\
\hline 2.1 & $1.094 E-1$ & $-1.708 E-1$ & $-3.281 E+0$ & $-5.854 E+0$ & $-3.048 E-1$ \\
\hline 2.2 & $9.352 E-2$ & $-1.464 E-1$ & $-3.443 E+0$ & $-6.832 E+0$ & $-2.904 E-1$ \\
\hline 2.3 & $7.997 \mathrm{E}-2$ & $-1.251 E-1$ & $-3.599 E+0$ & $-7.992 E+0$ & $-2.779 E-1$ \\
\hline 2.4 & $6.840 E-2$ & $-1.068 E-1$ & $-3.747 E+0$ & $-9.364 E+0$ & $-2.669 E-1$ \\
\hline 2.5 & $5.853 E-2$ & $-9.104 E-2$ & $-3.889 E+0$ & $-1.098 E+1$ & $-2.571 E-1$ \\
\hline 2.6 & $5.012 E-2$ & $-7.756 E-2$ & $-4.024 E+0$ & $-1.289 E+1$ & $-2.485 E-1$ \\
\hline 2.7 & $4.295 E-2$ & $-6605 E-2$ & $-4.152 E+0$ & $-1.514 E+1$ & $-2.408 E-1$ \\
\hline 2.8 & $3.685 E-2$ & $-5.625 E-2$ & $-4.274 E+0$ & $-1.778 E+1$ & $-2.340 E-1$ \\
\hline 2.9 & $3.165 E-2$ & $-4.791 E-2$ & $-4.390 E+0$ & $-2.087 E+1$ & $-2.278 E-1$ \\
\hline 3.0 & $2.722 E-2$ & $-4.084 E-2$ & $-4.500 E+0$ & $-2.449 E+1$ & $-2.222 E-1$ \\
\hline 3.1 & $2.345 E-2$ & $-3.483 E-2$ & $-4.604 E+0$ & $-2.871 E+1$ & $-2.172 E-1$ \\
\hline 3.2 & $2.023 E-2$ & $-2.973 E-2$ & $-4.703 E+0$ & $-3363 E+1$ & $-2.126 E-1$ \\
\hline 3.3 & $1.748 E-2$ & $-2.541 E-2$ & $-4.797 E+0$ & $-3.936 E+1$ & $-2.084 E-1$ \\
\hline 3.4 & $1.512 E-2$ & $-2.174 E-2$ & $-4.886 E+0$ & $-4.600 E+1$ & $-2.046 E-1$ \\
\hline
\end{tabular}


Table 1. Sensitivity coefficients for $R=\mathrm{p}_{\infty} / \mathrm{p}_{\mathrm{t}} \quad$ (Continued) $\gamma=1.40$

\begin{tabular}{|c|c|c|c|c|c|}
\hline $\mathbf{M}_{\infty}$ & $\mathbf{R}$ & $\frac{\partial R}{\partial M_{\infty}}$ & $\frac{M_{\infty}}{R} \frac{\partial R}{\partial M_{\infty}}$ & $\frac{\partial M_{\infty}}{\partial R}$ & $\frac{R}{M_{\infty}} \frac{\partial M_{\infty}}{\partial R}$ \\
\hline 3.5 & $1.311 E-2$ & $-1.862 E-2$ & $-4.971 E+0$ & $-5.370 E+1$ & $-2.012 E-1$ \\
\hline 3.6 & $1.135 E-2$ & $-1.597 E-2$ & $-5.051 E+0$ & $-6.260 E+1$ & $-1.980 E-1$ \\
\hline 3.7 & $9.903 E-3$ & $-1.372 E-2$ & $-5.127 E+0$ & $-7.287 E+1$ & $-1.950 E-1$ \\
\hline 3.8 & $8.629 E-3$ & $-1.181 E-2$ & $-5.200 E+0$ & $-8.469 E+1$ & $-1.923 E-1$ \\
\hline 3.9 & $7.532 E-3$ & $-1.317 E-2$ & $-5.268 E+0$ & $-9.829 E+1$ & $-1.898 E-1$ \\
\hline 4.0 & $6.586 E-3$ & $-8.781 E-3$ & $-5.333 E+0$ & $-1.139 E+2$ & $-1.875 E-1$ \\
\hline 4.1 & $5.769 E-3$ & $-7.591 E-3$ & $-5.395 E+0$ & $-1.317 E+2$ & $-1.853 E-1$ \\
\hline 4.2 & $5.062 \mathrm{E}-3$ & $-6.574 E-3$ & $-5.454 E+0$ & $-1.521 E+2$ & $-1.833 E-1$ \\
\hline 4.3 & $4.449 E-3$ & $-5.701 E-3$ & $-5.510 E+0$ & $-1.754 E+2$ & $-1.815 E-1$ \\
\hline 4.4 & $3.918 E-3$ & $-4.953 E-3$ & $-5.563 E+0$ & $-2.019 E+2$ & $-1.798 E-1$ \\
\hline 4.5 & $3.455 E-3$ & $-4.311 E-3$ & $-5.614 E+0$ & $-2.320 E+2$ & $-1.781 E-1$ \\
\hline 4.6 & $3.053 E-3$ & $-3.757 E-3$ & $-5.662 / \because+0$ & $-2.661 E+2$ & $-1.766 E-1$ \\
\hline 4.7 & $2.701 E-3$ & $-3.281 E-3$ & $-5.708 E+0$ & $-3.048 E+2$ & $-1.752 E-1$ \\
\hline 4.8 & $2.394 E-3$ & $-2.869 E-3$ & $-5.752 E+0$ & $-3.486 E+2$ & $-1.739 E-1$ \\
\hline 4.9 & $2.125 \mathrm{E}-3$ & $-2.513 E-3$ & $-5.794 E+0$ & $-3.979 E+2$ & $-1.726 E-1$ \\
\hline 5.0 & $1.890 \mathrm{E}-3$ & $-2.205 E-3$ & $-5.8 .33 E+0$ & $-4.535 E+2$ & $-1.714 E-1$ \\
\hline 5.1 & $1.683 E-3$ & $-1.938 E-3$ & $-5.871 E+0$ & $-5.161 E+2$ & $-1.703 E-1$ \\
\hline 5.2 & 1 i01E-3 & $-1.706 E-3$ & $-5.908 E+0$ & $-5.863 E+2$ & $-1.693 E-1$ \\
\hline 5.3 & $1.341 \mathrm{E}-3$ & $-1.504 E-3$ & $-5.942 E+0$ & $-6.651 E+2$ & $-1.6 B 3 E-1$ \\
\hline 5.4 & $1.200 E-3$ & $-1.328 E-3$ & $-5.975 E+0$ & $-7.533 E+2$ & $-1.674 E-1$ \\
\hline 5.5 & $1.075 E-3$ & $-1.174 E-3$ & $-6.007 E+0$ & $-8.518 E+2$ & $-1.665 E-1$ \\
\hline 5.6 & $9.643 E-4$ & $-1.040 E-3$ & $-6.037 E+0$ & $-9.619 E+2$ & $-1.656 \mathrm{E}-1$ \\
\hline 5.7 & $8.663 E-4$ & $-9.220 E-4$ & $-6.066 E+0$ & $-1.085 E+3$ & $-1.648 E-1$ \\
\hline 5.8 & $7.794 \mathrm{E}-4$ & $-8.189 E-4$ & $-6.094 E+0$ & $-1.221 E+3$ & $-1.641 E-1$ \\
\hline 5.9 & $7.021 E-4$ & $-7.284 E-4$ & $-6.121 E+0$ & $-1.373 E+3$ & $-1.634 E-1$ \\
\hline 6.0 & $6.334 E-4$ & $-6.488 E-4$ & $-6.146 E+0$ & $-1.541 E+3$ & $-1.627 E-1$ \\
\hline 6.1 & $5.721 E-4$ & $-5.787 E-4$ & $-6.171 E+0$ & $-1.728 E+3$ & $-1.621 E-1$ \\
\hline 6.2 & $5.173 E-4$ & $-5.169 E-4$ & $-6.194 E+0$ & $-1.935 E+3$ & $-1.614 E-1$ \\
\hline 6.3 & $4.684 E-4$ & $-4.623 E-4$ & $-6.217 E+0$ & $-2.163 E+3$ & $-1.609 E-1$ \\
\hline 6.4 & $4.247 E-4$ & $-4.140 E-4$ & $-6.238 E+0$ & $-2.416 E+3$ & $-1.603 E-1$ \\
\hline 6.5 & $3.855 E-4$ & $-3.712 E-4$ & $-6.259 E+0$ & $-2.694 E+3$ & $-1.598 E-1$ \\
\hline 6.6 & $3.503 E-4$ & $-3.333 E-4$ & $-6.279 E+0$ & $-3.001 E+3$ & $-1.593 E-1$ \\
\hline 6.7 & $3.187 E-4$ & $-2.996 E-4$ & $-6.298 E+0$ & $-3.338 E+3$ & $-1.588 E-1$ \\
\hline 6.8 & $2.902 E \cdot 4$ & $-2.696_{-}^{*-4}$ & $-6.317 E+0$ & $-3.709 E+3$ & $-1.583 E-1$ \\
\hline 6.9 & $2.646 \mathrm{E}-4$ & $-2.430 \mathrm{E}-4$ & $-6.335 E+0$ & $-4.116 E+3$ & $-1.579 E-1$ \\
\hline
\end{tabular}


Table 1. Sensitivity coefficients for $R=p_{\infty} / p_{t} \quad$ (Continued) $\gamma=1.40$

\begin{tabular}{|c|c|c|c|c|c|}
\hline$M_{\infty}$ & $\mathbf{R}$ & $\frac{\partial R}{\partial M_{\infty}}$ & $\frac{M_{\infty}}{R} \frac{\partial R}{\partial M_{\infty}}$ & $\frac{\partial \mathbf{M}_{\infty}}{\partial \mathrm{R}}$ & $\frac{R}{M_{\infty}} \frac{\partial M_{\infty}}{\partial R}$ \\
\hline 7.0 & $2.416 E-4$ & $-2.192 E-4$ & $-6.352 E+0$ & $-4.562 E+3$ & $-1.574 E-1$ \\
\hline 7.1 & $2.207 E-4$ & $-1.980 E-4$ & $-6.368 E+0$ & $-5.051 E+3$ & -1.570 E-1 \\
\hline 7.2 & $2.019 E-4$ & $-1.790 E-4$ & $-6.384 E+0$ & $-5.586 E+5$ & $-1.566 E-1$ \\
\hline 7.3 & $1.848 E-4$ & $-1.620 E-4$ & $-6.400 E+0$ & $.6 .171 E+3$ & $-1.563 E-1$ \\
\hline 7.4 & $1.694 E-4$ & $-1.469 E-4$ & $-6.414 E+0$ & $-6.810 E+3$ & $-1.559 E-1$ \\
\hline 7.5 & $1.554 E-4$ & $-1.332 E-4$ & $-6.429 E+0$ & $-7.506 E+3$ & $-1.556 E-1$ \\
\hline 7.6 & $1.427 E-4$ & $-1.210 E-4$ & $-6.442 E+0$ & $-8.265 E+3$ & $-1.552 E-1$ \\
\hline 7.7 & $1.312 E-4$ & $-1.100 E-4$ & $-6.456 E+0$ & $-9.092 E+3$ & $-1.549 E-1$ \\
\hline 7.8 & $1.207 E-4$ & $-1.001 E-4$ & $-6.468 E+0$ & $-9.991 E+3$ & $-1.546 E-1$ \\
\hline 7.9 & $1.111 E-4$ & $-9.117 E-5$ & $-6.481 E+0$ & $-1.097 E+4$ & $-1.543 E-1$ \\
\hline 8.0 & $1.024 E-4$ & $-8.313 E-5$ & $-6.493 E+0$ & $-1.203 E+4$ & $-1.540 E-1$ \\
\hline 8.1 & $9.449 E-5$ & $-7.587 E-5$ & $-6.504 E+0$ & $-1.318 E+4$ & $-1.537 E-1$ \\
\hline 8.2 & $8.723 E-5$ & $-6.931 E-5$ & $-6.516 E+0$ & $-1.443 E+4$ & $-1.535 E-1$ \\
\hline 8.3 & $8.060 E-5$ & $-6.338 E-5$ & $-6.526 E+0$ & $-1.578 E+4$ & $-1.532 E-1$ \\
\hline 8.4 & $7.454 E-5$ & $-5.800 E-5$ & $-6.537 E+0$ & $-1.724 E+4$ & $-1.530 E-1$ \\
\hline 8.5 & $6.898 E-5$ & $-5.313 E-5$ & $-6.547 E+0$ & $-1.882 E+4$ & $-1.527 E-1$ \\
\hline 8.6 & $6.390 \mathrm{E}-5$ & $-4.871 E-5$ & $-6.557 E+0$ & $-2.053 E+4$ & $-1.525 E-1$ \\
\hline 8.7 & 5.923E-5 & $-4.470 E-5$ & $-6.566 E+0$ & $-2.237 E+4$ & $-1.523 E-1$ \\
\hline 8.8 & $5.494 E-5$ & $-4.105 E-5$ & $-6.575 E+0$ & $-2.436 E+4$ & $-1.521 E-1$ \\
\hline 8.9 & $5.101 E-5$ & $-3.774 E-5$ & $-6.584 E+0$ & $-2.650 E+4$ & $-1.519 E-1$ \\
\hline 9.0 & 4.739E-5 & $-3.471 E-5$ & $-6.593 E+0$ & $-2.881 E+4$ & $-1.517 E-1$ \\
\hline 9.1 & $4.405 E-5$ & $-3.196 E-5$ & $-6.601 E+0$ & $-3.129 E+4$ & $-1.515 E-1$ \\
\hline 9.2 & $4.099 E-5$ & $-2.945 E-5$ & $-6.610 E+0$ & $-3.396 E+4$ & $-1.513 E-1$ \\
\hline 9.3 & $3.816 E-5$ & $-2.715 E-5$ & $-6.617 E+0$ & $-3.683 E+4$ & $-1.511 E-1$ \\
\hline 9.4 & $3.555 E-5$ & $-2.506 E-5$ & $-6.625 E+0$ & $-3.991 E+4$ & $-1.509 E-1$ \\
\hline 9.5 & $3.314 E-5$ & $-2.314 \mathrm{E}-5$ & $-6.633 E+0$ & $-4.322 E+4$ & $-1.508 E-1$ \\
\hline 9.6 & $3.092 E-5$ & $-2.138 E-5$ & $-6.640 E+0$ & $-4.677 E+4$ & $-1.506 E-1$ \\
\hline 9.7 & $2.886 E-5$ & $-1.978 E-5$ & $-6.647 E+0$ & $-5.057 E+4$ & $-1.504 E-1$ \\
\hline 9.8 & $2.696 E-5$ & $-1.830 E-5$ & $-6.654 E+0$ & $-5.464 E+4$ & $-1.503 E-1$ \\
\hline 9.9 & $2.520 E-5$ & $-1.695 E-5$ & $-6.660 E+0$ & $-5.900 E+4$ & $-1.501 E-1$ \\
\hline 10.0 & $2.356 E-5$ & $-1.571 E-5$ & $-6.667 E+0$ & $-6.366 E+4$ & $-1.500 E-1$ \\
\hline 10.1 & $2.205 E-5$ & $-1.457 E-5$ & $-6.673 E+0$ & $-6.864 E+4$ & $-1.499 E-1$ \\
\hline 10.2 & $2.065 E-5$ & $-1.352 E-5$ & $-6.679 E+0$ & $-7.397 E+4$ & $-1.497 E-1$ \\
\hline 10.3 & $1.934 \mathrm{E}-5$ & $-1.255 E-5$ & $-6.685 E+0$ & $-7.965 E+4$ & $-1.496 E-1$ \\
\hline 10.4 & $1.813 E-5$ & $-1.167 E-5$ & $-6.691 E+0$ & $-8.572 E+4$ & $-1.495 E-1$ \\
\hline
\end{tabular}


Table 1. Sensitivity coefficients for $R=p_{\infty} / p_{t} \quad$ (Continued) $\gamma=1.40$

\begin{tabular}{|c|c|c|c|c|c|}
\hline $\mathbf{M}_{\infty}$ & $\mathbf{R}$ & $\frac{\partial R}{\partial M_{\infty}}$ & $\frac{\mathbf{M}_{\infty}}{\mathrm{R}} \frac{\partial \mathrm{R}}{\partial \mathrm{M}_{\infty}}$ & $\frac{\partial M_{\infty}}{\partial R}$ & $\frac{R}{M_{\infty}} \frac{\partial M_{\infty}}{\partial R}$ \\
\hline 10.5 & $1.701 E-5$ & $-1.085 E-5$ & $-6.696 \mathrm{E}+0$ & $-9.219 E+4$ & $-1.493 E-1$ \\
\hline 10.6 & $1.596 \mathrm{E}-5$ & $-1.009 E-5$ & $-6.702 E+0$ & $-9.909 E+4$ & $-1.492 E-1$ \\
\hline 10.7 & $1.499 E-5$ & $-9.395 E-6$ & $-6.707 E+0$ & $-1.064 E+5$ & $-1.491 E-1$ \\
\hline 10.8 & $1.408 E-5$ & $-8.751 E-6$ & $-6.712 E+0$ & $-1.143 E+5$ & $-1.490 \mathrm{E}-1$ \\
\hline 10.9 & $1.324 E-5$ & $-8.157 E-6$ & $-6.717 E+0$ & $-1.226 E+5$ & $-1.489 E-1$ \\
\hline 11.0 & $1.245 E-5$ & $-7.607 E-6$ & $-6.722 E+0$ & $-1.315 E+5$ & $-1.488 E-1$ \\
\hline 11.1 & $1.171 E-5$ & $-7.099 E-6$ & $-6.727 E+0$ & $-1.409 E+5$ & $-1.487 E-1$ \\
\hline 11.2 & $1.103 E-5$ & $-6.628 E-6$ & $-6.732 E+0$ & $-1.509 E+5$ & $-1.486 E-1$ \\
\hline 11.3 & $1.039 E-5$ & $-6.192 E-6$ & $-6.736 E+0$ & $-1.615 E+5$ & $-1.485 E-1$ \\
\hline 11.4 & $9.788 E-6$ & $-5.787 E-6$ & $-6.741 E+0$ & $-1.728 E+5$ & $-1.484 E-1$ \\
\hline 11.5 & $9.228 E-6$ & $-5.412 E-6$ & $-6.745 E+0$ & $-1.848 E+5$ & $-1.483 E-1$ \\
\hline 11.6 & $8.704 \mathrm{E}-6$ & $-5.064 E-6$ & $-6.749 E+0$ & $-1.975 E+5$ & $-1.482 E-1$ \\
\hline 11.7 & $8.214 E-6$ & $-4.741 E-6$ & $-6.753 E+0$ & $-2.109 E+5$ & $-1.481 \mathrm{E}-1$ \\
\hline 11.8 & $7.755 E-6$ & $-4.441 E-6$ & $-6.757 E+0$ & $-2.252 E+5$ & $-1.480 E-1$ \\
\hline 11.9 & $7.325 E-6$ & $-4.162 E-6$ & $-6.761 E+0$ & $-2.403 E+5$ & $-1.479 E-1$ \\
\hline 12.0 & $6.922 E-6$ & $-3.902 E-6$ & $-6.765 E+0$ & $-2.563 E+5$ & $-1.478 E-1$ \\
\hline 12.1 & $6.544 E-6$ & $-3.661 E-6$ & $-6.769 \mathrm{E}+0$ & $-2.732 E+5$ & $-1.477 E-1$ \\
\hline 12.2 & $6.189 E-6$ & $-3.436 E-6$ & $-6.772 E+0$ & $-2.910 E+5$ & $-1.477 E-1$ \\
\hline 12.3 & $5.856 \mathrm{E} \cdot 6$ & $-3.226 E-6$ & $-6.776 E+0$ & $-3.100 E+5$ & $-1.476 E-1$ \\
\hline 12.4 & $5.544 E-6$ & $-3.031 E-6$ & $-6.780 E+0$ & $-3.299 E+5$ & $-1.475 E-1$ \\
\hline 12.5 & $5.250 E-6$ & $-2.849 E-6$ & $-6.783 E+0$ & $-3.510 E+5$ & $-1.474 E-1$ \\
\hline 12.6 & $4.974 \mathrm{E}-6$ & $-2.679 E-6$ & $-6.786 E+0$ & $-3.733 E+5$ & $-1.474 E-1$ \\
\hline 12.7 & $4.714 \mathrm{E}-6$ & -2.520 E- 6 & $-6.790 E+0$ & $-3.968 E+5$ & $-1.473 E-1$ \\
\hline 12.8 & $4.469 E-6$ & $-2.372 E-6$ & $-6.793 E+0$ & $-4.216 E+5$ & $-1.472 E-1$ \\
\hline 12.9 & $4.239 E-6$ & $-2.233 E-6$ & $-6.796 E+0$ & $-4.478 E+5$ & $-1.471 E-1$ \\
\hline 13.0 & $4.022 E-6$ & $-2.104 E-6$ & $-6.799 E+0$ & $-4.754 E+5$ & $-1.471 E-1$ \\
\hline 13.1 & $3.818 E-6$ & $-1.982 E-6$ & $-6.802 E+0$ & $-5.044 E+5$ & $-1.470 E-1$ \\
\hline 13.2 & $3.626 E-6$ & $-1.869 E-6$ & $-6.805 E+0$ & $-5.350 E+5$ & $-1.470 \mathrm{E}-1$ \\
\hline 13.3 & $3.444 E-6$ & $-1.763 E-6$ & $-6.808 E+0$ & $-5.673 E+5$ & $-1.469 E-1$ \\
\hline 13.4 & $3.273 E-6$ & $-1.663 E-6$ & $-6.810 E+0$ & $-6.012 E+5$ & $-1.468 E-1$ \\
\hline 13.5 & $3.111 \mathrm{E}-6$ & $-1.570 E-6$ & $-6.813 E+0$ & $-6.369 E+5$ & $-1.468 E-1$ \\
\hline 13.6 & $2.959 E-6$ & $-1.483 E-6$ & $-6.816 E+0$ & $-6.744 E+5$ & $-1.467 E-1$ \\
\hline 13.7 & $2.814 E-6$ & $-1.401 E-6$ & $-6.818 E+0$ & $-7.139 E+5$ & $-1.467 E-1$ \\
\hline 13.8 & $2.678 E-6$ & $-1.324 E-6$ & $-6.821 E+0$ & $-7.554 E+5$ & $-1.466 E-1$ \\
\hline 13.9 & $2.550 \mathrm{E}-6$ & $-1.252 E-6$ & $-6.823 E+0$ & $-7.990 E+5$ & $-1.466 \mathrm{E}-1$ \\
\hline
\end{tabular}


Table 1. Sensitivity coefficients for $R=p_{\infty} / p_{t} \quad$ (Continued) $\gamma=1.40$

\begin{tabular}{|c|c|c|c|c|c|}
\hline$M_{\infty}$ & $R$ & $\frac{\partial R}{\partial M_{\infty}}$ & $\frac{M_{\infty}}{R} \frac{\partial R}{\partial M_{\infty}}$ & $\frac{\partial M_{\infty}}{\partial R}$ & $\frac{R}{M_{\infty}} \frac{\partial M_{\infty}}{\partial R}$ \\
\hline \hline 14.0 & $2.428 E-6$ & $-1.184 E-6$ & $-6.826 E+0$ & $-8.448 E+5$ & $-1.465 E-1$ \\
14.1 & $2.313 E-6$ & $-1.120 E-6$ & $-6.828 E+0$ & $-8.929 E+5$ & $-1.464 E-1$ \\
14.2 & $2.204 E-6$ & $-1.060 E-6$ & $-6.831 E+0$ & $-9.434 E+5$ & $-1.464 E-1$ \\
14.3 & $2.101 E-6$ & $-1.004 E-6$ & $-6.833 E+0$ & $-9.963 E+5$ & $-1.464 E-1$ \\
14.4 & $2.003 E-6$ & $-9.507 E-7$ & $-6.835 E+0$ & $-1.052 E+6$ & $-1.463 E-1$ \\
& & & & & \\
14.5 & $1.910 E-6$ & $-9.008 E-7$ & $-6.837 E+0$ & $-1.110 E+6$ & $-1.463 E-1$ \\
14.6 & $1.823 E-6$ & $-8.538 E-7$ & $-6.840 E+0$ & $-1.171 E+6$ & $-1.462 E-1$ \\
14.7 & $1.739 E-6$ & $-8.096 E-7$ & $-6.842 E+0$ & $-1.235 E+6$ & $-1.462 E-1$ \\
14.8 & $1.661 E-6$ & $-7.679 E-7$ & $-6.844 E+0$ & $-1.302 E+6$ & $-1.461 E-1$ \\
14.9 & $1.586 E-6$ & $-7.286 E-7$ & $-6.846 E+0$ & $-1.373 E+6$ & $-1.461 E-1$ \\
15.0 & $1.515 E-6$ & $-6.915 E-7$ & $-6.848 E+0$ & $-1.446 E+6$ & $-1.460 E-1$ \\
\hline
\end{tabular}


Table 2. Sensitivity coefficients for $R=q_{\infty} / p_{t}$ $\gamma=1.40$

\begin{tabular}{|c|c|c|c|c|c|}
\hline $\mathbf{M}_{\infty}$ & $\mathrm{R}$ & $\frac{\partial R}{\partial M_{\infty}}$ & $\frac{M_{\infty}}{R} \frac{\partial R}{\partial M_{\infty}}$ & $\frac{\partial M_{\infty}}{\partial R}$ & $\frac{\mathrm{R}}{\mathrm{M}_{\infty}} \frac{\partial \mathrm{M}_{\infty}}{\partial \mathrm{R}}$ \\
\hline 0.1 & $6.951 \mathrm{E}-3$ & $1.381 E-1$ & $1.986 E+0$ & $7.244 E+0$ & $5.035 \mathrm{E}-1$ \\
\hline 0.2 & $2.723 E-2$ & $2.647 E-1$ & $1.944 E+0$ & $3.777 E+0$ & $5.143 E-1$ \\
\hline 0.3 & $5.919 E-2$ & $3.702 E-1$ & $1.876 E+0$ & $2.702 E+0$ & $5.330 E-1$ \\
\hline 0.4 & $1.003 \mathrm{E}-1$ & $4.471 E-1$ & $1.783 E+0$ & $2.237 E+0$ & $5.609 E-1$ \\
\hline 0.5 & $1.475 E-1$ & $4.918 E-1$ & $1.667 E+0$ & $2.034 E+0$ & $6.000 E-1$ \\
\hline 0.6 & $1.976 \mathrm{E}-1$ & $5.038 \mathrm{E}-1$ & $1.530 E+0$ & $1.985 E+0$ & $6.537 \mathrm{E}-1$ \\
\hline 0.7 & $2.473 E-1$ & $4.858 \mathrm{E}-1$ & $1.375 E+0$ & $2.058 E+0$ & $7.272 E-1$ \\
\hline 0.8 & $2.939 E-1$ & $4.429 E-1$ & $1.206 E+0$ & $2.258 E+0$ & $8.294 E-1$ \\
\hline 0.9 & $3.352 E-1$ & $3.815 \mathrm{E}-1$ & $1.024 E+0$ & $2.621 E+0$ & $9.765 E-1$ \\
\hline 1.0 & $3.698 E-1$ & $3.082 E-1$ & $8.333 E-1$ & $3.245 E+0$ & $1.200 E+0$ \\
\hline 1.1 & $3.967 \mathrm{E}-1$ & $2.294 \mathrm{E}-1$ & $6.361 \mathrm{E}-1$ & $4.359 E+0$ & $1.572 E+0$ \\
\hline 1.2 & 4.157E-1 & $1.506 \mathrm{E}-1$ & $4.348 E-1$ & $6.640 E+0$ & $2.300 E+0$ \\
\hline 1.3 & $4.270 \mathrm{E}-1$ & $7.609 E-2$ & $2.317 E-1$ & $1.314 E+1$ & $4.316 E+0$ \\
\hline 1.4 & $4.311 E-1$ & $8.849 E-3$ & $2.874 \mathrm{E}-2$ & $1.130 E+2$ & $3.480 E+1$ \\
\hline 1.5 & $4.290 E-1$ & $-4.931 E-2$ & $-1.724 E-1$ & $-2.028 E+1$ & $-5.800 E+0$ \\
\hline 1.6 & $4.216 E-1$ & $-9.759 E-2$ & $-3.704 E-1$ & $-1.025 E+1$ & $-2.700 E+0$ \\
\hline 1.7 & $4.098 E-1$ & $-1.360 E-1$ & $-5.640 E-1$ & $-7.354 E+0$ & $-1.773 E+0$ \\
\hline 1.8 & $3.947 E-1$ & $-1.650 E-1$ & $-7.524 E-1$ & $-6.061 E+0$ & $-1.329 E+0$ \\
\hline 1.9 & $3.771 \mathrm{E}-1$ & $-1.856 E-1$ & $-9.350 E-1$ & $-5.389 E+0$ & $-1.070 E+0$ \\
\hline 2.0 & $3.579 E-1$ & $-1.988 E-1$ & $-1.111 E+0$ & $-5.030 E+0$ & $-9.000 E-1$ \\
\hline 2.1 & $3.376 \mathrm{E}-1$ & $-2.058 E-1$ & $-1.281 E+0$ & $-4.858 E+0$ & $-7.809 E-1$ \\
\hline 2.2 & $3.169 E-1$ & $-2.078 E-1$ & $-1.443 E+0$ & $-4.811 E+0$ & $-6.930 E-1$ \\
\hline 2.3 & $2.961 \mathrm{E}-1$ & $-2.058 E-1$ & $-1.599 E+0$ & $-4.858 E+0$ & $-6.255 E-1$ \\
\hline 2.4 & $2.758 E-1$ & $-2.008 E-1$ & $-1.747 E+0$ & $-4.981 E+0$ & $-5.723 E-1$ \\
\hline 2.5 & $2.561 E-1$ & $-1.935 E-1$ & $-1.889 E+0$ & $-5.169 E+0$ & $-5.294 E-1$ \\
\hline 2.6 & $2.371 \mathrm{E}-1$ & $-1.846 E-1$ & $-2.024 E+0$ & $-5.417 E+0$ & $-4.941 E-1$ \\
\hline 2.7 & $2.192 \mathrm{E}-1$ & $-1.747 E-1$ & $-2.152 E+0$ & $-5.724 E+0$ & $-4.647 E-1$ \\
\hline 2.8 & $2.022 E-1$ & $-1.642 E-1$ & $-2.274 E+0$ & $-6.088 E+0$ & $-4.397 E-1$ \\
\hline 2.9 & $1.863 E-1$ & $-1.536 E-1$ & $-2.390 E+0$ & $-6.512 E+0$ & $-4.184 E-1$ \\
\hline 3.0 & $1.715 E-1$ & $-1.429 E-1$ & $-2.500 E+0$ & $-6.997 E+0$ & $-4.000 E-1$ \\
\hline 3.1 & $1.577 E-1$ & $-1.325 E-1$ & $-2.604 E+0$ & $-7.546 \mathrm{E}+0$ & $-3.840 E-1$ \\
\hline 3.2 & $1.450 E-1$ & $-1.225 E-1$ & $-2.703 E+0$ & $-8.164 E+0$ & $-3.699 E-1$ \\
\hline 3.3 & $1.332 \mathrm{E}-1$ & $-1.129 E-1$ & $-2.797 E+0$ & $-8.855 E+0$ & $-3.575 E-1$ \\
\hline 3.4 & $1.224 \mathrm{E}-1$ & $-1.039 E-1$ & $-2.886 E+0$ & $-9.624 E+0$ & $-3.464 E-1$ \\
\hline
\end{tabular}


Table 2. Sensitivity coefficients for $R=q_{\infty} / p_{t} \quad$ (Continued) $\gamma=1.40$

\begin{tabular}{|c|c|c|c|c|c|}
\hline $\mathbf{M}_{\infty}$ & $\mathbf{R}$ & $\frac{\partial R}{\partial M_{\infty}}$ & $\frac{M_{\infty}}{R} \frac{\partial R}{\partial M_{\infty}}$ & $\frac{\partial M_{\infty}}{\partial R}$ & $\frac{R}{M_{\infty}} \frac{\partial M_{\infty}}{\partial R}$ \\
\hline 3.5 & $1.124 \mathrm{E}-1$ & $-9.543 E-2$ & $-2.971 E+0$ & $-1.048 E+1$ & $-3.366 \mathrm{E}-1$ \\
\hline 3.6 & $1.033 \mathrm{E}-1$ & $-8.754 E-2$ & $-3.051 E+0$ & $-1.142 E+1$ & $-3.277 E-1$ \\
\hline 3.7 & $9.490 \mathrm{E}-2$ & $-8.021 E-2$ & $-3.127 E+0$ & $-1.247 E+1$ & $-3.198 E-1$ \\
\hline 3.8 & $8.722 E-2$ & $-7.344 \mathrm{E}-2$ & $-3.200 E+0$ & $-1.362 E+1$ & $-3.125 E-1$ \\
\hline 3.9 & $8.019 E-2$ & $-6.720 \mathrm{E}-2$ & $-3.268 E+0$ & $-1.488 E+1$ & $-3.060 E-1$ \\
\hline 4.0 & $7.376 \mathrm{E}-2$ & $-6.147 E-2$ & $-3.333 E+0$ & $-1.627 E+1$ & $-3.000 \mathrm{E}-1$ \\
\hline 4.1 & $6.788 \mathrm{E}-2$ & $-5.621 E-2$ & $-3.395 E+0$ & $-1.779 E+1$ & $-2.945 E-1$ \\
\hline 4.2 & $6.251 \mathrm{E}-2$ & $-5.140 E-2$ & $-3.454 E+0$ & $-1.945 E+1$ & $-2.895 E-1$ \\
\hline 4.3 & $5.759 E-2$ & $-4.701 E-2$ & $-3.510 E+0$ & $-2.127 E+1$ & $-2.849 E-1$ \\
\hline 4.4 & $5.309 E-2$ & $-4.299 \mathrm{E}-2$ & $-3.563 E+0$ & $-2.326 E+1$ & $-2.806 \mathrm{E}-1$ \\
\hline 4.5 & $4.898 E-2$ & $-3.933 E-2$ & $-3.614 E+0$ & $-2.542 E+1$ & $-2.767 \mathrm{E}-1$ \\
\hline 4.6 & $4.521 \mathrm{E}-2$ & $-3.600 \mathrm{E}-2$ & $-3.662 E+0$ & $-2.778 E+1$ & $-2.731 E-1$ \\
\hline 4.7 & 4.177E-2 & $-3.295 \mathrm{E}-2$ & $-3.708 E+0$ & $-3.035 E+1$ & $-2.697 E-1$ \\
\hline 4.8 & $3.861 \mathrm{E}-2$ & $-3.018 E-2$ & $-3.752 E+0$ & $-3.313 E+1$ & $-2.665 E-1$ \\
\hline 4.9 & $3.572 E-2$ & $-2.766 \mathrm{E}-2$ & $-3.794 E+0$ & $-3.616 E+1$ & $-2.636 \mathrm{E}-1$ \\
\hline 5.0 & $3.308 E-2$ & $-2.536 \mathrm{E}-2$ & $-3.833 E+0$ & $-3.944 E+1$ & $-2.609 \mathrm{E}-1$ \\
\hline 5.1 & $3.065 E-2$ & $-2.326 E-2$ & $-3.871 E+0$ & $-4.299 E+1$ & $-2.583 E-1$ \\
\hline 5.2 & $2.842 E-2$ & $-2.135 E-2$ & $-3.908 E+0$ & $-4.683 E+1$ & $-2.559 E-1$ \\
\hline 5.3 & $2.637 \mathrm{E}-2$ & $-1.961 E-2$ & $-3.942 E+0$ & $-5.098 E+1$ & $-2.537 E-1$ \\
\hline 5.4 & $2.449 E-2$ & $-1.803 E-2$ & $-3.975 E+0$ & $-5.547 E+1$ & $-2.515 \mathrm{E}-1$ \\
\hline 5.5 & $2.276 E-2$ & $-1.658 E-2$ & $-4.007 E+0$ & $-6.031 E+1$ & $-2.496 \mathrm{E}-1$ \\
\hline 5.6 & $2.117 E-2$ & $-1.526 \mathrm{E}-2$ & $-4.037 E+0$ & $-6.552 E+1$ & $-2.477 E-1$ \\
\hline 5.7 & $1.970 \mathrm{E}-2$ & $-1.406 E-2$ & $-4.066 E+0$ & $-7.114 E+1$ & $-2.459 E-1$ \\
\hline 5.8 & $1.835 E-2$ & $-1.296 \mathrm{E}-2$ & $-4.094 E+0$ & $-7.719 E+1$ & $-2.442 E-1$ \\
\hline 5.9 & $1.711 \mathrm{E}-2$ & $-1.195 \mathrm{E}-2$ & $-4.121 E+0$ & $-8.368 E+1$ & $-2.427 E-1$ \\
\hline 6.0 & $1.596 \mathrm{E}-2$ & $-1.103 E-2$ & $-4.146 E+0$ & $-9.066 E+1$ & $-2.412 E-1$ \\
\hline 6.1 & $1.490 \mathrm{E}-2$ & $-1.019 \mathrm{E}-2$ & $-4.171 E+0$ & $-9.815 E+1$ & $-2.398 \mathrm{E}-1$ \\
\hline 6.2 & $1.392 E-2$ & $-9.417 E-3$ & $-4.194 E+0$ & $-1.062 E+2$ & $-2.384 E-1$ \\
\hline 6.3 & $1.301 \mathrm{E}-2$ & $-8.711 E-3$ & $-4.217 E+0$ & $-1.148 E+2$ & $-2.371 \mathrm{E}-1$ \\
\hline 6.4 & $1.218 E-2$ & $-8.064 E-3$ & $-4.238 E+0$ & $-1.240 E+2$ & $-2.359 \mathrm{E}-1$ \\
\hline 6.5 & $1.140 E-2$ & $-7.470 E-3$ & $-4.259 E+0$ & $-1.339 E+2$ & $-2.348 E-1$ \\
\hline 6.6 & $1.068 E-2$ & $-6.925 E-3$ & $-4.279 E+0$ & $-1.444 E+2$ & $-2.337 \mathrm{E}-1$ \\
\hline 6.7 & $1.001 \mathrm{E}-2$ & $-6.424 \mathrm{E}-3$ & $-4.298 E+0$ & $-1.557 E+2$ & $-2.326 \mathrm{E}-1$ \\
\hline 6.8 & $9.395 E-3$ & $-5.964 \mathrm{E}-3$ & $-4.317 E+0$ & $-1.677 E+2$ & $-2.316 \mathrm{E}-1$ \\
\hline 6.9 & $8.820 E-3$ & $-5.541 E-3$ & $-4.335 E+0$ & $-1.805 E+2$ & $-2.307 \mathrm{E}-1$ \\
\hline
\end{tabular}


Table 2. Sensitivity coefficients for $R=q_{\infty} / p_{t}$ (Continued) $\gamma=1.40$

\begin{tabular}{|c|c|c|c|c|c|}
\hline $\mathbf{M}_{\infty}$ & $\mathbf{R}$ & $\frac{\partial R}{\partial M_{\infty}}$ & $\frac{\mathrm{M}_{\infty}}{\mathrm{R}} \frac{\partial \mathrm{R}}{\partial \mathrm{M}_{\infty}}$ & $\frac{\partial \mathbf{M}_{\infty}}{\partial \mathrm{R}}$ & $\frac{R}{M_{\infty}} \frac{\partial M_{\infty}}{\partial R}$ \\
\hline 7.0 & $8.285 E-3$ & $-5.151 E-3$ & $-4.352 E+0$ & $-1.941 E+2$ & $-2.298 E-1$ \\
\hline 7.1 & $7.788 E-3$ & $-4.792 E-3$ & $-4.368 E+0$ & $-2.087 E+2$ & $-2.289 E-1$ \\
\hline 7.2 & $7.326 \mathrm{E}-3$ & $-4.461 E-3$ & $-4.384 E+0$ & $-2.242 E+2$ & $-2.281 \mathrm{E}-1$ \\
\hline 7.3 & $6.895 E-3$ & $-4.156 E-3$ & $-4.400 E+0$ & $-2.406 E+2$ & $-2.273 E-1$ \\
\hline 7.4 & $6.494 \mathrm{E}-3$ & $-3.874 E-3$ & $-4.414 E+0$ & $-2.581 E+2$ & $-2.265 E-1$ \\
\hline 7.5 & $6.120 E-3$ & $-3.614 E-3$ & $-4.429 E+0$ & $-2.767 E+2$ & $-2.258 E-1$ \\
\hline 7.6 & $5.771 E-3$ & $-3.373 E-3$ & $-4.442 E+0$ & $-2.965 E+2$ & $-2.251 E-1$ \\
\hline 7.7 & $5.445 E-3$ & $-3.151 E-3$ & $-4.456 E+0$ & $-3.174 E+2$ & $-2.244 E-1$ \\
\hline 7.8 & $5.140 E-3$ & $-2.945 E-3$ & $-4.468 E+0$ & $-3.396 E+2$ & $-2.238 E-1$ \\
\hline 7.9 & $4.855 E-3$ & $-2.754 E-3$ & $-4.481 E+0$ & $-3.631 E+2$ & $-2.232 E-1$ \\
\hline 8.0 & $4.589 E-3$ & $-2.577 E-3$ & $-4.493 E+0$ & $-3.880 E+2$ & $-2.226 E-1$ \\
\hline 8.1 & $4.339 E-3$ & $-2.413 E-3$ & $-4.504 E+0$ & $-4.144 E+2$ & $-2.220 E-1$ \\
\hline 8.2 & $4.106 E-3$ & $-2.261 E-3$ & $-4.516 E+0$ & $-4.423 E+2$ & $-2.215 E-1$ \\
\hline 8.3 & $3.887 E-3$ & $-2.120 E-3$ & $-4.526 E+0$ & $-4.718 E+2$ & $-2.209 E-1$ \\
\hline 8.4 & $3.682 E-3$ & $-1.988 E-3$ & $-4.537 E+0$ & $-5.029 E+2$ & $-2.204 E-1$ \\
\hline 8.5 & $3.489 E-3$ & $-1.866 E-3$ & $-4.547 E+0$ & $-5.358 E+2$ & $-2.199 E-1$ \\
\hline 8.6 & $3.308 E-3$ & $-1.753 E-3$ & $-4.557 E+0$ & $-5.705 E+2$ & $-2.195 E-1$ \\
\hline 8.7 & $3.138 E-3$ & $-1.647 E-3$ & $-4.566 E+0$ & $-6.072 E+2$ & $-2.190 E-1$ \\
\hline 8.8 & $2.978 E-3$ & $-1.549 E-3$ & $-4.575 E+0$ & $-6.458 E+2$ & $-2.186 \mathrm{E}-1$ \\
\hline 8.9 & $2.828 E-3$ & $-1.457 E-3$ & $-4.584 E+0$ & $-6.865 E+2$ & $-2.181 E-1$ \\
\hline 9.0 & $2.687 E-3$ & $-1.371 E-3$ & $-4.593 E+0$ & $-7.293 E+2$ & $-2.177 \mathrm{E}-1$ \\
\hline 9.1 & $2.554 \mathrm{E}-3$ & $-1.291 E-3$ & $-4.601 E+0$ & $-7.744 E+2$ & $-2.173 E-1$ \\
\hline 9.2 & $2.428 E-3$ & $-1.217 E-3$ & $-4.610 E+0$ & $-8.219 E+2$ & $-2.169 E-1$ \\
\hline 9.3 & $2.310 E-3$ & $-1.147 E-3$ & $-4.617 E+0$ & $-8.718 E+2$ & $-2.166 E-1$ \\
\hline 9.4 & $2.199 E-3$ & $-1.082 E-3$ & $-4.625 E+0$ & $-9.243 E+2$ & $-2.162 E-1$ \\
\hline 9.5 & $2.094 \mathrm{E}-3$ & $-1.021 E-3$ & $-4.633 E+0$ & $-9.795 E+2$ & $-2.159 E-1$ \\
\hline 9.6 & $1.994 E-3$ & $-9.639 E-4$ & $-4.640 E+0$ & $-1.037 E+3$ & $-2.155 E-1$ \\
\hline 9.7 & $1.901 \mathrm{E}-3$ & $-9.106 E-4$ & $-4.647 E+0$ & $-1.098 E+3$ & $-2.152 E-1$ \\
\hline 9.8 & $1.812 E-3$ & $-8.606 E-4$ & $-4.654 E+0$ & $-1.162 E+3$ & $-2.149 E-1$ \\
\hline 9.9 & $1.729 E-3$ & $-8.137 E-4$ & $-4.660 E+0$ & $-1.229 E+3$ & $-2.146 E-1$ \\
\hline 10.0 & $1.649 \mathrm{E}-3$ & $-7.697 E-4$ & $-4.667 E+0$ & $-1.299 E+3$ & $-2.143 E-1$ \\
\hline 10.1 & $1.575 E-3$ & $-7.285 E-4$ & $-4.673 E+0$ & $-1.373 E+3$ & $-2.140 E-1$ \\
\hline 10.2 & $1.504 E-3$ & $-6.898 E-4$ & $-4.679 E+0$ & $-1.450 E+3$ & $-2.137 E-1$ \\
\hline 10.3 & $1.436 \mathrm{E}-3$ & $-6.534 E-4$ & $-4.685 E+0$ & $-1.530 E+3$ & $-2.134 E-1$ \\
\hline 10.4 & $1.373 E-3$ & $-6.192 E-4$ & $-4.691 E+0$ & $-1.615 E+3$ & $-2.132 E-1$ \\
\hline
\end{tabular}


Table 2. Sensitivity coefficients for $R=q_{\infty} / p_{t} \quad$ (Continued) $\gamma=1.40$

\begin{tabular}{|c|c|c|c|c|c|}
\hline $\mathbf{M}_{\infty}$ & $\mathbf{R}$ & $\frac{\partial R}{\partial M_{\infty}}$ & $\frac{\mathrm{M}_{\infty}}{\mathrm{R}} \frac{\partial \mathrm{R}}{\partial \mathrm{M}_{\infty}}$ & $\frac{\partial \mathrm{M}_{\infty}}{\partial \mathrm{R}}$ & $\frac{R}{M_{\infty}} \frac{\partial M_{\infty}}{\partial R}$ \\
\hline 10.5 & $1.313 E-3$ & $-5.871 E-4$ & $-4.696 E+0$ & $-1.703 E+3$ & $-2.129 \mathrm{E}-1$ \\
\hline 10.6 & $1.255 E-3$ & $-5.569 \mathrm{E}-4$ & $-4.702 E+0$ & $-1.796 E+3$ & $-2.127 E-1$ \\
\hline 10.7 & $1.201 E-3$ & $-5.284 E-4$ & $-4.707 E+0$ & $-1.892 E+3$ & $-2.124 E-1$ \\
\hline 10.8 & $1.150 \mathrm{E}-3$ & $-5.016 E-4$ & $-4.712 E+0$ & $-1.994 E+3$ & $-2.122 E-1$ \\
\hline 10.9 & $1.101 \mathrm{E}-3$ & $-4.764 E-4$ & $-4.717 E+0$ & $-2.099 E+3$ & $-2.120 E-1$ \\
\hline 11.0 & $1.054 E-3$ & $-4.526 E-4$ & $-4.722 E+0$ & $-2.209 E+3$ & $-2.118 E-1$ \\
\hline 11.1 & $1.010 \mathrm{E}-3$ & $-4.302 E-4$ & $-4.727 E+0$ & $-2.324 E+3$ & $-2.116 E-1$ \\
\hline 11.2 & $9.683 E-4$ & $-4.091 E-4$ & $-4.732 E+0$ & $-2.445 E+3$ & $-2.113 E-1$ \\
\hline 11.3 & $9.284 E-4$ & $-3.891 E-4$ & $-4.736 E+0$ & $-2.570 E+3$ & $-2.111 E-1$ \\
\hline 11.4 & $8.904 E-4$ & $-3.703 E-4$ & $-4.741 E+0$ & $-2.701 E+3$ & $-2.109 E-1$ \\
\hline 11.5 & $8.543 E-4$ & $-3.525 E-4$ & $-4.745 E+0$ & $-2.837 E+3$ & $-2.107 E-1$ \\
\hline 11.6 & $8.199 E-4$ & $-3.357 E-4$ & $-4.749 E+0$ & $-2.979 E+3$ & $-2.106 \mathrm{E}-1$ \\
\hline 11.7 & $7.871 E-4$ & $-3.198 E-4$ & $-4.753 E+0$ & $-3.127 E+3$ & $-2.104 E-1$ \\
\hline 11.8 & $7.559 E-4$ & $-3.047 E-4$ & $-4.757 E+0$ & $-3.281 E+3$ & $-2.102 E-1$ \\
\hline 11.9 & $7.261 E-4$ & $-2.905 E-4$ & $-4.761 E+0$ & $-3.442 E+3$ & $-2.100 E-1$ \\
\hline 12.0 & $6.978 E-4$ & $-2.771 E-4$ & $-4.765 E+0$ & $-3.609 E+3$ & $-2.099 \mathrm{E}-1$ \\
\hline 12.1 & $6.707 E-4$ & $-2.643 E-4$ & $-4.769 E+0$ & $-3.783 E+3$ & $-2.097 E-1$ \\
\hline 12.2 & $6.449 E-4$ & $-2.523 E-4$ & $-4.772 E+0$ & $-3.964 E+3$ & $-2.095 E-1$ \\
\hline 12.3 & $6.202 E-4$ & $-2.408 E-4$ & $-4.776 E+0$ & $-4.152 E+3$ & $-2.094 E-1$ \\
\hline 12.4 & $5.967 \mathrm{E}-4$ & $-2.300 E-4$ & $-4.780 E+0$ & $-4.348 E+3$ & $-2.092 E-1$ \\
\hline 12.5 & $5.742 E-4$ & $-2.197 E-4$ & $-4.783 E+0$ & $-4.551 E+3$ & $-2.091 E-1$ \\
\hline 12.6 & $5.527 E-4$ & $-2.100 E-4$ & $-4.786 E+0$ & $-4.763 E+3$ & $-2.089 E-1$ \\
\hline 12.7 & $5.322 E-4$ & $-2.007 E-4$ & $-4.790 E+0$ & $-4.982 E+3$ & $-2.088 E-1$ \\
\hline 12.8 & $5.126 \mathrm{E}-4$ & $-1.919 E-4$ & $-4.793 E+0$ & $-5.211 E+3$ & $-2.087 E-1$ \\
\hline 12.9 & $4.938 E-4$ & $-1.836 E-4$ & $-4.796 E+0$ & $-5.447 E+3$ & $-2.085 E-1$ \\
\hline 13.0 & $4.758 E-4$ & $-1.757 E-4$ & $-4.799 E+0$ & $-5.693 E+3$ & $-2.084 E-1$ \\
\hline 13.1 & $4.587 E-4$ & $-1.681 E-4$ & $-4.802 E+0$ & $-5.948 E+3$ & $-2.083 E-1$ \\
\hline 13.2 & $4.422 E-4$ & $-1.610 E-4$ & $-4.805 E+0$ & $-6.213 E+3$ & $-2.081 E-1$ \\
\hline 13.3 & $4.264 E-4$ & $-1.541 E-4$ & $-4.808 E+0$ & $-6.487 E+3$ & $-2.080 E-1$ \\
\hline 13.4 & $4.114 E-4$ & $-1.477 E-4$ & $-4.810 E+0$ & $-6.772 E+3$ & $-2.079 E-1$ \\
\hline 13.5 & $3.969 E-4$ & $-1.415 E-4$ & $-4.813 E+0$ & $-7.067 E+3$ & $-2.078 E-1$ \\
\hline 13.6 & $3.830 E-4$ & $-1.356 E-4$ & $-4.816 E+0$ & $-7.373 E+3$ & $-2.077 \mathrm{E}-1$ \\
\hline 13.7 & $3.698 E-4$ & $-1.300 E-4$ & $-4.818 E+0$ & $-7.689 E+3$ & $-2.075 E-1$ \\
\hline 13.8 & $3.570 E-4$ & $-1.247 E-4$ & $-4.821 E+0$ & $-8.018 E+3$ & $-2.074 \mathrm{E}-1$ \\
\hline 13.9 & $3.448 E-4$ & $-1.197 E-4$ & $-4.823 E+0$ & $-8.358 E+3$ & $-2.073 E-1$ \\
\hline
\end{tabular}


Table 2. Sensitivity coefficients for $R=q_{\infty} / p_{t} \quad$ (Continued) $\gamma=1.40$

\begin{tabular}{|c|c|c|c|c|c|}
\hline $\mathrm{M}_{\infty}$ & $\mathrm{R}$ & $\frac{\partial \mathrm{R}}{\partial \mathrm{M}_{\infty}}$ & $\frac{\mathrm{M}_{\infty}}{\mathrm{R}} \frac{\partial \mathrm{R}}{\partial \mathrm{M}_{\infty}}$ & $\frac{\partial \mathrm{M}_{\infty}}{\partial \mathrm{R}}$ & $\frac{\mathrm{R}}{\mathrm{M}_{\infty}} \frac{\partial \mathrm{M}_{\infty}}{\partial \mathrm{R}}$ \\
\hline \hline 14.0 & $3.331 \mathrm{E}-4$ & $-1.148 \mathrm{E}-4$ & $-4.826 \mathrm{E}+0$ & $-8.709 \mathrm{E}+3$ & $-2.072 \mathrm{E}-1$ \\
14.1 & $3.218 \mathrm{E}-4$ & $-1.102 \mathrm{E}-4$ & $-4.828 \mathrm{E}+0$ & $-9.074 \mathrm{E}+3$ & $-2.071 \mathrm{E}-1$ \\
14.2 & $3.110 \mathrm{E}-4$ & $-1.058 \mathrm{E}-4$ & $-4.831 \mathrm{E}+0$ & $-9.451 \mathrm{E}+3$ & $-2.070 \mathrm{E}-1$ \\
14.3 & $3.007 \mathrm{E}-4$ & $-1.016 \mathrm{E}-4$ & $-4.833 \mathrm{E}+0$ & $-9.841 \mathrm{E}+3$ & $-2.069 \mathrm{E}-1$ \\
14.4 & $2.907 \mathrm{E}-4$ & $-9.761 \mathrm{E}-5$ & $-4.835 \mathrm{E}+0$ & $-1.024 \mathrm{E}+4$ & $-2.068 \mathrm{E}-1$ \\
& & & & & \\
14.5 & $2.811 \mathrm{E}-4$ & $-9.379 \mathrm{E}-5$ & $-4.837 \mathrm{E}+0$ & $-1.066 \mathrm{E}+4$ & $-2.067 \mathrm{E}-1$ \\
14.6 & $2.719 \mathrm{E}-4$ & $-9.014 \mathrm{E}-5$ & $-4.840 \mathrm{E}+0$ & $-1.109 \mathrm{E}+4$ & $-2.066 \mathrm{E}-1$ \\
14.7 & $2.631 \mathrm{E}-4$ & $-8.666 \mathrm{E}-5$ & $-4.842 \mathrm{E}+0$ & $-1.154 \mathrm{E}+4$ & $-2.065 \mathrm{E}-1$ \\
14.8 & $2.546 \mathrm{E}-4$ & $-8.333 \mathrm{E}-5$ & $-4.844 \mathrm{E}+0$ & $-1.200 \mathrm{E}+4$ & $-2.065 \mathrm{E}-1$ \\
14.9 & $2.464 \mathrm{E}-4$ & $-8.015 \mathrm{E}-5$ & $-4.846 \mathrm{E}+0$ & $-1.248 \mathrm{E}+4$ & $-2.064 \mathrm{E}-1$ \\
15.0 & $2.386 \mathrm{E}-4$ & $-7.711 \mathrm{E}-5$ & $-4.848 \mathrm{E}+0$ & $-1.297 \mathrm{E}+4$ & $-2.063 \mathrm{E}-1$ \\
\hline
\end{tabular}


Table 3. Sensitivity coefficients for $R=q_{\infty} / p_{t_{2}}$ $\gamma=1.40$

\begin{tabular}{|c|c|c|c|c|c|}
\hline $\mathbf{M}_{\infty}$ & $\mathbf{R}$ & $\frac{\partial R}{\partial M_{\infty}}$ & $\frac{\mathrm{M}_{\infty}}{\mathrm{R}} \frac{\partial \mathrm{R}}{\partial \mathrm{M}_{\infty}}$ & $\frac{\partial \mathrm{M}_{\infty}}{\partial \mathrm{R}}$ & $\frac{\mathrm{R}}{\mathrm{M}_{\infty}} \frac{\partial \mathrm{M}_{\infty}}{\partial \mathrm{R}}$ \\
\hline 0.1 & $6.951 E-3$ & $1.381 \mathrm{E}-1$ & $1.986 E+0$ & $7.244 E+0$ & $5.035 \mathrm{E}-1$ \\
\hline 0.2 & $2.723 E-2$ & $2.647 E-1$ & $1.944 E+0$ & $3.777 E+0$ & $5.143 E-1$ \\
\hline 0.3 & $5.919 E-2$ & $3.702 E-1$ & $1.876 E+0$ & $2.702 E+0$ & $5.330 \mathrm{E}-1$ \\
\hline 0.4 & $1.003 E-1$ & $4.471 E-1$ & $1.783 E+0$ & $2.237 E+0$ & $5.609 E-1$ \\
\hline 0.5 & $1.475 E-1$ & $4.918 E-1$ & $1.667 E+0$ & $2.034 E+0$ & $6.000 \mathrm{E}-1$ \\
\hline 0.6 & $1.976 \mathrm{E}-1$ & $5.038 E-1$ & $1.530 E+0$ & $1.985 E+0$ & $6.537 E-1$ \\
\hline 0.7 & $2.473 E-1$ & $4.858 E-1$ & $1.375 E+0$ & $2.058 E+0$ & $7.272 E-1$ \\
\hline 0.8 & $2.939 E-1$ & $4.429 E-1$ & $1.206 E+0$ & $2.258 E+0$ & $8.294 E-1$ \\
\hline 0.9 & $3.352 E-1$ & $3.815 E-1$ & $1.024 E+0$ & $2.621 E+0$ & $9.765 E-1$ \\
\hline 1.0 & $3.698 \mathrm{E}-1$ & $3.082 E-1$ & $8.333 E-1$ & $3.245 E+0$ & $1.200 E+0$ \\
\hline 1.1 & $3.971 E-1$ & $2.416 \mathrm{E}-1$ & $6.693 \mathrm{E}-1$ & $4.138 E+0$ & $1.494 E+0$ \\
\hline 1.2 & $4.187 E-1$ & $1.921 E-1$ & $5.507 E-1$ & $5.205 E+0$ & $1.816 E+0$ \\
\hline 1.3 & $4.360 \mathrm{E}-1$ & $1.548 E-1$ & $4.617 \mathrm{E}-1$ & $6.459 E+0$ & $2.166 E+0$ \\
\hline 1.4 & $4.499 E-1$ & $1.263 E-1$ & $3.931 E-1$ & $7.916 E+0$ & $2.544 E+0$ \\
\hline 1.5 & $4.614 \mathrm{E}-1$ & $1.043 E-1$ & $3.390 \mathrm{E}-1$ & $9.590 E+0$ & $2.950 E+0$ \\
\hline 1.6 & $4.710 E-1$ & $8.698 E-2$ & $2.955 \mathrm{E}-1$ & $1.150 E+1$ & $3.384 E+0$ \\
\hline 1.7 & $4.789 E-1$ & $7.325 E-2$ & $2.600 \mathrm{E}-1$ & $1.365 E+1$ & $3.846 E+0$ \\
\hline 1.8 & $4.857 E-1$ & $6.223 E-2$ & $2.306 \mathrm{E}-1$ & $1.607 E+1$ & $4.336 E+0$ \\
\hline 1.9 & $4.915 \mathrm{E}-1$ & $5.329 E-2$ & $2.060 \mathrm{E}-1$ & $1.877 E+1$ & $4.854 E+0$ \\
\hline 2.0 & $4.964 \mathrm{E}-1$ & $4.596 \mathrm{E}-2$ & $1.852 E-1$ & $2.176 E+1$ & $5.400 E+0$ \\
\hline 2.1 & $5.007 E-1$ & $3.991 E-2$ & $1.674 \mathrm{E}-1$ & $2.506 E+1$ & $5.974 E+0$ \\
\hline 2.2 & $5.044 E-1$ & $3.487 E-2$ & $1.521 E-1$ & $2.868 E+1$ & $6.576 E+0$ \\
\hline 2.3 & $5.077 E-1$ & $3.063 E-2$ & $1.388 E-1$ & $3.264 E+1$ & $7.206 E+0$ \\
\hline 2.4 & $5.106 \mathrm{E}-1$ & $2.705 E-2$ & $1.272 \mathrm{E}-1$ & $3.697 E+1$ & $7.864 E+0$ \\
\hline 2.5 & $5.131 \mathrm{E}-1$ & $2.401 E-2$ & $1.170 E-1$ & $4.166 E+1$ & $8.550 E+0$ \\
\hline 2.6 & $5.154 \mathrm{E}-1$ & $2.140 E-2$ & $1.079 E-1$ & $4.673 E+1$ & $9.264 E+0$ \\
\hline 2.7 & $5.174 \mathrm{E}-1$ & $1.915 \mathrm{E}-2$ & $9.994 E-2$ & $5.221 E+1$ & $1.001 E+1$ \\
\hline 2.8 & $5.192 \mathrm{E}-1$ & $1.721 E-2$ & $9.280 E-2$ & $5.811 E+1$ & $1.078 E+1$ \\
\hline 2.9 & $5.209 E-1$ & $1.552 \mathrm{E}-2$ & $8.640 E-2$ & $6.444 E+1$ & $1.157 E+1$ \\
\hline 3.0 & $5.223 E-1$ & $1.404 E-2$ & $8.065 E-2$ & $7.122 E+1$ & $1.240 E+1$ \\
\hline 3.1 & $5.237 \mathrm{E}-1$ & $1.275 \mathrm{E}-2$ & $7.545 E-2$ & $7.846 E+1$ & 1.325E+1 \\
\hline 3.2 & $5.249 E-1$ & $1.160 \mathrm{E}-2$ & $7.074 \mathrm{E}-2$ & $8.618 E+1$ & $1.414 E+1$ \\
\hline 3.3 & $5.260 E-1$ & $1.059 E-2$ & $6.646 \mathrm{E}-2$ & $9.439 E+1$ & $1.505 E+1$ \\
\hline 3.4 & $5.270 E-1$ & $9.698 \mathrm{E}-3$ & $6.256 \mathrm{E}-2$ & $1.031 E+2$ & $1.598 E+1$ \\
\hline
\end{tabular}


Table 3. Sensitivity coefficients for $R=q_{\infty} / p_{t_{2}} \quad$ (Continued) $\gamma=1.40$

\begin{tabular}{|c|c|c|c|c|c|}
\hline$M_{\infty}$ & $\mathbf{R}$ & $\frac{\partial R}{\partial M_{\infty}}$ & $\frac{\mathbf{M}_{\infty}}{\mathbf{R}} \frac{\partial \mathrm{R}}{\partial \mathbf{M}_{\infty}}$ & $\frac{\partial M_{\infty}}{\partial R}$ & $\frac{R}{M_{\infty}} \frac{\partial M_{\infty}}{\partial R}$ \\
\hline 3.5 & $5.280 \mathrm{E}-1$ & 8.899E-3 & $5.900 \mathrm{E}-2$ & $1.124 E+2$ & $1.695 E+1$ \\
\hline 3.6 & $5.288 E-1$ & $8.186 E-3$ & $5.573 E-2$ & $1.222 E+2$ & $1.794 E+1$ \\
\hline 3.7 & $5.296 \mathrm{E}-1$ & $7.547 \mathrm{E}-3$ & $5.273 E-2$ & $1.325 E+2$ & $1.897 E+1$ \\
\hline 3.8 & $5.303 \mathrm{E}-1$ & $6.972 E-3$ & 4.996E-2 & $1.434 E+2$ & $2.002 E+1$ \\
\hline 3.9 & $5.310 \mathrm{E}-1$ & $6.454 E-3$ & $4.741 E-2$ & $1.549 E+2$ & $2.109 E+1$ \\
\hline 4.0 & $5.316 E-1$ & $5.987 E-3$ & $4.505 \mathrm{E}-2$ & $1.670 E+2$ & $2.220 E+1$ \\
\hline 4.1 & $5.322 \mathrm{E}-1$ & $5.563 E-3$ & $4.286 E-2$ & $1.798 E+2$ & $2.333 E+1$ \\
\hline 4.2 & $5.327 \mathrm{E}-1$ & $5.178 E-3$ & $4.082 E-2$ & $1.931 E+2$ & $2.450 E+1$ \\
\hline 4.3 & $5.332 \mathrm{E}-1$ & $4.828 E-3$ & 3.893E-2 & $2.071 E+2$ & $2.569 E+1$ \\
\hline 4.4 & 5.337E-1 & $4.508 E-3$ & $3.717 \mathrm{E}-2$ & $2.218 E+2$ & $2.690 \mathrm{E}+1$ \\
\hline 4.5 & $5.341 E-1$ & 4.217E-3 & $3.552 E-2$ & $2.372 E+2$ & $2.815 E+1$ \\
\hline 4.6 & $5.345 E-1$ & $3.949 E-3$ & $3.399 E-2$ & $2.532 E+2$ & $2.942 E+1$ \\
\hline 4.7 & $5.349 E-1$ & $3.704 E-3$ & $3.255 \mathrm{E}-2$ & $2.700 E+2$ & $3.073 E+1$ \\
\hline 4.8 & 5.353E-1 & $3.479 E-3$ & 3.120E-2 & $2.875 E+2$ & $3.206 E+1$ \\
\hline 4.9 & $5.356 \mathrm{E}-1$ & $3.271 E-3$ & $2.993 E-2$ & $3.057 E+2$ & $3.341 E+1$ \\
\hline 5.0 & $5.359 E-1$ & $3.080 E-3$ & $2.874 \mathrm{E}-2$ & $3.247 E+2$ & $3.480 E+1$ \\
\hline 5.1 & $5.362 E-1$ & $2.903 E-3$ & $2.761 E-2$ & $3.444 E+2$ & $3.621 E+1$ \\
\hline 5.2 & $5.365 E-1$ & $2.740 E-3$ & $2.656 \mathrm{E}-2$ & $3.650 E+2$ & $3.766 E+1$ \\
\hline 5.3 & $5.368 \mathrm{E}-1$ & $2.589 E-3$ & $2.556 \mathrm{E}-2$ & $3.863 E+2$ & $3.913 E+1$ \\
\hline 5.4 & $5.370 \mathrm{E}-1$ & $2.448 E-3$ & $2.462 E-2$ & $4.085 E+2$ & $4.062 E+1$ \\
\hline 5.5 & $5.373 E-1$ & $2.318 E-3$ & 2.372E-2 & $4.315 E+2$ & $4.215 E+1$ \\
\hline 5.6 & $5.375 \mathrm{E}-1$ & $2.196 E-3$ & $2.288 E-2$ & $4.553 E+2$ & $4.370 E+1$ \\
\hline 5.7 & $5.377 \mathrm{E}-1$ & $2.083 E-3$ & $2.208 E-2$ & $4.801 E+2$ & $4.529 E+1$ \\
\hline 5.8 & $5.379 E-1$ & $1.978 E-3$ & 2.132E-2 & $5.057 E+2$ & $4.690 E+1$ \\
\hline 5.9 & $5.381 \mathrm{E}-1$ & $1.879 E-3$ & $2.060 \mathrm{E}-2$ & $5.321 E+2$ & $4.853 E+1$ \\
\hline 6.0 & 5.383E-1 & $1.787 E-3$ & $1.992 E-2$ & $5.596 E+2$ & $5.020 E+1$ \\
\hline 6.1 & $5.385 E-1$ & $1.701 E-3$ & $1.927 E-2$ & $5.879 E+2$ & $5.189 E+1$ \\
\hline 6.2 & $5.386 \mathrm{E}-1$ & $1.620 \mathrm{E}-3$ & $1.865 E-2$ & $6.172 E+2$ & $5.362 E+1$ \\
\hline 6.3 & $5.388 E-1$ & $1.545 \mathrm{E}-3$ & $1.806 \mathrm{E}-2$ & $6.474 E+2$ & $5.537 E+1$ \\
\hline 6.4 & $5.389 E-1$ & $1.474 \mathrm{E}-3$ & $1.750 \mathrm{E}-2$ & $6.786 E+2$ & $5.714 E+1$ \\
\hline 6.5 & $5.391 E-1$ & $1.407 \mathrm{E}-3$ & $1.696 \mathrm{E}-2$ & $7.108 E+2$ & $5.895 E+1$ \\
\hline 6.6 & $5.392 E-1$ & $1.344 E-3$ & $1.645 \mathrm{E}-2$ & $7.440 E+2$ & $6.078 E+1$ \\
\hline 6.7 & $5.393 E-1$ & $1.285 E-3$ & $1.596 \mathrm{E}-2$ & $7.782 E+2$ & $6.265 E+1$ \\
\hline 6.8 & $5.395 \mathrm{E}-1$ & $1.229 E-3$ & $1.550 \mathrm{E}-2$ & $8.135 E+2$ & $6.454 E+1$ \\
\hline 6.9 & $5.396 \mathrm{E}-1$ & $1.177 \mathrm{E}-3$ & $1.505 E-2$ & $8.498 E+2$ & $6.645 E+1$ \\
\hline
\end{tabular}


Table 3. Sensitivity coefficients for $R=q_{\infty} / p_{t_{2}} \quad$ (Continued) $\gamma=1.40$

\begin{tabular}{|c|c|c|c|c|c|}
\hline$M_{\infty}$ & $\mathbf{R}$ & $\frac{\partial R}{\partial M_{\infty}}$ & $\frac{M_{\infty}}{R} \frac{\partial R}{\partial M_{\infty}}$ & $\frac{\partial M_{\infty}}{\partial R}$ & $\frac{\mathrm{R}}{\mathrm{M}_{\infty}} \frac{\partial \mathrm{M}_{\infty}}{\partial \mathrm{R}}$ \\
\hline 7.0 & $5.397 \mathrm{E}-1$ & $1.127 \mathrm{E}-3$ & $1.462 \mathrm{E}-2$ & $8.871 E+2$ & $6.840 E+1$ \\
\hline 7.1 & $5.398 E-1$ & $1.080 \mathrm{E}-3$ & $1.421 \mathrm{E}-2$ & $9.256 \mathrm{E}+2$ & $7.037 E+1$ \\
\hline 7.2 & $5.399 \mathrm{E}-1$ & $1.036 \mathrm{E}-3$ & $1.382 E-2$ & $9.651 E+2$ & $7.238 E+1$ \\
\hline 7.3 & $5.400 \mathrm{E}-1$ & $9.942 E-4$ & $1.344 \mathrm{E}-2$ & $1.006 \mathrm{E}+3$ & $7.441 E+1$ \\
\hline 7.4 & $5.401 \mathrm{E}-1$ & $9.546 \mathrm{E}-4$ & $1.308 E-2$ & $1.048 E+3$ & $7.646 E+1$ \\
\hline 7.5 & $5.402 E-1$ & $9.170 \mathrm{E}-4$ & $1.273 E-2$ & $1.091 E+3$ & $7.855 E+1$ \\
\hline 7.6 & $5.403 E-1$ & $8.814 E-4$ & $1.240 \mathrm{E}-2$ & $1.135 E+3$ & $8.066 E+1$ \\
\hline 7.7 & $5.404 \mathrm{E}-1$ & $8.475 E-4$ & $1.208 \mathrm{E}-2$ & $1.180 E+3$ & $8.281 E+1$ \\
\hline 7.8 & $5.405 E-1$ & $8.154 E-4$ & $1.177 \mathrm{E}-2$ & $1.226 E+3$ & $8.498 E+1$ \\
\hline 7.9 & $5.406 \mathrm{E}-1$ & $7.849 E-4$ & $1.147 \mathrm{E}-2$ & $1.274 \mathrm{E}+3$ & $8.717 E+1$ \\
\hline 8.0 & $5.406 \mathrm{E}-1$ & $7.559 E-4$ & $1.119 \mathrm{E}-2$ & $1.323 E+3$ & $8.940 E+1$ \\
\hline 8.1 & $5.407 \mathrm{E}-1$ & $7.283 E-4$ & $1.091 \mathrm{E}-2$ & $1.373 E+3$ & $9.165 E+1$ \\
\hline 8.2 & $5.408 \mathrm{E}-1$ & $7.021 E-4$ & $1.065 \mathrm{E}-2$ & $1.424 E+3$ & $9.394 E+1$ \\
\hline 8.3 & $5.408 \mathrm{E}-1$ & $6.770 \mathrm{E}-4$ & $1.039 \mathrm{E}-2$ & $1.477 E+3$ & $9.625 E+1$ \\
\hline 8.4 & $5.409 \mathrm{E}-1$ & $6.532 E-4$ & $1.014 \mathrm{E}-2$ & $1.531 E+3$ & $9.858 E+1$ \\
\hline 8.5 & $5.410 \mathrm{E}-1$ & $6.305 \mathrm{E}-4$ & $9.906 E-3$ & $1.586 E+3$ & $1.010 E+2$ \\
\hline 8.6 & $5.410 \mathrm{E}-1$ & $6.088 E-4$ & $9.676 E-3$ & $1.643 E+3$ & $1.033 E+2$ \\
\hline 8.7 & $5.411 \mathrm{E}-1$ & $5.880 E-4$ & $9.455 E-3$ & $1.701 E+3$ & $1.058 E+2$ \\
\hline 8.8 & $5.412 E-1$ & $5.683 E-4$ & $9.241 E-3$ & $1.760 E+3$ & $1.082 E+2$ \\
\hline 8.9 & $5.412 \mathrm{E}-1$ & $5.494 \mathrm{E}-4$ & $9.034 E-3$ & $1.820 E+3$ & $1.107 E+2$ \\
\hline 9.0 & $5.413 \mathrm{E}-1$ & $5.313 E-4$ & $8.834 E-3$ & $1.882 E+3$ & $1.132 E+2$ \\
\hline 9.1 & $5.413 \mathrm{E}-1$ & $5.140 \mathrm{E}-4$ & $8.641 \mathrm{E}-3$ & $1.946 E+3$ & $1.157 E+2$ \\
\hline 9.2 & $5.414 \mathrm{E}-1$ & $4.974 \mathrm{E}-4$ & $8.453 E-3$ & $2.010 E+3$ & $1.183 E+2$ \\
\hline 9.3 & $5.414 \mathrm{E}-1$ & $4.816 \mathrm{E}-4$ & $8.272 E-3$ & $2.076 E+3$ & $1.209 E+2$ \\
\hline 9.4 & $5.415 \mathrm{E}-1$ & $4.664 \mathrm{E}-4$ & $8.097 E-3$ & $2.144 E+3$ & $1.235 E+2$ \\
\hline 9.5 & $5.415 E-1$ & $4.519 E-4$ & $7.927 E-3$ & $2.213 E+3$ & $1.262 E+2$ \\
\hline 9.6 & $5.416 \mathrm{E}-1$ & $4.379 E-4$ & 7.763E-3 & $2.284 E+3$ & $1.288 E+2$ \\
\hline 9.7 & $5.416 \mathrm{E}-1$ & $4.245 E-4$ & $7.603 E-3$ & $2.356 \mathrm{E}+3$ & $1.315 E+2$ \\
\hline 9.8 & $5.416 \mathrm{E}-1$ & $4.117 \mathrm{E}-4$ & $7.448 E-3$ & $2.429 E+3$ & $1.343 E+2$ \\
\hline 9.9 & $5.417 E-1$ & $3.993 E-4$ & $7.299 E-3$ & $2.504 E+3$ & $1.370 E+2$ \\
\hline 10.0 & $5.417 \mathrm{E}-1$ & $3.875 E-4$ & $7.153 E-3$ & $2.581 E+3$ & $1.398 E+2$ \\
\hline 10.1 & $5.418 \mathrm{E}-1$ & $3.761 \mathrm{E}-4$ & $7.012 E-3$ & $2.659 E+3$ & 1. $426 E+2$ \\
\hline 10.2 & $5.418 E-1$ & $3.652 E-4$ & $6.875 E-3$ & $2.738 E+3$ & $1.455 E+2$ \\
\hline 10.3 & $5.418 E-1$ & $3.547 \mathrm{E}-4$ & $6.742 E-3$ & $2.820 E+3$ & $1.483 E+2$ \\
\hline 10.4 & $5.419 E-1$ & $3.445 \mathrm{E}-4$ & $6.613 E-3$ & $2.902 E+3$ & $1.512 E+2$ \\
\hline
\end{tabular}


Table 3. Sensitivity coefficients for $R=q_{\infty} / p_{t_{2}} \quad$ (Continued) $\gamma=1.40$

\begin{tabular}{|c|c|c|c|c|c|}
\hline $\mathbf{M}_{\infty}$ & $\mathbf{R}$ & $\frac{\partial R}{\partial M_{\infty}}$ & $\frac{\mathrm{M}_{\infty}}{\mathrm{R}} \frac{\partial \mathrm{R}}{\partial \mathrm{M}_{\infty}}$ & $\frac{\partial \mathrm{M}_{\infty}}{\partial \mathrm{R}}$ & $\frac{\mathrm{R}}{\mathrm{M}_{\infty}} \frac{\partial \mathrm{M}_{\infty}}{\partial \mathrm{R}}$ \\
\hline 10.5 & $5.419 E-1$ & $3.348 E-4$ & $6.487 E-3$ & $2.987 E+3$ & $1.542 E+2$ \\
\hline 10.6 & $5.419 E-1$ & $3.254 \mathrm{E}-4$ & $6.365 E-3$ & $3.073 E+3$ & $1.571 E+2$ \\
\hline 10.7 & $5.420 \mathrm{E}-1$ & $3.164 E-4$ & $6.247 E-3$ & $3.161 E+3$ & $1.601 E+2$ \\
\hline 10.8 & $5.420 \mathrm{E}-1$ & $3.077 E-4$ & $6.131 E-3$ & $3.250 E+3$ & $1.631 E+2$ \\
\hline 10.9 & $5.420 \mathrm{E}-1$ & $2.993 E-4$ & $6.019 E-3$ & $3.341 E+3$ & $1.661 E+2$ \\
\hline 11.0 & $5.421 E-1$ & $2.912 E-4$ & $5.910 E-3$ & $3.434 E+3$ & $1.692 E+2$ \\
\hline 11.1 & $5.421 E-1$ & $2.835 E-4$ & $5.804 E-3$ & $3.528 E+3$ & $1.723 E+2$ \\
\hline 11.2 & $5.421 E-1$ & $2.759 E-4$ & $5.701 E-3$ & $3.624 E+3$ & $1.754 E+2$ \\
\hline 11.3 & $5.421 E-1$ & $2.687 E-4$ & $5.600 E-3$ & $3.722 E+3$ & $1.786 E+2$ \\
\hline 11.4 & $5.422 E-1$ & $2.617 E-4$ & $5.502 E-3$ & $3.821 E+3$ & $1.817 E+2$ \\
\hline 11.5 & $5.422 E-1$ & $2.549 E-4$ & $5.407 E-3$ & $3.923 E+3$ & $1.850 E+2$ \\
\hline 11.6 & $5.422 E-1$ & $2.484 E-4$ & $5.314 \mathrm{E}-3$ & $4.026 E+3$ & $1.882 E+2$ \\
\hline 11.7 & $5.422 E-1$ & $2.421 E-4$ & $5.223 E-3$ & $4.131 E+3$ & $1.914 E+2$ \\
\hline 11.8 & $5.423 E-1$ & $2.360 E-4$ & $5.135 E-3$ & $4.238 E+3$ & $1.947 E+2$ \\
\hline 11.9 & $5.423 E-1$ & $2.301 E-4$ & $5.049 E-3$ & $4.346 E+3$ & $1.981 E+2$ \\
\hline 12.0 & $5.423 \mathrm{E}-1$ & $2.244 E-4$ & $4.965 E-3$ & $4.456 E+3$ & $2.014 E+2$ \\
\hline 12.1 & $5.423 E-1$ & $2.189 E-4$ & $4.883 E-3$ & $4.569 E+3$ & $2.048 E+2$ \\
\hline 12.2 & $5.424 E-1$ & $2.135 E-4$ & $4.804 E-3$ & $4.683 E+3$ & $2.082 E+2$ \\
\hline 12.3 & $5.424 E-1$ & $2.084 E-4$ & $4.726 \mathrm{E}-3$ & $4.799 E+3$ & $2.116 E+2$ \\
\hline 12.4 & $5.424 \mathrm{E}-1$ & $2.034 E-4$ & $4.650 E-3$ & $4.917 E+3$ & $2.151 E+2$ \\
\hline 12.5 & $5.424 E-1$ & $1.986 E-4$ & $4.576 E-3$ & $5.036 E+3$ & $2.186 E+2$ \\
\hline 12.6 & $5.424 E-1$ & $1.939 E-4$ & $4.503 E-3$ & $5.158 E+3$ & $2.221 E+2$ \\
\hline 12.7 & $5.425 \mathrm{E}-1$ & $1.893 E-4$ & $4.433 E-3$ & $5.282 E+3$ & $2.256 E+2$ \\
\hline 12.8 & $5.425 \mathrm{E}-1$ & $1.849 E-4$ & $4.363 E-3$ & $5.407 E+3$ & $2.292 E+2$ \\
\hline 12.9 & $5.425 \mathrm{E}-1$ & $1.807 E-4$ & $4.296 E-3$ & $5.535 E+3$ & $2.328 E+2$ \\
\hline 13.0 & $5.425 E-1$ & $1.765 E-4$ & $4.230 E-3$ & $5.665 E+3$ & $2.364 E+2$ \\
\hline 13.1 & $5.425 E-1$ & $1.725 E-4$ & $4.166 \mathrm{E}-3$ & $5.796 \mathrm{E}+3$ & $2.401 E+2$ \\
\hline 13.2 & $5.4^{\prime} 26 \mathrm{E}-1$ & $1.686 \mathrm{E}-4$ & $4.103 E-3$ & $5.930 E+3$ & $2.437 E+2$ \\
\hline 13.3 & $5.426 \mathrm{E}-1$ & $1.649 E-4$ & $4.041 E-3$ & $6.066 E+3$ & $2.474 E+2$ \\
\hline 13.4 & $5.426 E-1$ & $1.612 E-4$ & $3.981 E-3$ & $6.203 E+3$ & $2.512 E+2$ \\
\hline 13.5 & $5.426 \mathrm{E}-1$ & $1.576 \mathrm{E}-4$ & $3.922 E-3$ & $6.343 E+3$ & $2.550 E+2$ \\
\hline 13.6 & $5.426 E-1$ & $1.542 E-4$ & $3.865 E-3$ & $6.485 E+3$ & $2.587 E+2$ \\
\hline 13.7 & $5.426 E-1$ & $1.508 E-4$ & $3.809 E-3$ & $6.629 E+3$ & $2.626 E+2$ \\
\hline 13.8 & $5.426 E-1$ & $1.476 \mathrm{E}-4$ & $3.754 E-3$ & $6.775 E+3$ & $2.664 E+2$ \\
\hline 13.9 & $5.427 E-1$ & $1.444 E-4$ & $3.700 E-3$ & $6.923 E+3$ & $2.703 E+2$ \\
\hline
\end{tabular}


Table 3. Sensitivity coefficients for $R=q_{\infty \infty} / p_{t_{2}}$ (Continued) $\gamma=1.40$

\begin{tabular}{|c|c|c|c|c|c|}
\hline$M_{\infty}$ & $R$ & $\frac{\partial R}{\partial M_{\infty}}$ & $\frac{M_{\infty}}{R} \frac{\partial R}{\partial M_{\infty}}$ & $\frac{\partial M_{\infty}}{\partial R}$ & $\frac{R}{M_{\infty}} \frac{\partial M_{\infty}}{\partial R}$ \\
\hline \hline 14.0 & $5.427 E-1$ & $1.414 E-4$ & $3.647 E-3$ & $7.074 E+3$ & $2.742 E+2$ \\
14.1 & $5.427 E-1$ & $1.3844 E-4$ & $3.595 E-3$ & $7.226 E+3$ & $2.781 E+2$ \\
14.2 & $5.427 E-1$ & $1.355 E-4$ & $3.545 E-3$ & $7.381 E+3$ & $2.821 E+2$ \\
14.3 & $5.427 E-1$ & $1.327 E-4$ & $3.495 E-3$ & $7.538 E+3$ & $2.861 E+2$ \\
14.4 & $5.427 E-1$ & $1.299 E-4$ & $3.447 E-3$ & $7.697 E+3$ & $2.901 E+2$ \\
& & & & & \\
14.5 & $5.427 E-1$ & $1.272 E-4$ & $3.400 E-3$ & $7.859 E+3$ & $2.942 E+2$ \\
14.6 & $5.428 E-1$ & $1.247 E-4$ & $3.353 E-3$ & $8.022 E+3$ & $2.982 E+2$ \\
14.7 & $5.428 E-1$ & $1.221 E-4$ & $3.308 E-3$ & $8.188 E+3$ & $3.023 E+2$ \\
14.8 & $5.428 E-1$ & $1.197 E-4$ & $3.263 E-3$ & $8.356 E+3$ & $3.065 E+2$ \\
14.9 & $5.428 E-1$ & $1.173 E-4$ & $3.219 E-3$ & $8.527 E+3$ & $3.106 E+2$ \\
15.0 & $5.428 E-1$ & $1.150 E-4$ & $3.177 E-3$ & $8.699 E+3$ & $3.148 E+2$ \\
\hline
\end{tabular}


Table 4. Sensitivity coefficients for $R=p_{t_{2}} / p_{t_{1}}$ $\gamma=1.40$

\begin{tabular}{|c|c|c|c|c|c|}
\hline $\mathbf{M}_{\infty}$ & $\mathbf{R}$ & $\frac{\partial R}{\partial M_{\infty}}$ & $\frac{\mathrm{M}_{\infty}}{\mathrm{R}} \frac{\partial \mathrm{R}}{\partial \mathrm{M}_{\infty}}$ & $\frac{\partial M_{\infty}}{\partial R}$ & $\frac{\mathrm{R}}{\mathrm{M}_{\infty}} \frac{\partial \mathrm{M}_{\infty}}{\partial \mathrm{R}}$ \\
\hline 0.1 & $1.000 E+0$ & $0.000 E+0$ & $0.000 E+0$ & $\infty$ & $\infty$ \\
\hline 0.2 & $1.000 E+0$ & $0.000 E+0$ & $0.000 E+0$ & $\infty$ & $\infty$ \\
\hline 0.3 & $1.000 E+0$ & $0.000 E+0$ & $0.000 E+0$ & $\infty$ & $\infty$ \\
\hline 0.4 & $1.000 E+0$ & $0.0065+0$ & $0.000 E+0$ & $\infty$ & $\infty$ \\
\hline 0.5 & 1 SUOE+O & $0.000 E+0$ & $0.000 E+0$ & $\infty$ & $\infty$ \\
\hline 0.6 & $1.000 E+\prime$ & $0.000 E+0$ & $0.000 E+0$ & $\infty$ & $\infty$ \\
\hline 0.7 & $1.000 E+0$ & $0.000 E+0$ & $0.000 E+0$ & $\infty$ & $\infty$ \\
\hline 0.8 & $1.00 \cap E+0$ & $0.000 E+0$ & $0.000 E+0$ & $\infty$ & $\infty$ \\
\hline 0.9 & $1.000 E+0$ & $0.000 E+0$ & $0.000 E+0$ & $\infty$ & $\infty$ \\
\hline 1.0 & $1.000 E+0$ & $0.000 E+0$ & $0.000 E+0$ & $\infty$ & $\infty$ \\
\hline 1.1 & $9.989 E-1$ & $-3.022 E-2$ & $-3.327 E-2$ & $-3.309 E+1$ & $-3.005 E+1$ \\
\hline 1.2 & $9.8-3 E-1$ & $-9.587 E-2$ & $-1.159 E-1$ & $-1.043 E+1$ & $-8.630 E+0$ \\
\hline 1.3 & $9.7 \zeta \div E-1$ & $-1.733 E-1$ & $-2.300 \mathrm{E}-1$ & $-5.771 E+0$ & $-4.348 E+0$ \\
\hline 1.4 & $9.582 E-1$ & $-2.494 E-1$ & $-3.643 E-1$ & $-4.010 E+0$ & $-2.745 E+0$ \\
\hline 1.5 & $9.298 E-1$ & $-3.170 E-1$ & $-5.114 E-1$ & $-3.155 E+0$ & $-1.955 E+0$ \\
\hline 1.6 & $8.952 E-1$ & $-3.726 E-1$ & $-6.659 E-1$ & $-2.684 E+0$ & $-1.502 E+0$ \\
\hline 1.7 & $8.557 E-1$ & $-4.148 E-1$ & $-8.240 E-1$ & $-2.411 E+0$ & $-1.214 E+0$ \\
\hline 1.8 & $8.127 \sqsubset-1$ & $-4.438 E-1$ & $-9.831 E-1$ & $-2.253 E+0$ & $-1.017 E+0$ \\
\hline 1.9 & $7.674 E-1$ & $-4.608 E-1$ & $-1.141 E+0$ & $-2.170 E+0$ & $-8.764 E-1$ \\
\hline 2.0 & $7.209 E-1$ & $-4.672 E-1$ & $-1.296 E+0$ & $-2.140 E+0$ & $-7.714 \mathrm{E}-1$ \\
\hline 2.1 & $6.742 E-1$ & $-4.649 E-1$ & $-1.448 E+0$ & $-2.151 E+0$ & $-6.906 E-1$ \\
\hline 2.2 & $6.281 E-1$ & $-4.554 E-1$ & $-1.595 E+0$ & $-2.196 E+0$ & $-6.269 E-1$ \\
\hline 2.3 & $5.833 E-1$ & $-4.406 E-1$ & $-1.737 E+0$ & $-2.270 E+0$ & $-5.756 E-1$ \\
\hline 2.4 & $5.401 \mathrm{E}-1$ & $-4.218 E-1$ & $-1.874 E+0$ & $-2.371 E+0$ & $-5.335 E-1$ \\
\hline 2.5 & $4.990 E-1$ & $-4.004 E-1$ & $-2.006 E+0$ & $-2.498 E+0$ & $-4.985 E-1$ \\
\hline 2.6 & $4.601 E-1$ & $-3.773 E-1$ & $-2.132 E+0$ & $-2.651 E+0$ & $-4.691 \mathrm{E}-1$ \\
\hline 2.7 & $4.236 E-1$ & $-3.533 E-1$ & $-2.252 E+0$ & $-2.830 E+0$ & $-4.440 E-1$ \\
\hline 2.8 & $3.895 E-1$ & $-3.292 E-1$ & $-2.367 E+0$ & $-3.037 E+0$ & $-4.225 E-1$ \\
\hline 2.9 & $3.577 \mathrm{E}-1$ & $-3.055 E-1$ & $-2.476 E+0$ & $-3.274 E+0$ & $-4.038 E \cdot 1$ \\
\hline 3.0 & $3.283 E-1$ & $-2.824 E-1$ & $-2.581 E+0$ & $-3.540 E+0$ & $-3.875 E-1$ \\
\hline 3.1 & $3.012 E-1$ & $-2.604 E-1$ & $-2.680 E+0$ & $-3.840 E+0$ & $-3.732 E-1$ \\
\hline 3.2 & $2.762 E-1$ & $-2.395 E-1$ & $-2.774 E+0$ & $-4.176 E+0$ & $-3.605 E-1$ \\
\hline 3.3 & $2.53^{-} E-1$ & $-2.198 E-1$ & $-2.864 E+0$ & $-4.550 E+0$ & $-3.492 E-1$ \\
\hline 3.4 & $2.322 E-1$ & $-2.014 E-1$ & $-2.949 E+0$ & $-4.965 E+0$ & $-3.391 E-1$ \\
\hline
\end{tabular}


Table 4. Sensitivity coefficients for $R=p_{t_{2}} / p_{t_{1}}$ (Continued) $\gamma=1.40$

\begin{tabular}{|c|c|c|c|c|c|}
\hline $\mathrm{M}_{\infty}$ & $\mathrm{R}$ & $\frac{\partial R}{\partial M_{\infty}}$ & $\frac{M_{\infty}}{R} \frac{\partial R}{\partial M_{\infty}}$ & $\frac{\partial M_{\infty}}{\partial R}$ & $\frac{R}{M_{\infty}} \frac{\partial M_{\infty}}{\partial R}$ \\
\hline 3.5 & $2.129 E-1$ & $-1.844 \mathrm{E}-1$ & $-3.030 E+0$ & $-5.424 E+0$ & $-3.300 E-1$ \\
\hline 3.6 & $1.953 E-1$ & $-1.686 \mathrm{E}-1$ & $-3.107 E+0$ & $-5.933 E+0$ & $-3.219 \mathrm{E}-1$ \\
\hline 3.7 & $1.792 E-1$ & $-1.540 \mathrm{E}-1$ & $-3.180 E+0$ & $-6.493 E+0$ & $-3.145 \mathrm{E}-1$ \\
\hline 3.8 & $1.645 E-1$ & $-1.406 \mathrm{E}-1$ & $-3.250 E+0$ & $-7.110 E+0$ & $-3.077 \mathrm{E}-1$ \\
\hline 3.9 & $1.510 E-1$ & $-1.284 E-1$ & $-3.316 E+0$ & $-7.788 E+0$ & $-3.016 \mathrm{E}-1$ \\
\hline 4.0 & $1.388 E-1$ & $-1.172 E-1$ & $-3.378 E+0$ & $-8.533 E+0$ & $-2.960 \mathrm{E}-1$ \\
\hline 4.1 & $1.276 \mathrm{E}-1$ & $-1.070 E-1$ & $-3.438 E+0$ & $-9.349 E+0$ & $-2.909 E-1$ \\
\hline 4.2 & $1.173 \mathrm{E}-1$ & $-9.764 E-2$ & $-3.495 E+0$ & $-1.024 E+1$ & $-2.861 E-1$ \\
\hline 4.3 & $1.080 \mathrm{E}-1$ & $-8.914 E-2$ & $-3.549 E+0$ & $-1.122 E+1$ & $-2.818 E-1$ \\
\hline 4.4 & $9.948 E-2$ & $-8.140 E-2$ & $-3.600 E+0$ & $-1.228 E+1$ & $-2.777 E-1$ \\
\hline 4.5 & $9.170 \mathrm{E}-2$ & $-7.436 E-2$ & $-3.649 E+0$ & $-1.345 E+1$ & $-2.740 E-1$ \\
\hline 4.6 & $8.459 E-2$ & $-6.796 \mathrm{E}-2$ & $-3.696 E+0$ & $-1.471 E+1$ & $-2.706 \mathrm{E}-1$ \\
\hline 4.7 & $7.809 E-2$ & $-6.215 E-2$ & $-3.741 E+0$ & $-1.609 E+1$ & $-2.673 E-1$ \\
\hline 4.8 & $7.214 E-2$ & $-5.685 E-2$ & $-3.783 E+0$ & $-1.759 E+1$ & $-2.643 \mathrm{E}-1$ \\
\hline 4.9 & $6.670 \mathrm{E}-2$ & $-5.204 E-2$ & $-3.823 E+0$ & $-1.921 E+1$ & $-2.615 \mathrm{E}-1$ \\
\hline 5.0 & $6.172 \mathrm{E}-2$ & $-4.767 E-2$ & $-3.862 E+0$ & $-2.098 E+1$ & $-2.589 E-1$ \\
\hline 5.1 & $5.715 \mathrm{E}-2$ & $-4.369 E-2$ & $-3.899 E+0$ & $-2.289 E+1$ & $-2.565 E-1$ \\
\hline 5.2 & $5.297 \mathrm{E}-2$ & $-4.007 E-2$ & $-3.934 E+0$ & $-2.495 E+1$ & $-2.542 E-1$ \\
\hline 5.3 & $4.913 \mathrm{E}-2$ & $-3.678 E-2$ & $-3.968 E+0$ & $-2.719 E+1$ & $-2.520 \mathrm{E}-1$ \\
\hline 5.4 & $4.560 E-2$ & $-3.378 E-2$ & $-4.000 E+0$ & $-2.960 E+1$ & $-2.500 E-1$ \\
\hline 5.5 & $4.236 E-2$ & $-3.105 E-2$ & $-4.031 E+0$ & $-3.221 E+1$ & $-2.481 E-1$ \\
\hline 5.6 & $3.938 \mathrm{E}-2$ & $-2.855 E-2$ & $-4.060 E+0$ & $-3.502 E+1$ & $-2.463 E-1$ \\
\hline 5.7 & $3.664 \mathrm{E} \cdot 2$ & $-2.628 E-2$ & $-4.089 E+0$ & $-3.805 E+1$ & $-2.446 E-1$ \\
\hline 5.8 & $3.412 \mathrm{E}-2$ & $-2.421 E-2$ & $-4.116 E+0$ & $-4.130 E+1$ & $-2.430 \mathrm{E}-1$ \\
\hline 5.9 & $3.179 E-2$ & $-2.232 \mathrm{E}-2$ & $-4.141 E+0$ & $-4.481 E+1$ & $-2.415 E-1$ \\
\hline 6.0 & $2.965 E-2$ & $-2.059 E-2$ & $-4.166 E+0$ & $-4.857 E+1$ & $-2.400 E-1$ \\
\hline 6.1 & $2.767 E-2$ & $-1.901 E-2$ & $-4.190 E+0$ & $-5.261 E+1$ & $-2.387 E-1$ \\
\hline 6.2 & $2.584 \mathrm{E}-2$ & $-1.756 \mathrm{E}-2$ & $-4.213 E+0$ & $-5.694 E+1$ & $-2.374 E-1$ \\
\hline 6.3 & $2.416 E-2$ & $-1.624 E-2$ & $-4.235 E+0$ & $-6.159 E+1$ & $-2.361 E-1$ \\
\hline 6.4 & $2.259 E-2$ & $-1.502 E-2$ & $-4.256 E+0$ & $-6.656 E+1$ & $-2.350 E-1$ \\
\hline 6.5 & $2.115 \mathrm{E}-2$ & $-1.391 E-2$ & $-4.276 E+0$ & $-7.188 E+1$ & $-2.339 E-1$ \\
\hline 6.6 & $1981 E-2$ & $-1.289 E-2$ & $-4.296 E+0$ & $-7.757 E+1$ & $-2.328 E-1$ \\
\hline 6.7 & $1.857 E-2$ & $-1.196 E-2$ & $-4.314 E+0$ & $-8.364 E+1$ & $-2.318 E-1$ \\
\hline 6.8 & $1.741 E-2$ & $-1.110 E-2$ & $-4.332 E+0$ & $-9.013 E+1$ & $-2.308 E-1$ \\
\hline 6.9 & $1.634 \mathrm{E}-2$ & $-1.030 E-2$ & $-4.350 E+0$ & $-9.705 E+1$ & $-2.299 E-1$ \\
\hline
\end{tabular}


Table 4. Sensitivity coefficients for $R=p_{t_{2}} / p_{t_{1}}$ （Continued) $\gamma=1.40$

\begin{tabular}{|c|c|c|c|c|c|}
\hline $\mathbf{M}_{\infty}$ & $\mathbf{R}$ & $\frac{\partial R}{\partial M_{\infty}}$ & $\frac{M_{\infty}}{R} \frac{\partial R}{\partial M_{\infty}}$ & $\frac{\partial M_{\infty}}{\partial R}$ & $\frac{\mathrm{R}}{\mathrm{M}_{\infty}} \frac{\partial \mathrm{M}_{\infty}}{\partial \mathrm{R}}$ \\
\hline 7.0 & $1.535 \mathrm{E}-2$ & $-9.576 \mathrm{E}-3$ & $-4.366 E+0$ & $-1.044 E+2$ & $-2.290 \mathrm{E}-1$ \\
\hline 7.1 & $1.443 E-2$ & $-8.906 E-3$ & $-4.383 E+0$ & $-1.123 E+2$ & $-2.282 E-1$ \\
\hline 7.2 & 1.357E-2 & $-8.288 E-3$ & $-4.398 E+0$ & $-1.207 E+2$ & $-2.274 E-1$ \\
\hline 7.3 & $1.277 \mathrm{E}-2$ & $-7.719 E-3$ & $-4.413 E+0$ & $-1.296 E+2$ & $-2.266 \mathrm{E}-1$ \\
\hline 7.4 & $1.202 E-2$ & $-7.194 E-3$ & $-4.427 E+0$ & $-1.390 E+2$ & $-2.259 E-1$ \\
\hline 7.5 & $1.133 E-2$ & $-6.708 E-3$ & $-4.441 E+0$ & $-1.491 E+2$ & $-2.252 E-1$ \\
\hline 7.6 & $1.068 \mathrm{E}-2$ & $-6.260 E-3$ & $-4.455 E+0$ & $-1.597 E+2$ & $-2.245 E-1$ \\
\hline 7.7 & $1.008 E-2$ & $-5.846 E-3$ & $-4.468 E+0$ & $-1.711 E+2$ & $-2.238 E-1$ \\
\hline 7.8 & $9.510 E-3$ & $-5.462 E-3$ & $-4.480 E+0$ & $-1.831 E+2$ & $-2.232 E-1$ \\
\hline 7.9 & $8.982 E-3$ & $-5.107 E-3$ & $-4.492 E+0$ & $-1.958 E+2$ & $-2.226 E-1$ \\
\hline 8.0 & $8.488 E-3$ & $-4.779 E-3$ & $-4.504 E+0$ & $-2.093 E+2$ & $-2.220 E-1$ \\
\hline 8.1 & $8.025 E-3$ & $-4.474 E-3$ & $-4.515 E+0$ & $-2.235 E+2$ & $-2.215 E-1$ \\
\hline 8.2 & 7.592E-3 & $-4.191 E-3$ & $-4.526 E+0$ & $-2.386 E+2$ & $-2.209 E-1$ \\
\hline 8.3 & $7.187 E-3$ & $-3.928 E-3$ & $-4.537 E+0$ & $-2.546 E+2$ & $-2.204 E-1$ \\
\hline 8.4 & $6.806 E-3$ & $-3.684 E-3$ & $-4.547 E+0$ & $-2.714 E+2$ & $-2.199 E-1$ \\
\hline 8.5 & $6.449 E-3$ & $-3.457 E-3$ & $-4.557 E+0$ & $-2.892 E+2$ & $-2.195 E-1$ \\
\hline 8.6 & $6.114 \mathrm{E}-3$ & $-3.246 E-3$ & $-4.566 E+0$ & $-3.080 E+2$ & $-2.190 E-1$ \\
\hline 8.7 & $5.799 E-3$ & $-3.050 E-3$ & $-4.576 E+0$ & $-3.279 E+2$ & $-2.185 E-1$ \\
\hline 8.8 & $5.504 \mathrm{E}-3$ & -2.1367 E-3 & $-4.585 E+0$ & $-3.488 E+2$ & $-2.181 E-1$ \\
\hline 8.9 & $5.226 \mathrm{E}-3$ & $-2.697 E-3$ & $-4.593 E+0$ & $-3.708 E+2$ & $-2.177 E-1$ \\
\hline 9.0 & $4.964 E-3$ & $-2.538 E-3$ & $-4.602 E+0$ & $-3.940 E+2$ & $-2.173 E-1$ \\
\hline 9.1 & $4.718 E-3$ & $-2.390 E-3$ & $-4.610 E+0$ & $-4.184 E+2$ & $-2.169 E-1$ \\
\hline 9.2 & $4.486 \mathrm{E}-3$ & $-2.252 E-3$ & $-4.618 E+0$ & $-4.441 E+2$ & $-2.165 E-1$ \\
\hline 9.3 & $4.267 E-3$ & $-2.122 E-3$ & $-4.626 E+0$ & $-4.712 E+2$ & $-2.162 E-1$ \\
\hline 9.4 & $4.061 \mathrm{E}-3$ & $-2.002 E-3$ & $-4.633 E+0$ & $-4.996 E+2$ & $-2.158 E-1$ \\
\hline 9.5 & $3.866 \mathrm{E}-3$ & $-1.889 E-3$ & $-4.640 E+0$ & $-5.295 E+2$ & $-2.155 E-1$ \\
\hline 9.6 & $3.683 E-3$ & $-1.783 E-3$ & $-4.648 E+0$ & $-5.609 E+2$ & $-2.152 E-1$ \\
\hline 9.7 & $3.510 E-3$ & $-1.684 E-3$ & $-4.654 E+0$ & $-5.938 E+2$ & $-2.149 E-1$ \\
\hline 9.8 & $3.346 E-3$ & $-1.591 E-3$ & $-4.661 E+0$ & $-6.284 E+2$ & $-2.145 E-1$ \\
\hline 9.9 & $3.191 \mathrm{E}-3$ & $-1.504 E-3$ & $-4.668 E+0$ & $-6.647 E+2$ & $-2.142 E-1$ \\
\hline 10.0 & $3.045 E-3$ & $-1.423 E-3$ & $-4.674 E+0$ & $-7.027 E+2$ & $-2.140 E-1$ \\
\hline 10.1 & $2.906 E-3$ & $-1.347 E-3$ & $-4.680 E+0$ & $-7.426 E+2$ & $-2.137 E-1$ \\
\hline 10.2 & $2.775 E-3$ & $-1.275 E-3$ & $-4.686 E+0$ & $-7.843 E+2$ & $-2.134 E-1$ \\
\hline 10.3 & $2.651 E-3$ & $-1.208 E-3$ & $-4.692 E+0$ & $-8.281 E+2$ & $-2.131 E-1$ \\
\hline 10.4 & $2.534 E-3$ & $-1.144 E-3$ & $-4.697 E+0$ & $-8.739 E+2$ & $-2.129 E-1$ \\
\hline
\end{tabular}


Table 4. Sensitivity coefficients for $R=p_{t_{2}} / p_{t_{1}} \quad$ (Continued) $\gamma=1.40$

\begin{tabular}{|c|c|c|c|c|c|}
\hline $\mathrm{M}_{\infty}$ & $\mathbf{R}$ & $\frac{\partial R}{\partial M_{\infty}}$ & $\frac{M_{\infty}}{R} \frac{\partial R}{\partial M_{\infty}}$ & $\frac{\partial \mathrm{M}_{\infty}}{\partial \mathrm{R}}$ & $\frac{R}{M_{\infty}} \frac{\partial M_{\infty}}{\partial R}$ \\
\hline 10.5 & $2.422 E-3$ & $-1.085 E-3$ & $-4.703 E+0$ & $-9.218 E+2$ & $-2.126 E-1$ \\
\hline 10.6 & $2.317 E-3$ & $-1.029 E-3$ & $-4.708 E+0$ & $-9.719 E+2$ & $-2.124 \mathrm{E}-1$ \\
\hline 10.7 & $2.216 E-3$ & $-9.763 E-4$ & $-4.713 E+0$ & $-1.024 E+3$ & $-2.122 E-1$ \\
\hline 10.8 & $2.121 E-3$ & $-9.267 E-4$ & $-4.718 E+0$ & $-1.079 E+3$ & $-2.119 E-1$ \\
\hline 10.9 & $2.031 E-3$ & $-8.800 E-4$ & $-4.723 E+0$ & $-1.136 E+3$ & $-2.117 E-1$ \\
\hline 11.0 & $1.945 \mathrm{E}-3$ & $-8.360 E-4$ & $-4.728 E+0$ & $-1.196 E+3$ & $-2.115 \mathrm{E}-1$ \\
\hline 11.1 & $1.864 E-3$ & $-7.946 E-4$ & $-4.733 E+0$ & $-1.259 E+3$ & $-2.113 E-1$ \\
\hline 11.2 & $1.786 \mathrm{E}-3$ & $-7.555 E-4$ & $-4.737 E+0$ & $-1.324 E+3$ & $-2.111 \mathrm{E}-1$ \\
\hline 11.3 & $1.712 E-3$ & $-7.186 E-4$ & $-4.742 E+0$ & $-1.392 E+3$ & $-2.109 E-1$ \\
\hline 11.4 & $1.642 E-3$ & $-6.837 E-4$ & $-4.746 E+0$ & $-1.463 E+3$ & $-2.107 \mathrm{E}-1$ \\
\hline 11.5 & $1.576 E-3$ & $-6.508 E-4$ & $-4.750 E+0$ & $-1.536 \mathrm{E}+3$ & $-2.105 \mathrm{E}-1$ \\
\hline 11.6 & $1.512 E-3$ & $-6.198 E-4$ & $-4.755 E+0$ & $-1.614 E+3$ & $-2.103 E-1$ \\
\hline 11.7 & $1.452 E-3$ & $-5.904 E-4$ & $-4.759 E+0$ & $-1.694 E+3$ & $-2.101 \mathrm{E}-1$ \\
\hline 11.8 & $1.394 E-3$ & $-5.626 E-4$ & $-4.762 E+0$ & $-1.777 E+3$ & $-2.100 E-1$ \\
\hline 11.9 & $1.339 E-3$ & $-5.363 E-4$ & $-4.766 E+0$ & $-1.865 E+3$ & $-2.098 E-1$ \\
\hline 12.0 & $1.287 E-3$ & $-5.114 \mathrm{E}-4$ & $-4.770 E+0$ & $-1.955 E+3$ & $-2.096 E-1$ \\
\hline 12.1 & $1.237 E-3$ & $-4.879 E-4$ & $-4.774 E+0$ & $-2.050 E+3$ & $-2.095 E-1$ \\
\hline 12.2 & $1.189 E-3$ & $-4.656 \mathrm{E}-4$ & $-4.777 E+0$ & $-2.148 E+3$ & $-2.093 E-1$ \\
\hline 12.3 & $1.144 \mathrm{E}-3$ & $-4.445 E-4$ & $-4.781 E+0$ & $-2.250 E+3$ & $-2.092 E-1$ \\
\hline 12.4 & $1.100 \mathrm{E}-3$ & $-4.244 E-4$ & $-4.784 E+0$ & $-2.356 E+3$ & $-2.090 E-1$ \\
\hline 12.5 & $1.059 E-3$ & $-4.054 E-4$ & $-4.788 E+0$ & $-2.466 E+3$ & $-2.089 E-1$ \\
\hline 12.6 & $1.019 E-3$ & $-3.874 E-4$ & $-4.791 E+0$ & $-2.581 E+3$ & $-2.087 E-1$ \\
\hline 12.7 & $9.811 E-4$ & $-3.703 E-4$ & $-4.794 E+0$ & $-2.700 E+3$ & $-2.086 E-1$ \\
\hline 12.8 & $9.449 E-4$ & $-3.541 E-4$ & $-4.797 E+0$ & $-2.824 E+3$ & $-2.085 E-1$ \\
\hline 12.9 & $9.102 E-4$ & $-3.387 E-4$ & $-4.800 E+0$ & $-2.953 E+3$ & $-2.083 E-1$ \\
\hline 13.0 & $8.771 E-4$ & $-3.241 E-4$ & $-4.803 E+0$ & $-3.086 E+3$ & $-2.082 E-1$ \\
\hline 13.1 & $8.454 E-4$ & $-3.101 E-4$ & $-4.806 \mathrm{E}+0$ & $-3.224 E+3$ & $-2.081 E-1$ \\
\hline 13.2 & $8.150 E-4$ & $-2.969 \mathrm{E}-4$ & $-4.809 E+0$ & $-3.368 E+3$ & $-2.080 E-1$ \\
\hline 13.3 & $7.860 \mathrm{E}-4$ & $-2.843 E-4$ & $-4.812 E+0$ & $-3.517 E+3$ & $-2.078 \mathrm{E}-1$ \\
\hline 13.4 & $7.581 E-4$ & $-2.724 E-4$ & $-4.814 E+0$ & $-3.671 E+3$ & $-2.077 E-1$ \\
\hline 13.5 & $7.315 \mathrm{E}-4$ & $-2.610 \mathrm{E}-4$ & $-4.817 E+0$ & $-3.831 E+3$ & $-2.076 E-1$ \\
\hline 13.6 & $7.059 E-4$ & $-2.502 E-4$ & $-4.820 E+0$ & $-3.997 E+3$ & $-2.075 E-1$ \\
\hline 13.7 & $6.814 \mathrm{E}-4$ & $-2.399 E-4$ & $-4.822 E+0$ & $-4.169 E+3$ & $-2.074 E-1$ \\
\hline 13.8 & $6.579 E-4$ & $-2.300 E-4$ & $-4.825 E+0$ & $-4.347 E+3$ & $-2.073 E-1$ \\
\hline 13.9 & $6.354 \mathrm{E}-4$ & $-2.207 E-4$ & $-4.827 E+0$ & $-4.532 E+3$ & $-2.072 E-1$ \\
\hline
\end{tabular}


Table 4. Sensitivity coefficients for $R=p_{t_{2}} / p_{t_{1}} \quad$ (Continued) $\gamma=1.40$

\begin{tabular}{|c|c|c|c|c|c|}
\hline$M_{\infty}$ & $R$ & $\frac{\partial R}{\partial M_{\infty}}$ & $\frac{M_{\infty}}{R} \frac{\partial R}{\partial M_{\infty}}$ & $\frac{\partial M_{\infty}}{\partial R}$ & $\frac{R}{M_{\infty}} \frac{\partial M_{\infty}}{\partial R}$ \\
\hline \hline 14.0 & $6.138 E-4$ & $-2.117 E-4$ & $-4.830 E+0$ & $-4.723 E+3$ & $-2.071 E-1$ \\
14.1 & $5.931 E-4$ & $-2.032 E-4$ & $-4.832 E+0$ & $-4.921 E+3$ & $-2.070 E-1$ \\
14.2 & $5.731 E-4$ & $-1.951 E-4$ & $-4.834 E+0$ & $-5.125 E+3$ & $-2.069 E-1$ \\
14.3 & $5.540 E-4$ & $-1.874 E-4$ & $-4.836 E+0$ & $-5.337 E+3$ & $-2.068 E-1$ \\
14.4 & $5.356 E-4$ & $-1.800 E-4$ & $-4.839 E+0$ & $-5.556 E+3$ & $-2.067 E-1$ \\
& & & & & \\
14.5 & $5.180 E-4$ & $-1.729 E-4$ & $-4.841 E+0$ & $-5.783 E+3$ & $-2.066 E-1$ \\
14.6 & $5.011 E-4$ & $-1.662 E-4$ & $-4.843 E+0$ & $-6.017 E+3$ & $-2.065 E-1$ \\
14.7 & $4.848 E-4$ & $-1.598 E-4$ & $-4.845 E+0$ & $-6.259 E+3$ & $-2.064 E-1$ \\
14.8 & $4.691 E-4$ & $-1.536 E-4$ & $-4.847 E+0$ & $-6.509 E+3$ & $-2.063 E-1$ \\
14.9 & $4.540 E-4$ & $-1.478 E-4$ & $-4.849 E+0$ & $-6.768 E+3$ & $-2.062 E-1$ \\
15.0 & $4.395 E-4$ & $-1.421 E-4$ & $-4.851 E+0$ & $-7.035 E+3$ & $-2.061 E-1$ \\
\hline
\end{tabular}


Table 5. Sensitivity coefficients for $R=p_{\infty} / p_{t_{2}}$ $\gamma=1.40$

\begin{tabular}{|c|c|c|c|c|c|}
\hline $\mathbf{M}_{\infty}$ & $\mathbf{R}$ & $\frac{\partial \mathrm{R}}{\partial \mathrm{M}_{\infty}}$ & $\frac{\mathrm{M}_{\infty}}{\mathrm{R}} \frac{\partial \mathrm{R}}{\partial \mathrm{M}_{\infty}}$ & $\frac{\partial \mathrm{M}_{\infty}}{\partial \mathrm{R}}$ & $\frac{R}{M_{\infty}} \frac{\partial M_{\infty}}{\partial R}$ \\
\hline 0.1 & $9.930 E-1$ & $-1.387 E-1$ & $-1.397 E-2$ & $-7.207 E+0$ & $-7.157 E+1$ \\
\hline 0.2 & $9.725 E-1$ & $-2.701 E-1$ & $-5.556 E-2$ & $-3.702 E+0$ & $-1.800 E+1$ \\
\hline 0.3 & $9.395 \mathrm{E}-1$ & $-3.876 E-1$ & $-1.238 E-1$ & $-2.580 E+0$ & $-8.079 E+0$ \\
\hline 0.4 & $8.956 E-1$ & $-4.860 E-1$ & $-2.171 E-1$ & $-2.058 E+0$ & $-4.607 E+0$ \\
\hline 0.5 & $8.430 E-1$ & $-5.620 E-1$ & $-3.333 E-1$ & $-1.779 E+0$ & $-3.000 E+0$ \\
\hline 0.6 & $7.840 E-1$ & $-6.143 E-1$ & $-4.701 E-1$ & $-1.628 E+0$ & $-2.127 E+0$ \\
\hline 0.7 & $7.209 E-1$ & $-6.435 E-1$ & $-6.248 E-1$ & $-1.554 E+0$ & $-1.601 E+0$ \\
\hline 0.8 & $6.560 \mathrm{E}-1$ & $-6.514 E-1$ & $-7.943 E-1$ & $-1.535 E+0$ & $-1.259 E+0$ \\
\hline 0.9 & $5.913 E-1$ & $-6.411 E-1$ & $-9.759 E-1$ & $-1.560 E+0$ & $-1.025 E+0$ \\
\hline 1.0 & $5.283 E-1$ & $-6.163 E-1$ & $-1.167 E+0$ & $-1.623 E+0$ & $-8.571 E-1$ \\
\hline 1.1 & $4.689 E-1$ & $-5.672 E-1$ & $-1.331 E+0$ & $-1.763 E+0$ & $-7.515 E-1$ \\
\hline 1.2 & $4.154 \mathrm{E}-1$ & $-5.017 E-1$ & $-1.449 E+0$ & $-1.993 E+0$ & $-6.900 \mathrm{E}-1$ \\
\hline 1.3 & $3.685 \mathrm{E}-1$ & $-4.361 E-1$ & $-1.538 E+0$ & $-2.293 E+0$ & $-6.501 E-1$ \\
\hline 1.4 & $3.280 E-1$ & $-3.764 E-1$ & $-1.607 E+0$ & $-2.657 E+0$ & $-6.223 E-1$ \\
\hline 1.5 & $2.930 E-1$ & $-3.244 E-1$ & $-1.661 E+0$ & $-3.082 E+0$ & $-6.020 E-1$ \\
\hline 1.6 & $2.628 E-1$ & $-2.800 E-1$ & $-1.704 E+0$ & $-3.572 E+0$ & $-5.867 E-1$ \\
\hline 1.7 & $2.368 E-1$ & $-2.423 E-1$ & $-1.740 E+0$ & $-4.127 E+0$ & $-5.747 E-1$ \\
\hline 1.8 & $2.142 \mathrm{E}-1$ & $-2.105 E-1$ & $-1.769 E+0$ & $-4.750 E+0$ & $-5.652 E-1$ \\
\hline 1.9 & $1.945 E-1$ & $-1.836 \mathrm{E}-1$ & $-1.794 E+0$ & $-5.446 E+0$ & $-5.574 E-1$ \\
\hline 2.0 & $1.773 \mathrm{E}-1$ & $-1.609 E-1$ & $-1.815 E+0$ & $-6.216 E+0$ & $-5.510 E-1$ \\
\hline 2.1 & $1.622 E-1$ & $-1.415 E-1$ & $-1.833 E+0$ & $-7.065 E+0$ & $-5.457 E-1$ \\
\hline 2.2 & $1.489 E-1$ & $-1.251 E-1$ & $-1.848 E+0$ & $-7.996 E+0$ & $-5.411 E-1$ \\
\hline 2.3 & $1.371 E-1$ & $-1.109 E-1$ & $-1.861 E+0$ & $-9.013 E+0$ & $-5.373 E-1$ \\
\hline 2.4 & $1.266 \mathrm{E}-1$ & $-9.882 E-2$ & $-1.873 E+0$ & $-1.012 E+1$ & $-5.339 E-1$ \\
\hline 2.5 & $1.173 E-1$ & $-8.834 E-2$ & $-1.883 E+0$ & $-1.132 E+1$ & $-5.311 E-1$ \\
\hline 2.6 & $1.089 E-1$ & $-7.926 E-2$ & $-1.892 E+0$ & $-1.262 E+1$ & $-5.285 E-1$ \\
\hline 2.7 & $1.014 E-1$ & $-7.135 E-2$ & $-1.900 E+0$ & $-1.401 E+1$ & $-5.263 E-1$ \\
\hline 2.8 & $9.461 E-2$ & $-6.444 E-2$ & $-1.907 E+0$ & $-1.552 E+1$ & $-5.243 E-1$ \\
\hline 2.9 & $8.848 E-2$ & $-5.838 E-2$ & $-1.914 E+0$ & $-1.713 E+1$ & $-5.226 E-1$ \\
\hline 3.0 & $8.291 E-2$ & $-5.305 E-2$ & $-1.919 E+0$ & $-1.885 E+1$ & $-5.210 E-1$ \\
\hline 3.1 & $7.785 E-2$ & $-4.833 E-2$ & $-1.925 E+0$ & $-2.069 E+1$ & $-5.196 \mathrm{E}-1$ \\
\hline 3.2 & $7.323 E-2$ & $-4.415 E-2$ & $-1.929 E+0$ & $-2.265 E+1$ & $-5.183 E-1$ \\
\hline 3.3 & $6.900 \mathrm{E}-2$ & $-4.043 E-2$ & $-1.934 E+0$ & $-2.473 E+1$ & $-5.172 E-1$ \\
\hline 3.4 & $6.513 E-2$ & $-3.711 E-2$ & $-1.937 E+0$ & $-2.694 E+1$ & $-5.161 \mathrm{E}-1$ \\
\hline
\end{tabular}


Table 5. Sensitivity coefficients for $R=p_{\infty} / p_{t_{2}} \quad$ (Continued) $\gamma=1.40$

\begin{tabular}{|c|c|c|c|c|c|}
\hline$M_{\infty}$ & $\mathrm{R}$ & $\frac{\partial R}{\partial M_{\infty}}$ & $\frac{M_{\infty}}{R} \frac{\partial R}{\partial M_{\infty}}$ & $\frac{\partial M_{\infty}}{\partial R}$ & $\frac{R}{M_{\infty}} \frac{\partial M_{\infty}}{\partial R}$ \\
\hline 3.5 & 6.157E-2 & $-3.414 \mathrm{E}-2$ & $-1.941 E+0$ & $-2.929 E+1$ & $-5.152 E-1$ \\
\hline 3.6 & $5.829 E-2$ & $-3.148 E-2$ & $-1.944 E+0$ & $-3.177 E+1$ & $-5.143 E-1$ \\
\hline 3.7 & $5.526 E-2$ & $-2.908 E-2$ & $-1.947 E+0$ & $-3.438 E+1$ & $-5.135 E-1$ \\
\hline 3.8 & $5.247 E-2$ & $-2.692 E-2$ & $-1.950 E+0$ & $-3.714 E+1$ & $-5.128 E-1$ \\
\hline 3.9 & 4.987E-2 & $-2.497 E-2$ & $-1.953 E+0$ & $-4.005 E+1$ & $-5.121 E-1$ \\
\hline 4.0 & 4.747E-2 & $-2.320 \mathrm{E}-2$ & $-1.955 E+0$ & $-4.311 E+1$ & $-5.115 \mathrm{E}-1$ \\
\hline 4.1 & $4.523 E-2$ & $-2.159 E-2$ & $-1.957 E+0$ & $-4.632 E+1$ & $-5.109 E-1$ \\
\hline 4.2 & $4.314 \mathrm{E}-2$ & $-2.012 E-2$ & $-1.959 E+0$ & $-4.969 E+1$ & $-5.104 \mathrm{E}-1$ \\
\hline 4.3 & $4.120 E-2$ & $-1.879 \mathrm{E}-2$ & $-1.961 E+0$ & $-5.322 E+1$ & $-5.099 E-1$ \\
\hline 4.4 & $3.938 E-2$ & $-1.757 E-2$ & $-1.963 E+0$ & $-5.692 E+1$ & $-5.095 E-1$ \\
\hline 4.5 & $3.768 E-2$ & $-1.645 \mathrm{E}-2$ & $-1.964 E+0$ & $-6.079 E+1$ & $-5.090 E-1$ \\
\hline 4.6 & $3.609 E-2$ & $-1.542 E-2$ & $-1.966 E+0$ & $-6.483 E+1$ & $-5.086 E-1$ \\
\hline 4.7 & $3.459 \mathrm{E}-2$ & $-1.448 \mathrm{E}-2$ & $-1.967 E+0$ & $-6.906 E+1$ & $-5.083 E-1$ \\
\hline 4.8 & $3.319 E-2$ & $-1.361 E-2$ & $-1.969 E+0$ & $-7.346 E+1$ & $-5.079 E-1$ \\
\hline 4.9 & $3.187 E-2$ & $-1.281 \mathrm{E}-2$ & $-1.970 E+0$ & $-7.805 E+1$ & $-5.076 E-1$ \\
\hline 5.0 & $3.062 E-2$ & $-1.207 E-2$ & $-1.971 E+0$ & $-8.282 E+1$ & $-5.073 E-1$ \\
\hline 5.1 & $2.945 E-2$ & $-1.139 E-2$ & $-1.972 E+0$ & $-8.779 E+1$ & $-5.070 E-1$ \\
\hline 5.2 & $2.834 \mathrm{E}-2$ & $-1.076 \mathrm{E}-2$ & $-1.973 E+0$ & $-9.296 E+1$ & $-5.067 \mathrm{E}-1$ \\
\hline 5.3 & $2.730 \mathrm{E}-2$ & $-1.017 E-2$ & $-1.974 E+0$ & $-9.833 E+1$ & $-5.063 \mathrm{E}-1$ \\
\hline 5.4 & 2.631E-2 & $-9.624 \mathrm{E}-3$ & $-1.975 E+0$ & $-1.039 E+2$ & $-5.062 E-1$ \\
\hline 5.5 & $2.537 E-2$ & $-9.117 E-3$ & $-1.976 \mathrm{E}+0$ & $-1.097 E+2$ & $-5.060 E-1$ \\
\hline 5.6 & $2.448 E-2$ & $-8.645 E-3$ & $-1.977 E+0$ & $-1.157 E+2$ & $-5.058 E-1$ \\
\hline 5.7 & $2.364 E-2$ & $-8.204 E-3$ & $-1.978 E+0$ & $-1.219 E+2$ & $-5.056 E-1$ \\
\hline 5.8 & $2.284 \mathrm{E}-2$ & $-7.793 E-3$ & $-1.979 E+0$ & $-1.283 E+2$ & $-5.054 E-1$ \\
\hline 5.9 & $2.208 E-2$ & $-7.409 E-3$ & $-1.979 E+0$ & $-1.350 E+2$ & $-5.052 \mathrm{E}-1$ \\
\hline 6.0 & $2.136 \mathrm{E}-2$ & $-7.049 E-3$ & $-1.980 E+0$ & $-1.419 E+2$ & $-5.050 E-1$ \\
\hline 6.1 & $2.067 E-2$ & $-6.713 E-3$ & $-1.981 E+0$ & $-1.490 E+2$ & $-5.049 E-1$ \\
\hline 6.2 & $2.002 E-2$ & $-6.397 E-3$ & $-1.981 E+0$ & $-1.563 E+2$ & $-5.047 E-1$ \\
\hline 6.3 & $1.939 E-2$ & $-6.101 E-3$ & $-1.982 E+0$ & $-1.639 E+2$ & $-5.046 E-1$ \\
\hline 6.4 & $1.880 E-2$ & $-5.823 E-3$ & $-1.983 E+0$ & $-1.717 E+2$ & $-5.044 E-1$ \\
\hline 6.5 & $1.823 E-2$ & $-5.561 E-3$ & $-1.983 E+0$ & $-1.798 E+2$ & $-5.043 E-1$ \\
\hline 6.6 & $1.768 \mathrm{E}-2$ & $-5.315 E-3$ & $-1.984 E+0$ & $-1.882 E+2$ & $-5.041 E-1$ \\
\hline 6.7 & $1.716 \mathrm{E}-2$ & $-5.083 E-3$ & $-1.984 E+0$ & $-1.967 E+2$ & $-5.040 E-1$ \\
\hline 6.8 & $1.667 \mathrm{E}-2$ & $-4.864 E-3$ & $-1.985 E+0$ & $-2.056 E+2$ & $-5.039 E-1$ \\
\hline 6.9 & $1.619 \mathrm{E}-2$ & $-4.658 E-3$ & $-1.985 E+0$ & $-2.147 E+2$ & $-5.038 E-1$ \\
\hline
\end{tabular}


Table 5. Sensitivity coefficients for $R=p_{\infty} / p_{t_{2}}$ (Continued) $\gamma=1.40$

\begin{tabular}{|c|c|c|c|c|c|}
\hline $\mathbf{M}_{\infty}$ & $\mathbf{R}$ & $\frac{\partial R}{\partial M_{\infty}}$ & $\frac{\mathbf{M}_{\infty}}{\mathrm{R}} \frac{\partial \mathrm{R}}{\partial \mathbf{M}_{\infty}}$ & $\frac{\partial M_{\infty}}{\partial R}$ & $\frac{R}{M_{\infty}} \frac{\partial M_{\infty}}{\partial R}$ \\
\hline 7.0 & 1.573E-2 & $-4.463 E-3$ & $-1.985 E+0$ & $-2.241 E+2$ & $-5.037 \mathrm{E}-1$ \\
\hline 7.1 & 1.530E-2 & $-4.279 E-3$ & $-1.986 E+0$ & $-2.337 E+2$ & $-5.036 E-1$ \\
\hline 7.2 & $1.488 E-2$ & $-4.104 E-3$ & $-1.986 E+0$ & $-2.436 E+2$ & $-5.035 E-1$ \\
\hline 7.3 & $1.448 E-2$ & $-3.940 E-3$ & $-1.987 E+0$ & $-2.538 E+2$ & $-5.034 E-1$ \\
\hline 7.4 & $1.409 E-2$ & $-3.783 E-3$ & $-1.987 E+0$ & $-2.643 E+2$ & $-5.033 E-1$ \\
\hline 7.5 & $1.372 E-2$ & $-3.635 E-3$ & $-1.987 E+0$ & $-2.751 E+2$ & $-5.032 E-1$ \\
\hline 7.6 & $1.336 \mathrm{E}-2$ & $-3.495 E-3$ & $-1.988 E+0$ & $-2.861 E+2$ & $-5.031 E-1$ \\
\hline 7.7 & $1.302 E-2$ & $-3.362 E-3$ & $-1.988 E+0$ & $-2.975 E+2$ & $-5.030 E-1$ \\
\hline 7.8 & $1.269 E-2$ & $-3.235 E-3$ & $-1.988 E+0$ & $-3.091 E+2$ & $-5.030 E-1$ \\
\hline 7.9 & $1.237 E-2$ & $-3.115 E-3$ & $-1.989 E+0$ & $-3.211 E+2$ & $-5.029 E-1$ \\
\hline 8.0 & $1.207 E-2$ & $-3.000 E-3$ & $-1.989 E+0$ & $-3.333 E+2$ & $-5.028 E-1$ \\
\hline 8.1 & $1.177 E-2$ & $-2.891 E-3$ & $-1.989 E+0$ & $-3.459 E+2$ & $-5.027 E-1$ \\
\hline 8.2 & $1.149 E-2$ & $-2.787 E-3$ & $-1.989 E+0$ & $-3.588 E+2$ & $-5.027 E-1$ \\
\hline 8.3 & $1.122 \mathrm{E}-2$ & $-2.689 E-3$ & $-1.990 E+0$ & $-3.720 E+2$ & $-5.026 E-1$ \\
\hline 8.4 & $1.095 \mathrm{E}-2$ & $-2.594 E-3$ & $-1.990 E+0$ & $-3.855 E+2$ & $-5.025 E-1$ \\
\hline 8.5 & $1.070 \mathrm{E}-2$ & $-2.504 E-3$ & $-1.990 E+0$ & $-3.993 E+2$ & $-5.025 E-1$ \\
\hline 8.6 & $1.045 \mathrm{E}-2$ & $-2.419 E-3$ & $-1.990 E+0$ & $-4.135 E+2$ & $-5.024 E-1$ \\
\hline 8.7 & $1.021 E-2$ & $-2.337 E-3$ & $-1.991 E+0$ & $-4.280 E+2$ & $-5.024 E-1$ \\
\hline 8.8 & $9.983 E-3$ & $-2.258 E-3$ & $-1.991 E+0$ & $-4.428 E+2$ & $-5.023 E-1$ \\
\hline 8.9 & $9.761 E-3$ & $-2.184 \mathrm{E}-3$ & $-1.991 E+0$ & $-4.580 E+2$ & $-5.023 E-1$ \\
\hline 9.0 & $9.546 E-3$ & $-2.112 E-3$ & $-1.991 E+0$ & $-4.735 E+2$ & $-5.022 E-1$ \\
\hline 9.1 & $9.338 E-3$ & $-2.044 \mathrm{E}-3$ & $-1.991 E+0$ & $-4.893 E+2$ & $-5.022 E-1$ \\
\hline 9.2 & $9.137 E-3$ & $-1.978 E-3$ & $-1.992 E+0$ & $-5.056 E+2$ & $-5.021 E-1$ \\
\hline 9.3 & $8.943 E-3$ & $-1.915 E-3$ & $-1.992 E+0$ & $-5.221 E+2$ & $-5.021 E-1$ \\
\hline 9.4 & $8.754 E-3$ & $-1.855 E-3$ & $-1.992 E+0$ & $-5.391 E+2$ & $-5.020 E-1$ \\
\hline 9.5 & $8.572 E-3$ & $-1.797 E-3$ & $-1.992 E+0$ & $-5.564 E+2$ & $-5.020 E-1$ \\
\hline 9.6 & $8.395 E-3$ & $-1.742 E-3$ & $-1.992 E+0$ & $-5.740 E+2$ & $-5.019 E-1$ \\
\hline 9.7 & $8.223 E-3$ & $-1.689 E-3$ & $-1.992 E+0$ & $-5.920 E+2$ & $-5.019 E-1$ \\
\hline 9.8 & $8.057 E-3$ & $-1.638 E-3$ & $-1.993 E+0$ & $-6.105 E+2$ & $-5.019 E-1$ \\
\hline 9.9 & $7.895 E-3$ & $-1.589 E-3$ & $-1.993 E+0$ & $-6.292 E+2$ & $-5.018 E-1$ \\
\hline 10.0 & $7.739 E-3$ & $-1.542 E-3$ & $-1.993 E+0$ & $-6.484 E+2$ & $-5.018 E-1$ \\
\hline 10.1 & $7.587 E-3$ & $-1.497 \mathrm{E}-3$ & $-1.993 E+0$ & $-6.680 E+2$ & $-5.018 E-1$ \\
\hline 10.2 & $7.439 E-3$ & $-1.454 \mathrm{E}-3$ & $-1.993 E+0$ & $-6.879 E+2$ & $-5.017 E-1$ \\
\hline 10.3 & $7.296 \mathrm{E}-3$ & $-1.412 E-3$ & $-1.993 E+0$ & $-7.082 E+2$ & $-5.017 E-1$ \\
\hline 10.4 & $7.157 E-3$ & $-1.372 E-3$ & $-1.993 E+0$ & $-7.290 E+2$ & $-5.017 E-1$ \\
\hline
\end{tabular}


Table 5. Sensitivity coefficients for $\mathrm{R}=\mathrm{p}_{\infty} / \mathrm{p}_{\mathrm{t}_{2}} \quad$ (Continued) $\gamma=1.40$

\begin{tabular}{|c|c|c|c|c|c|}
\hline $\mathbf{M}_{\infty}$ & $\mathbf{R}$ & $\frac{\partial R}{\partial M_{\infty}}$ & $\frac{M_{\infty}}{R} \frac{\partial R}{\partial M_{\infty}}$ & $\frac{\partial \mathrm{M}_{\infty}}{\partial \mathrm{R}}$ & $\frac{R}{M_{\infty}} \frac{\partial M_{\infty}}{\partial R}$ \\
\hline 10.5 & $7.022 E-3$ & $-1.333 E-3$ & $-1.994 E+0$ & $-7.501 E+2$ & $-5.016 \mathrm{E}-1$ \\
\hline 10.6 & $6.890 E-3$ & $-1.296 E-3$ & $-1.994 E+0$ & $-7.717 E+2$ & $-5.016 \mathrm{E}-1$ \\
\hline 10.7 & $6.763 E-3$ & $-1.260 E-3$ & $-1.994 E+0$ & $-7.936 E+2$ & $-5.016 \mathrm{E}-1$ \\
\hline 10.8 & $6.638 E-3$ & $-1.226 \mathrm{E}-3$ & $-1.994 E+0$ & $-8.160 E+2$ & $-5.015 E-1$ \\
\hline 10.9 & $6.517 E-3$ & $-1.192 \mathrm{E}-3$ & $-1.994 E+0$ & $-8.387 E+2$ & $-5.015 E-1$ \\
\hline 11.0 & $6.400 E-3$ & $-1.160 \mathrm{E}-3$ & $-1.994 E+0$ & $-8.620 E+2$ & $-5.015 E-1$ \\
\hline 11.1 & $6.285 E-3$ & $-1.129 E-3$ & $-1.994 E+0$ & $-8.856 E+2$ & $-5.015 E-1$ \\
\hline 11.2 & $6.174 \mathrm{E}-3$ & $-1.099 \mathrm{E}-3$ & $-1.994 E+0$ & $-9.096 E+2$ & $-5.014 E-1$ \\
\hline 11.3 & $6.065 E-3$ & $-1.071 E-3$ & $-1.994 E+0$ & $-9.341 E+2$ & $-5.014 E-1$ \\
\hline 11.4 & $5.960 E-3$ & $-1.043 E-3$ & $-1.994 E+0$ & $-9.591 E+2$ & $-5.014 \mathrm{E}-1$ \\
\hline 11.5 & $5.857 \mathrm{E}-3$ & $-1.016 \mathrm{E}-3$ & $-1.995 E+0$ & $-9.844 E+2$ & $-5.014 E-1$ \\
\hline 11.6 & $5.757 E-3$ & $-9.899 \mathrm{E}-4$ & $-1.995 \mathrm{E}+0$ & $-1.010 E+3$ & $-5.013 E-1$ \\
\hline 11.7 & $5.659 E-3$ & $-9.648 E-4$ & $-1.995 E+0$ & $-1.036 E+3$ & $-5.013 E-1$ \\
\hline 11.8 & $5.564 \mathrm{E}-3$ & $-9.406 E-4$ & $-1.995 E+0$ & $-1.063 E+3$ & $-5.013 E-1$ \\
\hline 11.9 & $5.471 E-3$ & $-9.171 E-4$ & $-1.995 E+0$ & $-1.090 E+3$ & $-5.013 E-1$ \\
\hline 12.0 & $5.380 E-3$ & $-8.945 E-4$ & $-1.995 E+0$ & $-1.118 E+3$ & $-5.012 E-1$ \\
\hline 12.1 & $5.292 \mathrm{E}-3$ & $-8.725 E-4$ & $-1.995 E+0$ & $-1.146 E+3$ & $-5.012 E-1$ \\
\hline 12.2 & $5.206 \mathrm{E}-3$ & $-8.513 E-4$ & $-1.995 E+0$ & $-1.175 E+3$ & $-5.012 E-1$ \\
\hline 12.3 & $5.121 E-3$ & $-8.308 E-4$ & $-1.995 E+0$ & $-1.204 E+3$ & $-5.012 E-1$ \\
\hline 12.4 & $5.039 E-3$ & $-8.109 E-4$ & $-1.995 E+0$ & $-1.233 E+3$ & $-5.012 \mathrm{E}-1$ \\
\hline 12.5 & $4.959 E-3$ & $-7.917 E-4$ & $-1.995 E+0$ & $-1.263 E+3$ & $-5.011 E-1$ \\
\hline 12.6 & $4.881 \mathrm{E}-3$ & $-7.730 E-4$ & $-1.995 E+0$ & $-1.294 E+3$ & $-5.011 \mathrm{E}-1$ \\
\hline 12.7 & $4.805 E-3$ & $-7.550 E-4$ & $-1.996 E+0$ & $-1.325 E+3$ & $-5.011 \mathrm{E}-1$ \\
\hline 12.8 & $4.730 \mathrm{E}-3$ & $-7.375 E-4$ & $-1.996 E+0$ & $-1.356 E+3$ & $-5.011 E-1$ \\
\hline 12.9 & $4.657 \mathrm{E}-3$ & $-7.205 E-4$ & $-1.996 \mathrm{E}+0$ & $-1.388 E+3$ & $-5.011 E-1$ \\
\hline 13.0 & $4.586 E-3$ & $-7.040 E-4$ & $-1.996 E+0$ & $-1.420 E+3$ & $-5.011 E-1$ \\
\hline 13.1 & $4.516 \mathrm{E}-3$ & $-6.881 E-4$ & $-1.996 E+0$ & $-1.453 E+3$ & $-5.010 E-1$ \\
\hline 13.2 & $4.448 E-3$ & $-6.726 E-4$ & $-1.996 E+0$ & $-1.487 E+3$ & $-5.010 E-1$ \\
\hline 13.3 & $4.382 E-3$ & $-6.576 E-4$ & $-1.996 E+0$ & $-1.521 E+3$ & $-5.010 \mathrm{E}-1$ \\
\hline 13.4 & $4.317 E-3$ & $-6.430 E-4$ & $-1.996 E+0$ & $-1.555 E+3$ & $-5.010 E-1$ \\
\hline 13.5 & $4.253 E-3$ & $-6.289 E-4$ & $-1.996 E+0$ & $-1.590 E+3$ & $-5.010 E-1$ \\
\hline 13.6 & $4.191 E-3$ & $-6.151 E-4$ & $-1.996 E+0$ & $-1.626 E+3$ & $-5.010 E-1$ \\
\hline 13.7 & $4.130 \mathrm{E}-3$ & $-6.018 E-4$ & $-1.996 E+0$ & $-1.662 E+3$ & $-5.010 E-1$ \\
\hline 13.8 & $4.071 E-3$ & $-5.888 E-4$ & $-1.996 E+0$ & $-1.698 E+3$ & $-5.009 E-1$ \\
\hline 13.9 & $4.012 E-3$ & $-5.762 E-4$ & $-1.996 E+0$ & $-1.735 E+3$ & $-5.009 E-1$ \\
\hline
\end{tabular}


Table 5. Sensitivity coefficients for $R=\mathrm{p}_{\infty} / \mathrm{p}_{\mathrm{t}_{2}} \quad$ (Continued) $\gamma=1.40$

\begin{tabular}{|c|c|c|c|c|c|}
\hline$M_{\infty}$ & $R$ & $\frac{\partial R}{\partial M_{\infty}}$ & $\frac{M_{\infty}}{R} \frac{\partial R}{\partial M_{\infty}}$ & $\frac{\partial M_{\infty}}{\partial R}$ & $\frac{R}{M_{\infty}} \frac{\partial M_{\infty}}{\partial R}$ \\
\hline \hline 14.0 & $3.955 E-3$ & $-5.640 E-4$ & $-1.996 E+0$ & $-1.773 E+3$ & $-5.009 E-1$ \\
14.1 & $3.900 E-3$ & $-5.521 E-4$ & $-1.996 E+0$ & $-1.811 E+3$ & $-5.009 E-1$ \\
14.2 & $3.845 E-3$ & $-5.406 E-4$ & $-1.996 E+0$ & $-1.850 E+3$ & $-5.009 E-1$ \\
14.3 & $3.791 E-3$ & $-5.293 E-4$ & $-1.997 E+0$ & $-1.889 E+3$ & $-5.009 E-1$ \\
14.4 & $3.739 E-3$ & $-5.184 E-4$ & $-1.997 E+0$ & $-1.929 E+3$ & $-5.009 E-1$ \\
& & & & & \\
14.5 & $3.688 E-3$ & $-5.078 E-4$ & $-1.997 E+0$ & $-1.969 E+3$ & $-5.009 E-1$ \\
14.6 & $3.637 E-3$ & $-4.974 E-4$ & $-1.997 E+0$ & $-2.010 E+3$ & $-5.008 E-1$ \\
14.7 & $3.588 E-3$ & $-4.874 E-4$ & $-1.997 E+0$ & $-2.052 E+3$ & $-5.008 E-1$ \\
14.8 & $3.540 E-3$ & $-4.776 E-4$ & $-1.997 E+0$ & $-2.094 E+3$ & $-5.008 E-1$ \\
14.9 & $3.493 E-3$ & $-4.681 E-4$ & $-1.997 E+0$ & $-2.136 E+3$ & $-5.008 E-1$ \\
15.0 & $3.446 E-3$ & $-4.588 E-4$ & $-1.997 E+0$ & $-2.180 E+3$ & $-5.008 E-1$ \\
\hline
\end{tabular}


Table 6. Sensitivity coefficients for $R=A_{\infty} / A^{*}$ $\gamma=1.40$

\begin{tabular}{|c|c|c|c|c|c|}
\hline$M_{\infty}$ & $\mathbf{R}$ & $\frac{\partial R}{\partial M_{\infty}}$ & $\frac{M_{\infty}}{R} \frac{\partial R}{\partial M_{\infty}}$ & $\frac{\partial M_{\infty}}{\partial R}$ & $\frac{R}{M_{\infty}} \frac{\partial M_{\infty}}{\partial R}$ \\
\hline 0.1 & $5.822 E+0$ & $-5.752 E+1$ & $-9.880 E-1$ & $-1.738 E-2$ & $-1.012 E+0$ \\
\hline 0.2 & $2.964 E+0$ & $-1.411 E+1$ & $-9.524 E-1$ & $-7.086 \mathrm{E}-2$ & $-1.050 E+0$ \\
\hline 0.3 & $2.035 E+0$ & $-6.064 E+0$ & $-8.939 E-1$ & $-1.649 E-1$ & $-1.119 E+0$ \\
\hline 0.4 & $1.590 E+0$ & $-3.236 E+0$ & $-8.140 E-1$ & $-3.090 E-1$ & $-1.229 E+0$ \\
\hline 0.5 & $1.340 E+0$ & $-1.914 E+0$ & $-7.143 E-1$ & $-5224 E-1$ & $-1.400 E+0$ \\
\hline 0.6 & $1.188 E+0$ & $-1.182 E+0$ & $-5.970 E-1$ & $-8.458 E-1$ & $-1.675 E+0$ \\
\hline 0.7 & $1.094 E+0$ & $-7.262 E-1$ & $-4.645 E-1$ & $-1.377 E+0$ & $-2.153 E+0$ \\
\hline 0.8 & $1.038 E+0$ & $-4.142 E-1$ & $-3.191 E-1$ & $-2.414 E+0$ & $-3.133 E+0$ \\
\hline 0.9 & $1.009 E+0$ & $-1.833 E-1$ & $-1.635 E-1$ & $-5.456 E+0$ & $-6.116 E+0$ \\
\hline 1.0 & $1.000 E+0$ & $0.000 E+0$ & $0.000 E+0$ & $\infty$ & $\infty$ \\
\hline 1.1 & $1.008 E+0$ & $1.549 E-1$ & $1.691 \mathrm{E}-1$ & $6.455 E+0$ & $5.914 E+0$ \\
\hline 1.2 & $1.030 E+0$ & $2.933 E-1$ & $3.416 \mathrm{E}-1$ & $3.409 E+0$ & $2.927 E+0$ \\
\hline 1.3 & $1.066 E+0$ & $4.230 \mathrm{E}-1$ & $5.157 E-1$ & $2.364 E+0$ & $1.939 E+0$ \\
\hline 1.4 & $1.115 E+0$ & $5.492 E-1$ & $6.897 \mathrm{E}-1$ & $1.821 E+0$ & $1.450 E+0$ \\
\hline 1.5 & $1.176 \mathrm{E}+0$ & $6.760 E-1$ & $8.621 E-1$ & $1.479 E+0$ & $1.160 \mathrm{E}+0$ \\
\hline 1.6 & $1.250 E+0$ & $8.062 E-1$ & $1.032 E+0$ & $1.240 E+0$ & $9.692 E-1$ \\
\hline 1.7 & $1.338 E+0$ & $9.424 \mathrm{E}-1$ & $1.198 E+0$ & $1.061 E+0$ & $8.349 E-1$ \\
\hline 1.8 & $1.439 E+0$ & $1.087 E+0$ & $1.359 E+0$ & $9.203 E-1$ & $7.357 E-1$ \\
\hline 1.9 & $1.555 E+0$ & $1.241 E+0$ & $1.516 E+0$ & $8.060 E-1$ & $6.598 \mathrm{E}-1$ \\
\hline 2.0 & $1.687 E+0$ & $1.406 E+0$ & $1.667 E+0$ & $7.111 \mathrm{E}-1$ & $6.000 E-1$ \\
\hline 2.1 & $1.837 E+0$ & $1.585 E+0$ & $1.812 E+0$ & $6.309 E-1$ & $5.519 E-1$ \\
\hline 2.2 & $2.005 E+0$ & $1.778 E+0$ & $1.951 E+0$ & $5.624 \mathrm{E}-1$ & $5.125 E-1$ \\
\hline 2.3 & $2.193 E+0$ & $1.988 E+0$ & $2.085 E+0$ & $5.031 E-1$ & $4.797 E-1$ \\
\hline 2.4 & $2.403 E+0$ & $2.215 E+0$ & $2.212 E+0$ & $4.515 E-1$ & $4.521 E-1$ \\
\hline 2.5 & $2.637 E+0$ & $2.461 E+0$ & $2.333 E+0$ & $4.063 E-1$ & $4.286 E-1$ \\
\hline 2.6 & $2.896 E+0$ & $2.728 E+0$ & $2.449 E+0$ & $3.666 \mathrm{E}-1$ & $4.083 E-1$ \\
\hline 2.7 & $3.183 E+0$ & $3.017 E+0$ & $2.559 E+0$ & $3.315 \mathrm{E}-1$ & $3.908 E-1$ \\
\hline 2.8 & $3.500 E+0$ & $3.330 E+0$ & $2.664 E+0$ & $3.003 E-1$ & $3.754 E-1$ \\
\hline 2.9 & $3.850 E+0$ & $3.668 E+0$ & $2.763 E+0$ & $2.726 \mathrm{E}-1$ & $3.619 E-1$ \\
\hline 3.0 & $4.235 E+0$ & $4.033 E+0$ & $2.857 E+0$ & $2.480 \mathrm{E}-1$ & $3.500 E-1$ \\
\hline 3.1 & $4.657 E+0$ & $4.427 E+0$ & $2.947 E+0$ & $2.259 E-1$ & $3.394 \mathrm{E}-1$ \\
\hline 3.2 & $5.121 E+0$ & $4.851 E+0$ & $3.031 E+0$ & $2.061 \mathrm{E}-1$ & $3.299 E-1$ \\
\hline 3.3 & $5.629 E+0$ & $5.308 E+0$ & $3.112 E+0$ & $1.884 E-1$ & $3.213 E-1$ \\
\hline 3.4 & $6.184 E+0$ & $5.799 E+0$ & $3.188 E+0$ & $1.724 E-1$ & $3.136 E-1$ \\
\hline
\end{tabular}


Table 6. Sensitivity coefficients for $R=A_{\infty} / A^{*} \quad$ (Continued) $\gamma=1.40$

\begin{tabular}{|c|c|c|c|c|c|}
\hline $\mathbf{M}_{\infty}$ & $\mathbf{R}$ & $\frac{\partial R}{\partial M_{\infty}}$ & $\frac{M_{\infty}}{R} \frac{\partial R}{\partial M_{\infty}}$ & $\frac{\partial M_{\infty}}{\partial R}$ & $\frac{R}{M_{\infty}} \frac{\partial M_{\infty}}{\partial R}$ \\
\hline 3.5 & $6.790 E+0$ & $6.326 \mathrm{E}+0$ & $3.261 E+0$ & $1.581 E-1$ & $3.067 E-1$ \\
\hline 3.6 & $7.450 E+0$ & $6.891 E+0$ & $3.330 E+0$ & $1.451 \mathrm{E}-1$ & $3.003 E-1$ \\
\hline 3.7 & $8.169 E+0$ & $7.495 E+0$ & $3.395 E+0$ & $1.334 \mathrm{E}-1$ & $2.946 E-1$ \\
\hline 3.8 & $8.951 E+0$ & $8.142 E+0$ & $3.457 E+O$ & $1.228 \mathrm{E}-1$ & 2.893E-1 \\
\hline 3.9 & $9.799 E+0$ & $8.833 E+0$ & $3.516 E+0$ & $1.132 \mathrm{E}-1$ & $2.844 \mathrm{E}-1$ \\
\hline 4.0 & $1.072 E+1$ & $9.570 E+0$ & $3.571 E+0$ & $1.045 \mathrm{E}-1$ & $2.800 E-1$ \\
\hline 4.1 & $1.171 E+1$ & $1.036 E+1$ & $3.624 E+0$ & $9.656 \mathrm{E}-2$ & $2.759 E-1$ \\
\hline 4.2 & $1.279 E+1$ & $1.119 E+1$ & $3.675 E+0$ & $8.935 E-2$ & $2.721 E-1$ \\
\hline 4.3 & $1.395 E+1$ & $1.208 E+1$ & $3.723 E+0$ & 8.277E-2 & $2.686 \mathrm{E}-1$ \\
\hline 4.4 & $1.521 E+1$ & $1.303 E+1$ & $3.768 E+0$ & 7.676E-2 & $2.654 \mathrm{E}-1$ \\
\hline 4.5 & $1.656 \mathrm{E}+1$ & $1.403 E+1$ & $3.812 E+0$ & $7.128 E-2$ & $2.623 E-1$ \\
\hline 4.6 & $1.802 E+1$ & $1.509 \mathrm{E}+1$ & $3.853 E+0$ & $6.626 \mathrm{E}-2$ & $2.595 \mathrm{E}-1$ \\
\hline 4.7 & $1.958 E+1$ & $1.622 E+1$ & $3.893 E+0$ & $6.166 \mathrm{E}-2$ & $2.569 E-1$ \\
\hline 4.8 & $2.126 \mathrm{E}+1$ & $1.741 E+1$ & $3.930 E+0$ & $5.744 \mathrm{E}-2$ & $2.544 \mathrm{E}-1$ \\
\hline 4.9 & $2.307 E+1$ & $1.867 E+1$ & $3.966 \mathrm{E}+0$ & $5.356 \mathrm{E}-2$ & $2.522 \mathrm{E}-1$ \\
\hline 5.0 & $2.500 E+1$ & $2.000 E+1$ & $4.000 E+0$ & $5.000 \mathrm{E}-2$ & $2.500 \mathrm{E}-1$ \\
\hline 5.1 & $2.707 E+1$ & $2.140 E+1$ & $4.033 E+0$ & $4.672 E-2$ & $2.480 \mathrm{E}-1$ \\
\hline 5.2 & $2.928 E+1$ & $2.288 E+1$ & $4.064 E+0$ & $4.370 \mathrm{E}-2$ & $2.461 E-1$ \\
\hline 5.3 & $3.165 E+1$ & $2.444 E+1$ & $4.093 E+0$ & $4.091 \mathrm{E}-2$ & $2.443 E-1$ \\
\hline 5.4 & $3.417 E+1$ & 2. $609 E+1$ & $4.122 E+0$ & $3.834 \mathrm{E}-2$ & $2.426 \mathrm{E}-1$ \\
\hline 5.5 & $3.687 E+1$ & $2.781 E+1$ & $4.149 E+0$ & $3.596 \mathrm{E}-2$ & $2.410 E-1$ \\
\hline 5.6 & $3.974 E+1$ & $2.963 E+1$ & $4.175 E+0$ & $3.375 E-2$ & $2.395 \mathrm{E}-1$ \\
\hline 5.7 & $4.280 E+1$ & $3.153 E+1$ & $4.200 E+0$ & $3.171 E-2$ & $2.381 E-1$ \\
\hline 5.8 & $4.605 E+1$ & $3.353 E+1$ & $4.224 \mathrm{E}+0$ & $2.982 \mathrm{E}-2$ & $2.368 E-1$ \\
\hline 5.9 & $4.951 E+1$ & $3.563 E+1$ & $4.246 E+0$ & $2.806 \mathrm{E}-2$ & $2.355 \mathrm{E}-1$ \\
\hline 6.0 & $5.318 E+1$ & $3.783 E+1$ & $4.268 E+0$ & $2.643 E-2$ & $2.343 E-1$ \\
\hline 6.1 & $5.708 E+1$ & $4.013 E+1$ & $4.289 E+0$ & $2.492 \mathrm{E}-2$ & $2.331 E-1$ \\
\hline 6.2 & $6.121 E+1$ & $4.255 E+1$ & $4.309 E+0$ & $2.350 \mathrm{E}-2$ & $2.321 E-1$ \\
\hline 6.3 & $6.559 E+1$ & $4.507 E+1$ & $4.329 E+0$ & $2.219 E-2$ & $2.310 E-1$ \\
\hline 6.4 & $7.023 E+1$ & $4.770 E+1$ & $4.347 E+0$ & $2.096 E-2$ & $2.300 E-1$ \\
\hline 6.5 & $7.513 E+1$ & $5.046 E+1$ & $4.365 E+0$ & $1.982 E-2$ & $2.291 \mathrm{E}-1$ \\
\hline 6.6 & $8.032 E+1$ & $5.333 E+1$ & $4.382 E+0$ & $1.875 \mathrm{E}-2$ & $2.282 E-1$ \\
\hline 6.7 & $8.580 E+1$ & $5.633 E+1$ & $4.399 E+0$ & $1.775 \mathrm{E}-2$ & $2.273 E-1$ \\
\hline 6.8 & $9.159 E+1$ & $5.946 E+1$ & $4.415 E+0$ & $1.682 E-2$ & $2.265 E-1$ \\
\hline 6.9 & $9.770 E+1$ & $6.272 E+1$ & $4.430 E+0$ & $1.594 \mathrm{E}-2$ & $2.257 E-1$ \\
\hline
\end{tabular}


Table 6. Sensitivity coefficients for $R=A_{\infty} / A^{*} \quad$ (Continued)

$$
\gamma=1.40
$$

\begin{tabular}{|c|c|c|c|c|c|}
\hline $\mathbf{M}_{\infty}$ & $\mathrm{R}$ & $\frac{\partial R}{\partial M_{\infty}}$ & $\frac{M_{\infty}}{R} \frac{\partial R}{\partial M_{\infty}}$ & $\frac{\partial M_{\infty}}{\partial R}$ & $\frac{R}{M_{\infty}} \frac{\partial M_{\infty}}{\partial R}$ \\
\hline 7.0 & $1.041 E+2$ & $6.612 E+1$ & $4.444 E+0$ & $1.512 \mathrm{E}-2$ & $2.250 \mathrm{E}-1$ \\
\hline 7.1 & $1.109 E+2$ & $6.966 E+1$ & $4.459 E+0$ & $1.436 \mathrm{E}-2$ & $2.243 E-1$ \\
\hline 7.2 & $1.181 E+2$ & $7.334 E+1$ & $4.472 E+0$ & $1.363 \mathrm{E}-2$ & $2.236 \mathrm{E}-1$ \\
\hline 7.3 & $1.256 \mathrm{E}+2$ & $7.718 E+1$ & $4.485 E+0$ & $1.296 \mathrm{E}-2$ & $2.229 \mathrm{E}-1$ \\
\hline 7.4 & $1.335 E+2$ & $8.116 E+1$ & $4.498 E+0$ & $1.232 E-2$ & $2.223 E-1$ \\
\hline 7.5 & $1.418 E+2$ & $8.530 E+1$ & $4.510 E+0$ & $1.172 E-2$ & $2.217 \mathrm{E}-1$ \\
\hline 7.6 & $1.506 \mathrm{E}+2$ & $8.960 E+1$ & $4.522 E+0$ & $1.116 \mathrm{E}-2$ & $2.211 E-1$ \\
\hline 7.7 & $1.598 E+2$ & $9.406 \mathrm{E}+1$ & $4.533 E+0$ & $1.063 \mathrm{E}-2$ & $2.206 \mathrm{E}-1$ \\
\hline 7.8 & $1.694 \mathrm{E}+2$ & $9.870 E+1$ & $4.544 E+0$ & $1.013 E-2$ & $2.201 \mathrm{E}-1$ \\
\hline 7.9 & $1.795 E+2$ & $1.035 E+2$ & $4.555 E+0$ & $9.662 E-3$ & $2.195 \mathrm{E}-1$ \\
\hline 8.0 & $1.901 E+2$ & $1.085 E+2$ & $4.565 E+0$ & $9.218 E-3$ & $2.190 \mathrm{E}-1$ \\
\hline 8.1 & $2.012 E+2$ & $1.137 E+2$ & $4.575 E+0$ & $8.799 E-3$ & $2.186 \mathrm{E}-1$ \\
\hline 8.2 & $2.128 E+2$ & $1.190 E+2$ & $4.585 E+0$ & $8.403 E-3$ & $2.181 E-1$ \\
\hline 8.3 & $2.250 E+2$ & $1.245 E+2$ & $4.594 E+0$ & $8.029 E-3$ & $2.177 E-1$ \\
\hline 8.4 & $2.378 E+2$ & $1.303 E+2$ & $4.603 E+0$ & $7.675 \mathrm{E}-3$ & $2.173 E-1$ \\
\hline 8.5 & $2.511 E+2$ & $1.362 E+2$ & $4.612 E+0$ & $7.341 \mathrm{E}-3$ & $2.168 \mathrm{E}-1$ \\
\hline 8.6 & $2.650 E+2$ & $1.424 E+2$ & $4.620 E+0$ & $7.024 \mathrm{E}-3$ & $2.164 E-1$ \\
\hline 8.7 & $2.796 \mathrm{E}+2$ & $1.487 E+2$ & $4.628 E+0$ & $6.724 \mathrm{E}-3$ & $2.161 E-1$ \\
\hline 8.8 & $2.948 E+2$ & $1.553 E+2$ & $4.636 \mathrm{E}+0$ & $6.440 E-3$ & $2.157 E-1$ \\
\hline 8.9 & $3.106 E+2$ & $1.621 E+2$ & $4.644 E+0$ & $6.170 \mathrm{E}-3$ & $2.153 E-1$ \\
\hline 9.0 & $3.272 E+2$ & $1.691 E+2$ & $4.651 E+0$ & $5.914 \mathrm{E}-3$ & $2.150 E-1$ \\
\hline 9.1 & $3.445 E+2$ & $1.763 E+2$ & $4.658 E+0$ & $5.671 \mathrm{E}-3$ & $2.147 E-1$ \\
\hline 9.2 & $3.625 E+2$ & $1.838 E+2$ & $4.665 E+0$ & $5.441 \mathrm{E}-3$ & 2.143E-1 \\
\hline 9.3 & $3.812 E+2$ & $1.915 \mathrm{E}+2$ & $4.672 E+0$ & $5.221 \mathrm{E}-3$ & $2.140 E-1$ \\
\hline 9.4 & $4.008 E+2$ & $1.995 E+2$ & $4.679 E+0$ & $5.013 E-3$ & $2.137 E-1$ \\
\hline 9.5 & $4.211 E+2$ & $2.077 E+2$ & $4.685 E+0$ & $4.815 E-3$ & $2.134 E-1$ \\
\hline 9.6 & $4.423 E+2$ & 2.161E+2 & $4.691 E+0$ & $4.626 \mathrm{E}-3$ & $2.132 E-1$ \\
\hline 9.7 & $4.644 E+2$ & $2.249 E+2$ & $4.697 E+0$ & $4.447 E-3$ & $2.129 E-1$ \\
\hline 9.8 & $4.873 E+2$ & $2.339 E+2$ & $4.703 E+0$ & $4.276 \mathrm{E}-3$ & $2.126 E-1$ \\
\hline 9.9 & $5.112 E+2$ & $2.431 E+2$ & $4.709 E+0$ & $4.113 E-3$ & $2.124 E-1$ \\
\hline 10.0 & $5.359 E+2$ & $2.527 E+2$ & $4.714 E+0$ & $3.958 \mathrm{E}-3$ & $2.121 E-1$ \\
\hline 10.1 & $5.617 E+2$ & $2.625 E+2$ & $4.720 E+0$ & $3.810 \mathrm{E}-3$ & $2.119 E-1$ \\
\hline 10.2 & $5.884 E+2$ & $2.726 E+2$ & $4.725 E+0$ & $3.669 \mathrm{E}-3$ & $2.116 E-1$ \\
\hline 10.3 & $6.162 E+2$ & $2.830 E+2$ & $4.730 E+0$ & $3.534 \mathrm{E}-3$ & $2.114 E-1$ \\
\hline 10.4 & $6.450 E+2$ & $2.937 E+2$ & $4.735 E+0$ & $3.405 E-3$ & $2.112 E-1$ \\
\hline
\end{tabular}


Table 6. Sensitivity coefficients for $R=A_{\infty} / A^{*} \quad$ (Continued) $\gamma=1.40$

\begin{tabular}{|c|c|c|c|c|c|}
\hline $\mathrm{M}_{\infty}$ & $\mathrm{R}$ & $\frac{\partial \mathrm{R}}{\partial \mathrm{M}_{\infty}}$ & $\frac{M_{\infty}}{R} \frac{\partial R}{\partial M_{\infty}}$ & $\frac{\partial M_{\infty}}{\partial R}$ & $\frac{R}{M_{\infty}} \frac{\partial M_{\infty}}{\partial R}$ \\
\hline 10.5 & $6.750 E+2$ & $3.047 E+2$ & $4.740 E+0$ & $3.282 E-3$ & $2.110 \mathrm{E}-1$ \\
\hline 10.6 & $7.060 E+2$ & $3.160 E+2$ & $4.744 E+0$ & $3.165 \mathrm{E}-3$ & $2.108 \mathrm{E}-1$ \\
\hline 10.7 & $7.382 E+2$ & $3.276 \mathrm{E}+2$ & $4.749 E+0$ & $3.052 E-3$ & $2.106 \mathrm{E}-1$ \\
\hline 10.8 & $7.715 E+2$ & $3.396 \mathrm{E}+2$ & $4.753 E+0$ & $2.945 E-3$ & $2.104 \mathrm{E}-1$ \\
\hline 10.9 & $8.061 E+2$ & $3.518 E+2$ & $4.758 E+0$ & $2.842 E-3$ & $2.102 E-1$ \\
\hline 11.0 & $8.419 E+2$ & $3.645 E+2$ & $4.762 E+0$ & $2.744 \mathrm{E}-3$ & $2.100 \mathrm{E}-1$ \\
\hline 11.1 & $8.790 E+2$ & $3.774 \mathrm{E}+2$ & $4.766 E+0$ & $2.650 \mathrm{E}-3$ & $2.098 E-1$ \\
\hline 11.2 & $9.174 E+2$ & $3.907 E_{<2}$ & $4.770 E+O$ & $2.559 E-3$ & $2.096 \mathrm{E}-1$ \\
\hline 11.3 & $9.572 E+2$ & $4.044 E+2$ & $4.774 E+0$ & $2.473 E-3$ & $2.095 E-1$ \\
\hline 11.4 & $9.983 E+2$ & 4. $184 \mathrm{E}+2$ & $4.778 E+0$ & $2.390 E-3$ & $2.093 E-1$ \\
\hline 11.5 & $1.041 E+3$ & $4.328 E+2$ & $4.781 E+0$ & $2.311 \mathrm{E}-3$ & $2.091 \mathrm{E}-1$ \\
\hline 11.6 & $1.085 E+3$ & $4.475 E+2$ & $4.785 E+0$ & $2.235 \mathrm{E}-3$ & $2.090 \mathrm{E}-1$ \\
\hline 11.7 & $1.130 E+3$ & $4.626 E+2$ & $4.789 E+0$ & $2.162 E-3$ & $2.088 \mathrm{E}-1$ \\
\hline 11.8 & $1.177 E+3$ & $4.781 E+2$ & $4.792 E+0$ & $2.091 \mathrm{E}-3$ & $2.087 E-1$ \\
\hline 11.9 & $1.226 E+3$ & $4.940 E+2$ & $4.795 E+0$ & $2.024 \mathrm{E}-3$ & $2.085 E-1$ \\
\hline 12.0 & $1.276 E+3$ & $5.10 .3 E+2$ & $4.799 E+0$ & $1.959 E-3$ & $2.084 \mathrm{E}-1$ \\
\hline 12.1 & $1.328 E+3$ & $5.270 E+2$ & $4.802 E+0$ & $1.897 \mathrm{E}-3$ & $2.083 E-1$ \\
\hline 12.2 & $1.382 E+3$ & $5.442 \mathrm{E}+2$ & $4.805 E+0$ & $1.838 \mathrm{E}-3$ & $2.081 E-1$ \\
\hline 12.3 & $1.437 E+3$ & $5.617 E+2$ & $4.808 E+0$ & $1.780 E-3$ & $2.080 \mathrm{E}-1$ \\
\hline 12.4 & $1.494 E+3$ & $5.796 E+2$ & $4.811 E+0$ & $1.725 \mathrm{E}-3$ & $2.079 E-1$ \\
\hline 12.5 & $1.553 E+3$ & $5.980 E+2$ & $4.814 E+0$ & $1.672 \mathrm{E}-3$ & $2.077 E-1$ \\
\hline 12.6 & $1.614 E+3$ & $6.169 E+2$ & $4.817 E+0$ & $1.621 \mathrm{E}-3$ & $2.076 E-1$ \\
\hline 12.7 & $1.676 E+3$ & $6.361 E+2$ & $4.820 E+0$ & $1.572 E-3$ & $2.075 E-1$ \\
\hline 12.8 & $1.741 E+3$ & $6.559 E+2$ & $4.822 E+0$ & $1.525 \mathrm{E}-3$ & $2.074 E-1$ \\
\hline 12.9 & $1.807 E+3$ & $6.760 E+2$ & $4.825 E+0$ & $1.479 E-3$ & $2.073 E-1$ \\
\hline 13.0 & $1.876 E+3$ & $6.967 E+2$ & $4.828 E+0$ & $1.435 E-3$ & $2.071 E-1$ \\
\hline 13.1 & $1.947 E+3$ & $7.178 E+2$ & $4.830 E+0$ & $1.393 E \cdot 3$ & $2.070 \mathrm{E}-1$ \\
\hline 13.2 & $2.020 E+3$ & $7.394 E+2$ & $4.833 E+0$ & $1.352 E-3$ & $2.069 E-1$ \\
\hline 13.3 & $2.095 E+3$ & $7.615 E+2$ & $4.835 E+0$ & $1.313 E-3$ & $2.068 E-1$ \\
\hline 13.4 & $2.172 E+3$ & $7.841 E+2$ & $4.837 E+0$ & $1.275 \mathrm{E}-3$ & $2.067 \mathrm{E}-1$ \\
\hline 13.5 & $2.252 E+3$ & $8.072 E+2$ & $4.840 E+0$ & $1.239 E-3$ & $2.066 \mathrm{E}-1$ \\
\hline 13.6 & $2.333 E+3$ & $8.308 E+2$ & $4.842 E+0$ & $1.204 E-3$ & $2.065 E-1$ \\
\hline 13.7 & $2.418 E+3$ & $8.549 E+2$ & $4.844 E+0$ & $1.170 E-3$ & $2.064 \mathrm{E}-1$ \\
\hline 13.8 & $2.504 E+3$ & $8.795 E+2$ & $4.847 E+0$ & $1.137 \mathrm{E}-3$ & $2.063 E-1$ \\
\hline 13.9 & $2.594 E+3$ & $9.047 E+2$ & $4.849 E+0$ & $1.105 E-3$ & $2.062 \mathrm{E}-1$ \\
\hline
\end{tabular}


Table 6. Sensitivity coefficients for $R=A_{\infty} / A^{*} \quad$ (Continued) $\gamma=1.40$

\begin{tabular}{|c|c|c|c|c|c|}
\hline$M_{\infty}$ & $R$ & $\frac{\partial R}{\partial M_{\infty}}$ & $\frac{M_{\infty}}{R} \frac{\partial R}{\partial M_{\infty}}$ & $\frac{\partial M_{\infty}}{\partial R}$ & $\frac{R}{M_{\infty}} \frac{\partial M_{\infty}}{\partial R}$ \\
\hline \hline 14.0 & $2.685 E+3$ & $9.304 E+2$ & $4.851 E+0$ & $1.075 E-3$ & $2.062 E-1$ \\
14.1 & $2.780 E+3$ & $9.567 E+2$ & $4.853 E+0$ & $1.045 E-3$ & $2.061 E-1$ \\
14.2 & $2.877 E+3$ & $9.835 E+2$ & $4.855 E+0$ & $1.017 E-3$ & $2.060 E-1$ \\
14.3 & $2.976 E+3$ & $1.011 E+3$ & $4.857 E+0$ & $9.892 E-4$ & $2.059 E-1$ \\
14.4 & $2079 E+3$ & $1.039 E+3$ & $4.859 E+0$ & $9.626 E-4$ & $2.058 E-1$ \\
& & & & & \\
14.5 & $3.184 E+3$ & $1.067 E+3$ & $4.861 E+0$ & $9.368 E-4$ & $2.057 E-1$ \\
14.6 & $3.292 E+3$ & $1.097 E+3$ & $4.862 E+0$ & $9.120 E-4$ & $2.057 E-1$ \\
14.7 & $3.404 E+3$ & $1.126 E+3$ & $4.864 E+0$ & $8.879 E-4$ & $2.056 E-1$ \\
14.8 & $3.518 E+3$ & $1.157 E+3$ & $4.866 E+0$ & $8.646 E-4$ & $2.055 E-1$ \\
14.9 & $3.635 E+3$ & $1.188 E+3$ & $4.868 E+0$ & $8.421 E-4$ & $2.054 E-1$ \\
15.0 & $3.755 E+3$ & $1.219 E+3$ & $4.870 E+0$ & $8.203 E-4$ & $2.054 E-1$ \\
\hline
\end{tabular}


Table 7. Sensitivity coefficients for $R=\rho_{\infty} V_{\infty} / \rho^{*} V *$ $\gamma=1.40$

\begin{tabular}{|c|c|c|c|c|c|}
\hline $\mathbf{M}_{\infty}$ & $\mathbf{R}$ & $\frac{\partial R}{\partial M_{\infty}}$ & $\frac{M_{\infty}}{R} \frac{\partial R}{\partial M_{\infty}}$ & $\frac{\partial M_{\infty}}{\partial R}$ & $\frac{R}{M_{\infty}} \frac{\partial M_{\infty}}{\partial R}$ \\
\hline 0.1 & $1.718 E-1$ & $1.697 E+0$ & $9.880 E-1$ & $5.892 E-1$ & $1.012 E+0$ \\
\hline 0.2 & $3.374 E-1$ & $1.607 E+0$ & $9.524 E-1$ & $6.223 E-1$ & $1.050 E+0$ \\
\hline 0.3 & $4.914 E-1$ & $1.464 E+0$ & $8.939 E-1$ & $6.830 \mathrm{E}-1$ & $1.119 E+0$ \\
\hline 0.4 & $6.289 E-1$ & $1.280 E+0$ & $8.140 E-1$ & $7.814 \mathrm{E}-1$ & $1.229 E+0$ \\
\hline 0.5 & $7.464 \mathrm{E}-1$ & $1.066 E+0$ & $7.143 E-1$ & $9.379 E-1$ & $1.400 E+0$ \\
\hline 0.6 & $8.416 E-1$ & $8.374 E-1$ & $5.970 \mathrm{E}-1$ & $1.194 E+0$ & $1.675 E+0$ \\
\hline 0.7 & $9.138 E-1$ & $6.063 E-1$ & $4.645 E-1$ & $1.649 E+0$ & $2.153 E+0$ \\
\hline 0.8 & $9.632 E-1$ & $3.842 E-1$ & $3.191 \mathrm{E}-1$ & $2.602 E+0$ & $3.133 E+0$ \\
\hline 0.9 & $9.912 E-1$ & $1.801 \mathrm{E}-1$ & $1.635 \mathrm{E}-1$ & $5.553 E+0$ & $6.116 E+0$ \\
\hline 1.0 & $1.000 E+0$ & $0.000 E+0$ & $0.000 E+0$ & $\infty$ & $\infty$ \\
\hline 1.1 & $9.921 E-1$ & $-1.525 E-1$ & $-1.691 \mathrm{E}-1$ & $-6.557 E+0$ & $-5.914 E+0$ \\
\hline 1.2 & $9.705 E-1$ & $-2.763 E-1$ & $-3.416 E-1$ & $-3.620 E+0$ & $-2.927 E+0$ \\
\hline 1.3 & $9.378 E-1$ & $-3.720 E-1$ & $-5.157 E-1$ & $-2.688 E+0$ & $-1.939 E+0$ \\
\hline 1.4 & $8.969 E-1$ & $-4.418 E-1$ & $-6.897 E-1$ & $-2.263 E+0$ & $-1.450 E+0$ \\
\hline 1.5 & $8.5025-1$ & $-4.886 E-1$ & $-8.621 E-1$ & $-2.047 E+0$ & $-1.160 E+0$ \\
\hline 1.6 & $7.998 E-1$ & $-5.158 E-1$ & $-1.032 E+0$ & $-1.939 E+0$ & $-9.692 E-1$ \\
\hline 1.7 & $7.476 E-1$ & $-5.267 E-1$ & $-1.198 E+0$ & $-1.899 E+0$ & $-8.349 E-1$ \\
\hline 1.8 & $6.949 E-1$ & $-5.248 E-1$ & $-1.359 E+0$ & $-1.906 E+0$ & $-7.357 E-1$ \\
\hline 1.9 & $6.430 E-1$ & $-5.129 E-1$ & $.516 E+0$ & $-1.950 E+0$ & $-6.598 E-1$ \\
\hline 2.0 & $5.926 \mathrm{E}-1$ & $-4.938 E-1$ & $-1.667 E+0$ & $-2.025 E+0$ & $-6.000 E-1$ \\
\hline 2.1 & $5.444 E-1$ & $\therefore 697 \mathrm{E}-1$ & $-1.812 E+0$ & $-2.129 E+0$ & $-5.519 E-1$ \\
\hline 2.2 & $4.988 E-1$ & $-4.424 E-1$ & $-1.951 E+0$ & $-2.261 E+0$ & $-5.125 E-1$ \\
\hline 2.3 & $4.560 E-1$ & $-4.133 E-1$ & $-2.085 E+0$ & $-2.420 E+0$ & $-4.797 E-1$ \\
\hline 2.4 & 4.161E-1 & $-3.835 E-1$ & $-2.212 E+0$ & $-2.607 E+0$ & $-4.521 E-1$ \\
\hline 2.5 & $3.793 E-1$ & $-3.540 E-1$ & $-2.333 E+0$ & $-2.825 E+0$ & $-4.286 E-1$ \\
\hline 2.6 & $3.453 E-1$ & $-3.252 E-1$ & $-2.449 E+0$ & $-3.075 E+0$ & $-4.083 E-1$ \\
\hline 2.7 & $3.142 E-1$ & $-2.978 E-1$ & $-2.559 E+0$ & $-3.358 E+0$ & $-3.908 E-1$ \\
\hline 2.8 & $2.857 E-1$ & $-2.718 E-1$ & $-2.664 E+0$ & $-3.679 E+0$ & $-3.754 E-1$ \\
\hline 2.9 & $2.598 E-1$ & $-2.475 E-1$ & $-2.763 E+0$ & $-4.041 E+0$ & $-3.619 E-1$ \\
\hline 3.0 & $2.362 E-1$ & $-2.249 E-1$ & $-2.857 E+0$ & $-4.446 E+0$ & $-3.500 E-1$ \\
\hline 3.1 & $2.147 E-1$ & $-2.041 E-1$ & $-2.947 E+0$ & $-4.900 E+0$ & $-3.394 E-1$ \\
\hline 3.2 & $1.953 E-1$ & $-1.850 E-1$ & $-3.031 E+0$ & $-5.406 E+0$ & $-3.299 E-1$ \\
\hline 3.3 & $1.777 E-1$ & $-1.675 E-1$ & $-3.112 E+0$ & $-5.969 E+0$ & $-3.213 E-1$ \\
\hline 3.4 & $1.617 \mathrm{E}-1$ & $-1.517 E-1$ & $-3.188 E+0$ & $.6 .594 E+0$ & $-3.136 E-1$ \\
\hline
\end{tabular}


Table 7. Sensitivity coefficients for $\mathrm{R}=\rho_{\infty} \mathrm{V}_{\infty} / \rho^{*} \mathrm{~V} * \quad$ (Continued) $\gamma=1.40$

\begin{tabular}{|c|c|c|c|c|c|}
\hline $\mathbf{M}_{\infty}$ & $\mathbf{R}$ & $\frac{\partial R}{\partial M_{\infty}}$ & $\frac{M_{\infty}}{R} \frac{\partial R}{\partial M_{\infty}}$ & $\frac{\partial M_{\infty}}{\partial R}$ & $\frac{R}{M_{\infty}} \frac{\partial M_{\infty}}{\partial R}$ \\
\hline 3.5 & $1.473 \mathrm{E}-1$ & $-1.372 E-1$ & $-3.261 E+0$ & $-7.288 E+0$ & $-3.067 \mathrm{E}-1$ \\
\hline 3.6 & $1.342 E-1$ & $-1.241 \mathrm{E}-1$ & $-3.330 E+0$ & $-8.055 E+0$ & $-3.003 E-1$ \\
\hline 3.7 & $1.224 \mathrm{E}-1$ & $-1.123 E-1$ & $-3.395 E+0$ & $-8.903 E+0$ & $-2.946 \mathrm{E}-1$ \\
\hline 3.8 & $1.117 \mathrm{E}-1$ & $-1.016 E-1$ & $-3.457 E+0$ & $-9.839 E+0$ & $-2.893 E-1$ \\
\hline 3.9 & $1.021 E-1$ & $-9.199 E-2$ & $-3.516 E+0$ & $-1.087 E+1$ & $-2.844 E-1$ \\
\hline 4.0 & $9.329 \mathrm{E}-2$ & $-8.330 E-2$ & $-3.571 E+0$ & $-1.201 E+1$ & $-2.800 \mathrm{E}-1$ \\
\hline 4.1 & 8.536E-2 & $-7.546 E-2$ & $-3.624 E+0$ & $-1.325 E+1$ & $-2.759 E-1$ \\
\hline 4.2 & $7.818 \mathrm{E}-2$ & $-6.840 E-2$ & $-3.675 E+0$ & $-1.462 E+1$ & $-2.721 \mathrm{E}-1$ \\
\hline 4.3 & $7.166 \mathrm{E}-2$ & $-6.204 E-2$ & $-3.723 E+0$ & $-1.612 E+1$ & $-2.686 \mathrm{E}-1$ \\
\hline 4.4 & $6.575 \mathrm{E}-2$ & $-5.631 E-2$ & $-3.768 E+0$ & $-1.776 E+1$ & $-2.654 E-1$ \\
\hline 4.5 & $6.038 E-2$ & $-5.115 E-2$ & $-3.812 \mathrm{E}+0$ & $-1.955 E+1$ & $-2.623 \mathrm{E}-1$ \\
\hline 4.6 & $5.550 \mathrm{E}-2$ & $-4.649 E-2$ & $-3.853 E+0$ & $-2.151 E+1$ & $-2.595 \mathrm{E}-1$ \\
\hline 4.7 & $5.107 E-2$ & $-4.229 E-2$ & $-3.893 E+0$ & $-2.364 E+1$ & $-2.569 \mathrm{E}-1$ \\
\hline 4.8 & $4.703 \mathrm{E}-2$ & $-3.851 E-2$ & $-3.930 E+0$ & $-2.597 E+1$ & $-2.544 E-1$ \\
\hline 4.9 & $4.335 \mathrm{E}-2$ & $-3.509 E-2$ & $-3.966 E+0$ & $-2.850 E+1$ & $-2.522 E-1$ \\
\hline 5.0 & $4.000 E-2$ & $-3.200 E-2$ & $-4.000 E+0$ & $-3.125 E+1$ & $-2.500 E-1$ \\
\hline 5.1 & $3.694 E-2$ & $-2.921 E-2$ & $-4.033 E+0$ & $-3.423 E+1$ & $-2.480 E-1$ \\
\hline 5.2 & $3.415 \mathrm{E}-2$ & $-2.669 E-2$ & $-4.064 E+0$ & $-3.747 E+1$ & $-2.461 E-1$ \\
\hline 5.3 & $3.160 \mathrm{E}-2$ & $-2.440 \mathrm{E}-2$ & $-4.093 E+0$ & $-4.098 E+1$ & $-2.443 E-1$ \\
\hline 5.4 & $2.926 E-2$ & $-2.233 E-2$ & $-4.122 E+0$ & $-4.477 E+1$ & $-2.426 \mathrm{E}-1$ \\
\hline 5.5 & $2.712 E-2$ & $-2.046 \mathrm{E}-2$ & $-4.149 E+0$ & $-4.888 E+1$ & $-2.410 \mathrm{E}-1$ \\
\hline 5.6 & $2.516 \mathrm{E}-2$ & $-1.876 E-2$ & $-4.175 E+0$ & $-5.331 E+1$ & $-2.395 E-1$ \\
\hline 5.7 & $2.337 E-2$ & $-1.722 E-2$ & $-4.200 E+0$ & $-5.809 E+1$ & $-2.381 E-1$ \\
\hline 5.8 & $2.172 E-2$ & $-1.581 E-2$ & $-4.224 E+0$ & $-6.324 E+1$ & $-2.368 \mathrm{E}-1$ \\
\hline 5.9 & $2.020 E-2$ & $-1.454 E-2$ & $-4.246 E+0$ & $-6.879 E+1$ & $-2.355 E-1$ \\
\hline 6.0 & $1.880 \mathrm{E}-2$ & $-1.338 \mathrm{E}-2$ & $-4.268 E+0$ & $-7.476 E+1$ & $-2.343 E-1$ \\
\hline 6.1 & $1.752 \mathrm{E}-2$ & $-1.232 E-2$ & $-4.289 E+0$ & $-8.117 E+1$ & $-2.331 E-1$ \\
\hline 6.2 & $1.634 \mathrm{E}-2$ & $-1.136 \mathrm{E}-2$ & $-4.309 E+0$ & $-8.806 E+1$ & $-2.321 E-1$ \\
\hline 6.3 & $1.525 E-2$ & $-1.048 E-2$ & $-4.329 E+0$ & $-9.546 E+1$ & $-2.310 E-1$ \\
\hline 6.4 & $1.424 E-2$ & $-9.672 E-3$ & $-4.347 E+0$ & $-1.034 E+2$ & $-2.300 E-1$ \\
\hline 6.5 & $1.331 \mathrm{E}-2$ & $-8.938 E-3$ & $-4.365 E+0$ & $-1.119 E+2$ & $-2.291[E-1$ \\
\hline 6.6 & $1.245 E-2$ & $-8.266 E-3$ & $-4.382 E+0$ & $-1.210 E+2$ & $-2.282 E-1$ \\
\hline 6.7 & $1.165 \mathrm{E}-2$ & $-7.651 \mathrm{E} \cdot 3$ & $-4.399 E+0$ & $-1.307 E+2$ & $-2.273 E-1$ \\
\hline 6.8 & $1.092 \mathrm{E}-2$ & $-7.088 E-3$ & $-4.415 E+0$ & $-1.411 E+2$ & $-2.265 E-1$ \\
\hline 6.9 & $1.024 \mathrm{E}-2$ & $-6.571 E-3$ & $-4.430 E+0$ & $-1.522 E+2$ & $-2.257 E-1$ \\
\hline
\end{tabular}


Table 7. Sensitivity coefficients for $R=\rho_{\infty} V_{\infty} / \rho^{*} V^{*} \quad$ (Continued) $\gamma=1.40$

\begin{tabular}{|c|c|c|c|c|c|}
\hline $\mathbf{M}_{\infty}$ & $\mathbf{R}$ & $\frac{\partial R}{\partial M_{\infty}}$ & $\frac{M_{\infty}}{R} \frac{\partial R}{\partial M_{\infty}}$ & $\frac{\partial M_{\infty}}{\partial R}$ & $\frac{R}{M_{\infty}} \frac{\partial M_{\infty}}{\partial R}$ \\
\hline 7.0 & $9.602 E-3$ & $-6.097 E-3$ & $-4.444 E+0$ & $-1.640 \mathrm{E}+2$ & $-2.250 \mathrm{E}-1$ \\
\hline 7.1 & $9.015 \mathrm{E}-3$ & $-5.661 E-3$ & $-4.459 E+0$ & $-1.767 E+2$ & $-2.243 E-1$ \\
\hline 7.2 & $8.469 E-3$ & $-5.260 \mathrm{E}-3$ & $-4.472 E+0$ & $-1.901 E+2$ & $-2.236 E-1$ \\
\hline 7.3 & $7.961 E-3$ & $-4.892 E-3$ & $-4.485 E+0$ & $-2.044 E+2$ & $-2.229 E-1$ \\
\hline 7.4 & 7.490 E-3 & $-4.552 E-3$ & $-4.498 E+0$ & $-2.197 E+2$ & $-2.223 E-1$ \\
\hline 7.5 & $7.050 E-.3$ & $-4.240 \mathrm{E}-3$ & $-4.510 E+0$ & $-2.359 E+2$ & $-2.217 E-1$ \\
\hline 7.6 & $6.641 E-3$ & $-3.951 E-3$ & $-4.522 E+0$ & $-2.531 E+2$ & $-2.211 E-1$ \\
\hline 7.7 & $6.259 E-3$ & $-3.685 E-3$ & $-4.533 E+0$ & $-2.714 E+2$ & $-2.206 E-1$ \\
\hline 7.8 & $5.903 E-3$ & $-3.439 E-3$ & $-4.544 E+0$ & $-2.908 E+2$ & $-2.201 E-1$ \\
\hline 7.9 & $5.571 E-3$ & $-3.212 E-3$ & $-4.555 E+0$ & $-3.113 E+2$ & $-2.195 E-1$ \\
\hline 8.0 & $5.260 E-3$ & $-3.002 E-3$ & $-4.565 E+0$ & $-3.331 E+2$ & $-2.190 E-1$ \\
\hline 8.1 & $4.970 E-3$ & $-2.807 E-3$ & $-4.575 E+0$ & $-3.562 E+2$ & $-2.186 E-1$ \\
\hline 8.2 & $4.698 \mathrm{E}-3$ & $-2.627 E-3$ & $-4.585 E+0$ & $-3.807 E+2$ & $-2.181 E-1$ \\
\hline 8.3 & $4.444 E-3$ & $-2.460 \mathrm{E}-3$ & $-4.594 E+0$ & $-4.065 E+2$ & $-2.177 E-1$ \\
\hline 8.4 & $4.206 E-3$ & $-2.305 E-3$ & $-4.603 E+0$ & $-4.339 E+2$ & $-2.173 E-1$ \\
\hline 8.5 & $3.983 E-3$ & $-2.161 E-3$ & $-4.612 E+0$ & $-4.628 E+2$ & $-2.168 E-1$ \\
\hline 8.6 & $3.773 E-3$ & $-2.027 E-3$ & $-4.620 E+0$ & $-4.933 E+2$ & $-2.164 E-1$ \\
\hline 8.7 & $3.577 E-3$ & $-1.903 E-3$ & $-4.628 E+0$ & $-5.255 E+2$ & $-2.161 \mathrm{E}-1$ \\
\hline 8.8 & 3.3.93E-3 & $-1.787 \mathrm{E}-3$ & $-4.636 E+0$ & $-5.595 E+2$ & $-2.157 E-1$ \\
\hline 8.9 & $3.219 E-3$ & $-1.680 E-3$ & $-4.644 E+0$ & $-5.953 E+2$ & $-2.153 E-1$ \\
\hline 9.0 & $3.056 \mathrm{E}-3$ & $-1.579 E-3$ & $-4.651 E+0$ & $-6.331 E+2$ & $-2.150 E-1$ \\
\hline 9.1 & 2.903E-3 & $-1.486 E-3$ & $-4.658 E+0$ & $-6.729 E+2$ & $-2.147 E-1$ \\
\hline 9.2 & $2.759 E-3$ & $-1.399 \mathrm{E}-3$ & $-4.665 E+0$ & $-7.148 E+2$ & $-2.143 E-1$ \\
\hline 9.3 & $2.623 E-3$ & $-1.318 E-3$ & $-4.672 E+0$ & $-7.588 E+2$ & $-2.140 \mathrm{E}-1$ \\
\hline 9.4 & $2.495 E-3$ & $-1.242 E-3$ & $-4.679 E+0$ & $-8.052 E+2$ & $-2.137 E-1$ \\
\hline 9.5 & $2.375 E-3$ & $-1.171 \mathrm{E}-3$ & $.4 .685 E+0$ & $-8.539 E+2$ & $-2.134 E-1$ \\
\hline 9.6 & 2.261E-3 & $-1.105 E-3$ & $-4.691 E+0$ & $-9.052 E+2$ & $-2.132 E-1$ \\
\hline 9.7 & $2.153 E-3$ & $-1.043 E-3$ & $-4.697 E+0$ & $-9.589 E+2$ & $-2.129 \mathrm{E}-1$ \\
\hline 9.8 & $2.052 E-3$ & $-9.848 E-4$ & $-4.703 E+0$ & $-1.015 E+3$ & $-2.126 \mathrm{E}-1$ \\
\hline 9.9 & $1.956 \mathrm{E}-3$ & $-9.305 E-4$ & $-4.709 E+0$ & $-1.075 E+3$ & $-2.124 E-1$ \\
\hline 10.0 & $1.866 E-3$ & $-8.796 E-4$ & $-4.714 E+0$ & $-1.137 E+3$ & $-2.121 E-1$ \\
\hline 10.1 & $1.780 E-3$ & $-8.319 E-4$ & $-4.720 E+0$ & $-1.202 E+3$ & $-2.119 E-1$ \\
\hline 10.2 & $1.699 \mathrm{E}-3$ & $-7.872 E-4$ & $-4.725 E+0$ & $-1.270 E+3$ & $-2.116 E-1$ \\
\hline 10.3 & $1.623 E-3$ & $-7452 E-4$ & $-4.730 E+0$ & $-1.342 E+3$ & $-2.114 \mathrm{E}-1$ \\
\hline 10.4 & $1.550 \mathrm{E}-3$ & $-7.058 E-4$ & $-4.735 E+0$ & $-1.417 E+3$ & $-2.112 E-1$ \\
\hline
\end{tabular}


Table 7. Sensitivity coefficients for $R=\rho_{\infty} V_{\infty} / \rho^{*} V^{*} \quad$ (Continued) $\gamma=1.40$

\begin{tabular}{|c|c|c|c|c|c|}
\hline $\mathbf{M}_{\infty}$ & $\mathrm{R}$ & $\frac{\partial \mathrm{R}}{\partial \mathrm{M}_{\infty}}$ & $\frac{M_{\infty}}{R} \frac{\partial R}{\partial M_{\infty}}$ & $\frac{\partial \mathrm{M}_{\infty}}{\partial \mathrm{R}}$ & $\frac{\mathrm{R}}{\mathrm{M}_{\infty}} \frac{\partial \mathrm{M}_{\infty}}{\partial \mathrm{R}}$ \\
\hline 10.5 & $1.482 \mathrm{E}-3$ & $-6.688 E-4$ & $-4.740 E+0$ & $-1.495 E+3$ & $-2.110 E-1$ \\
\hline 10.6 & $1.416 \mathrm{E}-3$ & $-6.340 E-4$ & $-4.744 E+0$ & $-1.577 E+3$ & $-2.108 E-1$ \\
\hline 10.7 & $1.355 \mathrm{E}-3$ & $-6.012 E-4$ & $-4.749 E+0$ & $-1.663 E+3$ & $-2.106 \mathrm{E}-1$ \\
\hline 10.8 & $1.296 \mathrm{E}-3$ & $-5.705 E-4$ & $-4.753 F+0$ & $-1.753 E+3$ & $-2.104 E-1$ \\
\hline 10.9 & $1.241 \mathrm{E}-3$ & $-5.415 E-4$ & $-4.758 E+0$ & $-1.847 E+3$ & $-2.102 E-1$ \\
\hline 11.0 & $1.188 \mathrm{E}-3$ & $-5.142 E-4$ & $-4.762 E+0$ & $-1.945 E+3$ & $-2.100 E-1$ \\
\hline 11.1 & $1.138 \mathrm{E}-3$ & $-4.885 E-4$ & $-4.766 E+0$ & $-2.047 E+3$ & $-2.098 E-1$ \\
\hline 11.2 & $1.090 \mathrm{E}-3$ & $-4.642 E-4$ & $-4.770 E+0$ & $-2.154 E+3$ & $-2.096 \mathrm{E}-1$ \\
\hline 11.3 & $1.045 E-3$ & $-4.414 \mathrm{E}-4$ & $-4.774 E+0$ & $-2.266 E+3$ & $-2.095 E-1$ \\
\hline 11.4 & $1.002 E-3$ & $-4.198 E-4$ & $-4.778 E+0$ & $-2.382 E+3$ & $-2.093 E-1$ \\
\hline 11.5 & $9.608 \mathrm{E}-4$ & $-3.995 E-4$ & $-4.781 E+0$ & $-2.503 E+3$ & $-2.091 \mathrm{E}-1$ \\
\hline 11.6 & $9.218 E-4$ & $-3.802 E-4$ & $-4.785 E+0$ & $-2.630 E+3$ & $-2.090 E-1$ \\
\hline 11.7 & $8.847 E-4$ & $-3.621 E-4$ & $-4.789 E+0$ & $-2.762 E+3$ & $-2.088 E-1$ \\
\hline 11.8 & $8.493 E-4$ & $-3.449 \mathrm{E}-4$ & $-4.792 E+0$ & $-2.899 E+3$ & $-2.087 E-1$ \\
\hline 11.9 & $8.157 E-4$ & $-3.287 E-4$ & $-4.795 E+0$ & $-3.042 E+3$ & $-2.085 E-1$ \\
\hline 12.0 & $7.836 \mathrm{E}-4$ & $-3.133 E-4$ & $-4.799 E+0$ & $-3.191 E+3$ & $-2.084 \mathrm{E}-1$ \\
\hline 12.1 & $7.530 E-4$ & $-2.988 E-4$ & $-4.802 E+0$ & $-3.347 E+3$ & $-2.083 E-1$ \\
\hline 12.2 & $7.238 E-4$ & $-2.851 E-4$ & $-4.805 E+0$ & $-3.508 E+3$ & $-2.081 \mathrm{E}-1$ \\
\hline 12.3 & $6.959 E-4$ & $-2.720 E-4$ & $-4.808 E+0$ & $-3.676 E+3$ & $-2.080 E-1$ \\
\hline 12.4 & $6.693 E-4$ & $-2.597 E-4$ & $-4.811 E+0$ & $-3.851 E+3$ & $-2.079 E-1$ \\
\hline 12.5 & $6.440 \mathrm{E}-4$ & $-2.480 E-4$ & $-4.814 E+0$ & $-4.032 E+3$ & $-2.077 E-1$ \\
\hline 12.6 & $6.197 E-4$ & $-2.369 E-4$ & $-4.817 E+0$ & $-4.221 E+3$ & $-2.076 E-1$ \\
\hline 12.7 & $5.966 \mathrm{E}-4$ & $-2.264 E-4$ & $-4.820 E+0$ & $-4.417 E+3$ & $-2.075 \mathrm{E}-1$ \\
\hline 12.8 & $5.744 E-4$ & $-2.164 E-4$ & $-4.822 E+0$ & $-4.621 E+3$ & $-2.074 E-1$ \\
\hline 12.9 & $5.533 E-4$ & $-2.069 E-4$ & $-4.825 E+0$ & $-4.832 E+3$ & $-2.073 E-1$ \\
\hline 13.0 & $5.330 \mathrm{E}-4$ & $-1.979 E-4$ & $-4.828 E+0$ & $-5.052 E+3$ & $-2.071 E-1$ \\
\hline 13.1 & $5.137 E-4$ & $-1.894 E-4$ & $-4.830 E+0$ & $-5.280 E+3$ & $-2.070 E-1$ \\
\hline 13.2 & $4.951 E-4$ & $-1.813 E-4$ & $-4.833 E+0$ & $-5.517 E+3$ & $-2.069 E-1$ \\
\hline 13.3 & $4.774^{r}:-4$ & $-1.736 E-4$ & $-4.835 E+0$ & $-5.762 E+3$ & $-2.068 E-1$ \\
\hline 13.4 & $4.604 \mathrm{E}-4$ & $-1.662 \mathrm{E}-4$ & $-4.837 E+0$ & $-6.016 E+3$ & $-2.067 \mathrm{E}-1$ \\
\hline 13.5 & $4.441 \mathrm{E}-4$ & $-1.592 E-4$ & $-4.840 E+0$ & $-6.280 E+3$ & $-2.066 E-1$ \\
\hline 13.6 & $4.286 \mathrm{E}-4$ & $-1.526 E-4$ & $-4.842 E+0$ & $-6.554 E+3$ & $-2.065 E-1$ \\
\hline 13.7 & $4.136 \mathrm{E}-4$ & $-1.463 E-4$ & $-4.844 E+0$ & $-6.837 E+3$ & $-2.064 \mathrm{E}-1$ \\
\hline 13.8 & $3.993 E-4$ & $-1.402 E-4$ & $-4.847 E+0$ & $-7.131 E+3$ & $-2.063 E-1$ \\
\hline 13.9 & $3.856 E-4$ & $-1.345 E-4$ & $-4.849 E+0$ & $-7.435 E+3$ & $-2.062 E-1$ \\
\hline
\end{tabular}


Table 7. Sensitivity coefficients for $R=\rho_{\infty} V_{\infty} / \rho^{*} V^{*} \quad$ (Continued)

$$
\gamma=1.40
$$

\begin{tabular}{|c|c|c|c|c|c|}
\hline $\mathrm{M}_{\infty}$ & $\mathrm{R}$ & $\frac{\partial \mathrm{R}}{\partial \mathrm{M}_{\infty}}$ & $\frac{\mathrm{M}_{\infty}}{\mathrm{R}} \frac{\partial \mathrm{R}}{\partial \mathrm{M}_{\infty}}$ & $\frac{\partial \mathrm{M}_{\infty}}{\partial \mathrm{R}}$ & $\frac{\mathrm{R}}{\mathrm{M}_{\infty}} \frac{\partial \mathrm{M}_{\infty}}{\partial \mathrm{R}}$ \\
\hline \hline 14.0 & $3.724 \mathrm{E}-4$ & $-1.290 \mathrm{E}-4$ & $-4.851 \mathrm{E}+0$ & $-7.750 \mathrm{E}+3$ & $-2.062 \mathrm{E}-1$ \\
14.1 & $3.597 \mathrm{E}-4$ & $-1.238 \mathrm{E}-4$ & $-4.853 \mathrm{E}+0$ & $-8.077 \mathrm{E}+3$ & $-2.061 \mathrm{E}-1$ \\
14.2 & $3.476 \mathrm{E}-4$ & $-1.188 \mathrm{E}-4$ & $-4.855 \mathrm{E}+0$ & $-8.414 \mathrm{E}+3$ & $-2.060 \mathrm{E}-1$ \\
14.3 & $3.360 \mathrm{E}-4$ & $-1.141 \mathrm{E}-4$ & $-4.857 \mathrm{E}+0$ & $-8.764 \mathrm{E}+3$ & $-2.059 \mathrm{E}-1$ \\
14.4 & $3.248 \mathrm{E}-4$ & $-1.096 \mathrm{E}-4$ & $-4.859 \mathrm{E}+0$ & $-9.125 \mathrm{E}+3$ & $-2.058 \mathrm{E}-1$ \\
& & & & & \\
14.5 & $3.140 \mathrm{E}-4$ & $-1.053 \mathrm{E}-4$ & $-4.861 \mathrm{E}+0$ & $-9.499 \mathrm{E}+3$ & $-2.057 \mathrm{E}-1$ \\
14.6 & $3.037 \mathrm{E}-4$ & $-1.012 \mathrm{E}-4$ & $-4.862 \mathrm{E}+0$ & $-9.886 \mathrm{E}+3$ & $-2.057 \mathrm{E}-1$ \\
14.7 & $2.938 \mathrm{E}-4$ & $-9.722 \mathrm{E}-5$ & $-4.864 \mathrm{E}+0$ & $-1.029 \mathrm{E}+4$ & $-2.056 \mathrm{E}-1$ \\
14.8 & $2.843 \mathrm{E}-4$ & $-9.347 \mathrm{E}-5$ & $-4.866 \mathrm{E}+0$ & $-1.070 \mathrm{E}+4$ & $-2.055 \mathrm{E}-1$ \\
14.9 & $2.751 \mathrm{E}-4$ & $-8.988 \mathrm{E}-5$ & $-4.868 \mathrm{E}+0$ & $-1.113 \mathrm{E}+4$ & $-2.054 \mathrm{E}-1$ \\
15.0 & $2.663 \mathrm{E}-4$ & $-8.645 \mathrm{E}-5$ & $-4.870 \mathrm{E}+0$ & $-1.157 \mathrm{E}+4$ & $-2.054 \mathrm{E}-1$ \\
\hline
\end{tabular}


Table 8. Sensitivity coefficients for $R=T_{\infty} / T_{t}$ $\gamma=1.40$

\begin{tabular}{|c|c|c|c|c|c|}
\hline $\mathbf{M}_{\infty}$ & $\mathbf{R}$ & $\frac{\partial R}{\partial M_{\infty}}$ & $\frac{M_{\infty}}{R} \frac{\partial R}{\partial M_{\infty}}$ & $\frac{\partial \mathrm{M}_{\infty}}{\partial \mathrm{R}}$ & $\frac{R}{M_{\infty}} \frac{\partial M_{\infty}}{\partial R}$ \\
\hline 0.1 & $9.980 \mathrm{E}-1$ & $-3.984 E-2$ & $-3.992 E-3$ & $-2.510 E+1$ & $-2.505 E+2$ \\
\hline 0.2 & $9.921 E-1$ & $-7.874 E-2$ & $-1.587 E-2$ & $-1.270 E+1$ & $-6.300 E+1$ \\
\hline 0.3 & $9.823 E-1$ & $-1.158 \mathrm{E}-1$ & $-3.536 \mathrm{E}-2$ & $-8.636 E+0$ & $-2.828 E+1$ \\
\hline 0.4 & $9.690 \mathrm{E}-1$ & $-1.502 E-1$ & $-6.202 E-2$ & $-6.656 E+0$ & $-1.612 E+1$ \\
\hline 0.5 & $9.524 E-1$ & $-1.814 \mathrm{E}-1$ & $-9.524 E-2$ & $-5.512 E+0$ & $-1.050 E+1$ \\
\hline 0.6 & $9.328 E-1$ & $-2.088 E-1$ & $-1.343 \mathrm{E}-1$ & $-4.788 E+0$ & $-7.444 E+0$ \\
\hline 0.7 & $9.107 E-1$ & $-2.322 E-1$ & $-1.785 E-1$ & $-4.306 E+0$ & $-5.602 E+0$ \\
\hline 0.8 & $8.865 E-1$ & $-2.515 E-1$ & $-2.270 \mathrm{E}-1$ & $-3.976 E+0$ & $-4.406 E+0$ \\
\hline 0.9 & $8.606 \mathrm{E}-1$ & $-2.666 \mathrm{E}-1$ & $-2.788 E-1$ & $-3.751 E+0$ & $-3.586 E+0$ \\
\hline 1.0 & $8.333 \mathrm{E}-1$ & $-2.778 \mathrm{E}-1$ & $-3.333 E-1$ & $-3.600 E+0$ & $-3.000 E+0$ \\
\hline 1.1 & $8.052 E-1$ & $-2.852 E-1$ & $-3.897 E-1$ & $-3.506 E+0$ & $-2.566 E+0$ \\
\hline 1.2 & $7.764 \mathrm{E}-1$ & $-2.893 E-1$ & $-4.472 E-1$ & $-3.456 E+0$ & $-2.236 E+0$ \\
\hline 1.3 & $7.474 \mathrm{E}-1$ & $-2.905 E-1$ & $-5.052 E-1$ & $-3.443 E+0$ & $-1.979 E+0$ \\
\hline 1.4 & $7.184 \mathrm{E}-1$ & $-2.890 \mathrm{E}-1$ & $-5.632 E-1$ & $-3.460 E+0$ & $-1.776 \mathrm{E}+0$ \\
\hline 1.5 & $6.897 \mathrm{E}-1$ & $-2.854 E-1$ & $-6.207 E-1$ & $-3.504 E+0$ & $-1.611 \varepsilon+0$ \\
\hline 1.6 & $6.614 \mathrm{E}-1$ & $-2.799 E-1$ & $-6.772 E-1$ & $-3.572 E+0$ & $-1.477 E+0$ \\
\hline 1.7 & $6.337 \mathrm{E}-1$ & $-2.731 \mathrm{E}-1$ & $-7.326 \mathrm{E}-1$ & $-3.662 E+0$ & $-1.365 E+0$ \\
\hline 1.8 & $6.068 \mathrm{E}-1$ & $-2.651 E-1$ & $-7.864 \mathrm{E}-1$ & $-3.772 E+O$ & $-1.272 E+0$ \\
\hline 1.9 & $5.807 \mathrm{E}-1$ & $-2.563 E-1$ & $-8.386 E-1$ & $-3.902 E+0$ & $-1.193 E+0$ \\
\hline 2.0 & $5.556 \Xi-1$ & $-2.469 E-1$ & $-8.889 E-1$ & $-4.050 E+0$ & $-1.125 E+0$ \\
\hline 2.1 & $5.313 E-1$ & $-2.372 E-1$ & $-9.373 E-1$ & $-4.217 E+0$ & $-1.067 E+0$ \\
\hline 2.2 & $5.081 \mathrm{E}-1$ & $-2.272 E-1$ & $-9.837 E-1$ & $-4.401 E+0$ & $-1.017 E+0$ \\
\hline 2.3 & $4.859 \mathrm{E}-1$ & $-2.172 \mathrm{E}-1$ & $-1.028 E+0$ & $-4.604 E+0$ & $-9.726 E-1$ \\
\hline 2.4 & $4.647 \mathrm{E}-1$ & $-2.073 E-1$ & $-1.071 E+0$ & $-4.824 E+0$ & $-9.340 \mathrm{E}-1$ \\
\hline 2.5 & $4.444 \mathrm{E}-1$ & $-1.975 E-1$ & $-1.111 E+0$ & $-5.063 E+0$ & $-9.000 E-1$ \\
\hline 2.6 & $4.252 E-1$ & $-1.880 E-1$ & $-1.150 E+0$ & $-5.319 E+0$ & $-8.698 E-1$ \\
\hline 2.7 & $4.068 \mathrm{E}-1$ & $-1.788 E-1$ & $-1.186 E+0$ & $-5.594 E+0$ & $-8.429 E-1$ \\
\hline 2.8 & $3.894 \mathrm{E}-1$ & $-1.698 E-1$ & $-1.221 E+0$ & $-5.888 E+0$ & $-8.189 \mathrm{E}-1$ \\
\hline 2.9 & $3.729 E-1$ & $-1.613 E-1$ & $-1.254 E+0$ & $-6.201 E+0$ & $-7.973 E-1$ \\
\hline 3.0 & $3.571 \mathrm{E}-1$ & $-1.531 \mathrm{E}-1$ & $-1.286 E+0$ & $-6.533 E+0$ & $-7.778 \mathrm{E}-1$ \\
\hline 3.1 & $3.422 E-1$ & $-1.452 \mathrm{E}-1$ & $-1.316 E+0$ & $-6.886 E+0$ & $-7.601 E-1$ \\
\hline 3.2 & $3.281 \mathrm{E}-1$ & $-1.378 E-1$ & $-1.344 E+0$ & $-7.258 E+0$ & $-7.441 E-1$ \\
\hline 3.3 & $3.147 \mathrm{E}-1$ & $-1.307 E-1$ & $-1.371 E+0$ & $-7.651 E+0$ & $-7.296 \mathrm{E}-1$ \\
\hline 3.4 & $3.019 \mathrm{E}-1$ & $-1.240 E-1$ & $-1.396 E+0$ & $-8.066 E+0$ & $-7.163 \mathrm{E}-1$ \\
\hline
\end{tabular}


Table 8. Sensitivity coefficients for $R=T_{\infty} / T_{t} \quad$ (Continued) $\gamma=1.40$

\begin{tabular}{|c|c|c|c|c|c|}
\hline$M_{\infty}$ & $\mathrm{R}$ & $\frac{\partial R}{\partial M_{o \infty}^{-}}$ & $\frac{M_{\infty}}{R} \frac{\partial R}{\partial M_{\infty}}$ & $\frac{\partial \mathrm{M}_{\infty}}{\partial \mathrm{R}}$ & $\frac{R}{M_{\infty}} \frac{\partial M_{\infty}}{\partial R}$ \\
\hline 3.5 & $2.899 \mathrm{E}-1$ & $-1.176 \mathrm{E}-1$ & $-1.420 E+0$ & $-8.502 E+0$ & $-7.041 E-1$ \\
\hline 3.6 & $2.784 \mathrm{E}-1$ & $-1.116 E-1$ & $-1.443 E+0$ & $-8.960 E+0$ & $-6.929 E-1$ \\
\hline 3.7 & $2.675 \mathrm{E}-1$ & $-1.059 E-1$ & $-1.465 E+0$ & $-9.441 E+0$ & $-6.826 E-1$ \\
\hline 3.8 & $2.572 E-1$ & $-1.006 \mathrm{E}-1$ & $-1.486 E+0$ & $-9.945 E+0$ & $-6.731 E-1$ \\
\hline 3.9 & $2.474 E-1$ & $-9.548 E-2$ & $-1.505 E+0$ & $-1.047 E+1$ & $-6.644 E-1$ \\
\hline 4.0 & $2.381 E-1$ & $-9.070 \mathrm{E}-2$ & $-1.524 E+0$ & $-1.102 E+1$ & $-6.562 \mathrm{E}-1$ \\
\hline 4.1 & $2.293 E-1$ & $-8.619 E-2$ & $-1.541 E+0$ & $-1.160 E+1$ & $-6.487 E-1$ \\
\hline 4.2 & $2.208 E-1$ & $-8.194 E-2$ & $-1.558 E+0$ & $-1.220 E+1$ & $-6.417 E-1$ \\
\hline 4.3 & $2.129 E-1$ & $-7.793 E-2$ & $-1.574 E+0$ & $-1.283 E+1$ & $-6.352 E-1$ \\
\hline 4.4 & $2.053 E-1$ & $-7.415 E-2$ & $-1.589 E+0$ & $-1.349 E+1$ & $-6.291 E-1$ \\
\hline 4.5 & $1.980 E-1$ & $-7.058 E-2$ & $-1.604 E+0$ & $-1.417 E+1$ & $-6.235 E-1$ \\
\hline 4.6 & $1.911 E-1$ & $-6.722 E-2$ & $-1.618 E+0$ & $-1.488 E+1$ & $-6.181 E-1$ \\
\hline 4.7 & $1.846 \mathrm{E}-1$ & $-6.404 \mathrm{E}-2$ & $-1.631 E+0$ & $-1.561 E+1$ & $-6.132 E-1$ \\
\hline 4.8 & $1.783 \mathrm{E}-1$ & $-6.105 E-2$ & $-1.643 E+0$ & $-1.638 E+1$ & $-6.085 E-1$ \\
\hline 4.9 & $1.724 \mathrm{E}-1$ & $-5.822 E-2$ & $-1.655 E+0$ & $-1.718 E+1$ & $-6.041 E-1$ \\
\hline 5.0 & $1.667 \mathrm{E}-1$ & $-5.556 \mathrm{E}-2$ & $-1.667 E+0$ & $-1.800 E+1$ & $-6.000 \mathrm{E}-1$ \\
\hline 5.1 & $1.612 \mathrm{E}-1$ & $-5.304 E-2$ & $-1.678 E+0$ & $-1.886 E+1$ & $-5.961 E-1$ \\
\hline 5.2 & $1.561 \mathrm{E}-1$ & $-5.065 E-2$ & $-1.688 E+0$ & $-1.974 E+1$ & $-5.925 E-1$ \\
\hline 5.3 & $1.511 E-1$ & $-4.840 E-2$ & $-1.698 E+0$ & $-2.066 E+1$ & $-5.890 \mathrm{E}-1$ \\
\hline 5.4 & $1.464 \mathrm{E}-1$ & $-4.628 E-2$ & $-1.707 E+0$ & $-2.161 E+1$ & $-5.857 E-1$ \\
\hline 5.5 & $1.418 \mathrm{E}-1$ & $-4.426 E-2$ & $-1.716 E+0$ & $-2.259 E+1$ & $-5.826 \mathrm{E}-1$ \\
\hline 5.6 & $1.375 \mathrm{E}-1$ & $-4.236 E-2$ & $-1.725 E+0$ & $-2.361 E+1$ & $-5.797 E-1$ \\
\hline 5.7 & $1.334 \mathrm{E}-1$ & $-4.055 E-2$ & $-1.733 E+0$ & $-2.466 E+1$ & $-5.769 E-1$ \\
\hline 5.8 & $1.294 \mathrm{E}-1$ & $-3.885 E-2$ & $-1.741 E+0$ & $-2.574 E+1$ & $-5.743 E-1$ \\
\hline 5.9 & $1.256 \mathrm{E}-1$ & $-3.723 E-2$ & $-1.749 E+0$ & $-2.686 E+1$ & $-5.718 E-1$ \\
\hline 6.0 & $1.220 \mathrm{E}-1$ & $-3.569 E-2$ & $-1.756 E+0$ & $-2.802 E+1$ & $-5.694 E-1$ \\
\hline 6.1 & $1.185 \mathrm{E}-1$ & $-3.424 E-2$ & $-1.763 E+0$ & $-2.921 E+1$ & $-5.672 E-1$ \\
\hline 6.2 & $1.151 \mathrm{E}-1$ & $-3.286 E-2$ & $-1.770 E+0$ & $-3.044 E+1$ & $-5.650 E-1$ \\
\hline 6.3 & $1.119 \mathrm{E}-1$ & $-3.154 \mathrm{E}-2$ & $-1.776 \mathrm{E}+0$ & $\because 170 \mathrm{E}+1$ & $-5.630 \mathrm{E}-1$ \\
\hline 6.4 & $1.088 E-1$ & $-3.030 E-2$ & $-1.782 E+0$ & $-3.301 E+1$ & $-5.610 E-1$ \\
\hline 6.5 & $1.058 \mathrm{E}-1$ & $-2.911 E-2$ & $-1.788 E+0$ & $-3.435 E+1$ & $-5.592 E-1$ \\
\hline 6.6 & $1.030 \mathrm{E}-1$ & $-2.799 E-2$ & $-1.794 E+0$ & $-3.573 E+1$ & $-5.574 \mathrm{E} .1$ \\
\hline 6.7 & $1.002 E-1$ & $-2.692 E-2$ & $-1.800 E+0$ & $-3.715 E+1$ & $-5.557 E-1$ \\
\hline 6.8 & $9.758 E-2$ & $-2.590 E-2$ & $-1.805 E+0$ & $-3.861 E+1$ & $-5.541 E-1$ \\
\hline 6.9 & $9.504 \mathrm{E}-2$ & $-2.493 E-2$ & $-1.810 E+0$ & $-4.011 E+1$ & $-5.525 E-1$ \\
\hline
\end{tabular}


Table 8. Sensitivity coefficients for $R=T_{\infty} / T_{1} \quad$ (Continued) $\gamma=1.40$

\begin{tabular}{|c|c|c|c|c|c|}
\hline $\mathrm{M}_{\infty}$ & $\mathbf{R}$ & $\frac{\partial \mathrm{R}}{\partial \mathrm{M}_{\infty}}$ & $\frac{M_{\infty}}{R} \frac{\partial R}{\partial M_{\infty}}$ & $\frac{\partial \mathrm{M}_{\infty}}{\partial \mathrm{R}}$ & $\frac{R}{M_{\infty}} \frac{\partial M_{\infty}}{\partial R}$ \\
\hline 7.0 & $9.259 \mathrm{E}-2$ & $-2.401 E-2$ & $-1.815 E+0$ & $-4.166 E+1$ & $-5.510 \mathrm{E}-1$ \\
\hline 7.1 & $9.024 E-2$ & $-2.313 E-2$ & $-1.820 E+0$ & $-4.324 E+1$ & $-5.496 E-1$ \\
\hline 7.2 & 8.797E-2 & $-2.229 E-2$ & $-1.824 E+0$ & $-4.487 E+1$ & $-5.482 E-1$ \\
\hline 7.3 & $8.578 E-2$ & $-2.148 E-2$ & $-1.828 \Gamma+0$ & $-4.654 E+i$ & $-5.469 E-1$ \\
\hline 7.4 & 8.367E-2 & $-2.072 E-2$ & $-1.833 E+0$ & $-4.826 E+1$ & $-5.457 E-1$ \\
\hline 7.5 & $8.163 E-2$ & $-1.999 E-2$ & $-1.837 E+0$ & $-5.002 E+1$ & $-5.444 E-1$ \\
\hline 7.6 & $7.967 E-2$ & $-1.930 E-2$ & $-1.841 E+0$ & $-5.183 E+1$ & $-5.433 E-1$ \\
\hline 7.7 & $7.777 \mathrm{E}-2$ & $-1.863 \mathrm{E}-2$ & $-1.844 E+0$ & $-5.368 E+1$ & $-5.422 E-1$ \\
\hline 7.8 & $7.594 E-2$ & $-1.799 \mathrm{E}-2$ & $-1.848 E+0$ & $-5.558 E+1$ & $-5.411 \mathrm{E}-1$ \\
\hline 7.9 & $7.417 \mathrm{E}-2$ & $-1.739 \mathrm{E}-2$ & $-1.852 E+0$ & $-5.752 E+1$ & $-5.401 E-1$ \\
\hline 8.0 & $7.246 \mathrm{E}-2$ & $-1.680 \mathrm{E}-2$ & $-1.855 E+0$ & $-5.951 E+1$ & $-5.391 E-1$ \\
\hline 8.1 & $7.081 E-2$ & $-1.625 \mathrm{E}-2$ & $-1.858 E+0$ & $-6.155 E+1$ & $-5.381 E-1$ \\
\hline 8.2 & $6.921 E-2$ & $-1.571 E-2$ & $-1.862 E+0$ & $-6.364 E+1$ & $-5.372 E-1$ \\
\hline 8.3 & $6.767 E-2$ & $-1.520 \mathrm{E}-2$ & $-1.865 E+0$ & $-6.578 E+1$ & $-5.363 E-1$ \\
\hline 8.4 & $6.617 E-2$ & $-1.471 E-2$ & $-1.868 E+0$ & $-6.797 E+1$ & $-5.354 E-1$ \\
\hline 8.5 & $6.472 E-2$ & $-1.424 \mathrm{E}-2$ & $-1.871 E+0$ & $-7.021 E+1$ & $-5.346 \mathrm{E}-1$ \\
\hline 8.6 & $6.332 E-2$ & $-1.379 E-2$ & $-1.873 E+0$ & $-7.250 E+1$ & $-5.338 E-1$ \\
\hline 8.7 & $6.197 E-2$ & $-1.336 \mathrm{E}-2$ & $-1.876 E+0$ & $-7.484 E+1$ & $-5.330 E-1$ \\
\hline 8.8 & $6.065 E-2$ & $-1.295 \mathrm{E}-2$ & $-1.879 E+0$ & $-7.723 E+1$ & $-5.323 E-1$ \\
\hline 8.9 & $5.938 E-2$ & $-1.255 \mathrm{E}-2$ & $-1.881 E+0$ & $-7.968 E+1$ & $-5.316 \mathrm{E}-1$ \\
\hline 9.0 & $5.814 \mathrm{E}-2$ & $-1.217 \mathrm{E}-2$ & $-1.884 E+0$ & $-8.218 E+1$ & $-5.309 E-1$ \\
\hline 9.1 & $5.694 \mathrm{E}-2$ & $-1.180 E-2$ & $-1.886 E+0$ & $-8.473 E+1$ & $-5.302 E-1$ \\
\hline 9.2 & $5.578 \mathrm{E}-2$ & $-1.145 E-2$ & $-1.888 E+0$ & $-8.734 E+1$ & $-5.295 E-1$ \\
\hline 9.3 & $5.465 \mathrm{E}-2$ & $-1.111 \mathrm{E}-2$ & $-1.891 E+0$ & $-9.000 E+1$ & $-5.289 E-1$ \\
\hline 9.4 & $5.356 \mathrm{E}-2$ & $-1.078 E-2$ & $-1.893 E+0$ & $-9.272 E+1$ & $-5.283 E-1$ \\
\hline 9.5 & $5.249 E-2$ & $-1.047 \mathrm{E}-2$ & $-1.895 E+0$ & $-9.550 E+1$ & $-5.277 E-1$ \\
\hline 9.6 & $5.146 \mathrm{E}-2$ & $-1.017 E-2$ & $-1.897 E+0$ & $-9.833 E+1$ & $-5.271 E-1$ \\
\hline 9.7 & $5.046 E-2$ & $-9.879 E-3$ & $-1.899 E+0$ & $-1.012 E+2$ & $-5.266 \mathrm{E}-1$ \\
\hline 9.8 & $4.949 E-2$ & $-9.599 \mathrm{E}-3$ & $-1.901 E+0$ & $-1.042 E+2$ & $-5.260 \mathrm{E}-1$ \\
\hline 9.9 & $4.854 \mathrm{E}-2$ & $-9.330 E-3$ & $-1.903 E+0$ & $-1.072 E+2$ & $-5.255 E-1$ \\
\hline 10.0 & $4.762 E-2$ & $-9.070 E-3$ & $-1.905 E+0$ & $-1.103 E+2$ & $-5.250 E-1$ \\
\hline 10.1 & $4.672 E-2$ & $-8.820 E-3$ & $-1.907 E+0$ & $-1.134 E+2$ & $-5.245 E-1$ \\
\hline 10.2 & $4.585 E-2$ & $-8.579 E-3$ & $-1.908 E+0$ & $-1.166 E+2$ & $-5.240 \mathrm{E}-1$ \\
\hline 10.3 & $4.501 \mathrm{E}-2$ & $-8.346 \mathrm{E}-3$ & $-1.910 E+0$ & $-1.198 E+2$ & $-5.236 E-1$ \\
\hline 10.4 & $4.419 E-2$ & $-8.122 E-3$ & $-1.912 E+0$ & $-1.231 E+2$ & $-5.231 \mathrm{E}-1$ \\
\hline
\end{tabular}


Table 8. Sensitivity coefficients for $R=T_{\infty} / T_{t} \quad$ (Continued) $\gamma=1.40$

\begin{tabular}{|c|c|c|c|c|c|}
\hline $\mathbf{M}_{\infty}$ & $\mathbf{R}$ & $\frac{\partial \mathrm{R}}{\partial \mathrm{M}_{\infty}}$ & $\frac{M_{\infty}}{R} \frac{\partial R}{\partial M_{\infty}}$ & $\frac{\partial \mathrm{M}_{\infty}}{\partial \mathrm{R}}$ & $\frac{\mathrm{R}}{\mathrm{M}_{\infty}} \frac{\partial \mathrm{M}_{\infty}}{\partial \mathrm{R}}$ \\
\hline 10.5 & 4.338E-2 & $-7.905 E-3$ & $-1.913 E+0$ & $-1.265 E+2$ & $-5.227 E-1$ \\
\hline 10.6 & $4.260 \mathrm{E}-2$ & $-7.696 \mathrm{E}-3$ & $-1.915 E+0$ & $-1.299 E+2$ & $-5.222 E-1$ \\
\hline 10.7 & $4.184 \mathrm{E}-2$ & $-7.494 E-3$ & $-1.916 E+0$ & $-1.334 E+2$ & $-5.218 E-1$ \\
\hline 10.8 & $4.110 \mathrm{E}-2$ & $-7.299 E-3$ & $-1.918 E+0$ & $-1.370 E+2$ & $-5.214 \Gamma-1$ \\
\hline 10.9 & $4.038 E-2$ & $-7.111 E-3$ & $-1.919 E+0$ & $-1.406 E+2$ & $-5.210 \mathrm{E}-1$ \\
\hline 11.0 & $3.968 E-2$ & $-6.929 E-3$ & $-1.921 E+0$ & $-1.443 E+2$ & $-5.207 E-1$ \\
\hline 11.1 & $3.900 E-2$ & $-6.753 E-3$ & $-1.922 E+0$ & $-1.481 E+2$ & $-5.203 E-1$ \\
\hline 11.2 & $3.833 \mathrm{E}-2$ & $-6.583 E-3$ & $-1.923 E+0$ & $-1.519 E+2$ & $-5.199 \mathrm{E}-1$ \\
\hline 11.3 & $3.768 E-2$ & $-6.418 E-3$ & $-1.925 E+0$ & $-1.558 E+2$ & $-5.196 \mathrm{E}-1$ \\
\hline 11.4 & $3.705 \mathrm{E}-2$ & $-6.259 E-3$ & $-1.926 E+0$ & $-1.598 E+2$ & $-5.192 \mathrm{E}-1$ \\
\hline 11.5 & $3.643 E-2$ & $-6.105 E-3$ & $-1.927 E+0$ & $-1.638 E+2$ & $-5.189 \mathrm{E}-1$ \\
\hline 11.6 & $3.583 \mathrm{E}-2$ & $-5.956 E-3$ & $-1.928 E+0$ & $-1.679 E+2$ & $-5.186 E-1$ \\
\hline 11.7 & $3.524 \mathrm{E}-2$ & $-5.811 E-3$ & $-1.930 E+0$ & $-1.721 E+2$ & $-5.183 E-1$ \\
\hline 11.8 & $3.466 \mathrm{E}-2$ & $-5.672 E-3$ & $-1.931 E+0$ & $-1.763 E+2$ & $-5.180 E-1$ \\
\hline 11.9 & $3.410 \mathrm{E}-2$ & $-5.536 E-3$ & $-1.932 E+0$ & $-1.806 E+2$ & $-5.177 \mathrm{E}-1$ \\
\hline 12.0 & $3.356 \mathrm{E}-2$ & $-5.405 E-3$ & $-1.933 E+0$ & $-1.850 E+2$ & $-5.174 \mathrm{E}-1$ \\
\hline 12.1 & $3.302 E-2$ & $-5.278 E-3$ & $-1.934 E+0$ & $-1.895 E+2$ & $-5.171 \mathrm{E}-1$ \\
\hline 12.2 & $3.250 E-2$ & $-5.155 E-3$ & $-1.935 E+0$ & $-1.940 E+2$ & $-5.168 \mathrm{E}-1$ \\
\hline 12.3 & $3.199 \mathrm{E}-2$ & $-5.036 \mathrm{E}-3$ & $-1.936 E+0$ & $-1.986 E+2$ & $-5.165 E-1$ \\
\hline 12.4 & $3.149 \mathrm{E}-2$ & $-4.920 E-3$ & $-1.937 E+0$ & $-2.033 E+2$ & $-5.163 E-1$ \\
\hline 12.5 & $3.101 \mathrm{E}-2$ & $-4.807 E-3$ & $-1.938 E+0$ & $-2.080 E+2$ & $-5.160 E-1$ \\
\hline 12.6 & $3.053 E-2$ & $-4.698 E-3$ & $-1.939 E+0$ & $-2.128 E+2$ & $-5.157 E-1$ \\
\hline 12.7 & $3.007 \mathrm{E}-2$ & $-4.593 E-3$ & $-1.940 E+0$ & $-2.177 E+2$ & $-5.155 E-1$ \\
\hline 12.8 & $2.961 E-2$ & $-4.490 E-3$ & $-1.941 E+0$ & $-2.227 E+2$ & $-5.153 E-1$ \\
\hline 12.9 & $2.917 \mathrm{E}-2$ & $-4.391 E-3$ & $-1.942 E+0$ & $-2.278 E+2$ & $-5.150 E-1$ \\
\hline 13.0 & $2.874 \mathrm{E}-2$ & $-4.294 E-3$ & $-1.943 E+0$ & $-2.329 E+2$ & $-5.148 E-1$ \\
\hline 13.1 & $2.831 E-2$ & $-4.200 E-3$ & $-1.943 E+0$ & $-2.381 E+2$ & $-5.146 \mathrm{E}-1$ \\
\hline 13.2 & $2.790 \mathrm{E}-2$ & $-4.109 E-3$ & $-1.944 E+0$ & $-2.434 E+2$ & $-5.143 E-1$ \\
\hline 13.3 & $2.749 \mathrm{E}-2$ & $-4.020 E-3$ & $-1.945 E+0$ & $-2.488 E+2$ & $-E .141 E-1$ \\
\hline 13.4 & $2.709 E-2$ & $-3.934 E-3$ & $-1.946 E+0$ & $-2.542 E+2$ & $-5.139 E-1$ \\
\hline 13.5 & $2.670 E-2$ & $-3.850 E-3$ & $-1.947 E+0$ & $-2.597 E+2$ & $-5.137 E-1$ \\
\hline i3.6 & 2:632E-2 & $-3.769 E-3$ & $-1.947 E+0$ & $-2.653 E+2$ & $-5.135 E-1$ \\
\hline 13.7 & $2.595 \mathrm{E}-2$ & $-3.690 E-3$ & $-1.948 E+0$ & $-2.710 E+2$ & $-5.133 \mathrm{E}-1$ \\
\hline 13.8 & $2.55 \mathrm{dE}-2$ & $-3.613 E-3$ & $-1.949 E+0$ & $-2.768 E+2$ & $-5.1: 1 E-1$ \\
\hline 13.9 & $2.523 E-2$ & $-3.538 E-3$ & $-1.950 E+0$ & $-2.826 E+2$ & $-5.129 E-1$ \\
\hline
\end{tabular}


Table 8. Sensitivity coefficients for $R=T_{\infty} / T_{t}$ (Continued) $\gamma=1.40$

\begin{tabular}{|c|c|c|c|c|c|}
\hline $\mathrm{M}_{\infty}$ & $\mathrm{R}$ & $\frac{\partial \mathrm{R}}{\partial \mathrm{M}_{\infty}}$ & $\frac{\mathrm{M}_{\infty} \frac{\partial \mathrm{R}}{\partial}}{\partial \mathrm{M}_{\infty}}$ & $\frac{\partial \mathrm{M}_{\infty}}{\partial \mathrm{R}}$ & $\frac{\mathrm{R}}{\mathrm{M}_{\infty}} \cdot \frac{\partial \mathrm{M}_{\infty}}{\partial \mathrm{R}}$ \\
\hline \hline 14.0 & $2.488 \mathrm{E}-2$ & $-3.465 \mathrm{E}-3$ & $-1.950 \mathrm{E}+0$ & $-2.886 \mathrm{E}+2$ & $-5.128 \mathrm{E}-1$ \\
14.1 & $2.453 \mathrm{E}-2$ & $-3.394 \mathrm{E}-3$ & $-1.951 \mathrm{E}+0$ & $-2.946 \mathrm{E}+2$ & $-5.126 \mathrm{E}-1$ \\
14.2 & $2.420 \mathrm{E}-2$ & $-3.326 \mathrm{E}-3$ & $-1.952 \mathrm{E}+0$ & $-3.007 \mathrm{E}+2$ & $-5.124 \mathrm{E}-1$ \\
14.3 & $2.387 \mathrm{E}-2$ & $-3.258 \mathrm{E}-3$ & $-1.952 \mathrm{E}+0$ & $-3.069 \mathrm{E}+2$ & $-5.122 \mathrm{E}-1$ \\
14.4 & $2.354 \mathrm{E}-2$ & $-3.193 \mathrm{E}-3$ & $-1.953 \mathrm{E}+0$ & $-3.132 \mathrm{E}+2$ & $-5.121 \mathrm{E}-1$ \\
& & & & & \\
14.5 & $2.323 \mathrm{E}-2$ & $-3.130 \mathrm{E}-3$ & $-1.954 \mathrm{E}+0$ & $-3.195 \mathrm{E}+2$ & $-5.119 \mathrm{E}-1$ \\
14.6 & $2.292 \mathrm{E}-2$ & $-3.068 \mathrm{E}-3$ & $-1.954 \mathrm{E}+0$ & $-3.260 \mathrm{E}+2$ & $-5.117 \mathrm{E}-1$ \\
14.7 & $2.262 \mathrm{E}-2$ & $-3.007 \mathrm{E}-3$ & $-1.955 \mathrm{E}+0$ & $-3.325 \mathrm{E}+2$ & $-5.116 \mathrm{E}-1$ \\
14.8 & $2.232 \mathrm{E}-2$ & $-2.949 \mathrm{E}-3$ & $-1.955 \mathrm{E}+0$ & $-3.391 \mathrm{E}+2$ & $-5.114 \mathrm{E}-1$ \\
14.9 & $2.203 \mathrm{E}-2$ & $-2.891 \mathrm{E}-3$ & $-1.956 \mathrm{E}+0$ & $-3.459 \mathrm{E}+2$ & $-5.113 \mathrm{E}-1$ \\
15.0 & $2.174 \mathrm{E}-2$ & $-2.836 \mathrm{E}-3$ & $-1.957 \mathrm{E}+0$ & $-3.527 \mathrm{E}+2$ & $-5.111 \mathrm{E}-1$ \\
\hline
\end{tabular}


Table 9. Sensitivity coefficients for $\mathrm{R}=\mathrm{V}_{\infty} / \mathrm{a}_{\mathrm{t}}$ $\gamma=1.40$

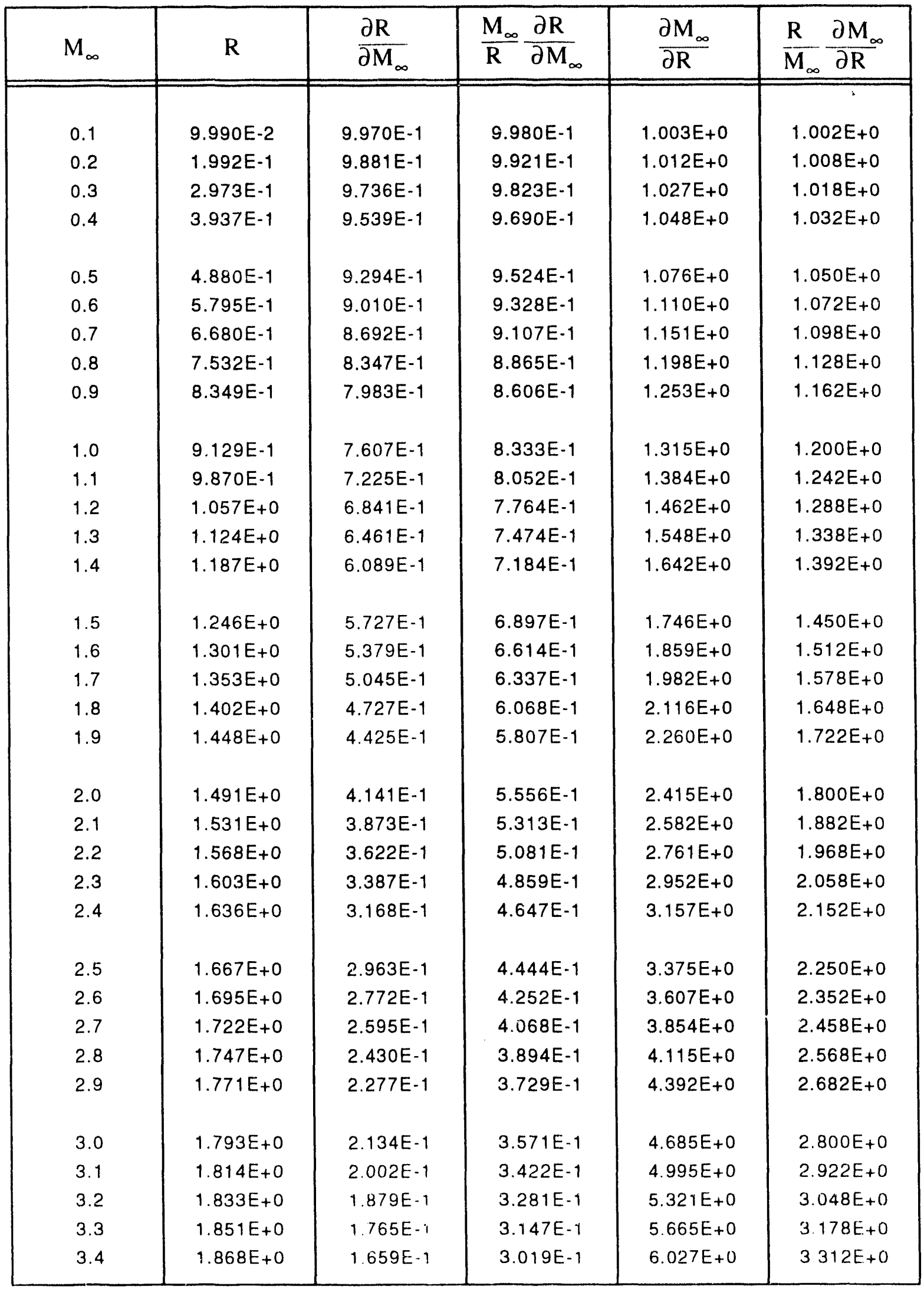


Table 9. Sensitivity coefficients for $R=V_{\infty} / a_{t}$ (Continued) $\gamma=1.40$

\begin{tabular}{|c|c|c|c|c|c|}
\hline $\mathbf{M}_{\infty}$ & $\mathbf{R}$ & $\frac{\partial R}{\partial M_{\infty}}$ & $\frac{M_{\infty}}{R} \frac{\partial R}{\partial M_{\infty}}$ & $\frac{\partial M_{\infty}}{\partial R}$ & $\frac{\mathrm{R}}{\mathrm{M}_{\infty}} \frac{\partial \mathrm{M}_{\infty}}{\partial \mathrm{R}}$ \\
\hline 3.5 & $1.884 E+0$ & $1.561 \mathrm{E}-1$ & $2.899 E-1$ & $6.408 E+0$ & $3.450 E+0$ \\
\hline 3.6 & $1.899 E+0$ & $1.469 \mathrm{E}-1$ & $2.784 E-1$ & $6.808 E+0$ & $3.592 E+0$ \\
\hline 3.7 & $1.914 \mathrm{E}+0$ & $1.384 \mathrm{E}-1$ & $2.675 E-1$ & $7.227 E+0$ & $3.738 E+0$ \\
\hline 3.8 & $1.927 E+0$ & $1.304 \mathrm{E}-1$ & $2.572 E-1$ & $7.666 \mathrm{E}+0$ & $3.888 E+0$ \\
\hline 3.9 & $1.940 E+0$ & $1.231 \mathrm{E}-1$ & $2.474 \mathrm{E}-1$ & $8.126 E+0$ & $4.042 E+0$ \\
\hline 4.0 & $1.952 E+0$ & $1.162 E-1$ & $2.381 E-1$ & $8.607 E+0$ & $4.200 E+0$ \\
\hline 4.1 & $1.963 E+0$ & $1.098 \mathrm{E}-1$ & $2.293 E-1$ & $9.110 E+0$ & $4.362 E+0$ \\
\hline 1.2 & $1.974 \mathrm{E}+0$ & $1.038 \mathrm{E}-1$ & $2.208 E-1$ & $9.635 E+0$ & $4.528 E+0$ \\
\hline 4.3 & $1.984 E+0$ & $9.820 \mathrm{E}-2$ & $2.129 \mathrm{E}-1$ & $1.018 E+1$ & $4.698 E+0$ \\
\hline 4.4 & $1.993 E+0$ & $9.299 E-2$ & $2.053 E-1$ & $1.075 E+1$ & $4.872 E+0$ \\
\hline 4.5 & $2.002 E+0$ & $8.812 E-2$ & $1.980 E-1$ & $1.135 E+1$ & $5.050 E+0$ \\
\hline 4.6 & $2.011 E+0$ & 8.356E-2 & $1.911 E-1$ & $1.197 E+1$ & $5.232 E+0$ \\
\hline 4.7 & $2.019 E+0$ & 7.929E-2 & $1.846 \mathrm{E}-1$ & $1.261 E+1$ & $5.418 E+0$ \\
\hline 4.8 & $2.027 E+0$ & $7.530 \mathrm{E}-2$ & $1.783 E-1$ & $1.328 E+1$ & $5.608 E+0$ \\
\hline 4.9 & $2.034 E+0$ & $7.155 \mathrm{E}-2$ & $1.724 \mathrm{E}-1$ & $1.398 E+1$ & $5.802 E+0$ \\
\hline 5.0 & $2.041 E+0$ & $6.804 \mathrm{E}-2$ & $1.667 E-1$ & $1.470 E+1$ & $6.000 E+0$ \\
\hline 5.1 & $2.048 E+0$ & $6.474 \mathrm{E}-2$ & $1.612 E-1$ & $1.545 E+1$ & $6.202 E+0$ \\
\hline 5.2 & $2.054 E+0$ & $6.165 E-2$ & $1.561 E-1$ & $1.622 E+1$ & $6.408 E+0$ \\
\hline 5.3 & $2.060 E+0$ & $5.874 \mathrm{E}-2$ & $1.511 \mathrm{E}-1$ & $1.703 E+1$ & $6.618 E+0$ \\
\hline 5.4 & $2.066 E+0$ & $5.600 E-2$ & $1.464 \mathrm{E}-1$ & $1.786 \mathrm{E}+1$ & $6.832 E+0$ \\
\hline 5.5 & $2.071 E+0$ & $5.342 \mathrm{E}-2$ & $1.418 E-1$ & $1.872 E+1$ & $7.050 E+0$ \\
\hline 5.6 & $2.077 E+0$ & $5.099 \mathrm{E}-2$ & $1.375 E-1$ & $1.961 E+1$ & $7.272 E+0$ \\
\hline 5.7 & $2.082 E+0$ & $4.871 E-2$ & $1.334 \mathrm{E}-1$ & $2.053 E+1$ & $7.498 E+0$ \\
\hline 5.8 & $2.086 E+0$ & $4.655 \mathrm{E}-2$ & $1.294 E-1$ & $2.148 E+1$ & $7.728 E+0$ \\
\hline 5.9 & $2.091 E+0$ & $4.451 \mathrm{E}-2$ & $1.256 \mathrm{E}-1$ & 2.247E+1 & $7.962 E+0$ \\
\hline 6.0 & $2.095 E+0$ & $4.259 E-2$ & $1.220 E-1$ & $2.348 E+1$ & $8.200 E+0$ \\
\hline 6.1 & $2.099 E+0$ & 4.077E-2 & $1.185 E-1$ & $2.453 E+1$ & $8.442 E+0$ \\
\hline 6.2 & $2.103 E+0$ & $3.905 \mathrm{E}-2$ & $1.151 E-1$ & $2.561 E+1$ & $8.688 E+0$ \\
\hline 6.3 & $2.1075+0$ & $3.742 \mathrm{E}-2$ & $1.119 \mathrm{E}-1$ & $2.672 E+1$ & $8.938 E+0$ \\
\hline 6.4 & $2.111 E+0$ & $3.588 E-2$ & $1.088 E-1$ & $2.787 E+1$ & $9.192 E+0$ \\
\hline 6.5 & $2.114 E+0$ & $3.442 E-2$ & $1.058 E-1$ & $2.905 E+1$ & $9.450 E+0$ \\
\hline 6.6 & $2.118 E+0$ & $3.304 E-2$ & $1.030 \mathrm{E}-1$ & $3.027 E+1$ & 9. ${ }^{\top} 12 E+0$ \\
\hline 6.7 & $2.121 E+0$ & $3.173 E-2$ & $1.002 E-1$ & $3.152 E+1$ & $9.978 E+0$ \\
\hline 6.8 & $2.124 E+0$ & $3.048 E-2$ & $9.758 \mathrm{E}-2$ & $3.281 E+i$ & $1.025 E+1$ \\
\hline 6.9 & $2.127 E+0$ & $2.930 E-2$ & $9.504 E-2$ & $3.413 E+1$ & $1.052 \bar{E}+1$ \\
\hline
\end{tabular}


Table 9. Sensitivity coefficients for $R=V_{\infty} / a_{t} \quad$ (Continued) $\gamma=1.40$

\begin{tabular}{|c|c|c|c|c|c|}
\hline$M_{\infty}$ & $\mathbf{R}$ & $\frac{\partial R}{\partial M_{\infty}}$ & $\frac{M_{\infty}}{R} \frac{\partial R}{\partial M_{\infty}}$ & $\frac{\partial M_{\infty}}{\partial R}$ & $\frac{\mathrm{R}}{\mathrm{M}_{\infty}} \frac{\partial \mathrm{M}_{\infty}}{\partial \mathrm{R}}$ \\
\hline 7.0 & $2.130 E+0$ & $2.818 E-2$ & $9.259 \mathrm{E}-2$ & $3.549 E+1$ & $1.080 E+1$ \\
\hline 7.1 & $2.133 E+0$ & $2.711 E-2$ & $9.024 E-2$ & $3.689 E+1$ & $1.108 E+1$ \\
\hline 7.2 & $2.135 E+0$ & $2.609 \mathrm{E}-2$ & $8.797 E-2$ & $3.833 E+1$ & $1.137 E+1$ \\
\hline 7.3 & $2.138 E+0$ & $2.512 E-2$ & $8.578 E-2$ & $3.980 E+1$ & $1.166 \mathrm{E}+1$ \\
\hline 7.4 & $2.140 E+0$ & $2.420 E-2$ & 8.367E-2 & 4. $132 E+1$ & $1.195 E+1$ \\
\hline 7.5 & $2.143 E+0$ & $2.332 \mathrm{E}-2$ & $8.163 E-2$ & $4.287 E+1$ & $1.225 E+1$ \\
\hline 7.6 & $2.145 E+0$ & $2.249 E-2$ & $7.967 E-2$ & $4.447 E+1$ & $1.255 E+1$ \\
\hline 7.7 & $2.147 E+0$ & 2.169E-2 & 7.777E-2 & $4.611 E+1$ & $1.286 E+1$ \\
\hline 7.8 & $2.149 E+0$ & $2.093 \mathrm{E}-2$ & $7.594 E-2$ & $4.778 E+1$ & $1.317 E+1$ \\
\hline 7.9 & $2.152 E+0$ & $2.020 \mathrm{E}-2$ & $7.417 E-2$ & $4.950 E+1$ & $1.348 E+1$ \\
\hline 8.0 & $2.154 E+0$ & $1.951 \mathrm{E}-2$ & $7.246 E-2$ & $5.126 \mathrm{E}+1$ & $1.380 E+1$ \\
\hline 8.1 & $2.155 E+0$ & $1.884 \mathrm{E}-2$ & $7.081 \mathrm{E}-2$ & $5.307 E+1$ & $1.412 E+1$ \\
\hline 8.2 & $2.157 E+0$ & $1.821 E-2$ & $6.921 E-2$ & $5.492 E+1$ & $1.445 E+1$ \\
\hline 8.3 & $2.159 E+0$ & $1.760 \mathrm{E}-2$ & $6.767 E-2$ & $5.681 E+1$ & $1.478 E+1$ \\
\hline 8.4 & 2.161E+0 & $1.702 E-2$ & $6.617 \mathrm{E}-2$ & $5.875 E+1$ & $1.511 E+1$ \\
\hline 8.5 & $2.162 E+0$ & $1.647 \mathrm{E}-2$ & $6.472 E-2$ & $6.073 E+1$ & $1.545 E+1$ \\
\hline 8.6 & $2.164 E+0$ & $1.593 \mathrm{E}-2$ & $6.332 E-2$ & $6.276 E+1$ & $1.579 E+1$ \\
\hline 8.7 & $2.166 E+0$ & $1.543 E-2$ & $6.197 E-2$ & $6.483 E+1$ & $1.614 E+1$ \\
\hline 8.8 & $2.167 E+0$ & $1.494 \mathrm{E}-2$ & $6.065 E-2$ & $6.695 E+1$ & $1.649 E+1$ \\
\hline 8.9 & $2.169 E+0$ & $1.447 \mathrm{E}-2$ & $5.938 E-2$ & $6.912 E+1$ & $1.684 E+1$ \\
\hline 9.0 & $2.170 E+0$ & $1.402 E-2$ & $5.814 E-2$ & $7.133 E+1$ & $1.720 E+1$ \\
\hline 9.1 & $2.171 E+0$ & 1.359E-2 & $5.694 \mathrm{E}-2$ & $7.360 \mathrm{E}+1$ & $1.756 E+1$ \\
\hline 9.2 & $2.173 E+0$ & 1.317E-2 & $5.578 E-2$ & $7.591 E+1$ & $1.793 E+1$ \\
\hline 9.3 & $2.174 E+0$ & $1.278 E-2$ & $5.465 \mathrm{E}-2$ & $7.827 E+1$ & $1.830 E+1$ \\
\hline 9.4 & $2.175 E+0$ & $1.239 E-2$ & $5.356 \mathrm{E}-2$ & $8.068 E+1$ & $1.867 E+1$ \\
\hline 9.5 & $2.177 E+0$ & $1.203 E-2$ & $5.249 E-2$ & $8.315 E+1$ & $1.905 E+1$ \\
\hline 9.6 & $2.178 E+0$ & $1.167 E-2$ & $5.146 E-2$ & $8.566 E+1$ & $1.943 E+1$ \\
\hline 9.7 & 2. $179 E+0$ & 1.133E-2 & $5.046 \mathrm{E}-2$ & $8.822 E+1$ & $1.982 E+1$ \\
\hline 9.8 & $2.180 E+0$ & $1.101 \mathrm{E}-2$ & $4.949 \mathrm{E}-2$ & $9.084 E+1$ & $2.021 E+1$ \\
\hline 9.9 & $2.181 E+0$ & $1.069 \mathrm{E}-2$ & $4.854 \mathrm{E}-2$ & $9.351 E+1$ & 2.06nE+1 \\
\hline 10.0 & $2.182 E+0$ & $1.039 E-2$ & $4.762 E-2$ & $9.6<3 E+1$ & 2. $100 E+1$ \\
\hline 10.1 & $2.183 E+0$ & $1.010 \mathrm{E}-2$ & $4.672 E-2$ & $9.901 E+1$ & $2.140 E+1$ \\
\hline 10.2 & 2. $184 E+0$ & $9.819 E-3$ & $4.585 E-2$ & $1.018 E+2$ & $2.181 E+1$ \\
\hline 10.3 & $2.185 E+0$ & $9.549 E-3$ & $4.501 \mathrm{E}-2$ & $1.047 E+?$ & $2.222 E+1$ \\
\hline 104 & $2.186 E+0$ & $9.288 E-3$ & $4.419 E-2$ & $1.077 E+2$ & $2.263 E+1$ \\
\hline
\end{tabular}




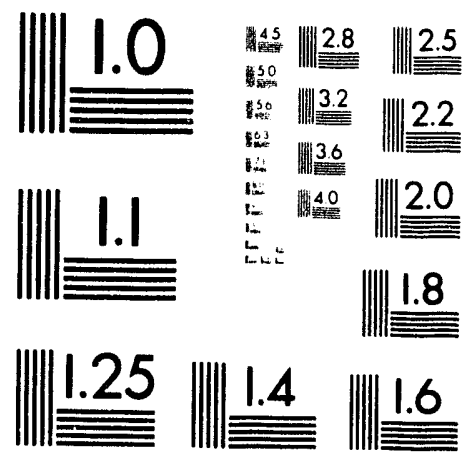



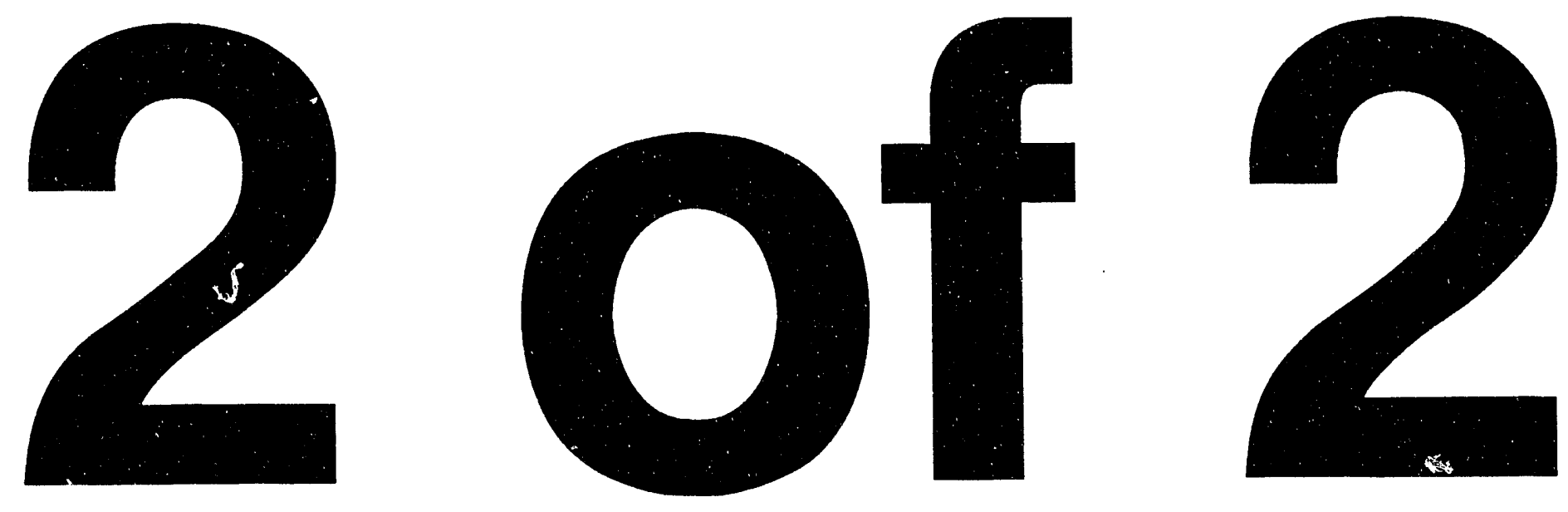
Table 9. Sensitivity coefficients for $R=V_{\infty} / a_{t} \quad$ (Continued) $\gamma=1.40$

\begin{tabular}{|c|c|c|c|c|c|}
\hline$M_{\infty}$ & $\mathrm{R}$ & $\frac{\partial R}{\partial M_{\infty}}$ & $\frac{M_{\infty}}{R} \frac{\partial R}{\partial M_{\infty}}$ & $\frac{\partial \mathbf{M}_{\infty}}{\partial R}$ & $\frac{\mathrm{R}}{\mathrm{M}_{\infty}} \frac{\partial \mathrm{M}_{\infty}}{\partial \mathrm{R}}$ \\
\hline 10.5 & $2.187 E+0$ & $9.036 \mathrm{E}-3$ & 4.338E-2 & $1.107 E+2$ & $2.305 E+1$ \\
\hline 10.6 & $2.188 E+0$ & $8.794 E-3$ & $4.260 \mathrm{E}-2$ & $1.137 E+2$ & $2.347 E+1$ \\
\hline 10.7 & $2.189 E+0$ & $8.560 E-3$ & $4.184 \mathrm{E}-2$ & $1.168 E+2$ & $2.390 E+1$ \\
\hline 10.8 & $2.190 E+0$ & $8.334 \mathrm{E}-3$ & 4.110E-2 & $1.200 E+2$ & $2.433 E+1$ \\
\hline 10.9 & $2.190 E+0$ & $8.116 E-3$ & $4.038 E-2$ & $1.232 E+2$ & 2. $476 E+1$ \\
\hline 11.0 & $2.191 E+0$ & $7.905 E-3$ & $3.968 E-2$ & $1.265 E+2$ & $2.520 E+1$ \\
\hline 11.1 & $2.192 E+0$ & $7.701 E-3$ & $3.900 \mathrm{E}-2$ & $1.298 E+2$ & $2.564 E+1$ \\
\hline 11.2 & $2.193 E+0$ & $7.505 E-3$ & 3.833E-2 & $1.332 E+2$ & $2.609 E+1$ \\
\hline 11.3 & 2.194E+0 & $7.315 \mathrm{E}-3$ & $3.768 E-2$ & $1.367 E+2$ & $2.654 E+1$ \\
\hline 11.4 & $2.194 E+0$ & $7.131 \mathrm{E}-3$ & $3.705 E-2$ & $1.402 E+2$ & $2.699 E+1$ \\
\hline 11.5 & $2.195 E+0$ & $6.953 E-3$ & $3.643 E-2$ & $1.438 E+2$ & $2.745 E+1$ \\
\hline 11.6 & $2.196 E+0$ & $6.781 \mathrm{E}-3$ & $3.583 E-2$ & $1.475 E+2$ & $2.791 E+1$ \\
\hline 11.7 & $2.196 E+0$ & $6.615 \mathrm{E}-3$ & $3.524 E-2$ & $1.512 E+2$ & $2.838 E+1$ \\
\hline 11.8 & $2.197 E+0$ & $6.454 \mathrm{E}-3$ & $3.466 \mathrm{E}-2$ & $1.549 E+2$ & $2.885 E+1$ \\
\hline 11.9 & $2.198 E+0$ & $6.298 E-3$ & $3.410 E-2$ & $1.588 \mathrm{E}+2$ & $2.932 E+1$ \\
\hline 12.0 & $2.198 E+0$ & $6.147 \mathrm{E}-3$ & $3.356 \mathrm{E}-2$ & $1.627 E+2$ & $2.980 E+1$ \\
\hline 12.1 & $2.199 E+0$ & $6.001 E-3$ & $3.302 E-2$ & $1.666 \mathrm{E}+2$ & $3.028 E+1$ \\
\hline 12.2 & $2.199 E+0$ & $5.859 E-3$ & $3.250 \mathrm{E}-2$ & $1.707 E+2$ & $3.077 E+1$ \\
\hline 12.3 & $2.200 E+0$ & $5.722 E-3$ & $3.199 E-2$ & $1.748 E+2$ & $3.126 E+1$ \\
\hline 12.4 & $2.201 E+0$ & $5.589 E-3$ & $3.149 \mathrm{E}-2$ & $1.789 E+2$ & 3. $175 E+1$ \\
\hline 12.5 & $2.201 E+0$ & $5.460 E-3$ & $3.101 E-2$ & $1.831 E+2$ & $3.225 E+1$ \\
\hline 12.6 & $2.202 E+0$ & $5.335 E-3$ & $3.053 E-2$ & $1.874 E+2$ & $3.275 E+1$ \\
\hline 12.7 & $2.202 E+0$ & $5.214 \mathrm{E}-3$ & $3.007 E-2$ & $1.918 E+2$ & $3.326 E+1$ \\
\hline 12.8 & $2.203 E+0$ & $5.096 \mathrm{E}-3$ & $2.961 E-2$ & $1.962 E+2$ & $3.377 E+1$ \\
\hline 12.9 & $2.203 E+0$ & $4.982 E-3$ & $2.917 E-2$ & $2.007 E+2$ & $3.428 E+1$ \\
\hline 13.0 & $2.204 E+0$ & $4.871 E-3$ & $2.874 E-2$ & $2.053 E+2$ & $3.480 E+1$ \\
\hline 13.1 & $2.204 E+0$ & $4.764 \mathrm{E}-3$ & 2.831E-2 & $2.099 E+2$ & $3.532 E+1$ \\
\hline 13.2 & $2.205 E+0$ & $4.659 E-3$ & $2.790 \mathrm{E}-2$ & $2.146 E+2$ & $3.585 E+1$ \\
\hline 13.3 & $2.205 E+0$ & $4.558 E-3$ & $2.749 \mathrm{E}-2$ & $2.194 E+2$ & $3.638 E+1$ \\
\hline 13.4 & $2.206 E+0$ & $4.459 E-3$ & $2.709 E-2$ & $2.243 E+2$ & $3.691 E+1$ \\
\hline 13.5 & $2.206 E+0$ & $4.363 E-3$ & $2.670 E-2$ & $2.292 E+2$ & $3.745 E+1$ \\
\hline 13.6 & $2.206 \mathrm{E}+0$ & $4.270 \mathrm{E}-3$ & 2.632E-2 & $2.342 E+2$ & $3.799 E+1$ \\
\hline 13.7 & $2.207 E+0$ & $4.180 E-3$ & $2.595 E-2$ & $2.392 E+2$ & $3.854 E+1$ \\
\hline 13.8 & $2.207 E+0$ & $4.092 E-3$ & $2.558 \mathrm{E}-2$ & $2.444 E+2$ & $3.909 E+1$ \\
\hline 13.9 & $2.208 E+0$ & $4.007 \mathrm{E}-3$ & $2.523 E-2$ & $2.496 \mathrm{E}+2$ & $3.964 E+1$ \\
\hline
\end{tabular}


lable 9. Sensitivity coefficients for $R=V_{\infty} / a_{t} \quad$ (Continued) $\gamma=1.40$

\begin{tabular}{|c|c|c|c|c|c|}
\hline$M_{\infty}$ & $R$ & $\frac{\partial R}{\partial M_{\infty}}$ & $\frac{M_{\infty} \frac{\partial R}{\partial M_{\infty}}}{R}$ & $\frac{\partial M_{\infty}}{\partial R}$ & $\frac{R}{M_{\infty}} \partial \mathrm{R}$ \\
\hline \hline 14.0 & $2.208 E+0$ & $3.923 E-3$ & $2.488 E-2$ & $2.549 E+2$ & $4.020 E+1$ \\
14.1 & $2.208 E+0$ & $3.843 E-3$ & $2.453 E-2$ & $2.602 E+2$ & $4.076 E+1$ \\
14.2 & $2.209 E+0$ & $3.764 E-3$ & $2.420 E-2$ & $2.657 E+2$ & $4.133 E+1$ \\
14.3 & $2.209 E+0$ & $3.687 E-3$ & $2.387 E-2$ & $2.712 E+2$ & $4.190 E+1$ \\
14.4 & $2.210 E+0$ & $3.613 E-3$ & $2.354 E-2$ & $2.768 E+2$ & $4.247 E+1$ \\
& & & & & \\
14.5 & $2.210 E+0$ & $3.540 E-3$ & $2.323 E-2$ & $2.825 E+2$ & $4.305 E+1$ \\
14.6 & $2.210 E+0$ & $3.470 E-3$ & $2.292 E-2$ & $2.882 E+2$ & $4.363 E+1$ \\
14.7 & $2.211 E+0$ & $3.401 E-3$ & $2.262 E-2$ & $2.940 E+2$ & $4.422 E+1$ \\
14.8 & $2.211 E+0$ & $3.334 E-3$ & $2.232 E-2$ & $2.999 E+2$ & $4.481 E+1$ \\
14.9 & $2.211 E+0$ & $3.269 E-3$ & $2.203 E-2$ & $3.059 E+2$ & $4.540 E+1$ \\
15.0 & $2.212 E+0$ & $3.205 E-3$ & $2.174 E-2$ & $3.120 E+2$ & $4.600 E+1$ \\
\hline
\end{tabular}


Table 10 . Sensitivity coefficients for $\mathrm{Re}$, linear viscosity relation $\gamma=1.40$

\begin{tabular}{|c|c|c|}
\hline$M_{\infty}$ & $\mathrm{Re} / \mathrm{Re}^{*}$ & $\frac{M_{\infty}}{R e} \frac{\partial R e}{\partial M_{\infty}}$ \\
\hline 0.1 & $1.434 \mathrm{E}-1$ & $9.920 \mathrm{E}-1$ \\
\hline 0.2 & $2.834 E-1$ & $9.683 \mathrm{E}-1$ \\
\hline 0.3 & $4.169 \mathrm{E}-1$ & $9.293 E-1$ \\
\hline 0.4 & $5.408 \mathrm{E}-1$ & $8.760 \mathrm{E}-1$ \\
\hline 0.5 & $6.531 \mathrm{E}-1$ & $8.095 E-1$ \\
\hline 0.6 & $7.518 E-1$ & $7.313 E-1$ \\
\hline 0.7 & $8.361 E-1$ & $6.430 \mathrm{E}-1$ \\
\hline 0.8 & $9.054 \mathrm{E}-1$ & $5.461 \mathrm{E}-1$ \\
\hline 0.9 & $9.598 E-1$ & $4.423 E-1$ \\
\hline 1.0 & $1.000 E+0$ & $3.333 E-1$ \\
\hline 1.1 & $1.027 E+0$ & $2.206 \mathrm{E}-1$ \\
\hline 1.2 & $1.042 E+0$ & $1.056 \mathrm{E}-1$ \\
\hline 1.3 & $1.046 E+0$ & $-1.046 E-2$ \\
\hline 1.4 & $1.040 E+0$ & $-1.264 \mathrm{E}-1$ \\
\hline 1.5 & $1.027 E+0$ & $-2.414 \mathrm{E}-1$ \\
\hline 1.6 & $1.008 E+0$ & $-3.545 E-1$ \\
\hline 1.7 & $9.831 E-1$ & $-4.651 E-1$ \\
\hline 1.8 & $9.544 \mathrm{E}-1$ & $-5.728 E-1$ \\
\hline 1.9 & $9.227 E-1$ & $-6.771 E-1$ \\
\hline 2.0 & $8.889 E-1$ & $-7.778 E-1$ \\
\hline 2.1 & $8.538 E-1$ & $-8.746 \mathrm{E}-1$ \\
\hline 2.2 & $8.180 E-1$ & $-9.675 E-1$ \\
\hline 2.3 & $7.820 \mathrm{E}-1$ & $-1.056 E+0$ \\
\hline 2.4 & $7.463 E-1$ & $-1.141 E+0$ \\
\hline 2.5 & $7.111 \mathrm{E}-1$ & $-1.222 E+0$ \\
\hline 2.6 & $6.768 \mathrm{E}-1$ & $-1.299 E+0$ \\
\hline 2.7 & $6.435 E-1$ & $-1.373 E+0$ \\
\hline 2.8 & $6.114 \mathrm{E}-1$ & $-1.442 E+0$ \\
\hline 2.9 & $5.806 \mathrm{E}-1$ & $-1.509 E+0$ \\
\hline 3.0 & $5.510 E-1$ & $-1.571 E+0$ \\
\hline 3.1 & $5.228 \mathrm{E}-1$ & $-1.631 E+0$ \\
\hline 3.2 & $4.960 \mathrm{E}-1$ & $-1.688 E+0$ \\
\hline 3.3 & $4.705 E-1$ & $-1.741 E+0$ \\
\hline 3.4 & $4.463 E-1$ & $-1.792 E+0$ \\
\hline
\end{tabular}


Table 10. Sensitivity coefficients for Re. linear viscosity relation $\gamma=1.40 \quad$ (Continued)

\begin{tabular}{|c|c|c|}
\hline$M_{\infty}$ & $\mathrm{Re} / \mathrm{Re}^{*}$ & $\frac{M_{\infty}}{\operatorname{Re}} \frac{\partial R e}{\partial M_{\infty}}$ \\
\hline 3.5 & $4.234 \mathrm{E}-1$ & $-1.841 E+0$ \\
\hline 3.6 & $4.018 E-1$ & $-1.886 E+0$ \\
\hline 3.7 & $3.813 E-1$ & $-1.930 E+0$ \\
\hline 3.8 & $3.620 \mathrm{E}-1$ & $-1.971 E+0$ \\
\hline 3.9 & $3.437 \mathrm{E}-1$ & $-2.010 E+0$ \\
\hline 4.0 & $3.265 \mathrm{E}-1$ & $-2.048 E+0$ \\
\hline 4.1 & $3.103 E-1$ & $-2.083 E+0$ \\
\hline 4.2 & $2.950 E-1$ & $-2.117 E+0$ \\
\hline 4.3 & $2.805 E-1$ & $-2.149 E+0$ \\
\hline 4.4 & $2.669 \mathrm{E}-1$ & $-2.179 E+0$ \\
\hline 4.5 & $2.54 \mid E-1$ & $-2.208 E+0$ \\
\hline 4.6 & $2.420 \mathrm{E}-1$ & $-2.235 E+0$ \\
\hline 4.7 & $2.306 \mathrm{E}-1$ & $-2.262 E+0$ \\
\hline 4.8 & $2.198 \mathrm{E}-1$ & $-2.287 E+0$ \\
\hline 4.9 & $2.096 \mathrm{E}-1$ & $-2.311 E+0$ \\
\hline 5.0 & $2.000 \mathrm{E}-1$ & $-2.333 E+0$ \\
\hline 5.1 & $1.909 \mathrm{E}-1$ & $-2.355 E+0$ \\
\hline 5.2 & $1.824 \mathrm{E}-1$ & $-2.376 E+0$ \\
\hline 5.3 & $1.743 E-1$ & $-2.396 E+0$ \\
\hline 5.4 & $1.666 \mathrm{E}-1$ & $-2.415 E+0$ \\
\hline 5.5 & $1.593 \mathrm{E}-1$ & $-2.433 E+0$ \\
\hline 5.6 & $1.525 \mathrm{E}-1$ & $-2.450 E+0$ \\
\hline 5.7 & $1.460 \mathrm{E}-1$ & $-2.467 E+0$ \\
\hline 5.8 & $1.398 \mathrm{E}-1$ & $-2.482 E+0$ \\
\hline 5.9 & $1.340 \mathrm{E}-1$ & $-2.498 E+0$ \\
\hline 6.0 & $1.285 \mathrm{E}-1$ & $-2.512 E+0$ \\
\hline 6.1 & $1.233 E-1$ & $-2.526 E+0$ \\
\hline 6.2 & $1.183 E-1$ & $-2.540 E+0$ \\
\hline 6.3 & $1.136 \mathrm{E}-1$ & $-2.552 E+0$ \\
\hline 6.4 & $1.091 \mathrm{E}-1$ & $-2.565 E+0$ \\
\hline 6.5 & $1.048 \mathrm{E}-1$ & $-2.577 E+0$ \\
\hline 6.6 & $1.008 \mathrm{E}-1$ & $-2.588 E+0$ \\
\hline 6.7 & $9.691 \mathrm{E}-2$ & $-2.599 E+0$ \\
\hline 6.8 & $9.324 E-2$ & $-2.610 E+0$ \\
\hline 6.9 & $8.975 E-2$ & $-2.620 E+0$ \\
\hline
\end{tabular}


Table 10. Sensitivity coefficients for $\mathrm{Re}$, linear viscosity relation $\gamma=1.4() \quad$ (Continued)

\begin{tabular}{|c|c|c|}
\hline$M_{\infty}$ & $\mathrm{Re} / \mathrm{Re}^{*}$ & $\frac{\mathrm{M}_{\infty}}{\mathrm{Re}} \frac{\partial \mathrm{Re}}{\partial \mathrm{M}_{\infty}}$ \\
\hline 7.0 & $8.642 \mathrm{E}-2$ & $-2.630 E+0$ \\
\hline 7.1 & $8.325 E-2$ & $-2.639 E+0$ \\
\hline 7.2 & $8.023 E-2$ & $-2.648 E+0$ \\
\hline 7.3 & $7.735 E-2$ & $-2.657 E+0$ \\
\hline 7.4 & $7.460 \mathrm{E}-2$ & $-2.665 E+0$ \\
\hline 7.5 & $7.197 \mathrm{E}-2$ & $-2.673 E+0$ \\
\hline 7.6 & $6.946 E-2$ & $-2.681 E+0$ \\
\hline 7.7 & $6.707 \mathrm{E}-2$ & $-2.689 E+0$ \\
\hline 7.8 & $6.478 E-2$ & $-2.696 E+0$ \\
\hline 7.9 & $6.259 \mathrm{E}-2$ & $-2.703 E+0$ \\
\hline 8.0 & $6.049 E-2$ & $-2.710 E+0$ \\
\hline 8.1 & $5.849 E-2$ & $-2.717 E+0$ \\
\hline 8.2 & $5.657 \mathrm{E}-2$ & $-2.723 E+0$ \\
\hline 8.3 & $5.473 E-2$ & $-2.729 E+0$ \\
\hline 8.4 & $5.297 \mathrm{E}-2$ & $-2.735 E+0$ \\
\hline 8.5 & $5.128 E-2$ & $-2.741 E+0$ \\
\hline 8.6 & $4.966 \mathrm{E}-2$ & $-2.747 E+0$ \\
\hline 8.7 & $4.810 \mathrm{E}-2$ & $-2.752 E+0$ \\
\hline 8.8 & $4.661 E-2$ & $-2.757 E+0$ \\
\hline 8.9 & $4.518 E-2$ & $-2.762 E+0$ \\
\hline 9.0 & $4.381 E-2$ & $-2.767 E+0$ \\
\hline 9.1 & $4.249 E-2$ & $-2.772 E+0$ \\
\hline 9.2 & $4.122 E-2$ & $-2.777 E+0$ \\
\hline 9.3 & $4.000 E-2$ & $-2.781 E+0$ \\
\hline 9.4 & $3.882 E-2$ & $-2.786 E+0$ \\
\hline 9.5 & $3.770 \mathrm{E}-2$ & $-2.790 E+0$ \\
\hline 9.6 & $3.661 \mathrm{E}-2$ & $-2.794 E+0$ \\
\hline 9.7 & $3.556 \mathrm{E}-2$ & $-2.798 E+0$ \\
\hline 9.8 & $3.456 \mathrm{E}-2$ & $-2.802 E+0$ \\
\hline 9.9 & $3.359 \mathrm{E}-2$ & $-2.806 E+0$ \\
\hline 10.0 & $3.265 E-2$ & $-2.810 E+0$ \\
\hline 10.1 & $3.175 \mathrm{E}-2$ & $-2.813 E+0$ \\
\hline 10.2 & $3.088 \mathrm{E}-2$ & $-2.817 E+0$ \\
\hline 10.3 & $3.005 E-2$ & $-2.820 E+0$ \\
\hline 10.4 & $2.924 E-2$ & $-2.823 E+0$ \\
\hline
\end{tabular}


Table 10: Sensitivity coefficients for $\mathrm{Re}$, linear viscosity relation $\gamma=1.40 \quad$ (Continued)

\begin{tabular}{|c|c|c|}
\hline$M_{\infty}$ & $\mathrm{Re} / \mathrm{Re}^{*}$ & $\frac{M_{\infty}}{\operatorname{Re}} \frac{\partial \operatorname{Re}}{\partial M_{\infty}}$ \\
\hline 10.5 & $2.846 \mathrm{E}-2$ & $-2.826 E+0$ \\
\hline 10.6 & $2.771 \mathrm{E}-2$ & $-2.830 E+0$ \\
\hline 10.7 & $2.698 E-2$ & $-2.833 E+0$ \\
\hline 10.8 & $2.628 \mathrm{E}-2$ & $-2,836 E+0$ \\
\hline 10.9 & $2.560 \mathrm{E}-2$ & $-2.838 E+0$ \\
\hline 11.0 & $2.494 \mathrm{E}-2$ & $-2.841 E+0$ \\
\hline 11.1 & $2.431 \mathrm{E}-2$ & $-2.844 E+0$ \\
\hline 11.2 & $2.370 E-2$ & $-2.847 E+0$ \\
\hline 11.3 & $2.310 E-2$ & $-2.849 E+0$ \\
\hline 11.4 & $2.253 E-2$ & $-2.852 E+0$ \\
\hline 11.5 & $2.198 E-2$ & $-2.854 E+0$ \\
\hline 11.6 & $2.144 E-2$ & $-2.857 E+0$ \\
\hline 11.7 & $2.092 E-2$ & $-2.859 E+0$ \\
\hline 11.8 & $2.042 E-2$ & $-2.861 E+0$ \\
\hline 11.9 & $1.993 E-2$ & $-2.864 E+0$ \\
\hline 12.0 & $1.946 \mathrm{E}-2$ & $-2.866 E+0$ \\
\hline 12.1 & $1.900 \mathrm{E}-2$ & $-2.868 E+0$ \\
\hline 12.2 & $1.856 \mathrm{E}-2$ & $-2.870 E+0$ \\
\hline 12.3 & $1.813 \mathrm{E}-2$ & $-2.872 E+0$ \\
\hline 12.4 & $1.771 \mathrm{E}-2$ & $-2.874 E+0$ \\
\hline 12.5 & $1.731 \mathrm{E}-2$ & $-2.876 E+0$ \\
\hline 12.6 & $1.691 \mathrm{E}-2$ & $-2.878 E+0$ \\
\hline 12.7 & $1.653 \mathrm{E}-2$ & $-2.880 E+0$ \\
\hline 12.8 & $1.616 \mathrm{E}-2$ & $-2.882 E+0$ \\
\hline 12.9 & $1.581 \mathrm{E}-2$ & $-2.883 E+0$ \\
\hline 13.0 & $1.546 \mathrm{E}-2$ & $-2.885 E+0$ \\
\hline 13.1 & $1.512 E-2$ & $-2.887 E+0$ \\
\hline 13.2 & $1.479 \mathrm{E}-2$ & $-2.888 E+0$ \\
\hline 13.3 & $1.447 \mathrm{E}-2$ & $-2.890 E+0$ \\
\hline 13.4 & $1.416 \mathrm{E}-2$ & $-2.892 E+0$ \\
\hline 13.5 & $1.386 \mathrm{E}-2$ & $-2.893 E+0$ \\
\hline 13.6 & $1.357 \mathrm{E} \cdot 2$ & $-2.895 E+0$ \\
\hline 13.7 & $1.328 \mathrm{E}-2$ & $-2.896 E+0$ \\
\hline 13.8 & $1.301 \mathrm{E}-2$ & $-2.898 E+0$ \\
\hline 13.9 & $1.274 \mathrm{E}-2$ & $-2.899 E+0$ \\
\hline
\end{tabular}


Table 10 . Sensitivity coefficients for $\mathrm{Re}$, linear viscosity relation $\gamma=1.40 \quad$ (Continued)

\begin{tabular}{|c|c|c|}
\hline$M_{\infty}$ & $R e / R e^{*}$ & $\frac{M_{\infty}}{R e} \frac{\partial R e}{\partial M_{\infty}}$ \\
\hline \hline 14.0 & $1.247 E-2$ & $-2.900 E+0$ \\
14.1 & $1.222 E-2$ & $-2.902 E+0$ \\
14.2 & $1.197 E-2$ & $-2.903 E+0$ \\
14.3 & $1.173 E-2$ & $-2.905 E+0$ \\
14.4 & $1.150 E-2$ & $-2.906 E+0$ \\
& & \\
14.5 & $1.127 E-2$ & $-2.907 E+0$ \\
14.6 & $1.104 E-2$ & $-2.908 E+0$ \\
14.7 & $1.083 E-2$ & $-2.910 E+0$ \\
14.8 & $1.061 E-2$ & $-2.911 E+0$ \\
14.9 & $1.041 E-2$ & $-2.912 E+0$ \\
15.0 & $1.021 E-2$ & $-2.913 E+0$ \\
\hline
\end{tabular}




\section{Appendix}

\section{Program DFDX, Sensitivity Coefficient Estimation by Sequential Perturbation}

C PROGRAM DFDX

C This code uses a finite differencing technique with a central difference to

C estimate sensitivity coefficients for uncertainty analyses. The function to be

C evaluated, $F$, is defined in FUNCTION $F(X)$ and has NX (up to 10) variables,

C denoted as $X(I)$. The increment for the difference is RDX which is a relative

C value, i.e., the actual increment is given by, $I N C=R D X^{*} X(I)$. If desired, an

C absolute increment can be used as indicated in the comments. In this case, the

C value of the increment, DX, will be a function of the particular variable and

C should be input as an array of NX values. The user must provide the function

C subprogram. For this example, $\mathrm{F}=$ Reynolds number with $\mathrm{Minf}, \mathrm{Pt}, \mathrm{Tt}$ and

C $L$ as the four variables, $X(1)$ thru $X(4)$. A linear viscosity relation is assumed.

C Program output is the absolute sensitivity coefficient, DFDX ( $=\mathrm{dF} / \mathrm{dX})$, and the

C relative sensitivity coefficient, $R D F D X[=(X / F)(d F / d X)]$, for each variable.

C

DIMENSION X(10),DFDX(10),RDFDX(10)

C... define relative interval for finite difference

$\mathrm{RDX}=0.005$

C... input number of variables and their nominal values

$\mathrm{NX}=0$

DO WHILE (NX.LT.1 .OR. NX.GT.10)

WRITE(6,'(/"No. of variables in function, $F$, is: ",\$)')

$\operatorname{READ}(5, *) N X$

ENDDO

WRITE(6,'(/"Nominal values for $X(1)$ thru $X(", I 1, "): ") ')$ NX

$\operatorname{READ}\left(5,{ }^{*}\right)(X(1), I=1, N X)$

C... calculate value of function for nominal values of variables 


\section{$F N O M=F(X)$}

C... calculate derivative, DFDX, for each variable

$\mathrm{DO} I=1, \mathrm{NX}$

$X S V=X(I)$ I save nominal value of $X(I)$

$X N=X S V^{*}(1.0-R D X / 2.0) \quad$ ! for absolute $d x, X N=X S V-D X / 2.0$

$X(1)=X N$

$F N=F(X)$

$X P=X S V^{*}(1.0+R D X / 2.0) \quad$ Ifor absolute $d x, X N=X S V+D X / 2.0$

$X(I)=X P$

$F P=F(X)$

DFDX $(I)=(F P-F N) /(X P-X N) \quad$ labsolute sensitivity coefficient

$X(I)=X S V \quad$ I restore nominal value of $X(I)$

$\operatorname{RDFDX}(I)=\operatorname{DFDX}(I) /(F N O M / X(1)) \quad$ I relative sensitivity coefficient ENDDO

C... print results

WRITE(50,'(5X,"l",9X,"X",11X,"dF/dX",5X,"(dF/dX)/(F/X)"/)')

DO $I=1, N X$

WRITE(50,'(16,1P3E14.4E1)') I,X(I),DFDX(I),RDFDX(I)

ENDDO

WRITE $\left(50,{ }^{\prime}(\right.$ " F(nominal) $=", 1 P E 11.4 E 1 /)$ ') FNOM

END

FUNCTION $F(X)$

DIMENSION $X\left(^{\star}\right)$

REAL MUINF

C $\quad F=$ Reynolds number $=$ RHOinf * Vinf * $L /$ MUinf

C The linear viscosity relation, MUinf $=C^{*}$ Tinf is used.

C $\quad X(1)=$ Minf

C $\quad X(2)=P t, I b f / i^{2}$

C $\quad X(3)=T t, \operatorname{deg} R$

C $\quad X(4)=L, f t$

$\mathrm{G}=1.400$

$R G=1716.55$

$\mathrm{C}=8.05 \mathrm{E}-10$

$\mathrm{FIP}=1.0+(\mathrm{G}-1.0) / 2.0^{*} \mathrm{X}(1)^{* * 2}$

I gamma, ratio of specific heats

$P I N F=X(2) / F I P^{\star \star}(G /(G-1.0))$ I gas costant, $\mathrm{ft}^{2} / \mathrm{sec}^{2}$-deg $\mathrm{R}$

$T I N F=X(3) / F I P$ I viscosity constant, lbf-sec / $\mathrm{tt}^{2}$

RHOINF=PINF * $144.0 /(R G$ * TINF) I isentropic flow function

$V I N F=X(1){ }^{*} \operatorname{SQRT}\left(G{ }^{*} R G\right.$ * $\left.T I N F\right)$ ! Pinf, Eq. (44)

I Tinf, Eq. (82)

I RHOinf, Eq. (114)

! Vinf, Eq. (115) 
MUINF $=C$ * TINF

$F=R_{H O I N F}^{*}$ VINF ${ }^{*} X(4) / M U I N F$

RETURN

END
IMUinf, Eq. (136)

I Re, Eq. (135)

Typical input:

No. of variables in function, F, is: 4

Nominal values of $\mathrm{X}(1)$ thru $\mathrm{X}(4)$ :

$5.0,150.0,800.0,1.0$

Typical output:

$\begin{array}{ccccl}\mathrm{I} & \mathrm{X} & \mathrm{dF} / \mathrm{dX} & (\mathrm{X} / \mathrm{F})^{*}(\mathrm{dF} / \mathrm{dX}) & \\ 1 & 5.0000 \mathrm{E}+0 & -2.1951 \mathrm{E}+6 & -2.3334 \mathrm{E}+0 & {\left[\mathrm{X}(1)=\mathrm{M}_{\infty}\right]} \\ 2 & 1.5000 \mathrm{E}+2 & 3.1357 \mathrm{E}+4 & 1.0000 \mathrm{E}+0 & {\left[\mathrm{X}(2)=\mathrm{p}_{\mathrm{t}}\right]} \\ 3 & 8.0000 \mathrm{E}+2 & -8.8190 \mathrm{E}+3 & -1.5000 \mathrm{E}+0 & {\left[\mathrm{X}(3)=\mathrm{T}_{\mathrm{t}}\right]} \\ 4 & 1.0000 \mathrm{E}+0 & 4.7035 \mathrm{E}+6 & 1.0000 \mathrm{E}+0 & {[\mathrm{X}(4)=l]} \\ & \mathrm{F}(\text { nominal })=4.7036 \mathrm{E}+6 & {[\mathrm{~F}=\mathrm{Re}]} & \end{array}$

From the output, it is seen that the Reynolds number relative sensitivity coefficient, $(X / F)^{*}(d F / d X)$, for $M_{\infty}$ is -2.3334 which agrees with the value in Table 10 for $M_{\infty}=5$. The relative sensitivity coefficients for $\mathrm{p}_{\mathrm{t}}, \mathrm{T}_{\mathrm{t}}$ and $l$, are 1.0, -1.5 and 1.0 , respectively, which agree with the values in Eq. (145). 


\section{DISTRIBUTION:}

1 T. W. Binion, Jr. AEDC/Calspan Corp. MS 4001

Arnold AFB, TN 37389

1 D. M. Cahill

AEDC/Calspan Corp.

MS 600

Arnold AFB, TN 37389

1 H. W. Coleman

Propulsion Research Center

College of Engineering

The University of Alabama in Huntsville

Huntsville, AL 35899

1 R. H. Dieck

Pratt \& Whitney

P. O. Box 109600

MS 725-01

West Palm Beach, FL 33410-9600

1 L. J. Healy

Hughes Missile Systems Co.

Bldg. 847 B3

P.O. Box 11337

Tucson, AZ 85754-1337

1 D. Juanarena

Pressure Systems Inc.

34 Research Drive

Hampton, VA 23666

1 K. L. Kushman

USAF-AEDC

DOT

Arnold AFB, TN 37389

1 D. Marren

Attn: K24

Naval Surface Weapons Center

10901 New Hampshire Ave.

Silver Spring, MD 20903-4631
1 W. G. Steele, Jr.

Mechanical and Nuclear Engineering Department

Mississippi State University

Mississippi State, MS 39762

1 J. L. Taylor

Sverdrup Technology

P. O. Box 884

Tullahoma, TN 37388

1 L. L. Trimmer

CSTAR

UTSI Research Park

Tullahoma, TN 37388-8897

1 A. Rupert

EG\&G ldaho, Inc.

P. O. Box 1625

1955 Freemont ECB-W2-D1

Idaho Falls, ID 83415

11500 D. J. McCloskey

11501 C. W. Peterson

Route to: $1512,1513,1551$, 1552

11502 P. J. Hommert

Route to: $1503,1511,1553$, 1554

11552 D. D. McBride

11554 D. P. Aeschliman

$201554 \quad$ E. L. Clark

11554 W. T. Gutierrez

11554 W. L. Oberkampf

51554 W. H. Rutledge

11554 R. E. Tate

$11561 \quad$ H. S. Morgan

Route to: 1562

$\begin{array}{rrl}1 & 8523-2 & \text { Central Technical Files } \\ 5 & 7141 & \text { Technical Library } \\ 1 & 7151 & \text { Technical Publications } \\ 10 & 7613-2 & \text { Document Processing } \\ & & \text { for DOE/OSTI }\end{array}$



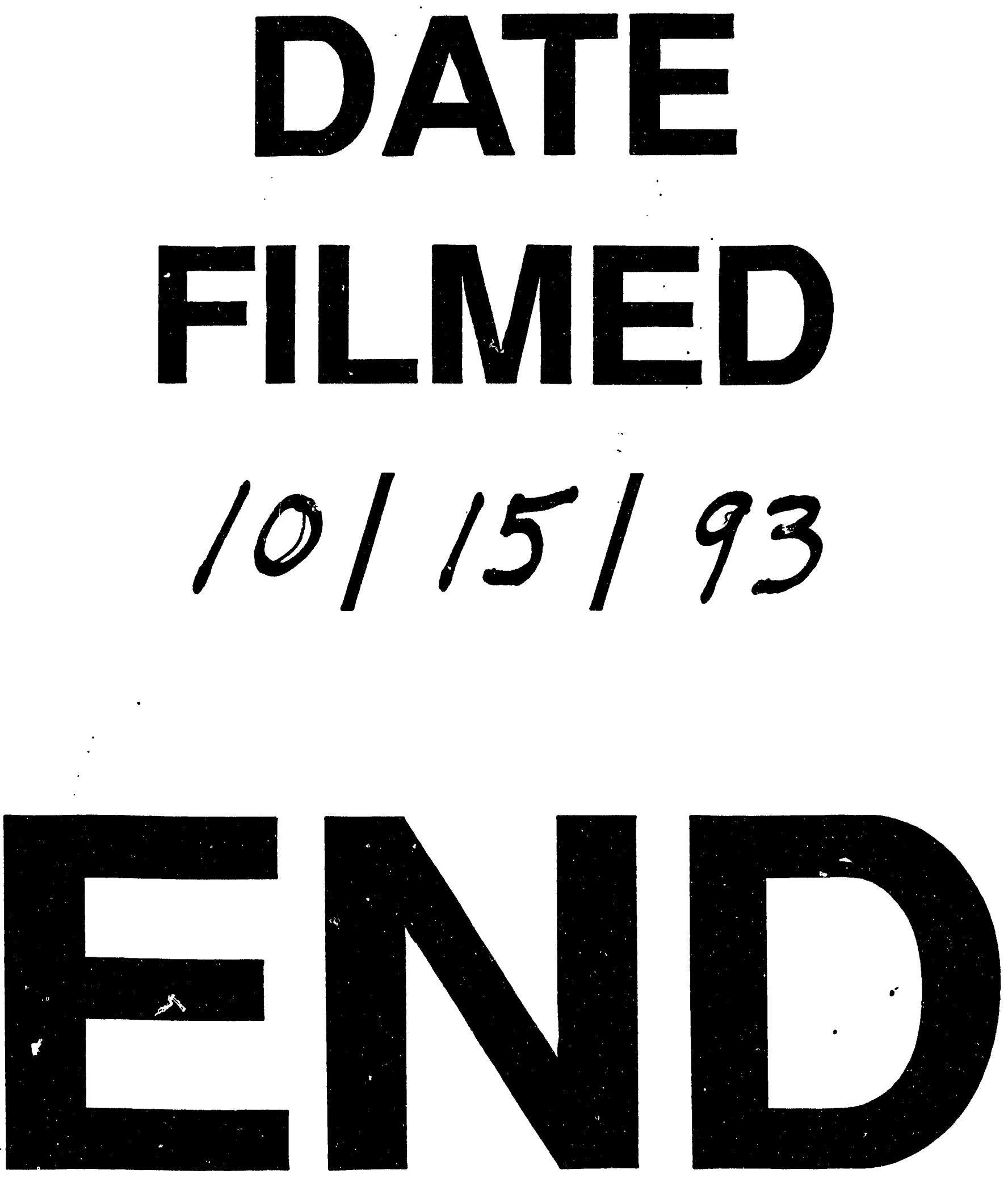
